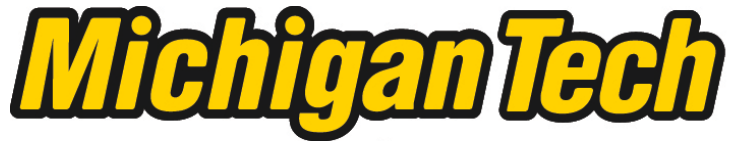 \\ Michigan Technological University Create the Future Digital Commons @ Michigan Tech
}

Dissertations, Master's Theses and Master's Reports - Open

Dissertations, Master's Theses and Master's

Reports

2013

Selective Mercury Sequestration from a Silver/Mercury Cyanide Solution

Kristen L. Gabby

Michigan Technological University

Follow this and additional works at: https://digitalcommons.mtu.edu/etds

Part of the Chemical Engineering Commons

Copyright 2013 Kristen L. Gabby

\section{Recommended Citation}

Gabby, Kristen L., "Selective Mercury Sequestration from a Silver/Mercury Cyanide Solution", Dissertation, Michigan Technological University, 2013.

https://doi.org/10.37099/mtu.dc.etds/595

Follow this and additional works at: https://digitalcommons.mtu.edu/etds

Part of the Chemical Engineering Commons 


\title{
SELECTIVE MERCURY SEQUESTRATION FROM A SILVER/MERCURY CYANIDE SOLUTION
}

\author{
By \\ Kristen Gabby \\ A DISSERTATION \\ Submitted in partial fulfillment of the requirements for the degree of \\ DOCTOR OF PHILOSOPHY \\ In Chemical Engineering
}

MICHIGAN TECHNOLOGICAL UNIVERSITY

2013

(C) 2013 Kristen L. Gabby 
This dissertation has been approved in partial fulfillment of the requirements for the Degree of DOCTOR OF PHILOSOPHY in Chemical Engineering

\section{Department of Chemical Engineering}

Dissertation Advisor: Timothy Eisele

Committee Member: C Caryn Heldt

Committee Member: Wenzhen $\mathrm{Li}$

Committee Member: $\quad$ Paul Sanders

Department Chair: Komar Kowatra 


\section{Table of Contents}

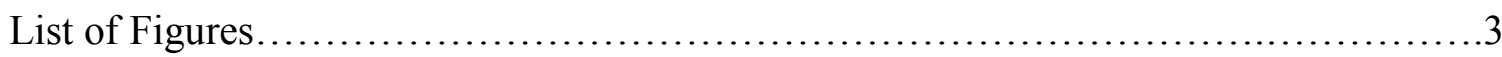

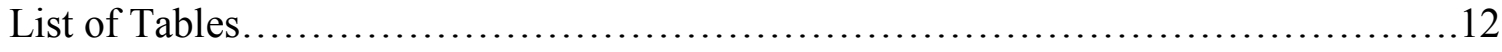

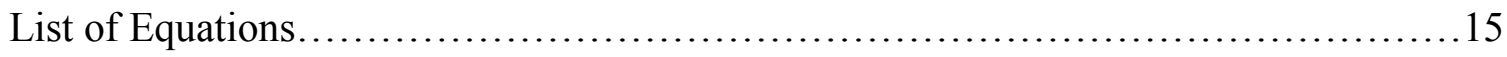

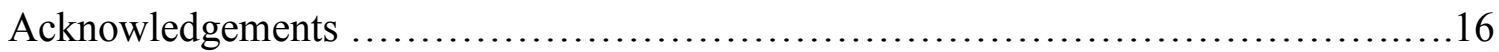

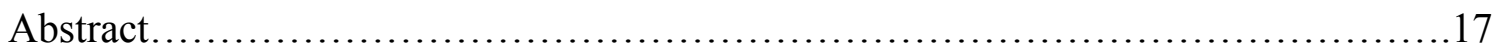

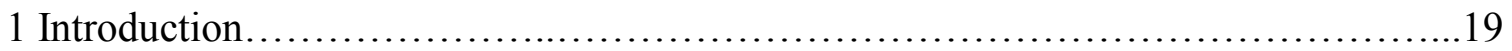

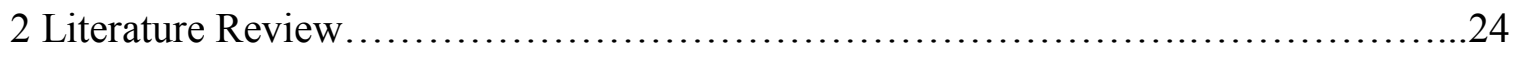

2.1 Chemistry of Silver, Mercury and Selenium - Metal Ion Species of Interest.......24

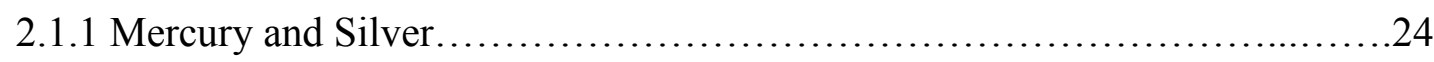

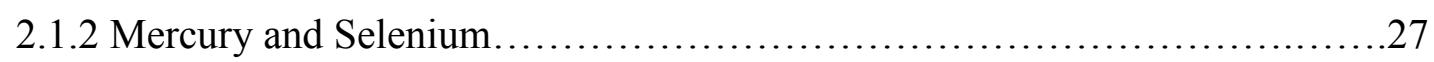

2.2 Treatment and Separation Methods......................................... 51

2.2.1. Prevent mercury dissolution during leaching and precipitate from process solution............................................................ 51

2.2.2 Remove Mercury from the Final Product......................................39

2.2.3 Selenium and Mercury .................................................... 40

3. Suppression of Mercury Dissolution using Selenium...............................41

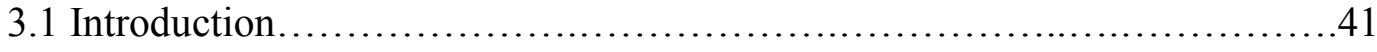

3.3 Theoretical Discussion............................................... 42

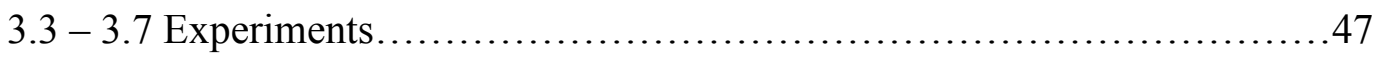

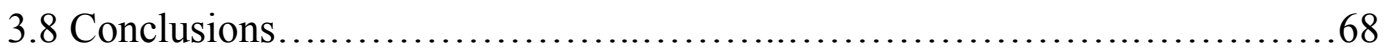

4. Selective Mercury Precipitation from Solution with Silver Sulfide....................70

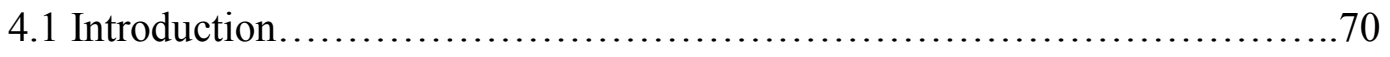


4.2 Theoretical Discussion ............................................. 71

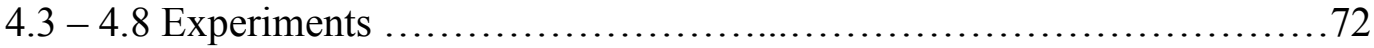

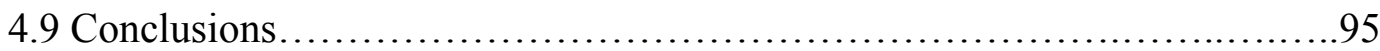

5. Zinc Sulfide Precipitation of Mercury Cyanide as Mercury Sulfide..................97

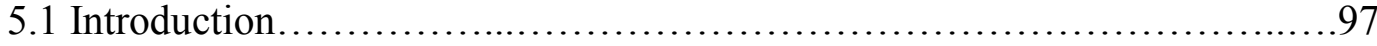

5.2 Theoretical Discussion ............................................. 98

$5.3-5.13$ Experiments............................................ 102

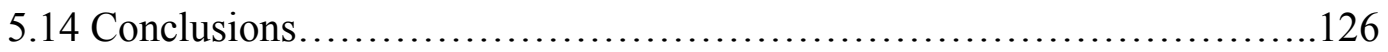

6. Zinc Sulfide Precipitation of Mercury Cyanide as Mercury Sulfide with the Use of Columns and Funnels............................................. 128

$6.1-6.5$ Experiments.............................................. 128

6.6 Conclusions........................................................ 141

7. Possible Complicating Ions.......................................... 142

7.1 Introduction..................................................... 142

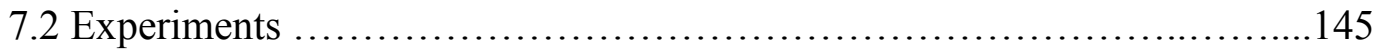

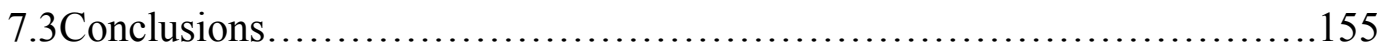

8. Overall Conclusions...................................................... 156

9. Proposed Implementation............................................. 158

10. References......................................................... 163

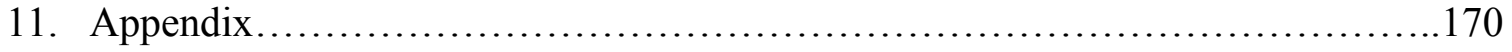




\section{List of Figures}

FIGURE 1.1. A SIMPLIFIED FLOW DIAGRAM OF THE HEAP LEACHING PROCESS TO RECOVER PRECIOUS METALS WITH CYANIDE IS SHOWN ................................21

FIgURE 2.1. POURBAIX DIAGRAM OF SELENIUM AND SULFUR, SHOWING THE DESIRED RANGE FOR REACTION IN CYANIDE LEACH SOLUTION WHERE MERCURY SELENATE PRECIPITATES, BUT DOES NOT PRECIPITATE SILVER SELENATE....................29

FIGURE 2.2 FLOW DIAGRAM FOR TESTING POLYTHIOCARBONATE (PTC) FOR MERCURY

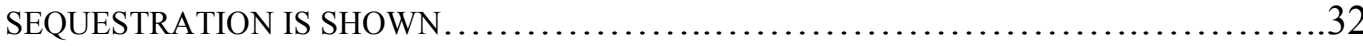

FigURE 2.3. HYPOTHESIZED PTC BINDING TO MERCURY ............................... 33

FIGURE 2.4. 1,3-BENZENEDIAMIDOETHANETHIOL SUSPECTED BINDING TO MERCURY IS SHOWN. SULFUR FROM TWO SEPARATE MOLECULES COULD ALSO BOND TO

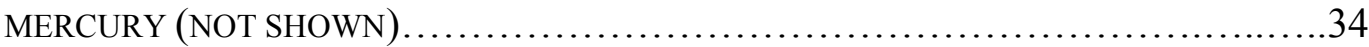

FigURE 2.5. HYPOTHESIZED KDTC BINDING TO MERCURY ............................... 35

FIGURE 2.6. THE PROCESS OF SILVER CHLORIDE AND MERCURY SULFIDE FORMED BY THE ADDITIONS OF SODIUM CHLORIDE AND FERROUS SULFIDE TO A SOLUTION IS

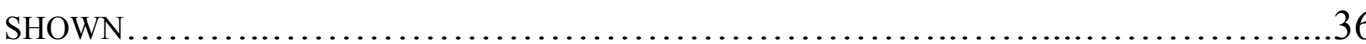

FIGURE 2.7. SELECTIVE PRECIPITATION OF SILVER FROM MERCURY BY USING CHLORIDE IS SHOWN. ...

FIGURE 3.1. FLOW DIAGRAM SHOWING EXPERIMENTS DONE WITH REGARDS TO EFFECTS OF SELENIUM

FIGURE 3.2. REACTIONS OF SELENIUM IN SOLUTION REACTING WITH MERCURY TO FORM HGSE, AND SHOWING SILVER DISSOLVING INTO SOLUTION.

Figure 3.3 POURBAIX DIAGRAM (EPH) OF SELENIUM IN WATER FROM PH 8 TO PH 12, SHOWING REGIONS OF SOLUBILITY .45

Figure 3.4. POSSIBLE USE OF HIGH SELENIUM ORE WITH HIGH MERCURY ORE IN HEAP LEACH OPERATIONS.............................................................. 46

FIGURE 3.5. EXPERIMENTAL SET-UP FOR A-HGS MOUNTED IN EPOXY AND ANALYZED IN THE SEM. THE SAME PROCEDURE WAS USED FOR THE SILVER SULFIDE SPECIMEN 
FIGURE 3.6. EXPERIMENTAL SET-UP FOR B-HGS AND SILVER SULFIDE MOUNTED ON CARBON TAPE AND ANALYZED IN THE SEM. THE SAME PROCEDURE WAS USED

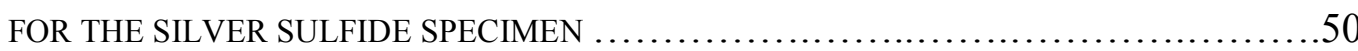

FIGURE 3.7. A B-MERCURY CRYSTAL NOT REACTED (TOP) AND REACTED WITH (BOTTOM) SELENIUM, ANALYZED BY SEM AT ACCELERATING VOLTAGE 20V, MAGNIFICATION 4,000X FOR THE TOP IMAGES, AND 1000X FOR THE LOWER IMAGES, IS SHOWN

Figure 3.8. SILVER SULFIDE AS A CRYSTAL IS SHOWN NOT REACTED (TOP) AND REACTED WITH (BOTTOM) SELENIUM AT ACCELERATING VOLTAGE 20V AND MAGNIFICATION 1,000X FOR THE UPPER IMAGES, AND 500X FOR THE LOWER IMAGES.

Figure 3.9. The Pourbaix diagram generated by FactSageC of Silver, MERCURY, AND SELENIUM IN AQUEOUS SOLUTION IS SHOWN FROM PH 8 TO

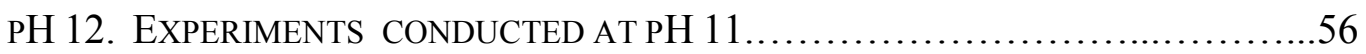

FIGURE 3.10. EXPERIMENT PROCEDURE SHOWING HOW ORES WERE LEACHED. .............58

FIGURE 3.11. RESULTS FROM NATURAL ORE LEACH, ANALYSIS BY MTU. NUMERICAL VALUES SHOWN IN TABLE 8

Figure 3.12. Pourbaix Diagram GENERATED by FACtSAGEC OF MERCURY AND SULFIDE IN AQUEOUS SOLUTION WITH THE BLACK CIRCLE LINES INDICATING THE CN- STABILITY REGION.

FIGURE 3.13. POURBAIX DIAGRAM OF SILVER AND SULFIDE IN AQUEOUS SOLUTION WITH THE BLACK CIRCLE LINES INDICATING THE CN- STABILITY REGION.

FIGURE 3.14. RESULTS FROM SYNTHETIC ORE LEACH, ANALYSIS BY MTU. RATIOS ARE SHOWN OF THE METAL IONS IN SOLUTION DIVIDED BY HOW MUCH WAS PUT INTO THE SAMPLE AS A SULFIDE.

FIGURE 3.15. THE SET UP FOR LEACHING SILVER AND MERCURY WITH OR WITHOUT SELENIUM IS SHOWN. THIS WAS CARRIED OUT FOR BOTH SODIUM HYDROXIDE AND AMMONIA 
FIGURE 3.16. RESULTS ARE SHOWN FOR THE EFFECT OF ADDING SODIUM SELENIDE TO SILVER OR MERCURY SULFIDE LEACHING.

FIGURE 4.1. FLOW DIAGRAM SHOWING EXPERIMENTS DONE WITH MERCURY CYANIDE

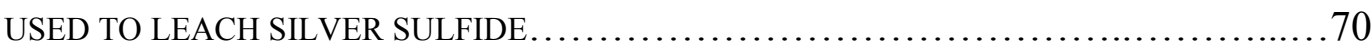

FIGURE 4.2. MERCURY CYANIDE REACTING WITH SILVER SULFIDE TO FORM MERCURY

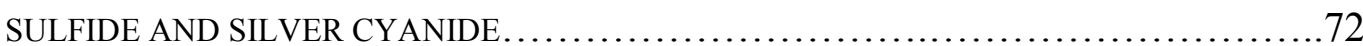

FIgURE 4.3. EXPERIMENTAL SET-UP SHOWING HG(CN) $4^{-2}$ ADDED TO SILVER SULFIDE .73

FigURE 4.4. PRE-LEACHED MERCURY CYANIDE WAS USED TO LEACH SILVER SULFIDE POWDER OVER A PERIOD OF TIME................................75

FIGURE 4.5. SILVER DISSOLUTION / MERCURY PRECIPITATION MOLE RATIO VERSUS TIME IS SHOWN .75

FIGURE 4.6. EDS MAPPING IMAGE OF A SILVER SULFIDE PARTICLE (ABOUT $500 \mu \mathrm{M}$ IN DIAMETER) REACTED WITH MERCURY CYANIDE SOLUTION AT 5,500 X

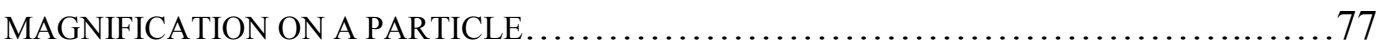

Figure 4.5 High SE ORE LEACHED WITH MERCURY CYANIDE SOLUTION.................80

FigURE 4.6. High Hg ORE LEACHED WITH MERCURY SOLUTION ........................81

FIGURE 4.7. LEACHING THE ORES WITH CYANIDE OR MERCURY CYANIDE AND THEIR

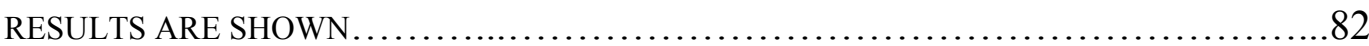

Figure 4.8. LEACHING High SE ORE WITH MERCURY CYANIDE, THEN LEACHED AGAIN WITH MORE MERCURY CYANIDE SOLUTION. THE PROCESS WAS CARRIED OUT FOR THE CONCENTRATED MERCURY CYANIDE SOLUTION AND FOR THE MERCURY CYANIDE WITH $0.01 \%$ KCN ADDED ...................................... 84

FIGURE 4.9. A LOWER CONCENTRATION OF MERCURY CYANIDE WAS USED TO LEACH THE HigH HG ORE......................................................... 85

FIGURE 4.10. A LOWER CONCENTRATION OF MERCURY CYANIDE WAS USED TO LEACH THE HIGH SE ORE. 
FIGURE 4.11. THE PREVIOUS EXPERIMENT'S RESULTS FOR USING A MERCURY SOLUTION TO LEACH ORE WITH NO EXCESS CYANIDE IS SHOWN COMPARED TO THIS EXPERIMENT'S (RED SQUARE) MERCURY SOLUTION WITH 0.01\% KCN TO LEACH ORE. .88

FIGURE 4.12. AN ILLUSTRATION SHOWING LEACHING OF ORE WITH CYANIDE OR MERCURY CYANIDE AND THEIR RESULTS ARE SHOWN

Figure 4.13. High SE ORE LEACHED WITH MERCURY SOLUTION AND NO EXCESS CYANIDE .90

FigURE 4.14. HigH SE ORE LEACHED WITH MERCURY SOLUTION WITH EXCESS

CYANIDE

FIGURE 4.15. COUNTER CURRENT FLOW OF MERCURY CYANIDE SOLUTION (WITH $0.01 \% \mathrm{KCN}$ ) WITH ORE IS SHOWN

FIGURE 5.1. DIAGRAM SHOWING WHAT EXPERIMENTS WERE DONE AND HOW THEY ARE RELATED. .97

FIGURE 5.2. THE ZINC SULFIDE SURFACE WILL PRECIPITATE BOTH SILVER AND MERCURY SULFIDES FROM CYANIDES. MERCURY CYANIDE WILL PROGRESSIVELY DISPLACE THE SILVER SULFIDE AS SILVER CYANIDE AND PRECIPITATE MERCURY SULFIDE. (ADAPTED FROM GABBY AND EISELE 2012) .98

FIGURE 5.3. THE ZINC SULFIDE CELL (SHOWN IN ITS MOST COMMONLY FOUND STRUCTURE AS ZINC BLENDE) IS SHOWN, WHERE THE LARGER IONS IN THE CELL ARE SULFUR AND THE SMALLER ONES ARE ZINC. SILVER AND MERCURY ARE ALSO SHOWN OFF TO THE SIDE, WITH MERCURY BEING SLIGHTLY LARGER THAN THE ZINC ION AND SILVER BEING SLIGHTLY SMALLER THAN THE SULFUR IONS

FIGURE 5.4. POURBAIX DIAGRAM OF MERCURY AND SULFIDE IN AQUEOUS SOLUTION....100 Figure 5.5. POURBAIX DIAGRAM OF SILVER AND SULFIDE IN AQUEOUS SOLUTION 101 
FIGURE 5.6. SEM ELEMENT MAP SHOWING MERCURY ON THE SURFACE OF THE ZNS PARTICLE (PARTICLES WERE 80\% PASSING ABOUT 220 $\mu$ M), ACCELERATING VOLTAGE 20KEV, MAGNIFICATION 5,500x.............................. 105

FIGURE 5.7. SPHALERITE PARTICLE SIZE EFFECTS ON MERCURY PRECIPITATION IS SHOWN ON A SEMI-LOG PLOT.

FIGURE 5.8. PERCENT OF MERCURY CYANIDE REMOVED FROM SOLUTION AT TIME OF FILTRATION ADJUSTED FOR FILTERING TIME.............................112

FIGURE 5.9. OVEN DRIED SPHALERITE AND FRESHLY GROUND SPHALERITE COMPARED FOR MERCURY PRECIPITATION

FIGURE 5.10. SPHALERITE FRESHLY GROUND, DRIED IN THE OVEN WITH WATER, AND DRIED IN THE OVEN WITH HYDROGEN PEROXIDE WERE TESTED FOR MERCURY

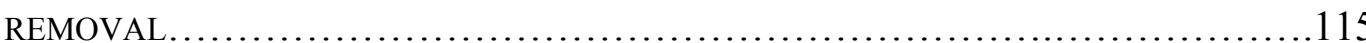

FIGURE 5.11. THE RESULTS OF DE-AERATION AND USE OF NITROGEN FOR A SILVER AND MERCURY CYANIDE SOLUTION REACTED WITH SPHALERITE ARE SHOWN....

FIGURE 5.12. RESULTS OF CHANGING REDUCTION POTENTIAL TO FILTER FUNNELS OF SPHALERITE TO REMOVE MERCURY SELECTIVELY FROM SILVER

FIGURE 5.13. POURBAIX DIAGRAMS OF SILVER AND MERCURY SULFIDE WITH THE REDUCTION POTENTIALS FROM THE AMMONIA EXPERIMENT PLOTTED AT $\mathrm{PH} 11$.

FIGURE 5.14 POURBAIX DIAGRAM OF MERCURY, ZINC, AND SULFUR....................126

FIGURE 6.1. “COLUMN” SET UP FOR MERCURY REMOVAL TESTING WITH SPHALERITE

FigURE 6.2. A FLOW DIAGRAM OF THE EXPERIMENT USING A MERCURY SOLUTION TO RINSE A PREVIOUSLY USED COLUMN IS SHOWN. .

FIGURE 6.3. RESULTS OF THE “COLUMN” USED VERSUS A VIAL, OR BATCH, OF MERCURY AND SPHALERITE.

FIGURE 6.4. SPHALERITE USED TO SEPARATE MERCURY FROM SILVER AND THEN MORE MERCURY WAS ADDED TO THE SAME SPHALERITE TO SHOW MERCURY REMOVAL AND SILVER RECOVERY 
FIGURE 6.5. SHOWS THE SIDE VIEW AND TOP VIEW OF THE FILTER FUNNEL WITH SPHALERITE SET UP

FIGURE 6.6 THREE BATCHES OF FRESH MERCURY AND SILVER CYANIDE SOLUTION WERE PASSED THROUGH FILTER FUNNELS WITH SPHALERITE..................134

FIGURE 6.7. SPHALERITE PRE-RINSED WITH DISTILLED WATER WAS USED FOR MERCURY AND SILVER CYANIDE SOLUTION PASSES ............................. 135

FIGURE 6.8. A COUNTER-CURRENT FLOW FOR NEW MERCURY AND SILVER CYANIDE SOLUTION PASSES THROUGH THE MOST USED SPHALERITE FIRST. (ADAPTED FROM GABBY AND EISELE 2012).

FIGURE 6.9 THREE BATCHES OF FRESH MERCURY AND SILVER CYANIDE SOLUTION WERE PASSED THROUGH FILTER FUNNELS WITH SPHALERITE.

FIGURE 6.10. SPHALERITE PRE-RINSED WITH DISTILLED WATER WAS USED FOR MERCURY AND SILVER CYANIDE SOLUTION PASSES

FIGURE 6.11. A COUNTER-CURRENT FLOW FOR NEW MERCURY AND SILVER CYANIDE SOLUTION PASSES THROUGH THE MOST USED SPHALERITE FIRST. (ADAPTED FROM GABBY AND EISELE 2012) 140

FIGURE 7.1. EXPERIMENTAL DESIGN FOR TESTING COMPLICATING ION EFFECTS ON SILVER AND MERCURY USING A SPHALERITE FILTER

FigURE 7.2. A DIAGRAM FOR THE METHOD OF LEACHING METALS, THEN ADDING THE SILVER/MERCURY CYANIDE SOLUTION IS SHOWN.

FIGURE 7.3. RESULTS FROM THE 10MM ADDITIONS OF POSSIBLE COMPLICATING IONS TO MERCURY AND SILVER SEPARATION BY SPHALERITE.

FIGURE 7.4. COPPER SULFATE (10MM) USED FOR THIS EXPERIMENT HAD A LOWER REDUCTION POTENTIAL BY USING AMMONIA. THE CU RESULTS ARE SHOWN WITH THE SODIUM HYDROXIDE EXPERIMENT FOR COMPARISON 
Figure 7.5. COMPLICATING IONS (1MM) RESUlTS SHOWN AS PERCENTS, WITH THE USE OF COPPER AND LEAD AS METALS. THE PURPOSE WAS TO SHOW WHAT EFFECT SMALLER AMOUNTS OF THE METAL COMPOUND WOULD HAVE ON THE SYSTEM AND TO SEE WHAT THE EFFECTS WERE FOR USING METALS CU AND PB. 151

FIGURE 7.6. COMPLICATING IONS (1MM) RESULTS SHOWN, WITH THE USE OF COPPER

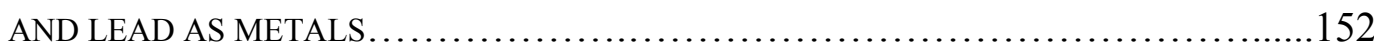

FIGURE 7.7. SILVER LOSS AND MERCURY REMOVAL, IN PERCENTS, IS SHOWN FOR A CONTROL AND WITH VARIOUS ADDITIONAL METALS............................. 154

FIGURE 7.8 SILVER AND MERCURY IN PPB FOR ALL EXPERIMENTS ARE SHOWN...........155 Figure 9.1. Suggested AdDition of ZnS to the MerriLl-Crowe Process By the ADDITION OF A COLUMN, OR SERIES OF COLUMNS, CONTAINING THE ZNS IS SHOWN..... 158 FIGURE 9.2 SUGGESTED ADDITION OF ZNS TO THE MERRILl-CROWE PROCESS IN THE

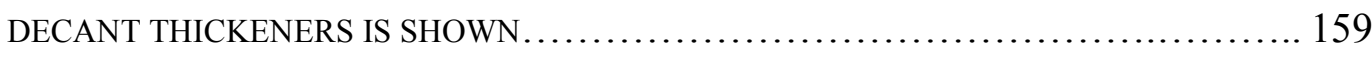
FIGURE 9.3 THE MERRILL-CROWE PROCESS WITH IMPLEMENTATION OF THE ADDITION OF SPHALERITE TO THE DECANT THICKENERS IS SHOWN............................ 160 FIGURE A4. RESULTS FROM NATURAL ORE LEACHED, ANALYSIS BY NEWMONT..........173 FigurE A9. RESULTS FROM NATURAL ORE LEACH, ANALYSIS BY NEWMONT............180 


\section{List of Tables}

TABLE 1. SOME COMPOUNDS INVESTIGATED FOR SELECTIVE REMOVAL OF MERCURY FROM SILVER IN SOLUTION, BOTH IN THE HEAP AND AS PRECIPITANTS ARE SHOWN. ... 38

TABle 2. Size distribution of the High Se (80\% PASSing $1.86 \mu \mathrm{M})$ AND High Hg ORE

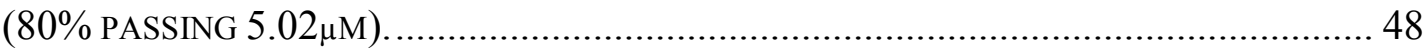

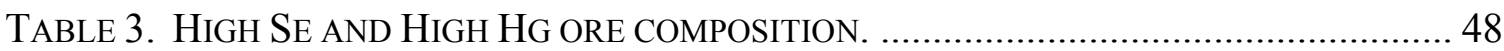

TABLE 4. EDS AT $20 \mathrm{KeV}$ ANALYSIS OF HGS CRYSTAL REACTED WITH SELENIUM, SHOWING ABOUT 4\% SELENIUM ON THE SURFACE OF THE PARTICLE............................. 51

TABLE 5. EDS at $20 \mathrm{KeV}$ ANALYSIS OF HGS PARTICLE REACTED WITH SELENIUM, SHOWING ABOUT 1\% SELENIUM ON THE SURFACE OF THE PARTICLE............................. 51

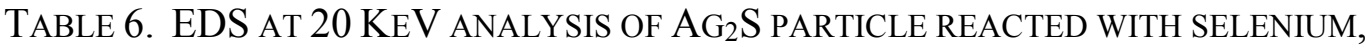
SHOWING NO SELENIUM ON THE SURFACE OF THE PARTICLE. ....................................... 52

TABLE 7. EDS AT 20 KEV ANALYSIS OF ACANTHITE CRYSTAL NOT REACTED WITH SELENIUM, SHOWING NO SELENIUM ON THE SURFACE OF THE PARTICLE. ...................... 52

Table 8. Results of the High Se ore and High Hg ORe done at MTU for Silver

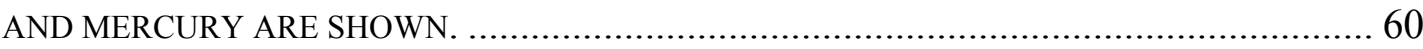

TABle 9. The total Mercury in the High Hg AND High Se ORES WaS Compared to HOW MUCH MERCURY WAS LEACHED OUT DURING A CYANIDE LEACH.

TABLE 10. THE TOTAL MOLES OF MERCURY PRECIPITATED AND TOTAL MOLES OF SILVER DISSOLVED AT A GIVEN TIME ARE SHOWN, ALONG WITH THE SILVER TO MERCURY

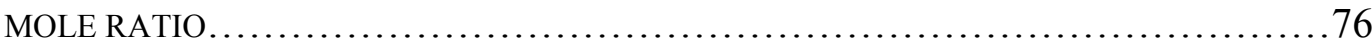

TABLE 11. EDS QUANTITATIVE ANALYSIS OF SILVER SULFIDE PARTICLE REACTED WITH MERCURY CYANIDE SOLUTION AT $20 \mathrm{KEV}$ 77

TABLE 12. A SUMMARY OF THE SOLUTION USED IN THIS EXPERIMENT IS GIVEN................... 78

TABLE 13. HIGH SE ORE RESULTS FROM COUNTER CURRENT FLOW TRIAL. ......................... 93

TABLE 14 HIGH Hg ORE RESULTS FROM COUNTER CURRENT FLOW TRIAL ......................... 94

TABLE 15. SUMMARY OF EXPERIMENT FOR INITIAL FEASIBILITY TESTS ARE SHOWN........ 102 
TABLE 16. SEM EDS SHOWING NEARLY 2\% MERCURY ON THE SURFACE OF THE ZNS PARTICLE, ACCELERATING VOLTAGE 20 KEV FOR A DWELL TIME OF 60 SECONDS.... 104

TABLE 17. VARIOUS AMOUNTS OF POWDERED SPHALERITE WERE USED WITH THE SAME SOLUTION (930 PPB MERCURY AND 300 PPB SILVER) FOR ONE HOUR. (GABBY AND EISELE 2013. USE AGREEMENT FOUND IN APPENDIX 3)..

TABLE 18. TIME TRIALS USING 0.0625 GRAMS PUCK MILL- GROUND SPHALERITE WERE CARRIED OUT IN VIALS WITH NO STIRRING. (GABBY AND EISELE 2012)................... 107

TABLE 19. SPHALERITE PARTICLE SIZE FRACTIONS USED, 80\% PASSING. ........................ 108

TABLE 20. THE LOG (BASE 10) OF THE MOLE MERCURY REMOVED DIVIDED BY THE SPECIFIC SURFACE AREA AND THE SIZE FRACTION OF PARTICLES IS SHOWN.

TABLE 21. REDUCTION POTENTIAL EFFECTS ON MERCURY AND SILVER REACTION WITH SPHALERITE.

TABLE 22. USE OF METAL COMPOUND AND METALS WITH A SILVER/MERCURY CYANIDE SOLUTION, WHICH WERE PASSED THROUGH SPHALERITE, IS SHOWN. THE \% SILVER LOSS AND \% MERCURY LOSS ARE SHOWN FOR EACH.

TABLE 23. NEWMONT ANALYSIS WITH AMMONIA AND SODIUM HYDROXIDE FOR THE High SE ORE AND HigH HG ORES ARE SHOWN.

\section{List of Equations}

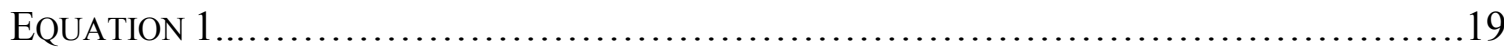

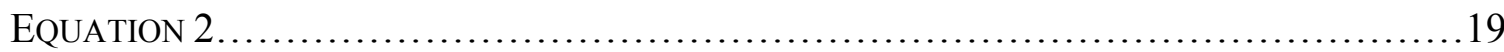

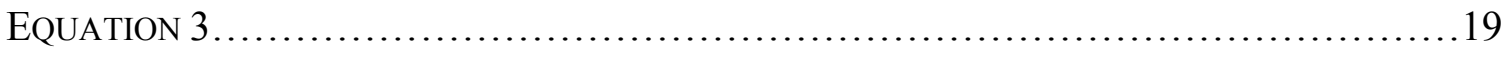

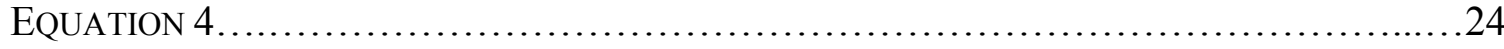

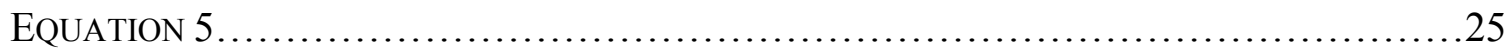

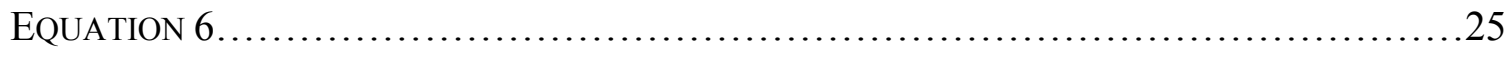

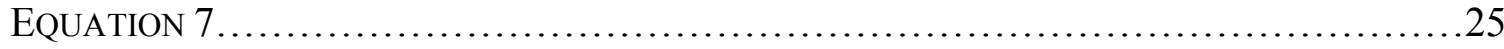




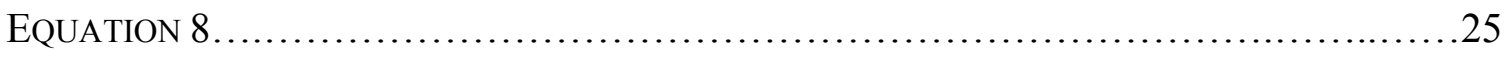

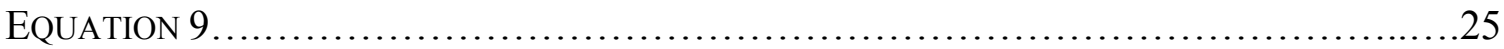

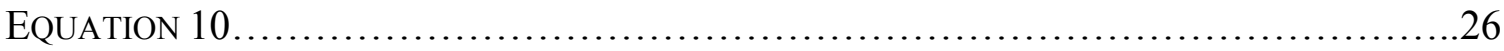

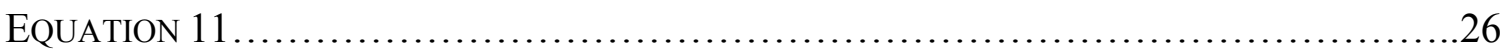

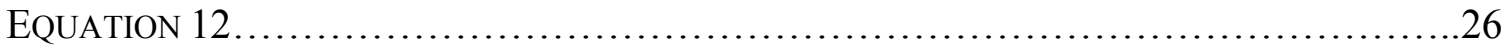

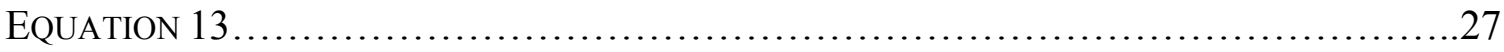

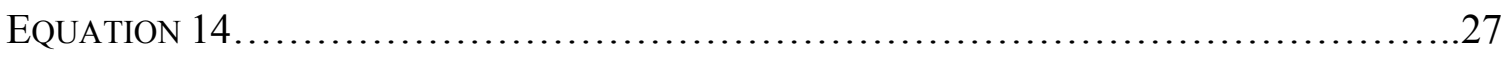

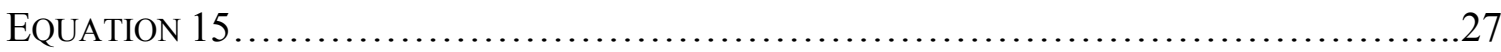

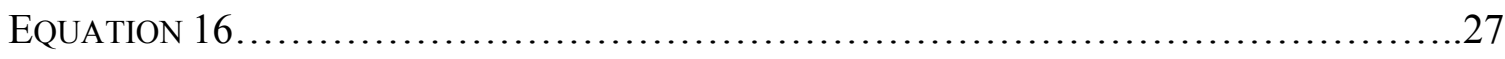

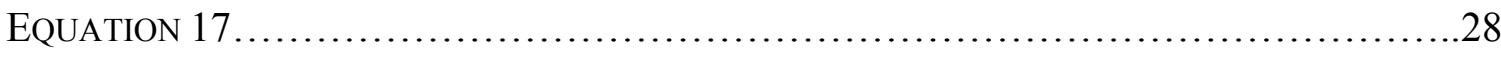

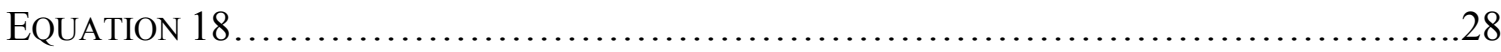

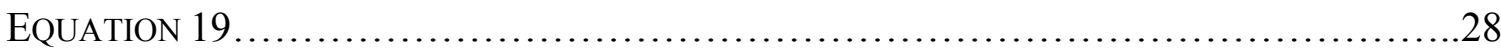

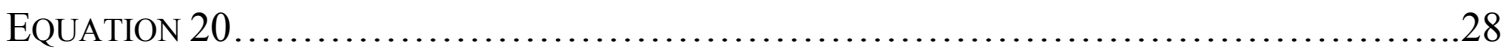

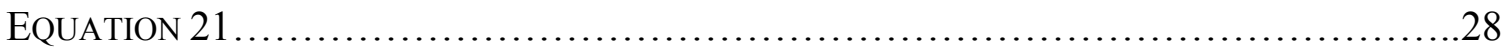

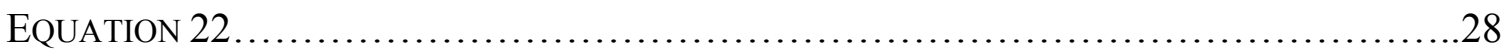

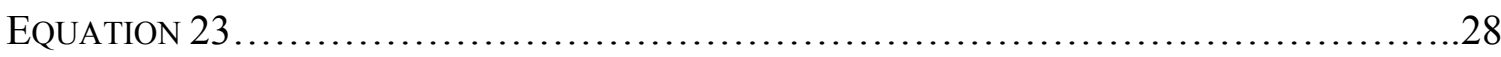

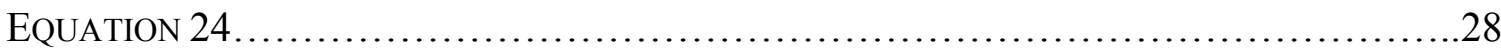

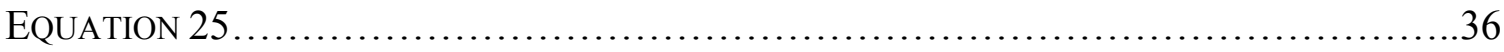

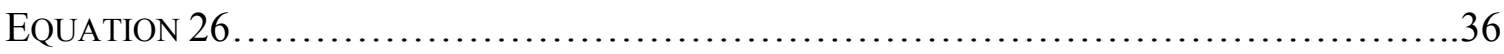

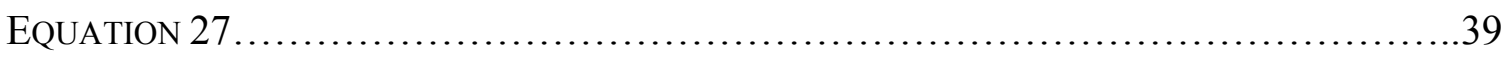

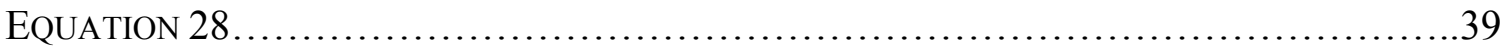

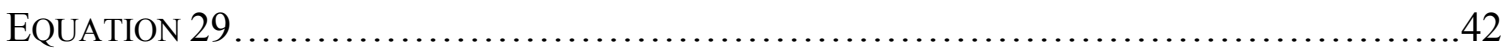

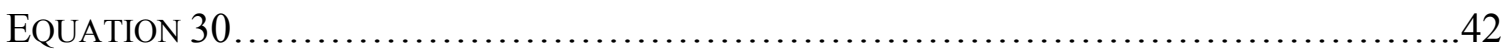

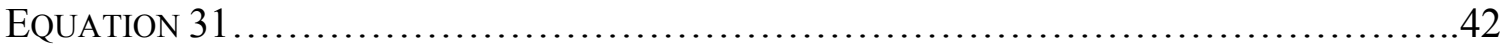

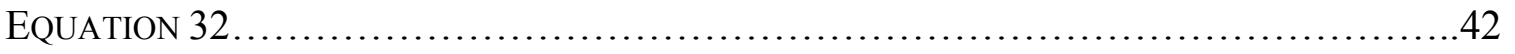

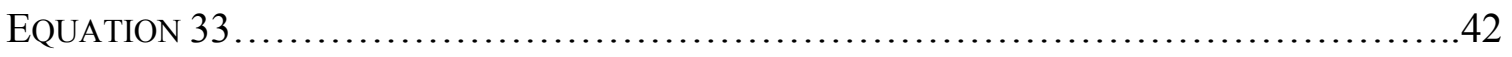

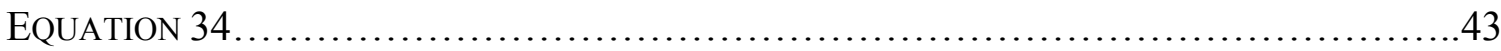

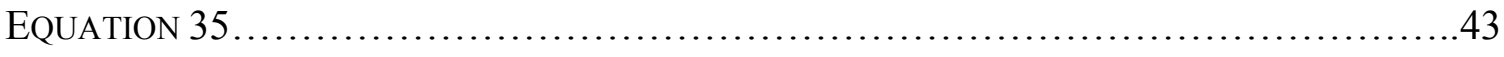

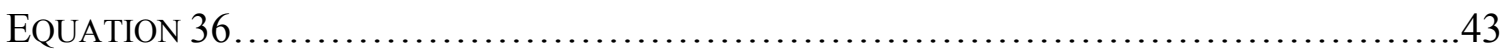




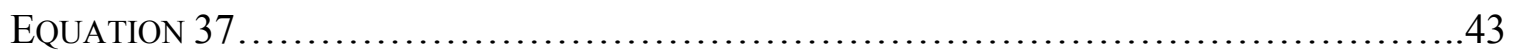

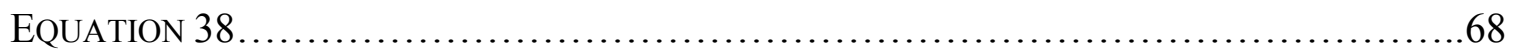

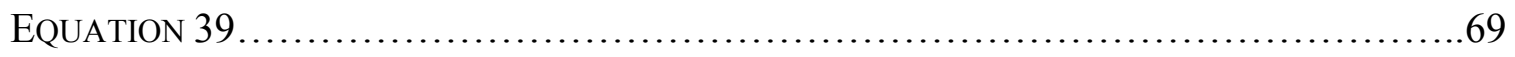

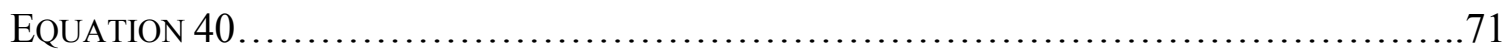

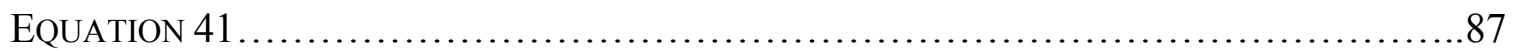

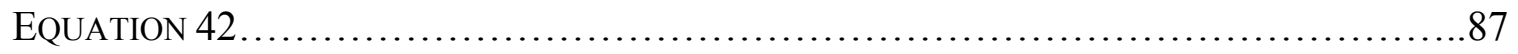

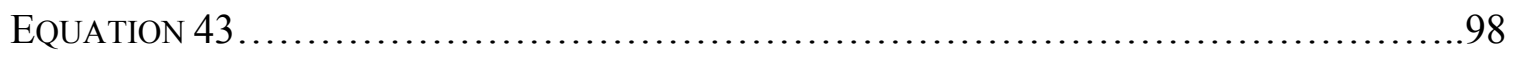

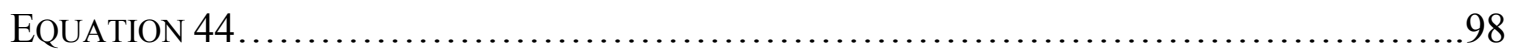

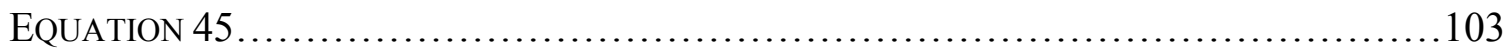

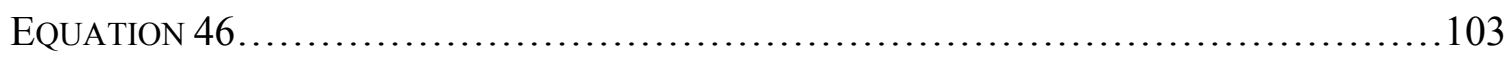

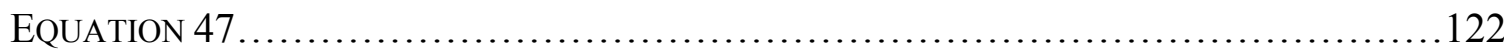

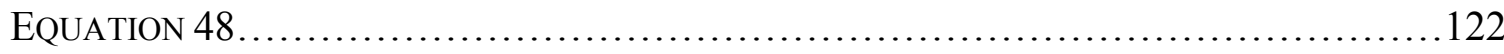

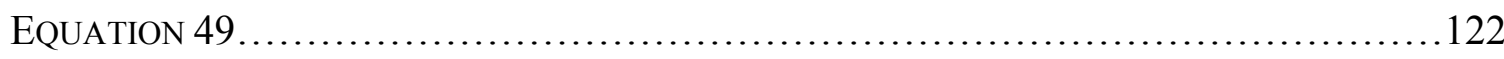

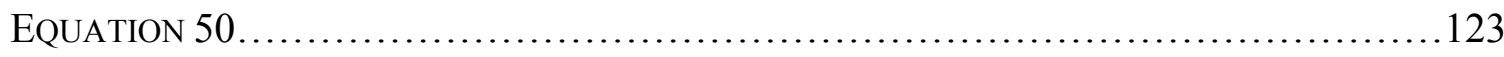

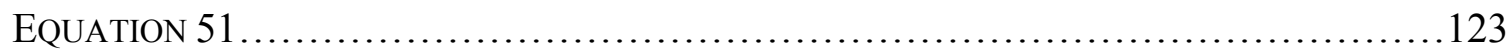

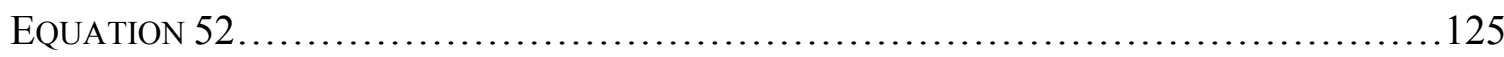

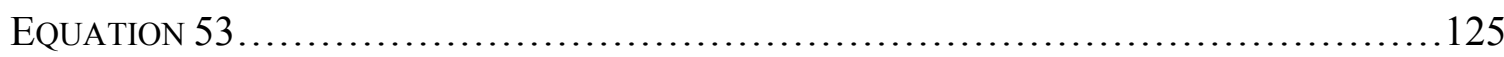

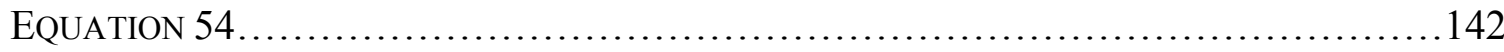

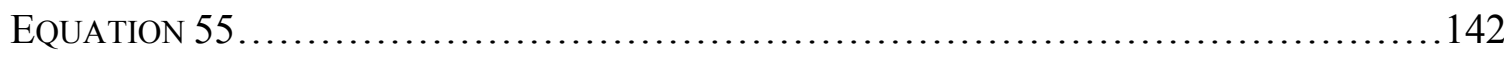

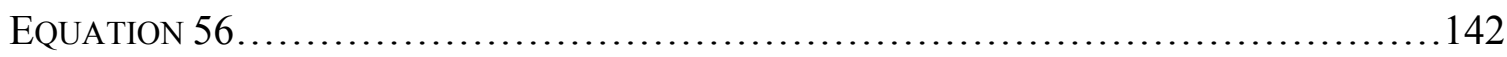

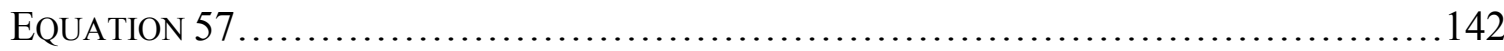

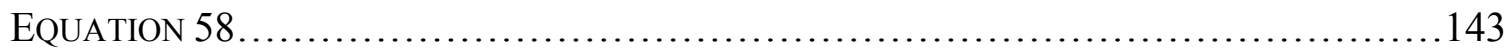

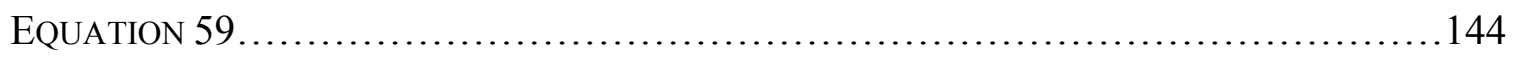

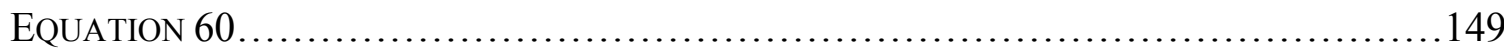

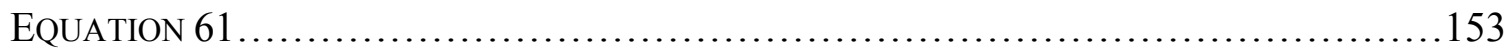

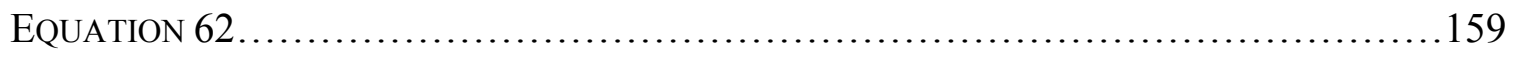




\section{Acknowledgements}

There are many people who supported me through my graduate career. First, I would like to acknowledge my adviser, Dr. Timothy Eisele. I cannot express my gratitude enough for his patience, encouragement, constructive criticism, and willingness to assist me through this process. Second, I would like to thank Newmont for sponsoring the project. Third, I would like to thank all the graduate students who have assisted me in one way or another, in alphabetical order: Justin Carlson, Joseph Halt, Howard Haselhuhn, Jacob McDonald, Brett Spigarelli. Finally, I would like to thank my family and Patrick Quimby for encouragement during my career as a student. 


\begin{abstract}
Silver and mercury are both dissolved in cyanide leaching and the mercury coprecipitates with silver during metal recovery. Mercury must then be removed from the silver/mercury amalgam by vaporizing the mercury in a retort, leading to environmental and health hazards. The need for retorting silver can be greatly reduced if mercury is selectively removed from leaching solutions.
\end{abstract}

Theoretical calculations were carried out based on the thermodynamics of the $\mathrm{Ag} / \mathrm{Hg} / \mathrm{CN}^{-}$ system in order to determine possible approaches to either preventing mercury dissolution, or selectively precipitating it without silver loss. Preliminary experiments were then carried out based on these calculations to determine if the reaction would be spontaneous with reasonably fast kinetics.

In an attempt to stop mercury from dissolving and leaching the heap leach, the first set of experiments were to determine if selenium and mercury would form a mercury selenide under leaching conditions, lowering the amount of mercury in solution while forming a stable compound. From the results of the synthetic ore experiments with selenium, it was determined that another effect was already suppressing mercury dissolution and the effect of the selenium could not be well analyzed on the small amount of change. The effect dominating the reactions led to the second set of experiments in using silver sulfide as a selective precipitant of mercury.

The next experiments were to determine if adding solutions containing mercury cyanide to un-leached silver sulfide would facilitate a precipitation reaction, putting silver in solution and precipitating mercury as mercury sulfide. Counter current flow experiments using the high selenium ore showed a $99.8 \%$ removal of mercury from solution. As compared to leaching with only cyanide, about $60 \%$ of the silver was removed per pass for the high selenium ore, and around $90 \%$ for the high mercury ore. Since silver sulfide 
is rather expensive to use solely as a mercury precipitant, another compound was sought which could selectively precipitate mercury and leave silver in solution. In looking for a more inexpensive selective precipitant, zinc sulfide was tested.

The third set of experiments did show that zinc sulfide (as sphalerite) could be used to selectively precipitate mercury while leaving silver cyanide in solution. Parameters such as particle size, reduction potential, and amount of oxidation of the sphalerite were tested. Batch experiments worked well, showing $99.8 \%$ mercury removal with only $\approx 1 \%$ silver loss (starting with $930 \mathrm{ppb}$ mercury, $300 \mathrm{ppb}$ silver) at one hour.

A continual flow process would work better for industrial applications, which was demonstrated with the filter funnel set up. Funnels with filter paper and sphalerite tested showed good mercury removal (from 31 ppb mercury and 333 ppb silver with a $87 \%$ mercury removal and $7 \%$ silver loss through one funnel). A counter current flow set up showed $100 \%$ mercury removal and under $0.1 \%$ silver loss starting with $704 \mathrm{ppb}$ silver and $922 \mathrm{ppb}$ mercury. The resulting sphalerite coated with mercury sulfide was also shown to be stable (not releasing mercury) under leaching tests. Use of sphalerite could be easily implemented through such means as sphalerite impregnated filter paper placed in currently existing processes.

In summary, this work focuses on preventing mercury from following silver through the leaching circuit. Currently the only possible means of removing mercury is by retort, creating possible health hazards in the distillation process and in transportation and storage of the final mercury waste product. Preventing mercury from following silver in the earlier stages of the leaching process will greatly reduce the risk of mercury spills, human exposure to mercury, and possible environmental disasters. This will save mining companies millions of dollars from mercury handling and storage, projects to clean up spilled mercury, and will result in better health for those living near and working in the mines. 


\section{Introduction}

In lower grade ores, silver and gold are often recovered using a cyanide leach. Leaching can be done in Pachuca tanks (for 8 to 24 hours) or heap leaching (for days or weeks) (Kongolo 1998). After leaching, recovery can be done in a variety of ways: the two most used are zinc cementation and carbon adsorption. Zinc cementation is most often used with high grade solutions, while carbon is used when there are particulates remaining in the solution (Kongolo 1998). Ammoniacal thiosulfate can also leach gold ore (Equation 1) where cyanide is prohibited or not wanted for use, the only advantage being it is less toxic than cyanide (Rath et al 2003).

$$
\mathrm{Au}\left(\mathrm{NH}_{3}\right)_{2}{ }^{+}(\mathrm{aq})+2 \mathrm{~S}_{2} \mathrm{O}_{3}{ }^{-2}(\mathrm{aq}) \rightarrow \mathrm{Au}\left(\mathrm{S}_{2} \mathrm{O}_{3}\right)_{2}^{-3}(\mathrm{aq})+2 \mathrm{NH}_{3}(\mathrm{aq}) \quad \text { Equation } 1
$$

(Rath et al 2003)

Zinc is used to precipitate gold and silver for recovery in the Merrill-Crowe Process (Grosse 2003; Kongolo 1998; Martinez et al 2012; Parga-Torres 2011) (Equation 2 and Equation 3, respectively).

$2 \mathrm{Au}(\mathrm{CN})_{2}^{-}(\mathrm{aq})+\mathrm{Zn}(\mathrm{s}) \rightarrow \mathrm{Zn}(\mathrm{CN})_{4}^{-2}(\mathrm{aq})+2 \mathrm{Au}(\mathrm{s})$ Equation 2

$2 \mathrm{Ag}(\mathrm{CN})_{2}^{-}(\mathrm{aq})+\mathrm{Zn}(\mathrm{s}) \rightarrow \mathrm{Zn}(\mathrm{CN}) 4^{-2}(\mathrm{aq})+2 \mathrm{Ag}(\mathrm{s})$ Equation 3

This process will also precipitate other metals like copper and mercury if present (Washburn 2003).

In the carbon-in-pulp process, activated carbon is used to adsorb $\mathrm{Au}(\mathrm{CN}) 2_{2}^{-}$from solution, (Kongolo 1998) being efficient, low in cost, and having a good purity in the product (Grosse 2003). Activated carbon adsorbs silver, gold and mercury (Washburn 2003). The carbon is then stripped of $\mathrm{Au}, \mathrm{Ag}, \mathrm{Hg}$, and other ions in a stripping solution, then 
processed by electrowinning. In the electrowinning process, all three of these metals then plate out together as an amalgam.

Gold can fairly easily be separated from the other elements, but silver and mercury stay together until the end process; retorting. To further refine the unwanted mercury from the amalgam, the low boiling point $\left(357^{\circ} \mathrm{C}\right)$ and low heat of vaporization $(295.6 \mathrm{~J} / \mathrm{g})$ of mercury is utilized for distillation refining (Washburn 2003; Aktas 2011), known as retorting. Since mercury is vaporized during retorting, there is considerable opportunity for mercury vapor to escape from the process. This also produces metallic mercury, which is hazardous to handle or ship (Hennessy 2005), and has very limited marketability.

A simplified flow diagram of the process, from leach to retort, is shown in Figure 1.1. The main focus of this paper will be on silver and mercury separation. Ideally, mercury would be prevented from dissolving at all, or precipitated, in the heap leach (Figure 1.1, step 1). The other option is removing mercury from silver while in the aqueous form (Figure 1.1, step 2). The current practice is shown is step three in Figure 1.1 as retorting, which is desired to be avoided. 


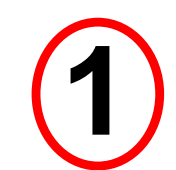

$\approx 20 \mathrm{ft}$ tall, low grade ore pile for leaching
Cyanide solution for leaching

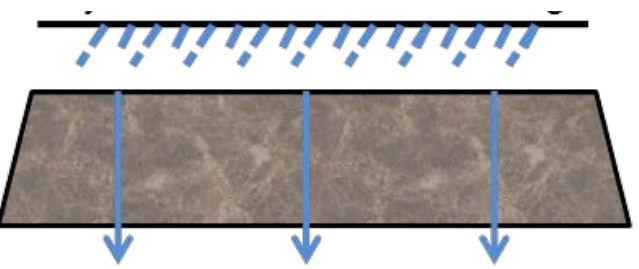

Silver, mercury, and other trace ions

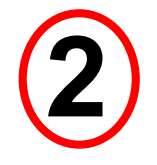

Merrill-Crowe Process

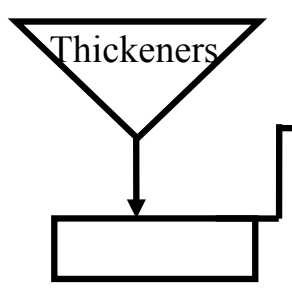

Pressure clarifiers

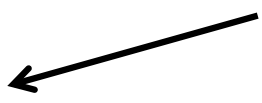

OR

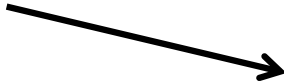

Carbon Adsorption with Electrowinning

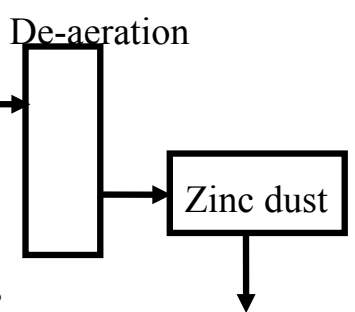

Precipitated metals
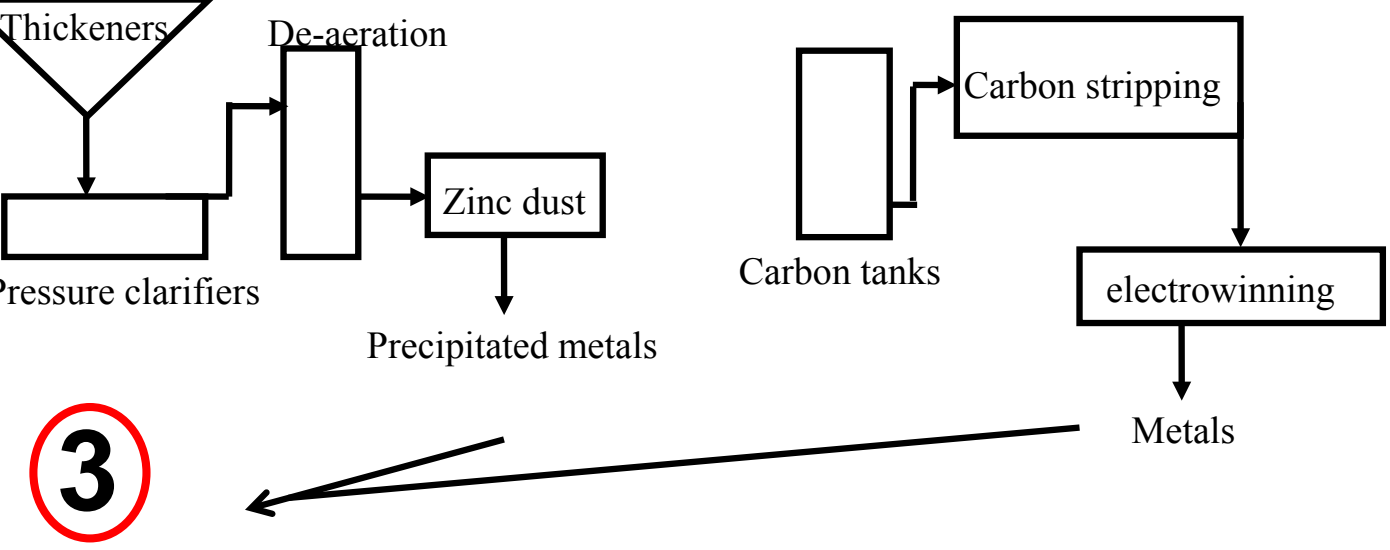

Metals

Cooling towers with filters

Pans of amalgam in oven
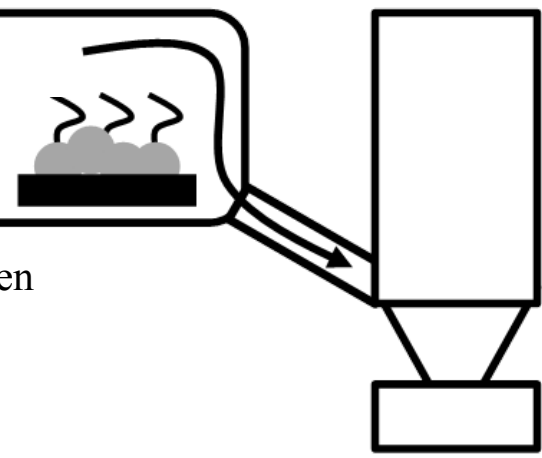

Collection of metallic mercury

Figure 1.1. A simplified flow diagram of the heap leaching process to recover precious metals with cyanide is shown. 
Mercury removal from silver is difficult due to their similar chemistries and similar concentrations in many ores. Silver from leaching operations is currently recovered as a silver/mercury amalgam which must be separated into solid silver and mercury vapor in a retort, as shown earlier. Finding a method to remove mercury from silver selectively under leach conditions before final metal recovery would be beneficial economically and environmentally.

The reason to consider mercury removal from silver is their similar leaching behavior in cyanide. Leaching of gold and silver containing ores is most commonly carried out with a cyanide solution (Washburn 2003; Kongolo 1998)and added ) and oxygen for oxidation (Grosse 2003), dissolving and mobilizing the metals in aqueous form to be concentrated and purified. Even with various purification steps, mercury contamination still poses a problem industrially and environmentally (Grosse 2003; Ravichandran 2004; Misra 1998; Pai 2000; Pedroso 1994).

Better sequestration of mercury can be accomplished by understanding the precious metals' various reactions and stable forms, the species that are present in the leaching process, and possible treatment and separation methods.

The main focus of this study is on silver and mercury separation, with the objective of the research conducted being to prevent mercury from reaching final silver recovery in precious metal leaching. This could be accomplished by either leaving mercury behind in ore, or selectively precipitating mercury from the cyanide leach solution before precipitating metallic silver, and to avoid silver losses. A secondary consideration was to determine whether selenium could play a role in preventing mercury dissolution and consider means for selenium management.

The literature review will cover chemistry and thermodynamics for treatment and separation of mercury from silver and experimental work done to date by other 
researchers will be reviewed. The main body of the dissertation, with theory and experiments, will focus on three avenues of research which were explored and developed based on thermodynamic considerations and confirmed by experiments. The first was the use of selenium to bind mercury, as selenium is well-known to have a strong affinity for mercury (Raymond and Ralston 2004). Initial studies with the use of SEM suggested this might work, after which ores were tested by attempting to bind mercury with selenium in natural and synthetic ores. Upon observing that although selenium was not preventing mercury dissolution under the conditions used, another factor was lowering the mercury. This turned out to be a reaction of mercury cyanide with silver sulfide. The second set of experiments studied the use of silver sulfide to precipitate mercury cyanide from solution, without also precipitating silver. This approach was found to work, but silver sulfide is too expensive to be used except under certain conditions with low-grade ore. An alternative to using silver sulfide was found to be zinc sulfide. This third method used zinc sulfide as a selective precipitant for mercury from a silver and mercury cyanide solution. This method has the potential to be applicable in industry, particularly in the Merrill-Crowe process. 


\section{Literature Review}

\subsection{Chemistry of Silver, Mercury, and Selenium - Metal Ion Species of Interest}

\subsubsection{Mercury and Silver}

In considering possible reactions, the Gibbs free energy is a relevant thermodynamic parameters for the equations: Gibbs free energy $(\Delta \mathrm{G})$ suggests whether the reaction will be spontaneous at a given temperature (negative is spontaneous). From the Gibbs free energy the $K_{\text {eq }}$ value could also be calculated using the equation $\Delta \mathrm{G}=-\mathrm{RT}\left(\ln \mathrm{K}_{\mathrm{eq}}\right)$, where larger $\mathrm{K}_{\mathrm{eq}}$ values are more favorable of the products. Since the $\mathrm{K}_{\mathrm{eq}}$ values are a function of only the $\Delta \mathrm{G}$ values, they are not shown separately. Values for $\mathrm{E}(\mathrm{v})$, or the volts needed as calculated by FactSage $\odot$ from the Nernst equation, for equations showing electrons are also included.

Silver is present in the ore (usually as acanthite, $\mathrm{Ag}_{2} \mathrm{~S}$ ) and is dissolved by the reaction in Equation 4 at room temperature $(298 \mathrm{~K})$. The product $\mathrm{Ag}(\mathrm{CN}) 2^{-}$being the most predominant silver species after cyanide leaching (Equation 4).

$\mathrm{Ag}_{2} \mathrm{~S}(\mathrm{~s})+4 \mathrm{CN}^{-}(\mathrm{aq})+2 \mathrm{O}_{2}(\mathrm{aq}) \rightarrow 2 \mathrm{Ag}(\mathrm{CN})_{2}^{-}(\mathrm{aq})+\mathrm{SO}_{4}^{-2}(\mathrm{aq}) \quad$ Equation 4 $\Delta \mathrm{G}=-815 \mathrm{~kJ}$

Mercury (most often found as cinnabar $(\mathrm{HgS})$ and velikite $\left.\left(\mathrm{Cu}_{2} \mathrm{HgSnS}_{4}\right)\right)$ forms similar cyanide complexes at $298 \mathrm{~K}$, but first must go through an intermediate step (Equation 5), after which it reacts with additional $\mathrm{CN}^{-}$to form the complex $\mathrm{Hg}(\mathrm{CN})_{4}^{-2}$, which is the most predominant mercury species produced by cyanide leaching (Misra 1998) (Equation $6)$. 
$\mathrm{HgS}(\mathrm{s})+2 \mathrm{CN}^{-}(\mathrm{aq})+2 \mathrm{O}_{2}(\mathrm{aq}) \rightarrow \mathrm{Hg}(\mathrm{CN})_{2}(\mathrm{aq})+\mathrm{SO}_{4}^{-2}(\mathrm{aq}) \quad$ Equation 5 $\Delta \mathrm{G}=-763 \mathrm{~kJ}$

$\mathrm{Hg}(\mathrm{CN})_{2}(\mathrm{aq})+2 \mathrm{CN}^{-}(\mathrm{aq}) \rightarrow \mathrm{Hg}(\mathrm{CN})_{4}^{-2}(\mathrm{aq})$

Equation 6 $\Delta \mathrm{G}=-38 \mathrm{~kJ}$

The overall equation is shown in Equation 7. Conditions for cyanide leaching are around $\mathrm{pH} 11$, reduction potential is slightly positive $(\approx 0.1 \mathrm{mV})$ to zero, and cyanide concentrations range from $0.02 \%$ to $0.05 \%$.

$\mathrm{HgS}(\mathrm{s})+4 \mathrm{CN}^{-}(\mathrm{aq})+2 \mathrm{O}_{2}(\mathrm{aq}) \rightarrow \mathrm{Hg}(\mathrm{CN})_{4}^{-2}(\mathrm{aq})+\mathrm{SO}_{4}^{-2}(\mathrm{aq})$

Equation 7 $\Delta \mathrm{G}=-801 \mathrm{~kJ}$

Mercury and silver have very similar electrochemistries (Atkas 2011), which make separation in the aqueous stage difficult (Equation 8 and Equation 9) as the volts needed to electroplate out silver and mercury metals are only $0.02 \mathrm{~V}$ apart. The electrode potentials are given $(\mathrm{E})$ due to the necessity of electrons for the reaction.

$\mathrm{Hg}(\mathrm{CN})_{4}^{-2}(\mathrm{aq})+2 \mathrm{e}^{-}(\mathrm{aq}) \rightarrow \mathrm{Hg}(\mathrm{l})+4 \mathrm{CN}^{-}(\mathrm{aq})$ Equation 8 $\Delta \mathrm{G}=+70 \mathrm{~kJ} ; \mathrm{E}=-0.18 \mathrm{~V}$

$\mathrm{Ag}(\mathrm{CN})_{2}^{-}(\mathrm{aq})+\mathrm{e}^{-}(\mathrm{aq}) \rightarrow \mathrm{Ag}(\mathrm{s})+2 \mathrm{CN}^{-}(\mathrm{aq})$ Equation 9 
$\Delta \mathrm{G}=+38 \mathrm{~kJ} ; \mathrm{E}=-0.20 \mathrm{~V}$

Equations 10,11, and 12 show silver and mercury sulfide dissolution under nonoxidizing conditions to demonstrate the needed for oxygen to drive the dissolution of silver and mercury with cyanide forward. The positive $\Delta \mathrm{G}$ values, and therefore resulting small $\mathrm{K}_{\mathrm{eq}}$ values if calculated, indicate that the reaction essentially does not occur under reducing conditions.

$\mathrm{Ag}_{2} \mathrm{~S}(\mathrm{~s})+4 \mathrm{CN}^{-}(\mathrm{aq}) \rightarrow 2 \mathrm{Ag}(\mathrm{CN})_{2}{ }^{-}(\mathrm{aq})+\mathrm{S}^{-2}(\mathrm{aq})$

Equation 10

$\Delta \mathrm{G}=+47 \mathrm{~kJ}$

$\mathrm{HgS}(\mathrm{s})+2 \mathrm{CN}^{-}(\mathrm{aq}) \rightarrow \mathrm{Hg}(\mathrm{CN})_{2}(\mathrm{aq})+\mathrm{S}^{-2}(\mathrm{aq})$

Equation 11

$\Delta \mathrm{G}=+99 \mathrm{~kJ}$

$\mathrm{HgS}(\mathrm{s})+4 \mathrm{CN}^{-}(\mathrm{aq}) \rightarrow \mathrm{Hg}(\mathrm{CN})_{4}^{-2}(\mathrm{aq})+\mathrm{S}^{-2}(\mathrm{aq})$

Equation 12

$\Delta \mathrm{G}=+61 \mathrm{~kJ}$

The silver cyanide complex is also more likely to form than the final mercury cyanide product (Equation 4) by a small amount of $14 \mathrm{~kJ}$. Equation 10 for silver indicates the products are more favorable than that from the overall mercury reaction. This suggests that silver will always be more favorable under these conditions for dissolving with cyanide than mercury. The important aspect to note is that the silver dissolves in one step (Equation 10), whereas the mercury dissolves to its final, most predominate form found in leach heaps, in two steps (Equation 5 and Equation 6). It is the first step of mercury going to an intermediate phase that required oxygen (Equation 5), whereas the second 
step does not (Equation 6). These two step from mercury dissolution are important to consider in the dissolution and precipitation of mercury versus silver in cyanide.

\subsubsection{Mercury and Selenium}

Selenium is also a highly dangerous element found in silver-bearing ores that leaches out with cyanide. Preventing the leaching of selenium or selectively removing it from the leach liquor, as well as mercury, would be highly desirable. The strong binding between mercury and selenium is well known, (Pettine et al 2012; Raymond and Ralston 2004; Winkle et al 2011). It has been anecdotally reported that high selenium ores do not exhibit mercury problems, which maybe the results a naturally occurring prevention of mercury leaching by selenium. Equation 13 shows the precipitation reaction of mercury selenide, which is favorable under room temperature conditions.

$\mathrm{Hg}^{+2}(\mathrm{aq})+\mathrm{Se}^{-2}(\mathrm{aq}) \rightarrow \mathrm{HgSe}(\mathrm{s})$

Equation 13

$\Delta \mathrm{G}=-380 \mathrm{~kJ}$

Binding selenium in a stable form is also important due to toxicity of selenium (Raymond and Ralston, 2004; Wright 1999). Equation 14 shows that HgSe will not re-leach under non-oxygenated conditions. Equation 14 through 24 shows possible dissolutions with oxygen.

$\mathrm{HgSe}(\mathrm{s})+0.5 \mathrm{O}_{2}(\mathrm{aq})+2 \mathrm{e}^{-}(\mathrm{aq}) \rightarrow \mathrm{HgO}(\mathrm{s})+\mathrm{Se}^{-2}(\mathrm{aq}) \quad$ Equation 14 $\Delta \mathrm{G}=+149 \mathrm{~kJ}$

$\mathrm{HgSe}(\mathrm{s})+0.5 \mathrm{O}_{2}(\mathrm{aq}) \rightarrow \mathrm{Hg}^{+2}(\mathrm{aq})+\mathrm{SeO}_{2}(\mathrm{~s})$ Equation 15

$\Delta \mathrm{G}=+15 \mathrm{~kJ}$ 
$\mathrm{HgSe}(\mathrm{s})+0.5 \mathrm{O}_{2}(\mathrm{aq}) \rightarrow \mathrm{HgO}(\mathrm{s})+\mathrm{Se}(\mathrm{s})$

Equation 16

$\Delta \mathrm{G}=-28 \mathrm{~kJ}$ 
$\mathrm{HgSe}(\mathrm{s})+2.5 \mathrm{O}_{2}(\mathrm{aq}) \rightarrow \mathrm{HgO}(\mathrm{s})+\mathrm{SeO}_{2}(\mathrm{~s}) \quad$ Equation 17 $\Delta \mathrm{G}=-216 \mathrm{~kJ}$

$\mathrm{HgSe}(\mathrm{s})+2 \mathrm{O}_{2}(\mathrm{aq}) \rightarrow \mathrm{Hg}^{+2}(\mathrm{aq})+\mathrm{SeO}_{4}^{-2}(\mathrm{aq})$

Equation 18

$\Delta \mathrm{G}=-271 \mathrm{~kJ}$

$\mathrm{HgSe}(\mathrm{s})+2 \mathrm{O}_{2}(\mathrm{aq})+2 \mathrm{e}^{-}(\mathrm{aq}) \rightarrow \mathrm{Hg}(\mathrm{aq})+\mathrm{SeO}_{4}^{-2}(\mathrm{aq})$

Equation 19

$\Delta \mathrm{G}=-369 \mathrm{~kJ}$

$\mathrm{HgSe}(\mathrm{s})+2 \mathrm{O}_{2}(\mathrm{aq})+2 \mathrm{e}^{-}(\mathrm{aq}) \rightarrow \mathrm{Hg}(\mathrm{l})+\mathrm{SeO}_{4}^{-2}(\mathrm{aq})$

Equation 20

$\Delta \mathrm{G}=-435 \mathrm{~kJ}$

$\mathrm{HgSe}(\mathrm{s})+2.5 \mathrm{O}_{2}(\mathrm{aq})+2 \mathrm{e}^{-}(\mathrm{aq}) \rightarrow \mathrm{HgO}(\mathrm{s})+\mathrm{SeO}_{4}^{-2}(\mathrm{aq})$

Equation 21

$\Delta \mathrm{G}=-502 \mathrm{~kJ}$

$\mathrm{Se}^{-2}(\mathrm{aq})+\mathrm{HgS}(\mathrm{s}) \rightarrow \operatorname{HgSe}(\mathrm{s})+\mathrm{S}^{-2}(\mathrm{aq})$

Equation 22

$\Delta \mathrm{G}=-84 \mathrm{~kJ}$

$\mathrm{HgSe}(\mathrm{s})+4 \mathrm{CN}^{-}(\mathrm{aq}) \rightarrow \mathrm{Hg}(\mathrm{CN})_{4}^{-2}(\mathrm{aq})+\mathrm{Se}(\mathrm{s})+2 \mathrm{e}^{-}(\mathrm{aq})$

Equation 23

$\Delta \mathrm{G}=-32 \mathrm{~kJ}$

$\mathrm{HgSe}(\mathrm{s})+2 \mathrm{CN}^{-}(\mathrm{aq}) \rightarrow \mathrm{Hg}(\mathrm{CN})_{2}(\mathrm{aq})+\mathrm{Se}(\mathrm{s})+\mathrm{e}^{-}(\mathrm{aq})$

Equation 24

$\Delta \mathrm{G}=+5.9 \mathrm{~kJ}$

The reaction with the most negative $\Delta \mathrm{G}$ would result in two toxic substances (Equation 21). Under leach conditions however, looking at the Pourbaix diagram ( also known as an $\mathrm{EpH}$ diagram) (Figure 2.1), the selenium solid and mercury selenide are more likely to 
form and if the reduction potential does get above about zero, then the selenium oxide might leach out. Figure 2.1 has the $\mathrm{pH}$ on the $\mathrm{x}$-axis and electrode potential on the $\mathrm{y}$ axis. The solubility of select compounds and elements are displayed for a given $\mathrm{pH}$ at a given reduction potential. The voltage potential, calculated from the Nernst equation, is with respects to the standard hydrogen electrode (SHE). For example, at pH 8 with -0.2 $\mathrm{mV}, \mathrm{HgSe}, \mathrm{Ag}_{2} \mathrm{~S}$, and Se are expected to precipitate, or remain, as solids. The dashed lines indicate the water stability region in the middle of the graph, which at atmospheric pressure cannot be crossed without water decomposing (at $\mathrm{pH} 8$, above $\approx 0.8 \mathrm{mV}$ and below $\approx-0.48 \mathrm{mV}$ water decomposes). The " $\mathrm{m}=.001$ " refers to the molality of the 
calculated solution which equals $1 \times 10^{-8} \mathrm{~g} / \mathrm{mol}$.

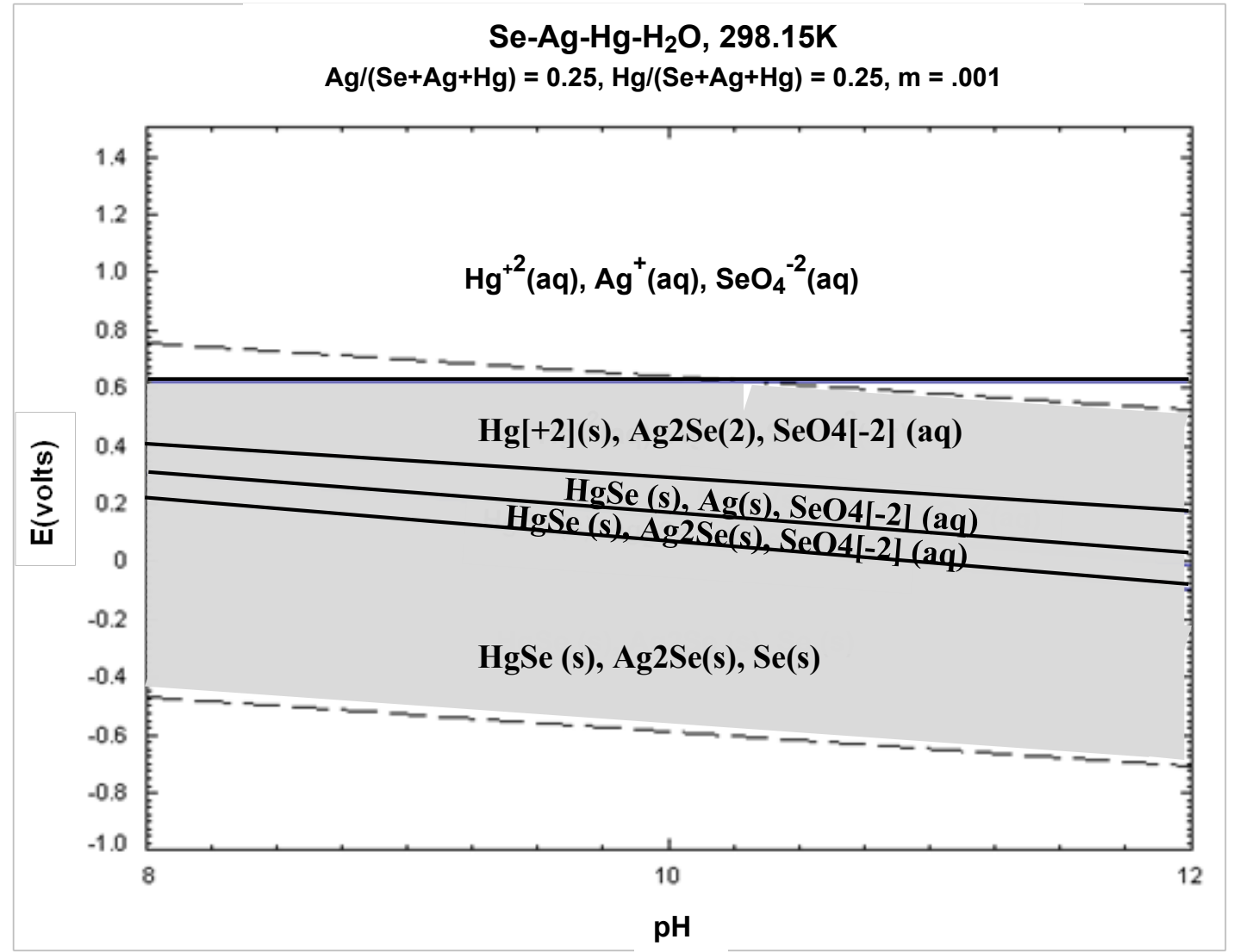

Figure 2.1. Pourbaix $(\mathrm{EpH})$ diagram, generated by FactSage $\mathrm{C}$, of selenium, mercury and silver is shown from $\mathrm{pH} 8$ to $\mathrm{pH} 12$. The solubility of select compounds and elements are displayed for a given $\mathrm{pH}$ at a given reduction potential. Work with cyanide is carried out around $\mathrm{pH} 11$ on the x-axis. At $\mathrm{pH} 11$, following the $y$-axis with reduction potential up, the expected compounds and solubility of the elements are shown.

In a leach heap, with cyanide being present, the re-dissolution of $\mathrm{HgSe}$ in cyanide must be considered. Equation 23 and 24 shows that re-dissolution of mercury selenide with cyanide to form $\mathrm{Hg}(\mathrm{CN}) 4^{-2}$ is favorable, but the necessary intermediate step of forming $\mathrm{Hg}(\mathrm{CN})_{2}$ is not favorable, and so the kinetics would be slow. Equation 22 shows selenium precipitating with mercury sulfide even under conditions without oxygen. 
Important to mention is that while selenocyanide complexes are known to form readily, the thermodynamics of selenium cyanide complexes is largely unknown (Ahrland et al 1974; Loewenschuss and Marcus 1996; Papadoyannis 1984; Skopenko et al 1982). As a result, the Pourbaix diagram is necessarily incomplete and should be regarded as a general guide.

There are several ions that can complex with cyanide. The alkali earth metals (sodium and potassium are most often found) can form salts, which are soluble in water. Weak to moderate complexes include copper, zinc, and cadmium that will ready disassociate from the cyanide with lowering of the $\mathrm{pH}$. Ions that are more stable with cyanide include gold, iron, cobalt. Other metals such as titanium, chromium, lead, arsenic, and cobalt will form ligand-like complexes. Cyanide can also bind to carbon, replacing halogens like chloride. Other minerals in the ore may affect dissolution and precipitation as well, but will not be discussed in depth here. 


\subsection{Treatment and Separation Methods}

There are a variety of treatments for separation of silver and mercury. Some methods are heavily used in industry (discussed in the Introduction), some have only been carried out on an experimental level thus far.

There are three basic areas where mercury could be prevented from dissolving or removed from contaminating the other metals: 1) avoid leach of mercury during the initial leaching process; 2) remove mercury in the leachate/solution before precipitating; 3) remove the mercury after recovery of the metals.

\subsubsection{Prevent Mercury Dissolution during Leaching and Precipitate Mercury from Process Solution}

Various compounds have been studied to selectively remove mercury from leach solutions, both in the heap leach and as precipitants. Issues with these methods for use in the mining industry include expense, poor selectivity, and reaction conditions that were developed for waste treatment. Some of these methods are discussed below. Another interesting, but underdeveloped, possibility for mercury removal would be the use of bacteria, but would most probably be used for wastewater treatment in any initial industrial application (Schaefer et al 2011; Smith et al 1998; Wagner-Döbler 2003) and will not be discussed further.

Using solution directly from leach heaps, and mixed in with the leach heaps, Newmont Metallurgical Services tested the use of polythiocarbonate (PTC) to separate and stabilize mercury from a cyanide leach (Bucknam and McComb 2007). A flow diagram of the tested chemical is shown in Figure 2.2. 


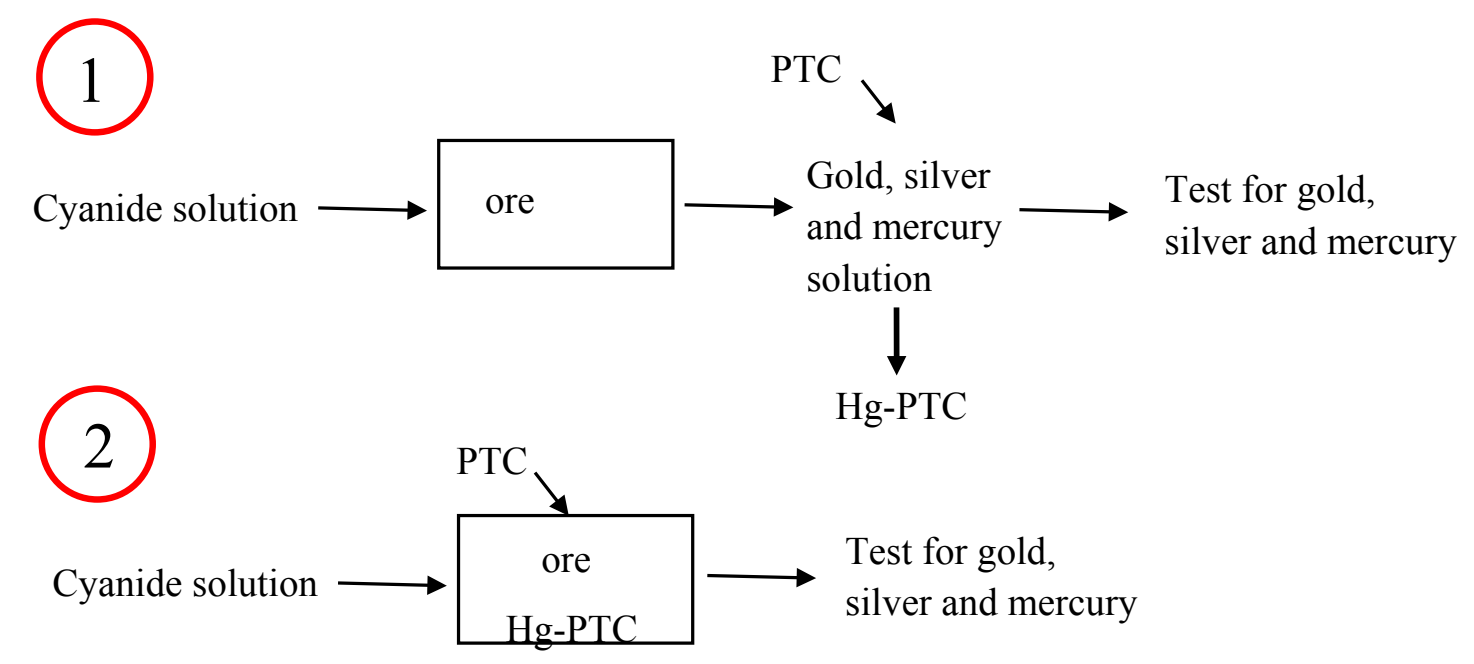

Figure 2.2. Flow diagrams for testing polythiocarbonate (PTC) for mercury sequestration is shown for 1) precipitation of mercury after solution leaves the heap, and 2) precipitation of mercury within the heap.

A diagram of PTC with suspected binding sites to mercury is shown in Figure 2.3. PTC with mercury was shown to be stable after 20 weeks of leaching with water, but did show mercury in solution when leached with cyanide (Bucknam and McComb 2007). For minimal gold and silver loss, the PTC sludge was suggested to be rinsed quickly with cyanide to recover gold and silver, then with water as the mercury leached more slowly than the other two metals (Bucknam and McComb2007). Although a positive step toward reduction of mercury in run-off, there is the cost of the compound to add to the heap, the small amount of silver that is still lost, and the additional time spent in treating the heaps. A preventative method for keeping mercury from entering the solution or a more selective precipitation would benefit the process. 


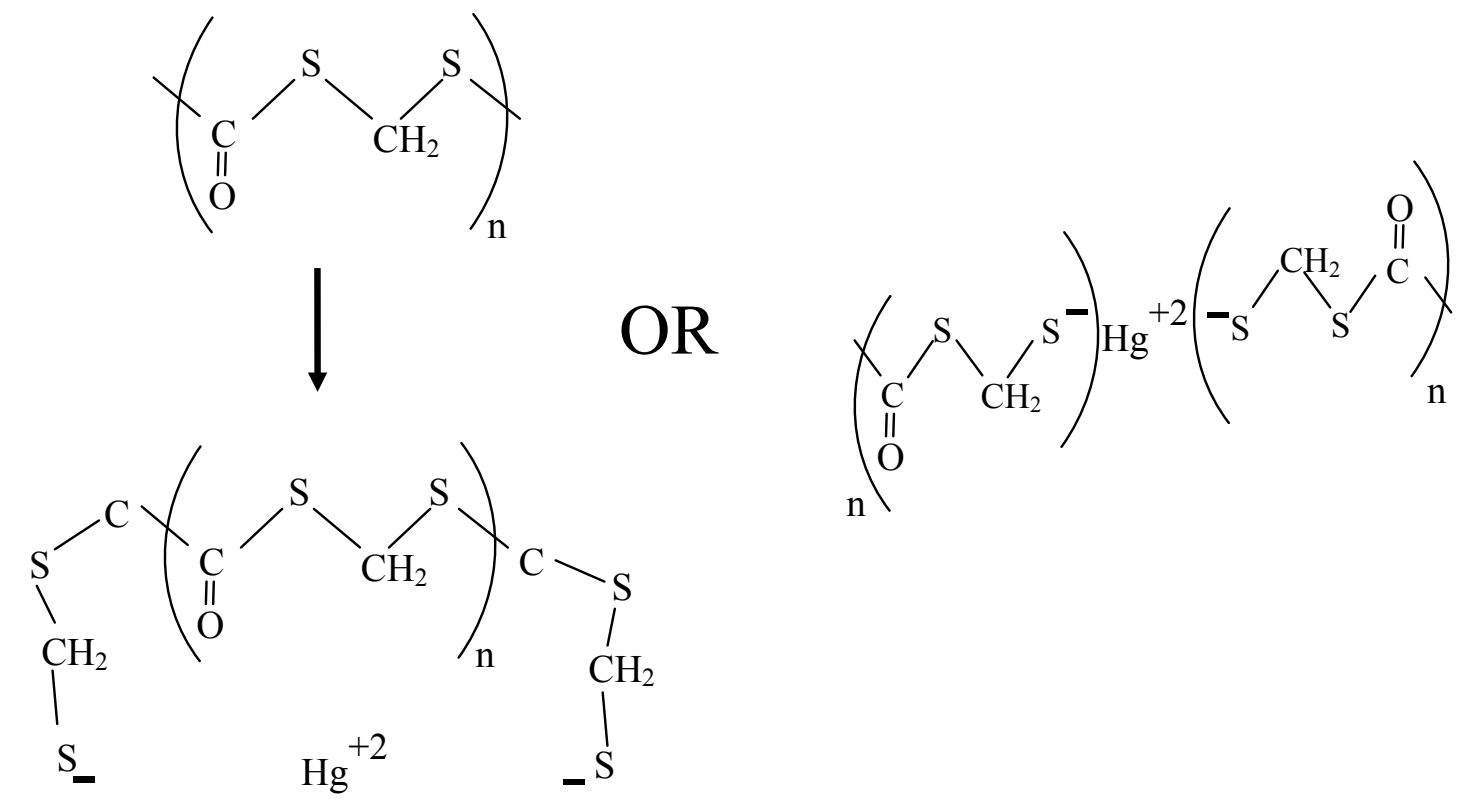

Figure 2.3. Hypothesized polythiocarbonate (PTC) bonding to mercury.

Another potentially promising ligand is 1,3-benzenediamidoethanethiol (BDET or $\mathrm{BDTH}_{2}$ ), tested by Matlock et al. (b. 2002) with leached silver and gold in a cyanide solution. The binding happens through the sulfur atoms (Blue et al. 2008) and also binds to other metal ions particularly copper in leaching operations. A diagram with suspected binding sites to mercury is shown in Figure 2.4. Mercury was shown to be removed with $99.9 \%$ efficiency, down to $0.001 \mathrm{ppm}$ from $0.998 \mathrm{ppm}$. Gold and silver were minimally affected, with only about a $1 \%$ decrease in both. Matlock et al. (b. 2002) also states that the BDET-Hg complex's stability would be sufficient that it would not release mercury in landfills and the ligand might be economically feasible for use in industry. Further work has shown BDET stable and able to bind mercury and other metals (such as arsenic and selenium) in a variety of conditions and the ligand is considered non toxic (Blue et al. 2010). 
Matlock et. al (a. 2002) also used a 1,3-benzenediamidoethanethiol salt to precipitate mercury from solution collected from a gold mining operation in Peru down to 0.008 (part per million) from $34.5 \mathrm{ppm}$ in 15 minutes and claims that prices are low enough to be used in industry. The down side is that other ions (mainly copper) interact with the ligand and decrease effectiveness unless higher doses are added. Gold and silver levels are also slightly affected, about $4.7 \%$ and $6 \%$ losses, respectively.

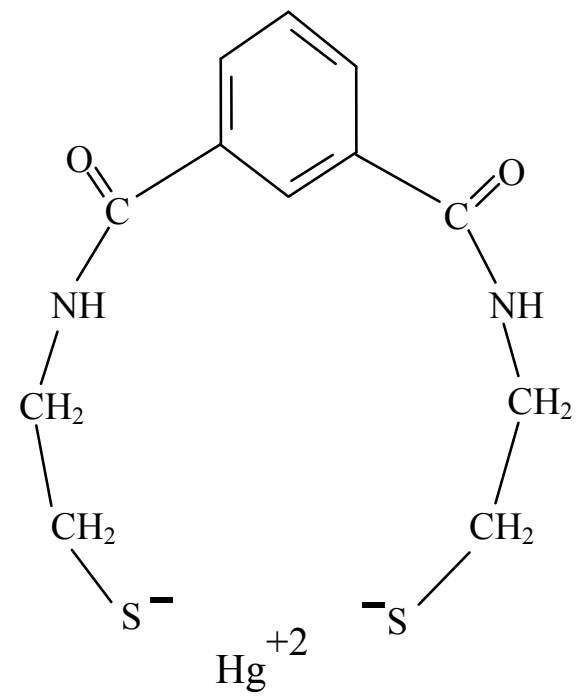

Figure 2.4. 1,3-benzenediamidoethanethiol suspected binding to mercury is shown. Sulfur from two separate molecules could also bond to mercury (not shown).

Misra et al. (1998) demonstrated that $98 \%$ of mercury could be removed (starting from $6.8 \mathrm{ppm}$ ) from gold mine process water with potassium dimethyl dithiocarbamate (KDTC) and gold was not shown to react or be affected by the reagent addition. A diagram with possible binding sites to mercury is shown in Figure 2.5. Furthermore, the resulting complex with mercury was shown to be relatively stable in water: over a 20 day period, only a maximum of 20ppb mercury per day came out of the column. This additive has shown potential in gold mining, but no study has been done, to our 
knowledge, of selective separation of mercury with silver in solution. The economics of using KDCT would also have to be determined.

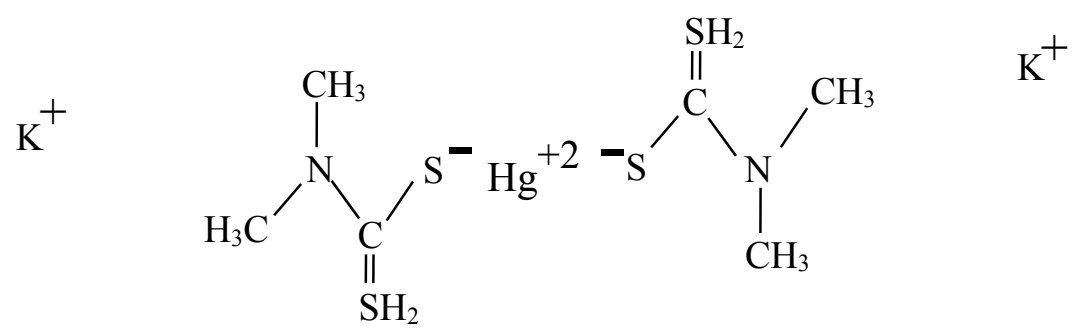

Figure 2.5. Hypothesized KDTC bonding to mercury.

Pedroso et al. (1994) removed mercury by precipitation as mercury oxide from waste sludge from chlorine plants with the strong oxidant sodium hypochlorite. In order to increase extraction over a period of 15 minutes, a drop in $\mathrm{pH}$ from 11 to 7.5 greatly increased recovery by $26 \%$, but a low $\mathrm{pH} 5.5$ resulted in the process not working. Kinetics were also important, as an increased stirring speed was correlated with increased mercury extraction. The best performance of mercury removal from the sludge was $97 \%$, with $0.15 \%$ active chlorine for three hours at slightly elevated temperatures (Pedroso et al. 1994). This could potentially be applied and used to extract mercury selectively from silver, but no literature could be found on attempting this.

Electrocoagulation has been used to removed gold and silver from a cyanide solution, with $96 \%$ and $99 \%$ recovery at $\mathrm{pH} 11.2$ (Martinez et al. 2012). This process used carbon steel sacrificial electrodes, which precipitates silver and gold on to various iron oxide compounds. This methods does work well at precipitating silver and gold in a basic solution even at low concentrations, however one of the major issues would be how to separate the precious metals from the iron oxides. A summary of electrocoagulation theory and practice, along with experimental data and analysis, has been covered by 
Parga et al. (2012), but no information was found on experiments containing mercury. Since mercury is so similar to silver, it is expected that mercury would be plated out, resulting in a silver/mercury amalgam.

Chemical oxygen demand tests (COD) use both silver and mercury for analysis, which led Aslam and Walker (1982) to develop a method of separating the two from solution. Silver chloride (Equation 25) and mercury sulfide (Equation 26) were be formed by the additions of sodium chloride and ferrous sulfide to a solution (Aslam and Walker 1982), as shown in Figure 2.6. The negative aspect of this process, besides the cost of acids, is the formation of the intermediate step of mercuric chloride.

$$
\begin{array}{ll}
\mathrm{Ag}^{+}(\mathrm{aq})+\mathrm{Hg}^{+2}(\mathrm{aq})+3 \mathrm{Cl}^{-}(\mathrm{aq}) \rightarrow \mathrm{AgCl}(\mathrm{s})+\mathrm{HgCl}_{2}(\mathrm{aq}) & \text { Equation } 25 \\
\Delta \mathrm{G}=-130 \mathrm{~kJ} &
\end{array}
$$

$\mathrm{HgCl}_{2}(\mathrm{aq})+\mathrm{H}_{2} \mathrm{~S}(\mathrm{aq}) \rightarrow \mathrm{HgS}(\mathrm{s})+2 \mathrm{H}^{+}(\mathrm{aq})+2 \mathrm{Cl}^{-}(\mathrm{aq}) \quad$ Equation 26 $\Delta \mathrm{G}=-107 \mathrm{~kJ}$

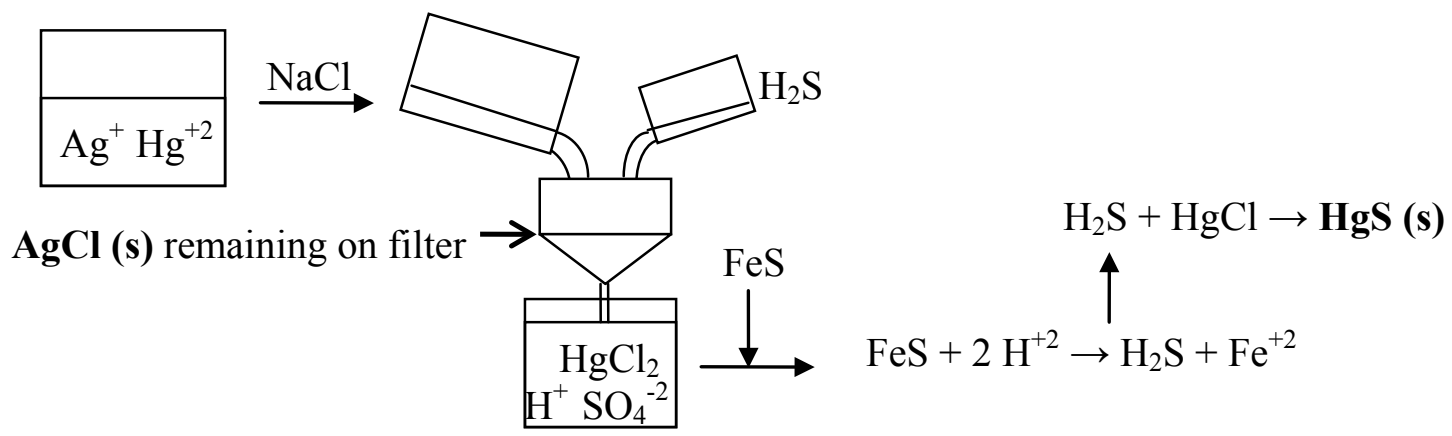

Figure 2.6. The process of silver chloride and mercury sulfide formed by the additions of sodium chloride and ferrous sulfide to a solution is shown. 
A variety of methods have been tested, each with particular conditions, but none showing good selectivity between mercury and silver that could be used on an industrial scale for primary recovery of silver. These methods are summarized in Table 1. 
Table 1. Some compounds investigated for selective removal of mercury from silver in solution, both in the heap and as precipitants are shown. The particular disadvantages of the processes are in bold.

\begin{tabular}{|c|c|c|c|c|c|c|}
\hline Reagent & Dosage & Mercury removal & Selectivity from Silver & $\mathrm{pH}$ & Estimated cost & Source \\
\hline $\begin{array}{l}\text { Sodium polymeric thiocarbonate } \\
\text { precipitates from } \mathrm{Hg}(\mathrm{CN})_{4}^{-2}\end{array}$ & $\begin{array}{l}5 \% \text { of } 2 \mathrm{~kg} \\
\text { residue } \\
\text { weight }\end{array}$ & $\begin{array}{l}95 \% \text { from about } \\
6 \text { ppm, but re- } \\
\text { leaching of } \mathbf{H g}\end{array}$ & $5 \%$ silver loss & 10 & - & $\begin{array}{l}\text { Bucknam } \\
\text { and } \\
\text { McComb } \\
2007\end{array}$ \\
\hline $\begin{array}{l}\text { 1,3-benzenediamidoethanethiol } \\
\text { precipitates from } \mathrm{Hg}(\mathrm{CN})_{4}^{-2}\end{array}$ & $\begin{array}{l}1: 1 \text { with } \\
\text { mercury }\end{array}$ & $\begin{array}{l}34.5 \mathrm{ppm} \text { to } \\
0.008 \mathrm{ppm} \\
\end{array}$ & $\begin{array}{l}6 \% \text { silver loss from } \\
39.8 \mathrm{ppm}\end{array}$ & 0 to14 & $\$ 200 / \mathrm{lbs}$ & $\begin{array}{l}\text { Matlock et } \\
\text { al. a. } 2002\end{array}$ \\
\hline $\begin{array}{l}\text { potassium dimethyl } \\
\text { dithiocarbamate precipitates from } \\
\mathrm{Hg}(\mathrm{CN})_{4}^{-2}\end{array}$ & $\begin{array}{l}2: 1 \text { with } \\
\text { mercury }\end{array}$ & $\begin{array}{l}6.8 \mathrm{ppm} \text { to } 0.13 \\
\mathrm{ppm}\end{array}$ & Not tested & 10.5 & - & $\begin{array}{l}\text { Misra et } \\
\text { al. } 1998\end{array}$ \\
\hline $\begin{array}{l}\text { Sodium sulfide precipitates from } \\
\text { mercury nitrate }\end{array}$ & $\begin{array}{l}\text { 1:1 with } \\
\text { mercury }\end{array}$ & $\begin{array}{l}5 \mathrm{ppm} \text { to } 0.25 \\
\mathrm{ppm}\end{array}$ & Not tested & 10.5 & $\begin{array}{l}60 \% \mathrm{Na}_{2} \mathrm{~S} \$ 0.44 / \mathrm{kg} \\
\text { (Alababa (a) 2013) }\end{array}$ & $\begin{array}{l}\text { Misra et } \\
\text { al. } 1998\end{array}$ \\
\hline $\begin{array}{l}\text { Hypochlorite precipitates mercury } \\
\text { from chlorine-alkali sludge }\end{array}$ & $\begin{array}{l}0.3 \\
\text { solid/liquid } \\
(\mathrm{w} / \mathrm{w}) \text { ratio }\end{array}$ & $\begin{array}{l}97 \% \text { from } 152 \\
\mathrm{mg} \mathrm{Hg} / \mathrm{kg}\end{array}$ & Not tested & 7.5 & $\begin{array}{l}\text { Calcium } \\
\text { Hypochlorite, } 60 \% \text {, } \\
\$ 0.83 / \mathrm{kg} \text { (Alababa } \\
\text { (b) } 2013 \text { ) }\end{array}$ & $\begin{array}{l}\text { Pedroso et } \\
\text { al. } 1994\end{array}$ \\
\hline Electrocoagulation & $\begin{array}{l}13.25 \mathrm{ppm} \\
\mathrm{Au}, \text { and } \\
1357 \mathrm{ppm} \\
\text { Ag per } 400 \\
\mathrm{~mL}\end{array}$ & Not tested & $99.5 \%$ in 5 minutes & $\begin{array}{l}7 \text { to } \\
\text { alkaline }\end{array}$ & $\begin{array}{l}\text { Costs of electricity } \\
\text { and sacrificial iron } \\
\text { electrodes }\end{array}$ & $\begin{array}{l}\text { Martinez } \\
\text { et al } 2012\end{array}$ \\
\hline $\begin{array}{l}\text { Two step precipitation with } \\
\text { chloride and sulfate from } \\
\text { chemical oxygen demand tests }\end{array}$ & $\begin{array}{l}10 \mathrm{gr} / \mathrm{L} \mathrm{NaCl} \\
\text { for } \mathrm{Ag} ; 10 \\
\text { gr FeS for } \\
\mathrm{Hg}(\approx 3 \mathrm{ppm})\end{array}$ & $98 \%$ & Nearly complete & acidic & $\begin{array}{l}\text { estimated } 90 \% \text { cost } \\
\text { reduction from } \\
\text { previous method }\end{array}$ & $\begin{array}{l}\text { Aslam and } \\
\text { Walker } \\
1982\end{array}$ \\
\hline
\end{tabular}




\subsubsection{Remove Mercury from Final Product}

Retorting is the industrial standard for removing mercury from the final silver/mercury amalgam. A few other methods for separating mercury and silver have been research.

Aktas (2010) carried out a study using nitric acid to dissolve silver, mercury, and zinc. Silver was then selectively precipitated by potassium chloride, as shown from Equation 27 and Equation 28, and the process is shown in Figure 2.7.

$\mathrm{Ag}^{+}(\mathrm{aq})+\mathrm{Cl}^{-}(\mathrm{aq}) \rightarrow \mathrm{AgCl}(\mathrm{s})$

Equation 27

$\mathrm{Hg}\left(\mathrm{NO}_{3}\right)_{2}(\mathrm{aq})+\mathrm{KCl}(\mathrm{aq}) \rightarrow \mathrm{Hg}^{+2}(\mathrm{aq})+2 \mathrm{NO}_{3}{ }^{-}(\mathrm{aq})+\mathrm{K}^{+}(\mathrm{aq})+\mathrm{Cl}^{-}(\mathrm{aq})$ Equation 28

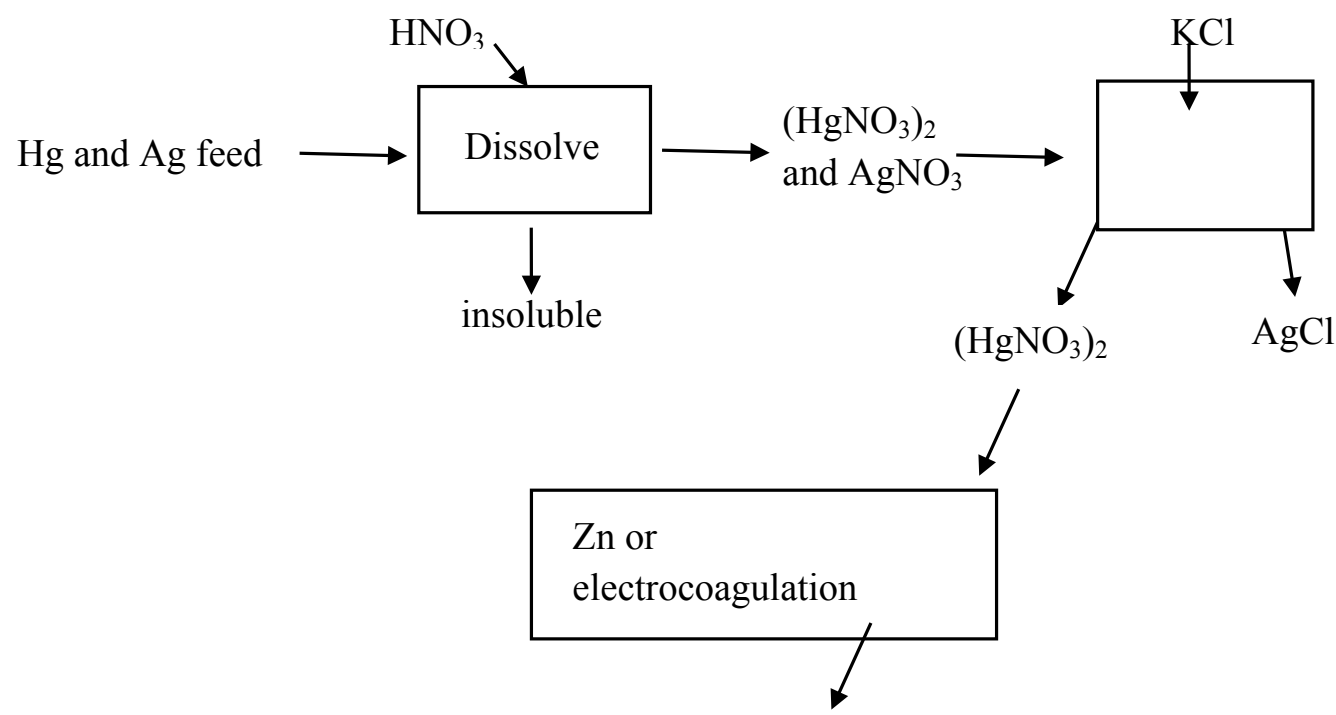

$\operatorname{Hg}(1)$

Figure 2.7. Selective precipitation of silver from mercury by using chloride is shown. 
Mercury was recovered by zinc powder addition at 99\% efficiency and zinc recovered with sodium hydroxide. Due to the use of nitric acid, which dissolves a host of other metals, this method would most likely be useful only as a method for refining silver or replacement for the retorting process.

\subsubsection{Selenium and Mercury}

There are many methods in place for various industries to remove selenium (NAMC 2010), and many studies have been done on selenium, and selenium compounds, removal techniques including the use of iron (Meng et al 2002), iron on calcite (Chakraborty et al 2010), and iron oxide (Jordan et al 2012), treatment with alkali to form a selenocyanate then precipitation with acid (Waehner and Giammarise 1976), and the use of wetlands to remove selenocyanate from wastewater (Ye et al 2003). .

To the best of our knowledge, no studies have been carried out on attempting to stabilize or precipitate mercury with selenium during the cyanide leaching process. 


\section{Suppression of Mercury Dissolution Using Selenium}

\subsection{Introduction}

The goals of the selenium experiments were to determine if mercury could be prevented from dissolving in the heap leach when reacted with selenium according to the reaction

$\mathrm{HgS}+\mathrm{Se}^{-} \rightarrow \mathrm{HgSe}+\mathrm{S}^{-}$producing a low solubility surface layer. The industrial sponsor of this project had made the observation that ores high in selenium had low mercury in the leachate, and those high in mercury had low selenium in the leachate. It was therefore hypothesized that when both mercury sulfide and silver sulfide were exposed to selenium ions in the cyanide leach, mercury sulfide would become selectively coated with $\mathrm{HgSe}$, shielding the mercury sulfide from further dissolution by cyanide solution while the silver sulfide would dissolve. Silver ores exist that are high in selenium, while there are other silver ores that are high in mercury, and leaving mercury un-dissolved in the leaching heap is ideal. It was theorized that the two types of ores could be combined to prevent mercury and selenium leaching. A flow diagram of the experiment is shown in Figure 3.1. 


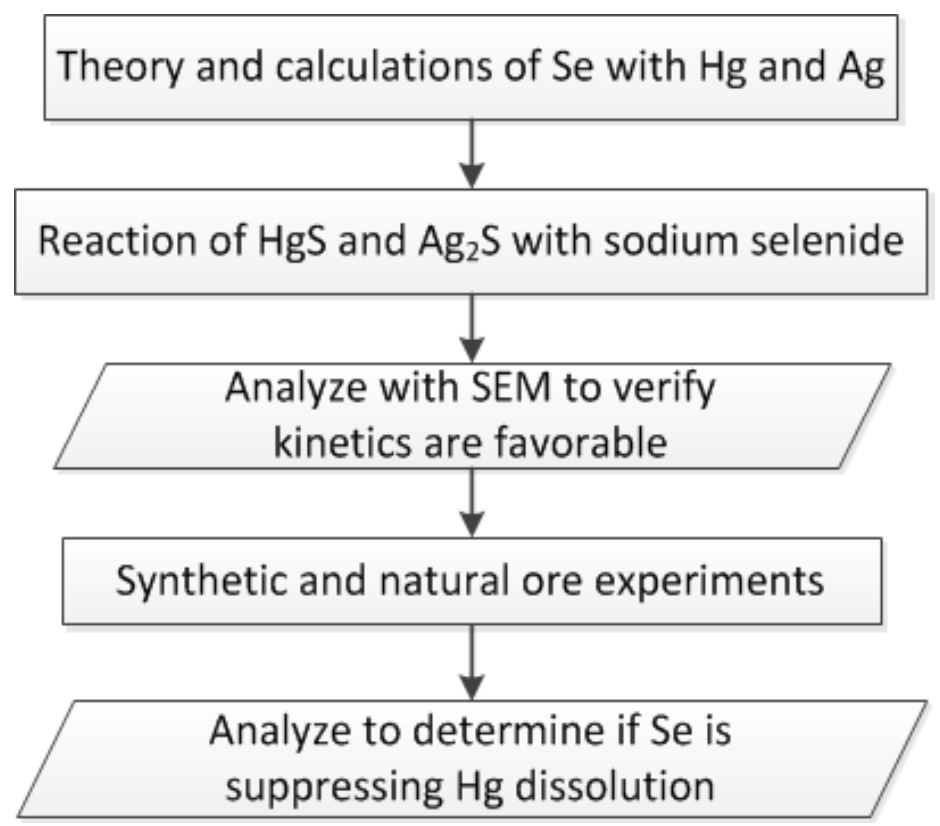

Figure 3.1. Flow diagram showing experiments done with regards to effects of selenium.

\subsection{Theoretical Discussion}

The first goal was to determine if the reactions proposed were thermodynamically favorable for the desired effects under leaching conditions.

Selenium can form several salts, with or without oxygen, that readily react with mercury. When reacted with mercury sulfide, all three forms of selenium are favorable for precipitating mercury selenide at 298K. FactSage C (version 6.2, 2010), a thermochemical software and database, was used to determine thermodynamic reactivity of compounds in a silver cyanide leach with high mercury concentrations and the possibility of the addition of ore with high selenium concentrations. Equations 29 through 31 show possible reactions with $\mathrm{Se}^{-2}$;

$\mathrm{HgS}(\mathrm{s})+\mathrm{Se}^{-2}(\mathrm{aq}) \rightarrow \operatorname{HgSe}(\mathrm{s})+\mathrm{S}^{-2}(\mathrm{aq})$ Equation 29 $\Delta \mathrm{G}=-84 \mathrm{~kJ}$; 
$\mathrm{HgS}(\mathrm{s})+\mathrm{Se}^{-2}(\mathrm{aq})+\mathrm{O}_{2}(\mathrm{aq}) \rightarrow \mathrm{HgSe}(\mathrm{s})+\mathrm{SO}_{2}(\mathrm{aq})+2 \mathrm{e}^{-}(\mathrm{aq}) \quad$ Equation 30 $\Delta \mathrm{G}=-487 \mathrm{~kJ}$;

$\mathrm{Ag}_{2} \mathrm{~S}(\mathrm{~s})+\mathrm{Se}^{-2}(\mathrm{aq})+\mathrm{O}_{2}(\mathrm{aq}) \rightarrow \mathrm{Ag}_{2} \mathrm{Se}(\mathrm{s})+\mathrm{SO}_{2}(\mathrm{aq})+2 \mathrm{e}^{-}(\mathrm{aq}) \quad$ Equation 31 $\Delta \mathrm{G}=-505 \mathrm{~kJ}$;

Equations 32 and 33 show possible reactions with $\mathrm{SeO}_{3}{ }^{-2}$.

$\mathrm{HgS}(\mathrm{s})+\mathrm{SeO}_{3}^{-2}(\mathrm{aq}) \rightarrow \mathrm{HgSe}(\mathrm{s})+\mathrm{SO}_{3}^{-2}(\mathrm{aq})$

Equation 32

$\Delta \mathrm{G}=-99 \mathrm{~kJ}$;

$\mathrm{Ag}_{2} \mathrm{~S}(\mathrm{~s})+\mathrm{SeO}_{3}{ }^{-2}(\mathrm{aq}) \rightarrow \mathrm{Ag}_{2} \mathrm{Se}(\mathrm{s})+\mathrm{SO}_{3}{ }^{-2}(\mathrm{aq})$

Equation 33

$\Delta \mathrm{G}=-117 \mathrm{~kJ}$

Equation 34 and 35 show possible reactions with $\mathrm{SeO}_{4}{ }^{-2}$.

$\mathrm{SeO}_{4}{ }^{-2}(\mathrm{aq})+\mathrm{Ag}_{2} \mathrm{~S}(\mathrm{~s}) \rightarrow \mathrm{Ag}_{2} \mathrm{Se}(\mathrm{s})+\mathrm{SO}_{4}{ }^{-2}(\mathrm{aq})$

Equation 34

$\Delta \mathrm{G}=-313 \mathrm{~kJ}$

$\mathrm{SeO}_{4}^{-2}(\mathrm{aq})+\mathrm{HgS}(\mathrm{s}) \rightarrow \mathrm{HgSe}(\mathrm{s})+\mathrm{SO}_{4}^{-2}(\mathrm{aq})$

Equation 35

$\Delta \mathrm{G}=-295 \mathrm{~kJ}$

In the lab, $\mathrm{SeO}_{4}{ }^{-2}$ was used, due to its being the most common form of selenium in basic solutions, its stability in oxidizing conditions, use in animal feed stocks, the fact that is less deadly than the next most reaction selenium salt $\mathrm{SeO}_{3}{ }^{-2}$ (having a higher toxicity thresh hold than the others) (Abdo 1994), and it is one of the more reactive salts 
according to the Gibbs free energy. If aqueous selenium selenate were added to silver and mercury sulfides, their Gibbs free energy to form selenides are similar (Equation 34 and Equation 35). If the silver and mercury selenides are then leached with cyanide, taking into account that mercury must form $\mathrm{Hg}(\mathrm{CN})_{2}$ as an intermediate before proceeding to $\mathrm{Hg}(\mathrm{CN}) 4^{-2}$, silver would dissolve in a cyanide complex and mercury would tend to remain as a solid mercury selenide (Equation 36 and Equation 37).

$\mathrm{Ag}_{2} \mathrm{Se}(\mathrm{s})+4 \mathrm{CN}^{-}(\mathrm{aq}) \rightarrow 2 \mathrm{Ag}(\mathrm{CN})_{2}{ }^{-}(\mathrm{aq})+\mathrm{Se}(\mathrm{s})+2 \mathrm{e}^{-}(\mathrm{aq}) \quad$ Equation 36 $\Delta \mathrm{G}=-27 \mathrm{~kJ}$

$\mathrm{HgSe}(\mathrm{s})+2 \mathrm{CN}^{-}(\mathrm{aq}) \rightarrow \mathrm{Hg}(\mathrm{CN})_{2}(\mathrm{aq})+\mathrm{Se}(\mathrm{s})+2 \mathrm{e}^{-}(\mathrm{aq})$ Equation 37 $\Delta \mathrm{G}=+5.8 \mathrm{~kJ}$

Since the $\Delta \mathrm{G}$ for the initial stage of $\mathrm{HgSe}$ dissolution is positive, while $\mathrm{Ag}_{2} \mathrm{Se}$ dissolution is negative, mercury selenide should selectively remain solid as silver cyanide leaches out (Equation 36 and Equation 37, respectively) as shown in Figure 3.2.

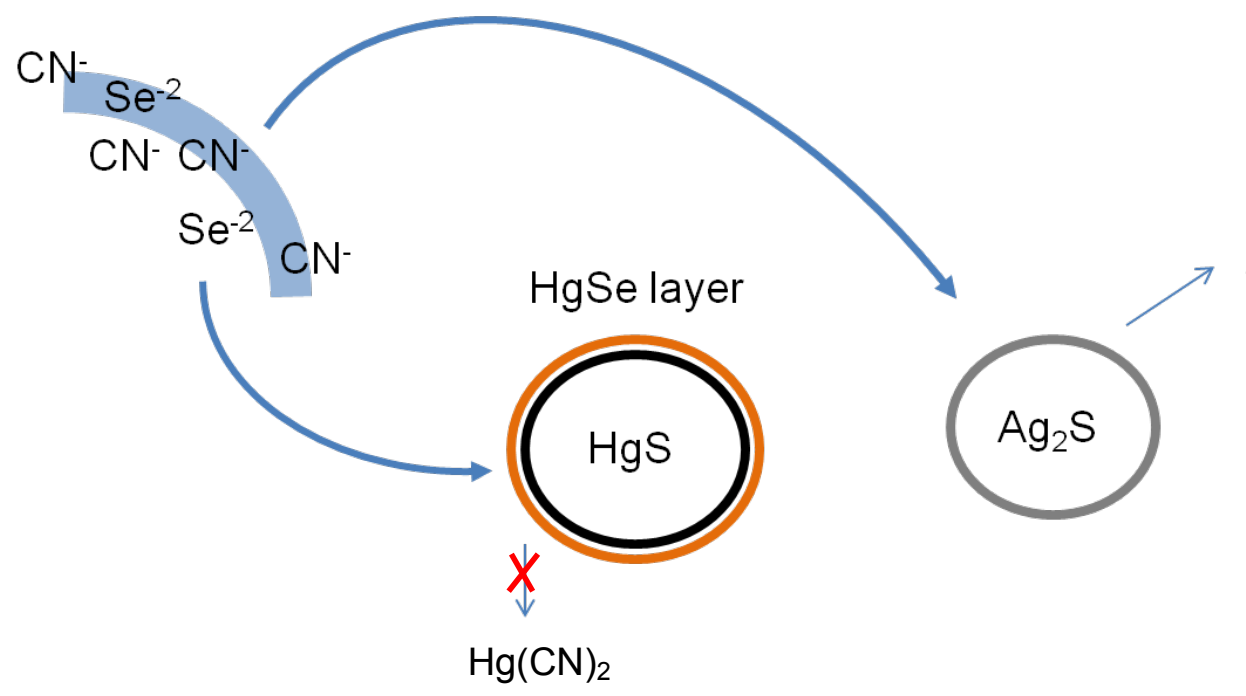

$\mathrm{Ag}(\mathrm{CN})_{2}^{-}$

$\downarrow \mathrm{Se}^{-2}$

AgSe $\mathrm{CN}^{-}$ $\mathrm{Ag}(\mathrm{CN})_{2}^{-}$

Figure 3.2. Reactions of selenium in solution reacting with mercury to form $\mathrm{HgSe}$, and showing silver dissolving into solution. 
Also important to consider is the affect reduction potential will have on selenium. Figure 3.3 shows the EpH diagram for selenium in water. From this, we can theorize that in order for selenium in the experiments to remain as a solid at $\mathrm{pH} 11$, a negative reduction potential will be needed. 


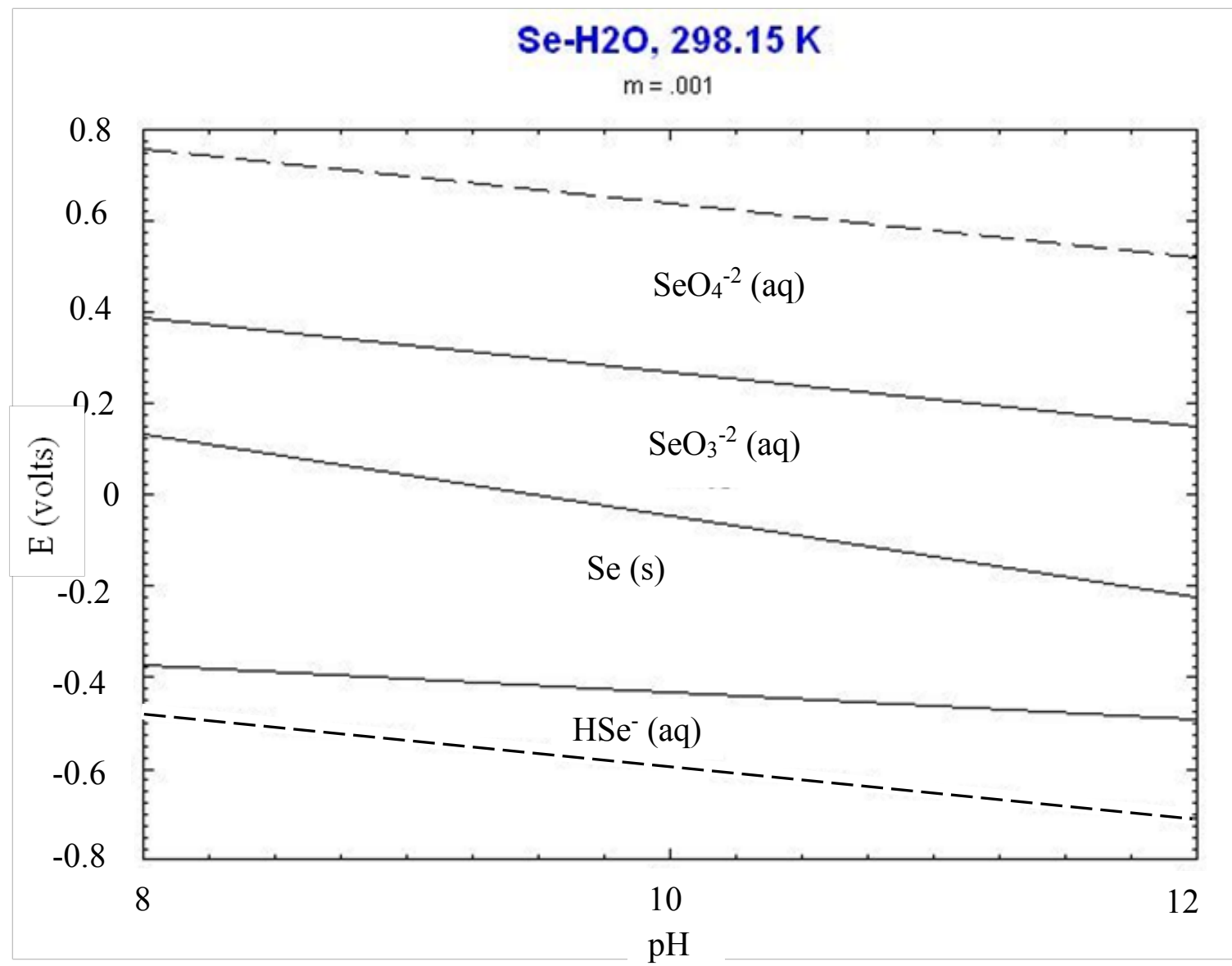

Figure 3.3. Pourbaix $(\mathrm{EpH})$ diagram, generated by FactSage $\mathrm{C}$, of selenium in water from $\mathrm{pH} 8$ to $\mathrm{pH} 12$, showing regions of solubility.

There are two possible ways in which to include selenium in the heap leach process (Figure 3.4). One possibility could be blending high-mercury ore with high-selenium ore from another site then leaching the heap with cyanide. The second option could be leaching a high selenium ore by itself then using the Se-bearing leachate from the high selenium ore to leach a high mercury ore. It should be noted that, for a variety of reasons, (toxicity, lack of interest for application) little work has been done with selenium and selenide compounds to determine the thermodynamics of their reactions in cyanide solution. Calculations from the limited data availability may therefore not reflect what happens in experiments. 

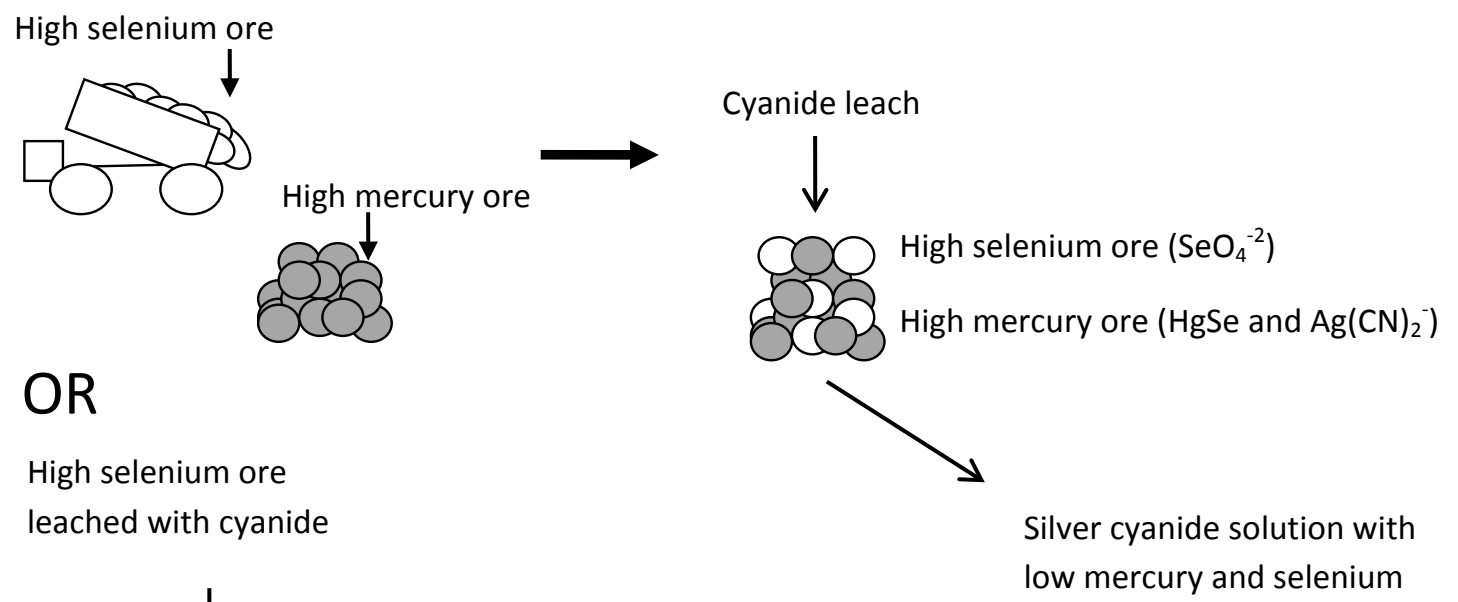

High selenium ore leached with cyanide low mercury and selenium

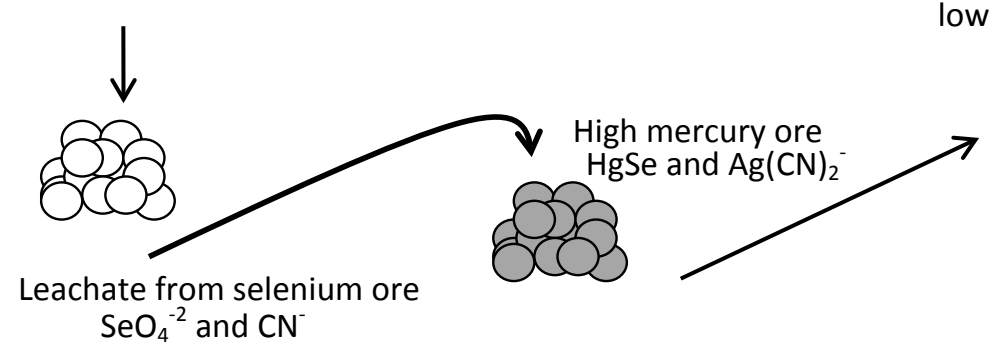

Figure 3.4. Possible use of high selenium ore with high mercury ore in heap leach operations. 


\subsection{Experimental Procedures}

The goal here was to determine whether selenium could be used to suppress mercury dissolution without impairing silver dissolution. The first step for use of the selenium with the mercury was to provide evidence that $\mathrm{HgSe}$ actually formed preferentially on the $\mathrm{HgS}$ surface. To determine whether the reaction was happening, samples of mercury sulfide were immersed in a selenium solution and the surface analyzed under the SEM. The second step was the use of synthetic "ore" and natural ore were used in determining what the effects were on the leaching of mercury and silver. The natural ores were provided by the sponsoring company Newmont.

\section{Materials}

Reagents used were:

- distilled water

- mercury sulfide: chemical grade particles, $\beta$ form (particle top size $0.5 \mathrm{~mm}$ ), and a pure crystal for the $\alpha$ form (obtained by gracious donation from A.E. Seaman Mineral Museum by Dr. George Robinson). The exposed crystal surface of the $\alpha$ mercury sulfide crystal was $2 \mathrm{~mm}$ at the thickest part, $1 \mathrm{~mm}$ at the thinnest, $5 \mathrm{~mm}$ long, and ranged from half to $1 \mathrm{~mm}$ thick

- silver sulfide: chemical grade particles, essentially powder ( $0.5 \mathrm{~mm}$ top size), and a mineral from Reyes Mine, Guanajuato, Mexico. The acanthite from Reyes Mine was about $1 \mathrm{~mm}$ thick, nearly $1 \mathrm{~mm}$ wide, and $2 \mathrm{~mm}$ long in a rough rectangular shape

- sodium selenate

- ammonia

- $\quad$ sodium hydroxide

- nitric acid and hydrochloric acid (ratio 1:4 respectively)

- a high selenium ore ("High Se”) (particles size Table 2, elements Table 3)

- a high mercury ore ("High Hg”) (particles size Table 2, elements Table 3) 
All experiments were done at room temperature.

Table 2. Size distribution of the High Se $(80 \%$ passing $1.86 \mathrm{~mm})$ and High $\mathrm{Hg}(80 \%$ passing $5.02 \mathrm{~mm}$ ) ores.

\begin{tabular}{|r|r|r|}
\hline $\begin{array}{l}\text { mesh opening } \\
(\mathrm{mm})\end{array}$ & $\begin{array}{l}\text { High Se ore } \\
\text { cumulative \% passing }\end{array}$ & $\begin{array}{l}\text { High Hg ore } \\
\text { cumulative \% passing }\end{array}$ \\
\hline 4.699 & 99.9 & 74.8 \\
\hline 2.362 & 90.9 & 50.1 \\
\hline 0.85 & 48.9 & 27.9 \\
\hline 0.3 & 31.3 & 14.1 \\
\hline 0.104 & 22.5 & 6.4 \\
\hline 0.061 & 16.7 & 4.1 \\
\hline
\end{tabular}

Table 3. High Se and High $\mathrm{Hg}$ ore composition (information from sponsoring company). Other ions not shown include $\mathrm{S}, \mathrm{SO}_{4}$, and oxygen .

\begin{tabular}{|l|l|l|}
\hline Element & High Se ore $(\mathrm{ppm})$ & High Hg ore $(\mathrm{ppm})$ \\
\hline $\mathrm{Ag}$ & Not given & 18.1 \\
\hline $\mathrm{Al}$ & 35773 & 2804 \\
\hline $\mathrm{As}$ & 20 & 1078 \\
\hline $\mathrm{Ca}$ & 53369 & 2133 \\
\hline $\mathrm{Cu}$ & 78 & 318 \\
\hline $\mathrm{Fe}$ & 26907 & 25322 \\
\hline $\mathrm{Hg}$ & 0.46 & 11.89 \\
\hline $\mathrm{K}$ & 31886 & 464 \\
\hline $\mathrm{Mg}$ & 4725 & 105 \\
\hline $\mathrm{Na}$ & 6344 & 1100 \\
\hline $\mathrm{Pb}$ & 21 & 706 \\
\hline $\mathrm{Se}$ & 29 & 0.48 \\
\hline $\mathrm{Zn}$ & 92 & 46.5 \\
\hline
\end{tabular}

All mercury, silver, and zinc analysis carried out at Michigan Technological University was done with a Varian Atomic Absorption spectrophotometer (240FS), using a Varian Cold-Vapor apparatus for the mercury analysis (Shrader and Hobbins 1983). All particle size analysis was done at Michigan Technological University with a Microtrac, software 
version 7.02. Reasons for the variations in starting concentrations for silver and mercury are found in Appendix 1. Measurements of reduction potential and $\mathrm{pH}$ of solution were carried out with a Thermo Scientific Orion Dual Star $\mathrm{pH} / \mathrm{ISE}$ Bench top system with $\mathrm{pH}$ $( \pm 0.002)$ and reduction potential $( \pm 0.2 \mathrm{mV})$ electrodes.

\subsection{SEM Images of Selenium Reacted with Mercury or Silver Sulfide}

Initial experiments were carried out to determine if selenium in solution would react with mercury in both the $\alpha$ and $\beta$ forms (crystal structure difference, negligible difference in thermodynamic calculation), and with silver sulfide. The goal of this experiment was to show whether or not selenium would selectively react with mercury sulfide in preference to silver sulfide.

\section{Methods}

Mercury sulfide ( $\alpha$ as a natural crystal, and $\beta$ as a synthetic powder) and silver sulfide (as natural acanthite and also as a synthetic powder) were reacted with sodium selenate in solution and analyzed under the SEM. Reaction procedures are shown in Figure 3.5 and Figure 3.6. Solutions used for reactions with sodium selenate $(7.56 \mathrm{mM})$ were at $\mathrm{pH} 11$ with ammonia. The ammonia was used to bring the $\mathrm{pH}$ to 11 while also maintaining the redox potential in the range where elemental selenium would be stable, giving the solution a negative reduction potential. Solutions raised to $\mathrm{pH} 11$ by sodium hydroxide were also tested. Mercury sulfide and silver sulfide samples were exposed to the selenium solution for 24 hours. Both samples of reacted mercury sulfide and both samples of reacted silver sulfide were rinsed with distilled water before, drying, mounting (in the case of the synthetic particles only), and analysis.

The JEOL JSM-6400 scanning electron microscope (SEM) was used for the energydispersive x-ray spectrometer (EDS) imaging and analysis to show the extent of reactions 
between the compounds. Background on the use of the EDS is given in Appendix 2. All SEM work was done at accelerating voltage $20 \mathrm{~V}$ and dwell time of 60 seconds for EDS analysis.

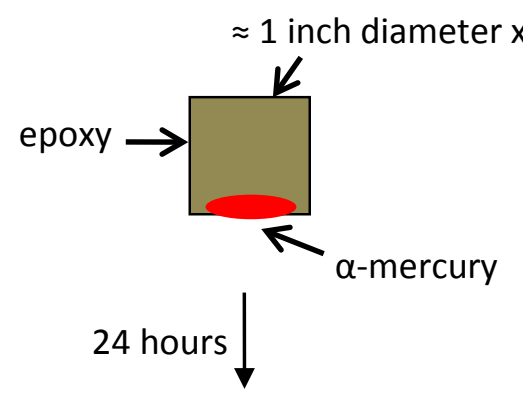

Analyzed in SEM

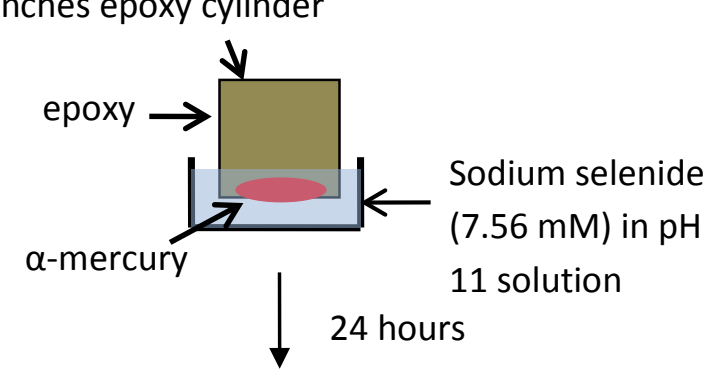

Analyzed in SEM

Figure 3.5. Experimental set-up for $\alpha$-Hgs mounted in epoxy and analyzed in the SEM. The same procedure was used for the silver sulfide specimen.

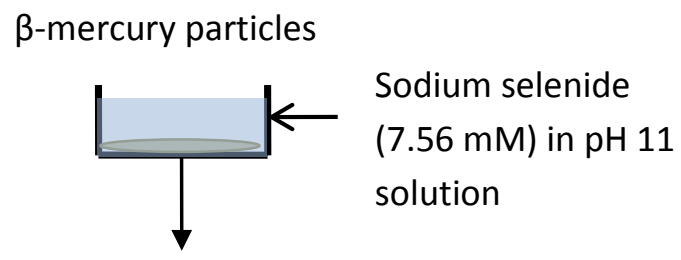
$\beta$-mercury particles mounted
Reacted and rinsed $\beta$-mercury particles mounted

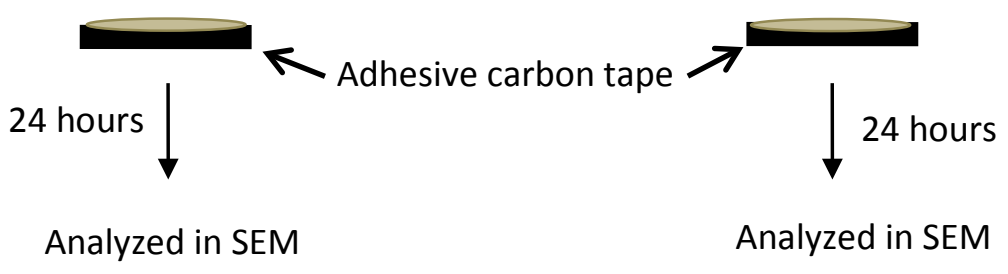

Figure 3.6. Experimental set-up for $\beta-\mathrm{HgS}$ and silver sulfide mounted on carbon tape and analyzed in the SEM. The same procedure was used for the silver sulfide specimen. 


\section{Experimental Results and Discussion}

Results from the sodium hydroxide trials showed no changes to the surface of the particles. Results from the ammonia experiments with the SEM indicated that about $4 \%$ selenium was on the surface of the cinnabar crystal reacted with selenium and no selenium was found on the non-reacted cinnabar (Table 4). The synthetic $\mathrm{HgS}$ also precipitated selenium at about $1.6 \%$ and the non-reacted synthetic $\mathrm{HgS}$ also did not precipitate selenium (Table 5). The synthetic silver sulfide analysis showed no selenium on the surface (Table 6). The crystal acanthite not reacted and reacted with selenium showed no selenium on the surface (Table 7).

Table 4. EDS at $20 \mathrm{KeV}$ analysis of $\mathrm{HgS}$ crystal reacted with selenium and the $\mathrm{HgS}$ crystal not reacted, showing about $3.9 \%$ selenium on the surface of the reacted particle.

\begin{tabular}{|l|l|l|}
\hline Element & $\begin{array}{l}\text { Weight } \% \alpha-\mathrm{HgS} \\
\text { reacted with selenium }\end{array}$ & $\begin{array}{l}\text { Weight } \% \alpha-\mathrm{HgS} \text { not } \\
\text { reacted }\end{array}$ \\
\hline mercury & 60.9 & 63.5 \\
\hline selenium & 3.9 & 0.01 \\
\hline Sulfur & 35.0 & 36.4 \\
\hline
\end{tabular}

Table 5. EDS at $20 \mathrm{KeV}$ analysis of $\mathrm{HgS}$ particle reacted with selenium and before the reaction, showing about $1.6 \%$ selenium on the surface of the reacted particle.

\begin{tabular}{|l|l|l|}
\hline Element & $\begin{array}{l}\text { Weight } \% \beta-\mathrm{HgS} \\
\text { reacted with selenium }\end{array}$ & $\begin{array}{l}\text { Weight } \% \beta-\mathrm{HgS} \text { not } \\
\text { reacted }\end{array}$ \\
\hline mercury & 60.4 & 65.2 \\
\hline selenium & 1.6 & 0.06 \\
\hline Sulfur & 37.8 & 34.6 \\
\hline
\end{tabular}


Table 6. EDS at $20 \mathrm{KeV}$ analysis of synthetic $\mathrm{Ag}_{2} \mathrm{~S}$ particle reacted with selenium, showing no selenium on the surface of the particle. The untreated sample was essentially identical.

\begin{tabular}{|l|l|}
\hline Element & $\begin{array}{l}\text { Weight \% synthetic } \mathrm{Ag}_{2} \mathrm{~S} \\
\text { reacted with selenium }\end{array}$ \\
\hline selenium & 0.01 \\
\hline Silver & 80.9 \\
\hline Sulfur & 19.0 \\
\hline
\end{tabular}

Table 7. EDS at $20 \mathrm{KeV}$ analysis of acanthite reacted with selenium and not reacted with selenium, showing no selenium on the surface of the particle after the reaction. No significant change from the not reacted sample. The data on the not reacted sample was included in case naturally occurring selenium had been in the sample.

\begin{tabular}{|l|l|l|}
\hline Element & $\begin{array}{l}\text { Weight \% acanthite } \\
\text { reacted with selenium }\end{array}$ & $\begin{array}{l}\text { Weight \% acanthite } \\
\text { not reacted }\end{array}$ \\
\hline Selenium & 0.01 & 0.01 \\
\hline Silver & 77.0 & 77.3 \\
\hline Sulfur & 22.9 & 22.6 \\
\hline
\end{tabular}

The images from the $\beta$-mercury crystal are shown in Figure 3.7 and the images from the silver sulfide sample in Figure 3.8. 


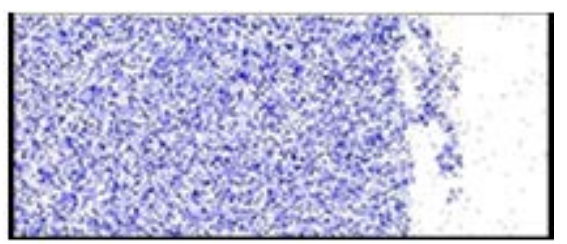

Sulfur

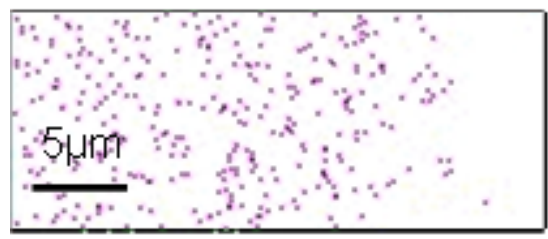

Selenium

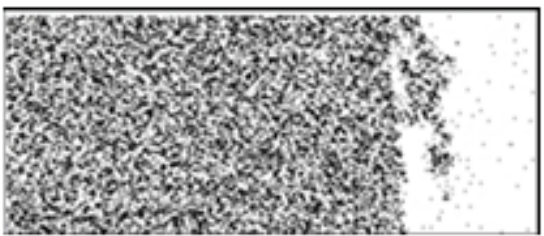

Mercury

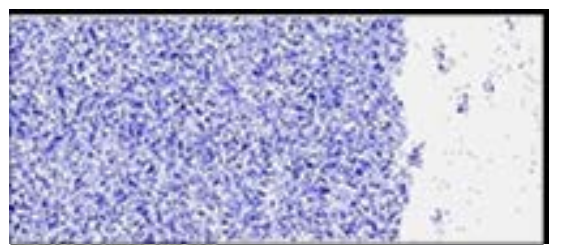

Sulfur

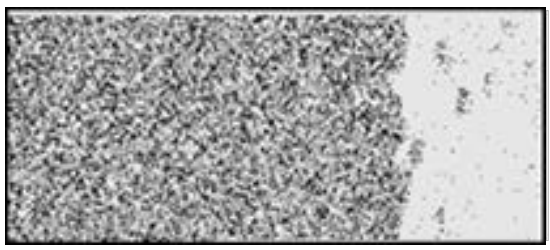

Mercury

Figure 3.7. A $\beta$-mercury crystal not reacted (top) and reacted with (bottom) selenium, analyzed by SEM at accelerating voltage $20 \mathrm{~V}$, magnification $4,000 \mathrm{x}$ for the top images, and 1000x for the lower images, is shown. 


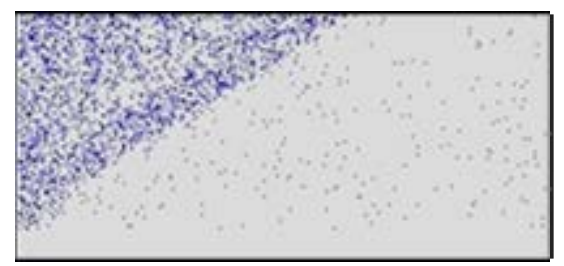

Sulfur
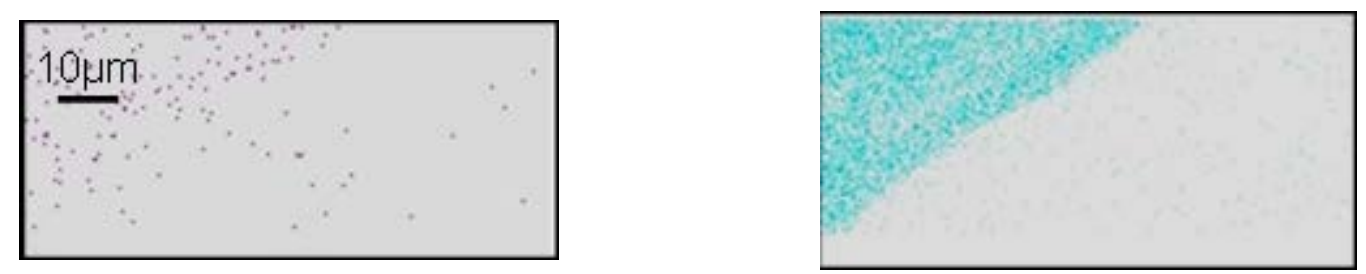

Selenium

Silver

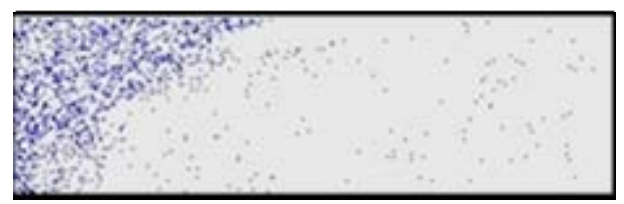

Sulfur

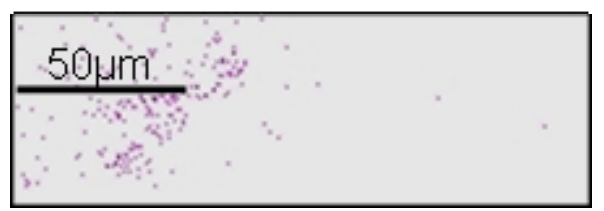

Selenium
Silver

Figure 3.8. Silver sulfide as a crystal is shown not reacted (top) and reacted with (bottom) selenium at accelerating voltage $20 \mathrm{~V}$ and magnification $1,000 \mathrm{x}$ for the upper images, and 500x for the lower images. 
The goal was to demonstrate that selenium was found on the surface of the particles, which was accomplished by the EDS quantitative analysis, since not a large difference was seen in the images.

Selenium was clearly present on the surface of the $\alpha-\mathrm{HgS}$ crystal. The lower percent for selenium on the $\beta-\mathrm{HgS}$ particles may be from the geometry of the particle with a rough surface versus the $\alpha-\mathrm{HgS}$ crystal which had a polished surface. The reaction was expected due to the thermodynamics (Equation 35) and suggested products from the Pourbaix diagram of mercury, silver, and selenium at $298 \mathrm{~K}$ (Figure 3.9), where $\mathrm{HgSe}$ is form at $\mathrm{pH} 11$ lower than around $+0.2 \mathrm{mV}$.

The silver sulfide, in both synthetic and natural forms, did not show selenium on the surface even though the thermodynamics suggested silver selenide would precipitate (Equation 34), which is also suggested by the Pourbaix diagram (Figure 3.9). Ammonia was used to ensure the reduction potential was low enough to form selenide compounds. Ammonia is a mild reducing agent and a stronger one was not preferred, because in the lowest reduction potential region shown, a fairly large area would precipitate selenium. This may prevent any reaction with mercury or silver due to all the selenium precipitating out before use. What the results suggests is that even with the use of ammonia, the sodium selenide probably raised the reduction potential high enough to be in the region where mercury selenide can form, but silver does not react (at $\mathrm{pH} 11$, around $+0.1 \mathrm{mV}$ ). There is only a very small region in which both mercury selenide and silver selenide would form (directly below the previously mentioned region), which the ammonia did not drive the potential low enough to get in that region.

In regards to the sodium hydroxide experiments not showing any changes, this could be expected by looking at the upper region in the Pourbaix diagram (Figure 3.9), where mercury and silver remain and do not react with the selenate (at $\mathrm{pH} 11$, less than -0.1 $\mathrm{mV})$. 


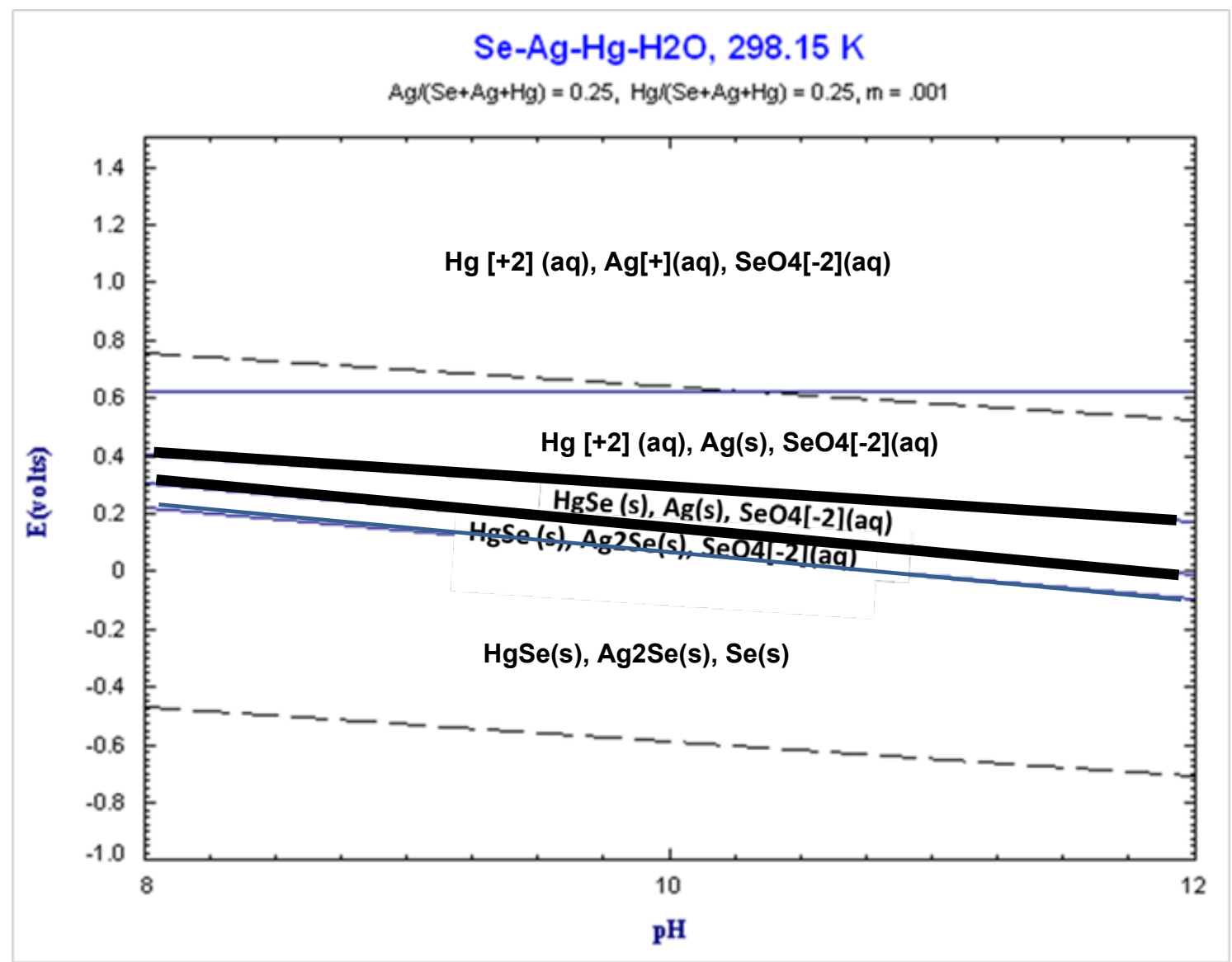

Figure 3.9. The Pourbaix diagram generated by FactSage $(\mathrm{C}$ of silver, mercury, and selenium in aqueous solution is shown from $\mathrm{pH} 8$ to $\mathrm{pH} 12$. Experiments conducted at $\mathrm{pH} 11$.

There appeared to be sufficient evidence to indicate that selenium and mercury form a mercury selenide from the SEM images and analysis to continue with testing on the natural and synthetic ores. 
From the initial SEM verification that mercury selenide did form, the ores used were a High Se (high selenium containing ore with silver), High $\mathrm{Hg}$ (high mercury containing ore with silver), and also a synthetic "ore" were leached in various combinations, shown previously in Figure 3.4.

\subsection{Leaching with Selenium in Leach Solution}

\section{Methods}

The natural ores were used ("High Se" and "High Hg", one un-pulverized gram of each), and also synthetic "ore" which consisted of powder mercury sulfide, silver sulfide in both synthetic "ores", and sodium selenate only in the mimic of the High Se ore. The amounts of synthetic material used to mimic the High Se ore were: 0.0023 grams mercury sulfide, 0.0024 grams silver sulfide, and 0.0013 grams sodium selenate. The amounts of synthetic material used to mimic the High Se ore were: 0.409 grams mercury sulfide, and 0.002 grams silver sulfide. The mimic of the High $\mathrm{Se}+$ High $\mathrm{Hg}$ ore mixed then leached used the same amounts from the previous two stated "ores" simply mixed together and half the sample leached. The mimic of the High Se ore leached and then the leachate used to leach the High $\mathrm{Hg}$ ore was accomplished by leaching the mimic of the High Se "ore" and using the leachate to leach the mimic of the High $\mathrm{Hg}$ "ore".

With the un-pulverized natural ore samples, the relatively coarse particle size could make sample variations large even though proper sampling technique was used. The ores were leached with $0.02 \% \mathrm{KCN}$ solution at $\mathrm{pH} 11$ with ammonia in distilled water (200 $\mathrm{mL}$ each vial). All leach times were for 48 hours. Figure 3.10 illustrates the procedure. Analysis was carried out at Michigan Technological University (MTU) on ions in solution (Appendix 3). Samples were also sent to Newmont for analysis. From Figure 3.10 the first process on the left shows leaching a high selenium ore by itself, then using the Se-bearing leachate from the high selenium ore to leach a high mercury ore. The next process from the left illustrates blending high-mercury ore with high-selenium ore, then 
leaching the heap with cyanide. The final two illustrated processes are the ores leached separately.

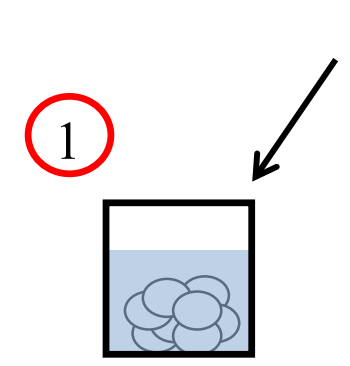

High Se ore $0.02 \% \mathrm{KCN}$ solution at $\mathrm{pH} 1$

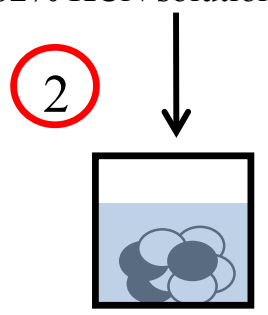

High $\mathrm{Se}+$ High $\mathrm{Hg}$ ores

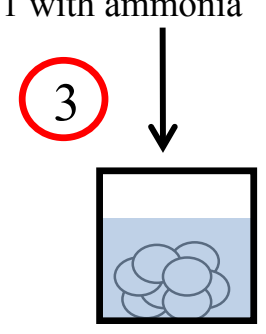

High Se ore

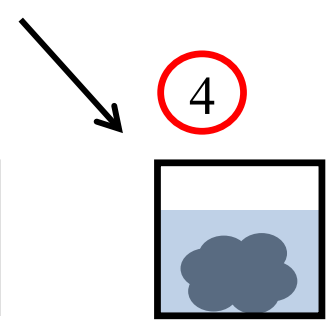

High $\mathrm{Hg}$ ore

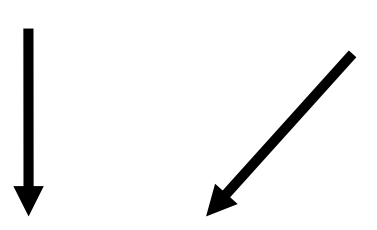

Leached for 48 hours, filtered

Solution analyzed
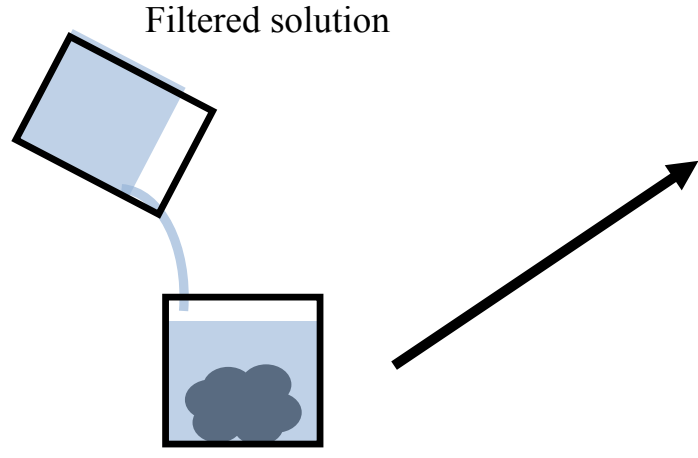

High $\mathrm{Hg}$ ore

Figure 3.10. Experiment procedure showing how ores were leached: 1) shows leaching a high selenium ore by itself, then using the Se-bearing leachate from the high selenium ore to leach a high mercury ore; 2) illustrates blending high-mercury ore with high-selenium ore, then leaching the heap with cyanide; 3 ) shows only the High Se ore leached with cyanide; 4) shows only the High Hg ore leached with cyanide.

\section{Experimental Results and Discussion}

Analysis done at Michigan Tech using the AA is shown in Figure 3.11 in parts per billion of silver and mercury, and Table 8 . Results from both the sodium hydroxide and the ammonia leach are shown. The first two column groups in Figure 3.11 are results 
from the ores leached separately. The third column grouping is where both ores were mixed together and leached, and the last grouping is where the High Se ore was leached, then the leachate used to leach the High Hg ore. Results showed that the highest silver recovered was with the sodium hydroxide experiments for the "High Se leach to High Hg", which also had the lowest mercury. The trials where the two ores were mixed together ("High Se + High Hg"), then leached showed the highest mercury in solution. Using the sodium hydroxide recovered more silver for all cases, except in the two step leach ("High Se to High Hg") with the same trend being observed with the mercury.

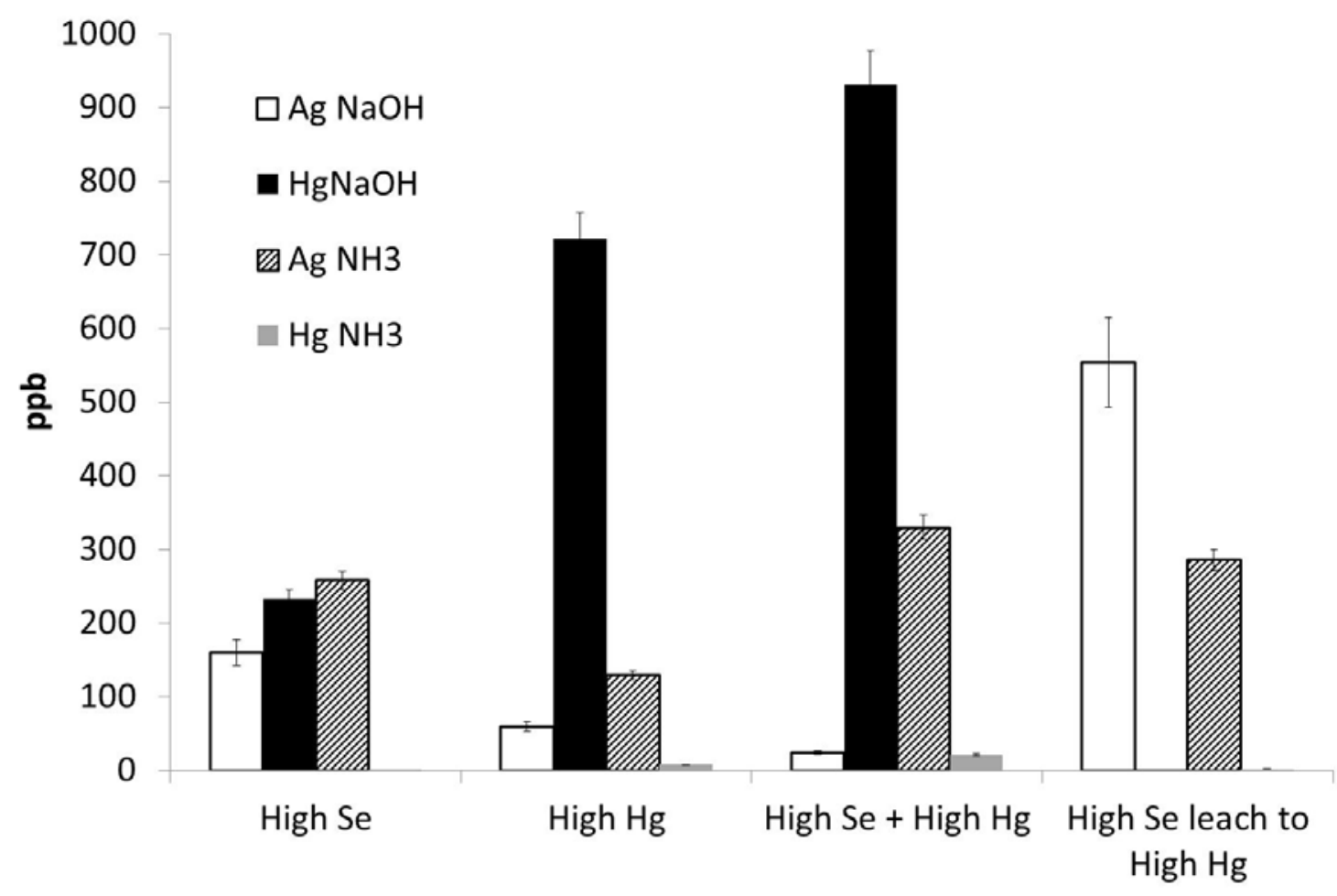

Figure 3.11. Results from natural ore leach, analysis by MTU. Numerical values shown in Table 8. 
Table 8. Results of the High Se ore and High $\mathrm{Hg}$ ore done at MTU for silver and mercury are shown. Error around $+/-11 \%$.

\begin{tabular}{|l|l|l|l|l|}
\hline Sample & $\begin{array}{l}\text { High Se } \\
(\mathrm{ppb})\end{array}$ & $\begin{array}{l}\text { High Hg } \\
(\mathrm{ppb})\end{array}$ & $\begin{array}{l}\text { High Se + High Hg } \\
(\mathrm{ppb})\end{array}$ & $\begin{array}{l}\text { High Se to High Hg } \\
(\mathrm{ppb})\end{array}$ \\
\hline Silver NaOH & 160 & 59 & 24 & 554 \\
\hline $\begin{array}{l}\text { Mercury } \\
\mathrm{NaOH}\end{array}$ & 233.7 & 721.6 & 930.7 & 1.0 \\
\hline Silver NH3 & 258 & 130 & 330 & 286 \\
\hline Mercury NH3 & 0.3 & 7.5 & 21.2 & 2.3 \\
\hline
\end{tabular}

In looking at the Pourbaix diagram for mercury and silver with sulfide (Figure 3.12 and Figure 3.13, where the black dotted line indicate the FactSage $($ generated stability region of cyanide), silver would stay dissolved as silver cyanide over a wider range than mercury, especially at lower reduction potentials. Although the FactSage $\mathbb{C}$ diagram indicates a solid for silver, since cyanide is known to dissolve silver under those conditions (as shown in Equation 4), this allows the assumption the "solid" silver would indeed be a silver cyanide complex within the cyanide lines. As the ores sat waiting for analysis, particularly in the case of the Newmont analysis, more of the other salts naturally occurring in the ore would have dissolved out or allowed for reaction (such are aqueous oxygen reacting with mercury) as the reduction potential changed. Also, other ions are present in the ore $(\mathrm{As}, \mathrm{Pb}, \mathrm{Cu}, \mathrm{Fe})$, which may have an effect on silver and mercury given enough time. 


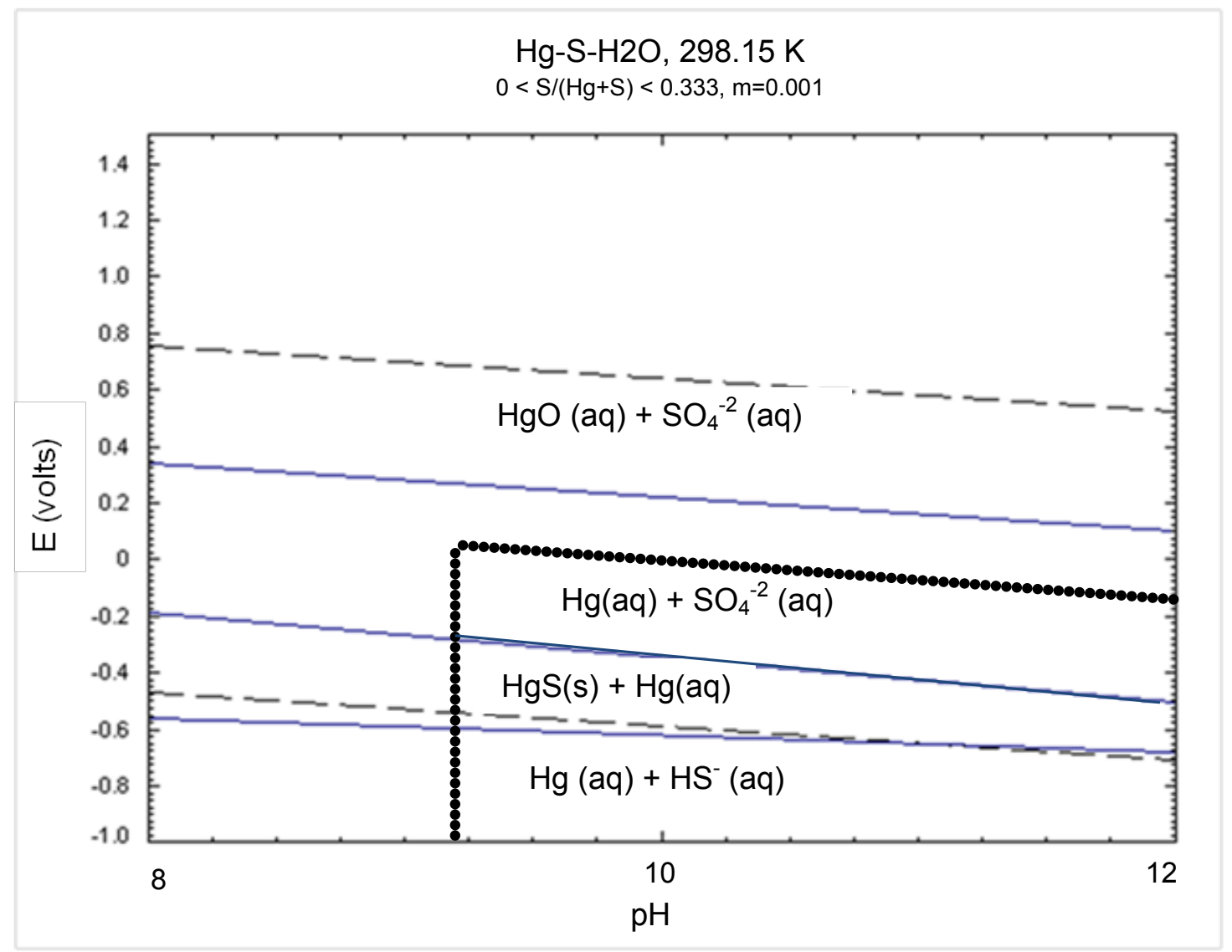

Figure 3.12. Pourbaix diagram generated by FactSage $\mathbb{C}$ of mercury and sulfide in aqueous solution with the black circle lines indicating the $\mathrm{CN}^{-}$stability region. 


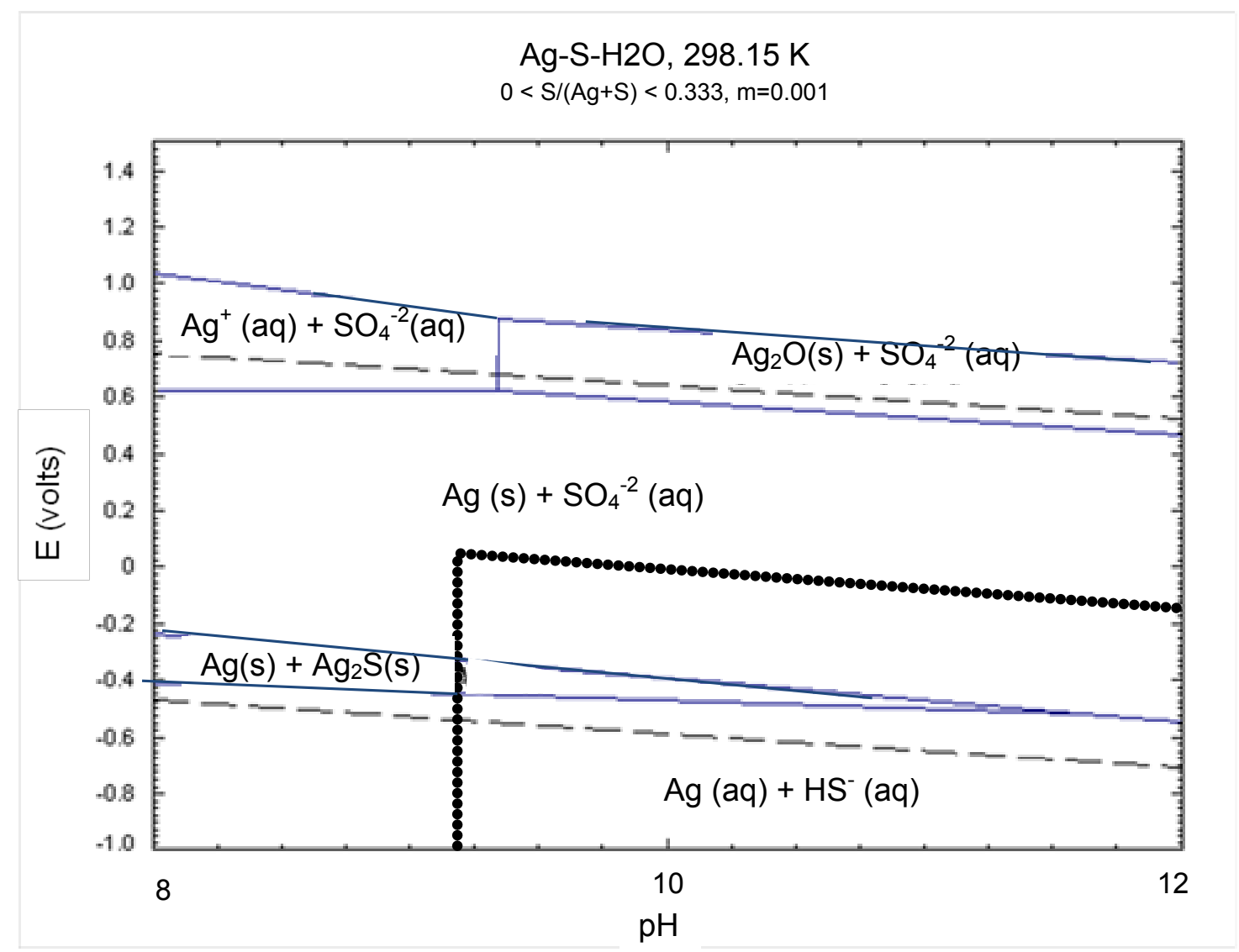

Figure 3.13. Pourbaix diagram generated by FactSage $(\mathcal{C}$ of silver and sulfide in aqueous solution with the black circle lines indicating the $\mathrm{CN}^{-}$stability region.

The sample sent to the sponsoring company for analysis varied significantly in the mercury amounts. It is expected that the mercury cyanide had precipitated out of solution from the remaining fine particulates containing sulfur. The analysis of the sponsoring companies results are in Appendix 4.

To remove the possibility that complicating minerals and ions interfere with results, a synthetic "ore" was made from reagent grade mercury sulfide and silver sulfide. Figure 3.14 shows the fraction of the metal (silver and mercury) in solution, with mercury being 
shown in black and silver in white. The two step process ("synthetic High Se leach to synthetic High Hg ore") shows more silver being dissolved and more mercury removed. This experiment also demonstrates that the pre-leached ore with selenium used to leach the high mercury containing ore suggest selenium may have an effect on the prevention of mercury leaching from the ore.

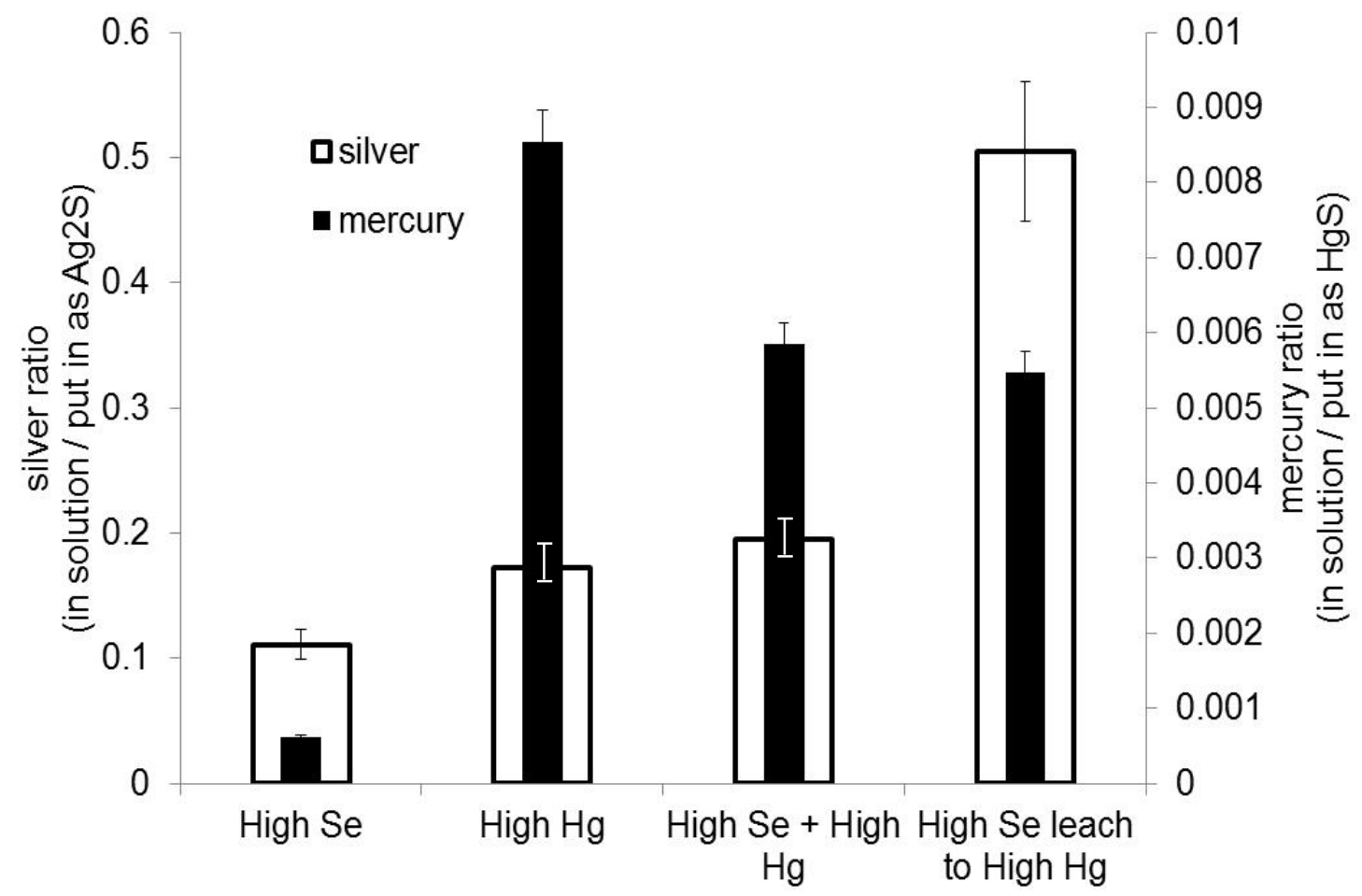

Figure 3.14. Results from synthetic ore leach, analysis by MTU. Ratios are shown of the metal ions in solution divided by how much was put into the sample as a sulfide.

The synthetic ore results are particularly useful in this case, because the fractions of silver and mercury dissolved could be calculated. As shown, very little mercury dissolved into solution in the first place, even without selenium, as can be observed by noting the orders of magnitude lower $\mathrm{Hg}$ fractions dissolved than the silver. What little mercury was in solution did appear to be suppressed even lower by the selenium. Lower mercury is the 
goal, but the selenium was not the cause since even the ore with no selenium in it had only low amounts of mercury dissolved.

Some other effect seemed to be keeping the mercury low and leaving very little mercury dissolution for the selenium to suppress. Since only three compounds were in the synthetic ore (sodium selenide, mercury sulfide, and silver sulfide), silver sulfide was the only other compound that could be affecting mercury dissolution.

\subsection{Determination of Total and Cyanide-Leached Mercury}

\section{Methods}

This experiment was to test the observation stated earlier that mercury in the leachate is not a problem in high selenium ores and vice versa. For one set of data to determine all mercury in the samples, High $\mathrm{Hg}$ and High Se ores (from 0.9 to 0.5 grams used as is) were dissolved separately in aqua regia $(10 \mathrm{~mL}$, which completely dissolves $\mathrm{HgS}$, nitric acid and hydrochloric acid at a ratio 1:4, respectively) for 24 hours and filtered (method adapted from EPA 2001, Digestion Process II). For determining how much mercury was leached out with cyanide $(0.02 \% \mathrm{KCN}$ solution at $\mathrm{pH} 11$ with sodium hydroxide), the High Hg and High Se ores were leached with cyanide solution (separately) for19 days in $0.02 \% \mathrm{KCN}$ solution $(50 \mathrm{~mL})$. The amount of mercury recovered by cyanide was compared to that of total mercury in the ore sample. The High Hg and High Se ore's mercury availability were then compared to determine if selenium was keeping the mercury low in the High Se ore or if the mercury levels were naturally low.

\section{Experimental Results and Discussion}

The determination of total and cyanide-leached mercury was analyzed. In the High Se ore, the low mercury amounts might be from mercury and selenium binding. This was tested by analyzing for total mercury in both High $\mathrm{Hg}$ and High Se ores by completely 
dissolving all mercury in the sample. Cyanide was then used to leach out as much mercury as possible and compared to the total mercury from the ores. Results are shown in Table 9.

Table 9. The total mercury in the High Hg and High Se ores was compared to how much mercury was leached out during a cyanide leach.

\begin{tabular}{|l|c|}
\hline Samples & $\begin{array}{l}\text { \% mercury in ore leachable } \\
\text { by cyanide }\end{array}$ \\
\hline High Hg & 17.9 \\
\hline High Se & 16.7 \\
\hline
\end{tabular}

As shown, the High $\mathrm{Hg}$ and High Se ores had only about a $1 \%$ difference in the amount of mercury in the ore that was leachable by cyanide. This would suggest that cyanide leaching does not differentiate between mercury as a sulfide and if mercury is bound to selenium. Therefore, selenium is probably not binding and preventing mercury dissolution in the High Se or High $\mathrm{Hg}$ ore, but instead the before mentioned observation that high selenium ores do not have mercury leachate problems, and vise versa, might be due to geological deposition of selenium and mercury bearing ores.

\subsection{Silver and Mercury Sulfide Leached With and Without Selenium}

\section{Methods}

Silver sulfide and mercury sulfide were leached with, and without, sodium selenide. One set of this experiment was done with sodium hydroxide and another set was carried out using ammonia to bring the solutions to $\mathrm{pH} 11$. The ammonia was used to test the affects of reduction potential on the dissolution and precipitation reactions. A diagram of the set up is shown in Figure 3.15. 


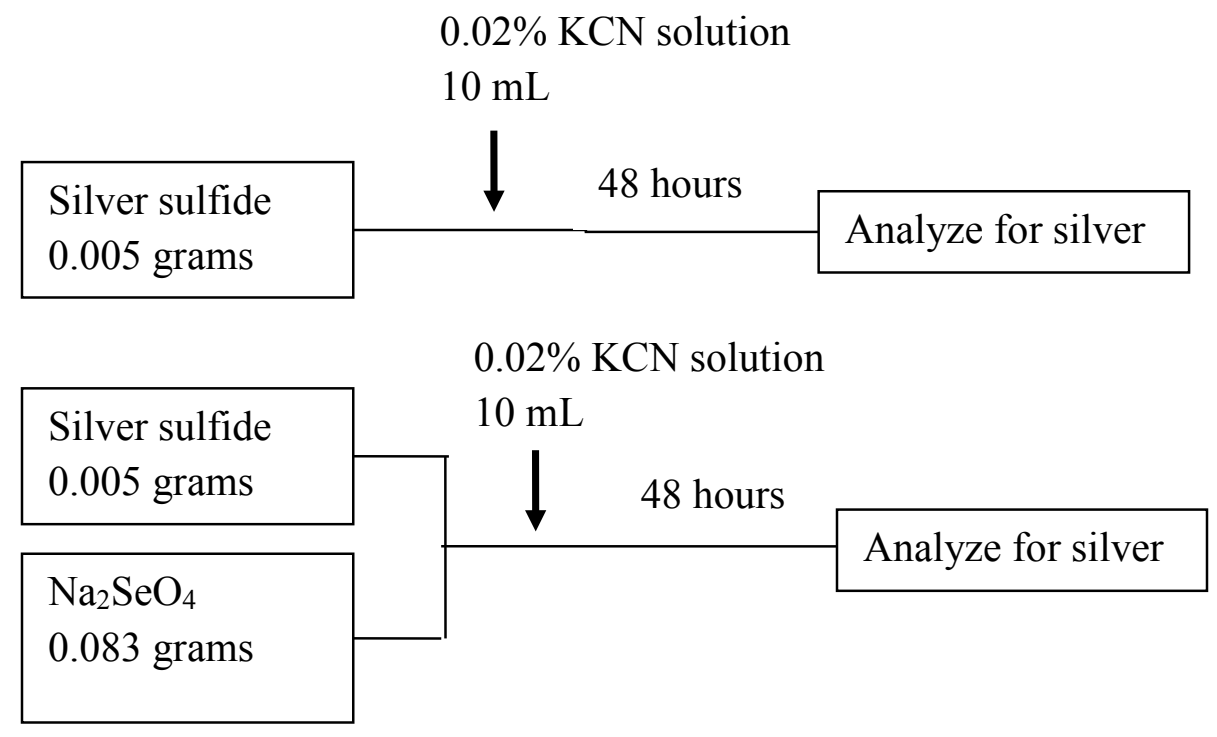

Figure 3.15. The set up for leaching silver and mercury with or without selenium is shown for silver. The same trail was done with $\mathrm{HgS}$, but with 0.01 grams (about 4.3 $\mathrm{x}$ 10-5 moles of $\mathrm{Ag}, \mathrm{Hg}$, and $\mathrm{Se}$ ). This was carried out for both sodium hydroxide and ammonia solutions.

\section{Experimental Results and Discussion}

When leaching either pure silver sulfide or pure mercury sulfide with selenium present, the sodium hydroxide trials reduction potentials varied around $+0.1 \mathrm{mV}$ and the ammonia hydroxide trials reduction potentials varied around $-0.1 \mathrm{mV}$. The results from silver and mercury dissolution are shown in Figure 3.16. Note that silver and mercury values are on the $y$-axis and black is for sodium hydroxide while white is for ammonia. 


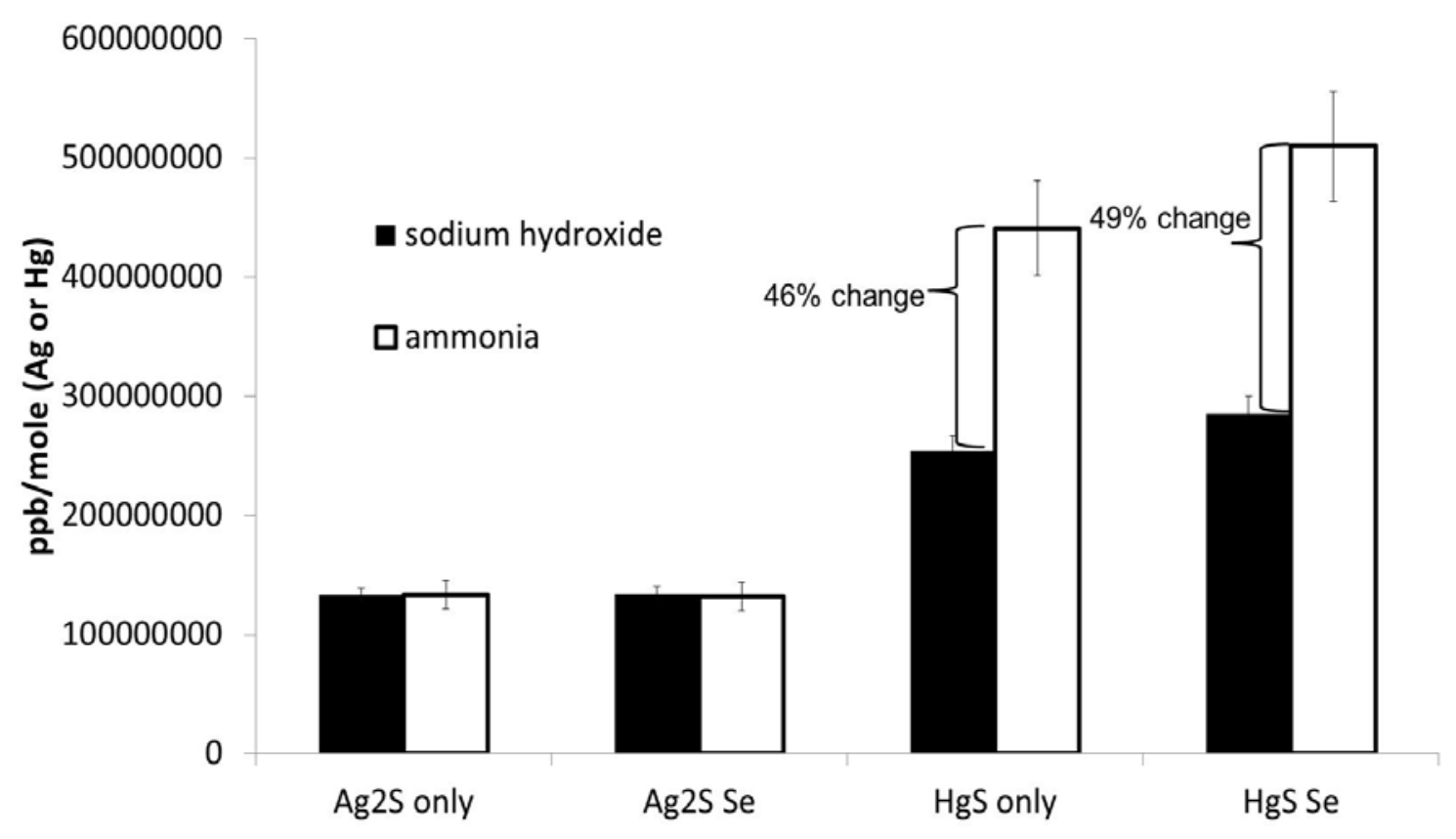

Figure 3.16. Results are shown for the effect of adding sodium selenide to silver or mercury sulfide leaching.

Silver dissolution was not affected by additions of selenium or reduction potential changes. Mercury changed slightly with the addition of selenium by increasing the amount of mercury dissolved. Reduction potential also had an effect on mercury dissolution, with lower reduction potential leaching more mercury. Looking at the Pourbaix diagrams (Figure 3.9), some selenium most likely precipitated out as $\mathrm{Se}^{0}$ before reacting with the mercury or silver, particularly in the ammonia trial. This would leave more $\mathrm{HgS}$ available for dissolution with $\mathrm{CN}^{-}(\mathrm{aq})$. At higher reduction potentials, the selenium probably remained as $\mathrm{SeO}_{4}^{-2}$ (aq) which is expected to react with mercury and prevent some from leaching. In regards to the changes seen between having no selenium and having an addition of selenium, the samples were diluted in order to test for mercury, introducing error. The important point to take away from this experiment is to show that selenium does not appear to prevent mercury from dissolving in cyanide solution. 


\subsection{Conclusions}

A selenium salt and mercury were shown to bind by analyzing SEM results, demonstrating that mercury selenide would form without cyanide in solution. Selenium was found at around $4 \%$ on the naturally occurring $\mathrm{HgS}$ crystal and no selenium was found on the $\mathrm{Ag}_{2} \mathrm{~S}$ samples. This suggests that at those particular aqueous reaction conditions ( $\mathrm{pH} 11$, around $+0.1 \mathrm{mV}$ measured reduction potential), mercury selenide will precipitate, but silver selenide will not.

Real ores were tested, but the results from Newmont and MTU differed, which might be due to the late analysis by the Newmont lab with the samples sitting for months before analysis. The Newmont samples did have fine particles in the bottle when shipped, which may have affected results as the samples had longer to react. The important point to note is that both analyses showed a lowered mercury amount in the two-step process of leached than simply mixing the two ore together for leaching. This indicated that some reaction was indeed lowering the mercury in the final solution when the High Se ore was used to leach the High $\mathrm{Hg}$ ore. The synthetic analysis was most useful in that only three compounds were present and no other ions or metals to complicate reactions. The observation was made that a small amount of mercury was being suppressed even lower by the selenium in solution. In was initially thought that the effects of selenium could not be obviously observed due to something else suppressing the mercury so low.

The experiments to compare total mercury to the amount of mercury that could be leached by cyanide indicated that selenium does not appear to prevent mercury from dissolving in a cyanide solution as initially thought from Equation 37 . Instead, with oxygen present, the reaction most likely happening is Equation 38.

$\mathrm{HgSe}(\mathrm{s})+2 \mathrm{CN}^{-}(\mathrm{aq})+2 \mathrm{O}_{2}(\mathrm{aq}) \rightarrow \mathrm{Hg}(\mathrm{CN})_{2}(\mathrm{aq})+\mathrm{SeO}_{4}^{-2}(\mathrm{aq})$ 
$\Delta \mathrm{G}=-468 \mathrm{~kJ}$

Equation 38

This suggests that with insufficient oxygen, the mercury selenate could be stable in a cyanide solution and selenium still might hold the possibility of selectively preventing mercury dissolution in solution.

In further exploring the effect of reduction potential on silver sulfide and mercury sulfide leaching with and without selenium present, a lower reduction potential was found to leach more mercury and not have an affect silver. The selenium addition again had no affect on silver dissolution and only had a slight affect on mercury. This further indicates that Equation 38 far outweighs any precipitation on $\mathrm{HgSe}$ which might occur. Further, if the reduction potential were low enough to precipitate $\mathrm{Ag}_{2} \mathrm{Se}$, the dissolution of silver back into a cyanide complex would again dominate at 298K (Equation 39)

$\mathrm{Ag}_{2} \mathrm{Se}(\mathrm{s})+4 \mathrm{CN}^{-}(\mathrm{aq})+2 \mathrm{O}_{2}(\mathrm{aq}) \rightarrow 2 \mathrm{Ag}(\mathrm{CN})_{2}^{-}(\mathrm{aq})+\mathrm{SeO}_{4}{ }^{-2}(\mathrm{aq})$ $\Delta \mathrm{G}=-501 \mathrm{~kJ}$

Equation 39

Since a direct lowering of mercury in leachate by adding selenium in a cyanide solution did would not work, the reaction observed occurring in the two step process in the synthetic leaching was explored. Since there were only three compounds in the synthetic solution, there was a possibility that silver sulfide was suppressing mercury in solution. 


\section{Selective Mercury Precipitation from Solution with Silver Sulfide}

\subsection{Introduction}

The goal of the selective precipitation of mercury using silver sulfide powder experiments was to see if silver sulfide could selectively precipitate mercury as mercury sulfide, while allowing silver to dissolve. After initial trials with synthetic materials to see if the process would work, experiments were carried out with High $\mathrm{Hg}$ and High $\mathrm{Se}$ ores, using a solution of mercury cyanide that would theoretically come from a used mercury cyanide leach solution to simulate potential industrial use conditions. A flow diagram showing what experiments were done is shown in Figure 4.1.

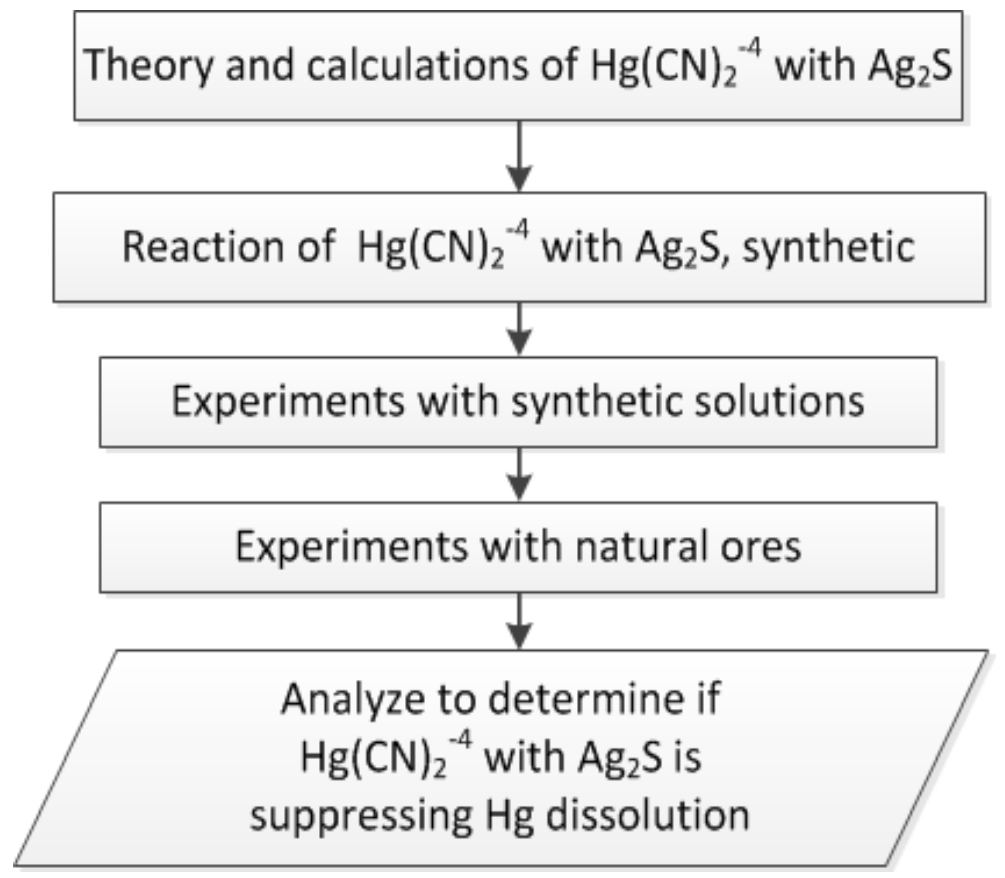

Figure 4.1. Flow diagram showing experiments done with mercury cyanide used to leach silver sulfide. 


\subsection{Theoretical Discussion}

Currently in industry, a mercury cyanide solution would be a waste product, its only use would be to precipitate the mercury for hazardous waste disposal and reuse the cyanide solution. Instead, the $\mathrm{Hg}(\mathrm{CN})_{4}^{-2}$ solution could be used as a leaching reagent for silver sulfide containing ores, leaving mercury behind in the ore as mercury sulfide. A solution of leached mercury cyanide passing through silver sulfide ore will precipitate mercury as mercury sulfide through a replacement reaction (Equation 40), which is stable in water for disposal later.

$\mathrm{Ag}_{2} \mathrm{~S}(\mathrm{~s})+\mathrm{Hg}(\mathrm{CN})_{4}^{-2}(\mathrm{aq}) \rightarrow \mathrm{HgS}(\mathrm{s})+2 \mathrm{Ag}(\mathrm{CN})_{2}{ }^{-}(\mathrm{aq})$

Equation 40 $\Delta \mathrm{G}=-13 \mathrm{~kJ}$

Also, any excess silver cyanide leached is not thermodynamically favorable to precipitate since 1) mercury sulfide is more thermodynamically stable, and 2) precipitation of $\mathrm{Ag}(\mathrm{CN})^{-}$onto $\mathrm{Ag}_{2} \mathrm{~S}$ would simply swap one silver atom for another, leading to no net loss of silver from solution.

One potential downside is the expectation that some silver sulfide may be encapsulated by the formation of mercury sulfide around a silver sulfide core, resulting in silver loss (Figure 4.2). If this method of precipitation will be plausible for use, it might only be useful when leaching a poor grade silver ore that was not worth using fresh cyanide solution. 


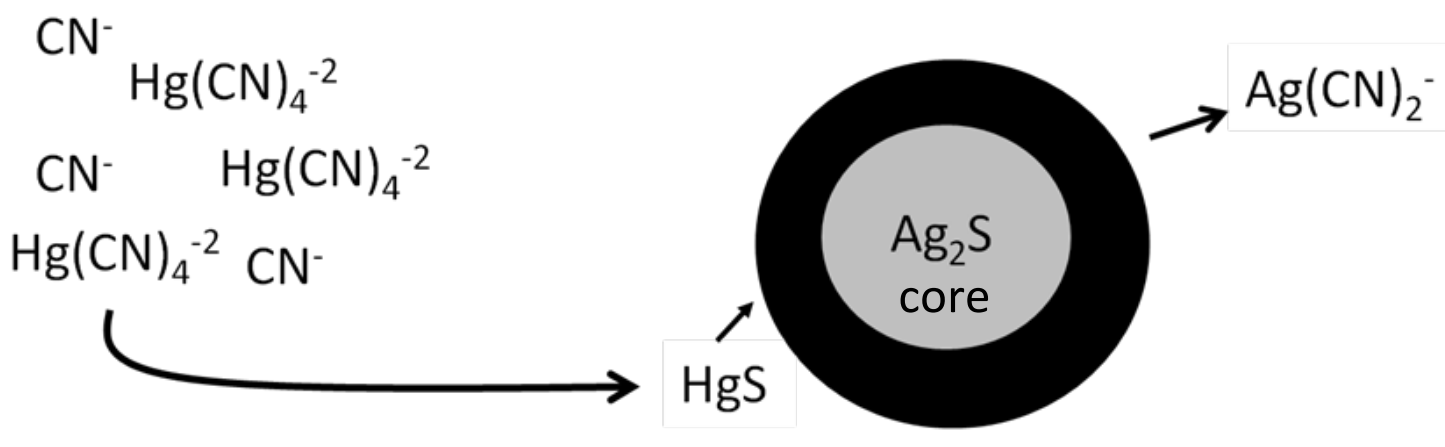

Figure 4.2. Mercury cyanide reacting with silver sulfide to form mercury sulfide and silver cyanide.

\subsection{Experimental Procedures}

Experiments carried out were to 1) determine if the process shown in Figure 4.2 would work with synthetic "ores", 2) test mercury cyanide leaching with the High Se and High $\mathrm{Hg}$ ores, since the natural ores might behave differently due to other compounds in the ores, and 3) determine if a counter current flow would be beneficial for mercury removal and silver recovery using real ores.

\section{Materials}

The synthetic "ores" used were chemical grade mercury and silver sulfide powders from Alfa Aesar. Characterization of the High Se and High $\mathrm{Hg}$ ores are found in section 3.1.3.2. Other reagents used include distilled water, sodium hydroxide, and potassium cyanide. 


\subsection{Feasibility of Leaching Silver Sulfide with Mercury Cyanide}

\section{Methods}

Reactions were carried out in small, $30 \mathrm{~mL}$ vials with screw-top caps. All experiments were done at room temperature.

The experimental set-up was to determine if the addition of $\mathrm{Hg}(\mathrm{CN})_{4}{ }^{-2}$ to silver sulfide would leach the silver and precipitate mercury. Mercury sulfide (0.0096 grams) was leached in $0.02 \% \mathrm{KCN}$ for 48 hours $(200 \mathrm{~mL})$ resulting in a $760 \mathrm{ppb} \mathrm{Hg}$ solution. The filtered solution of mercury cyanide ( $20 \mathrm{~mL}$ for each vial) was added to silver sulfide (about 0.0025 grams) for 1.5, 3, 6, 24, 48, and 72 hours. These were six separate vials, one for each time interval. The starting mercury cyanide solution and the final solution with silver cyanide were analyzed (Figure 4.3).

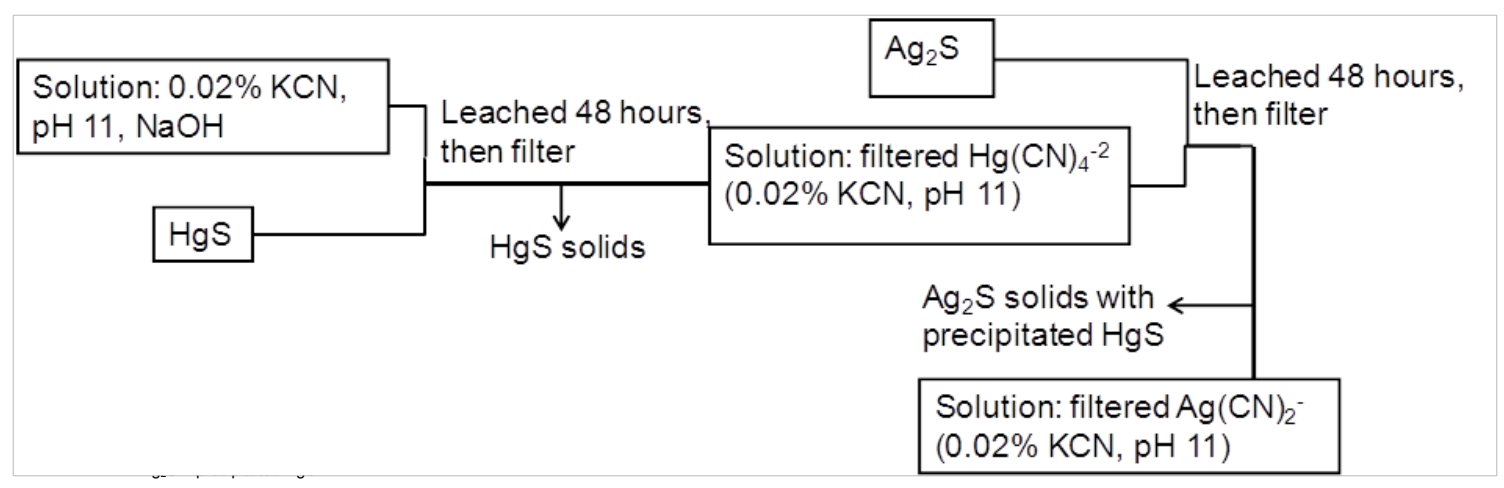

Figure 4.3. Experimental set-up showing $\mathrm{Hg}(\mathrm{CN})_{4}{ }^{-2}$ added to silver sulfide.

Experimental Results and Discussion 
Feasibility experiments of the leaching process are shown in Figure 4.4 over a period of 72 hours. Mercury is shown in black and silver in white. Time zero (0) shows silver concentrations as zero and mercury concentrations at $760 \mathrm{ppb}$. The times recorded were at $1.5,3,6,24,48$, and 72 hours. Figure 4.5 shows a plot of silver dissolved in solution versus mercury precipitated from solution. From 6 to 48 hours, there is a steady rate of $0.1642 \mathrm{ppm} \mathrm{Ag} \mathrm{dissolved/Hg} \mathrm{precipitated.} \mathrm{There} \mathrm{is} \mathrm{a} \mathrm{linear} \mathrm{correlation} \mathrm{between} \mathrm{the} \mathrm{last}$ three times, showing the reaction is slowing down. There is also good correlation for times $1,1.5$, and 6 , showing a faster initial reaction. The slower time later on is expected as mercury sulfide covers the surface of the silver sulfide particle, effectively blocking silver dissolution.

The mercury precipitated out over a relatively short period of time (99\% in 48 hours). The rate may increase upon adding stirring, whereas the vials were stationary. The initial silver dissolution is seen to be quite rapid, but the dissolution rate drops off over time. This is most likely due to the silver sulfide becoming coated by a layer of mercury sulfide (Figure 4.2). Figure 4.5 shows the ratio of silver/mercury plotted against time: more moles of mercury are precipitating out than moles of silver being dissolved. In theory, after the dissolution starts and if there were a one to two exchange of mercury for silver moles. Table 10 shows the moles (total moles of silver dissolved at a given time and total mole of mercury precipitated at a given time) and mole ratios of these two used for Figure 4.5.

From this data, the observation can be made that mercury was initially precipitating faster than silver was dissolving up unto the third hour. At six hours, more silver is dissolving than mercury is precipitating. This is most likely due to initial large amounts of mercury being removed, leaving more free cyanide to dissolved the silver due to one molecule of mercury precipitated leaves two cyanide available for dissolution of silver. 


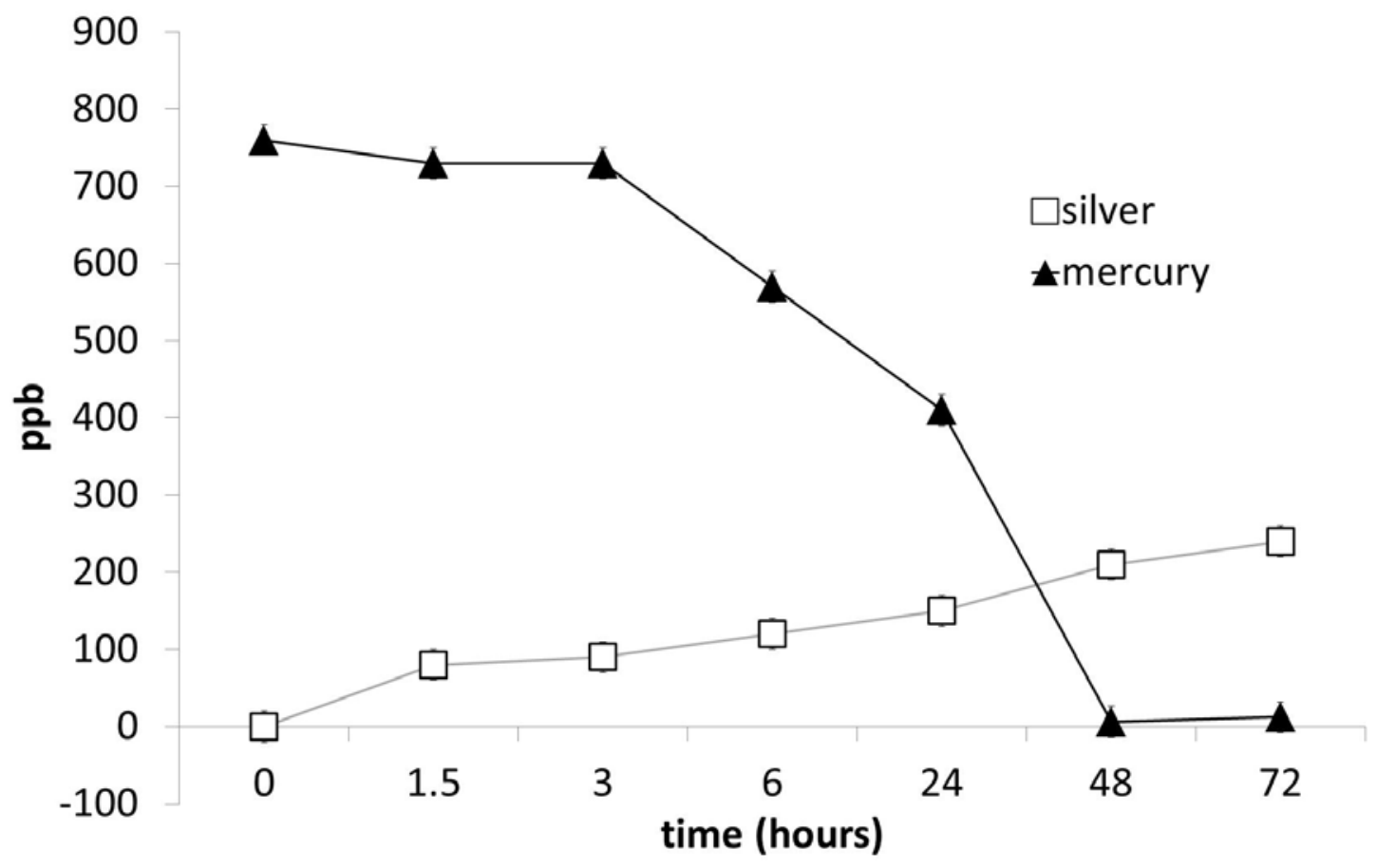

Figure 4.4. Pre-leached mercury cyanide was used to leach silver sulfide powder over a period of time. 


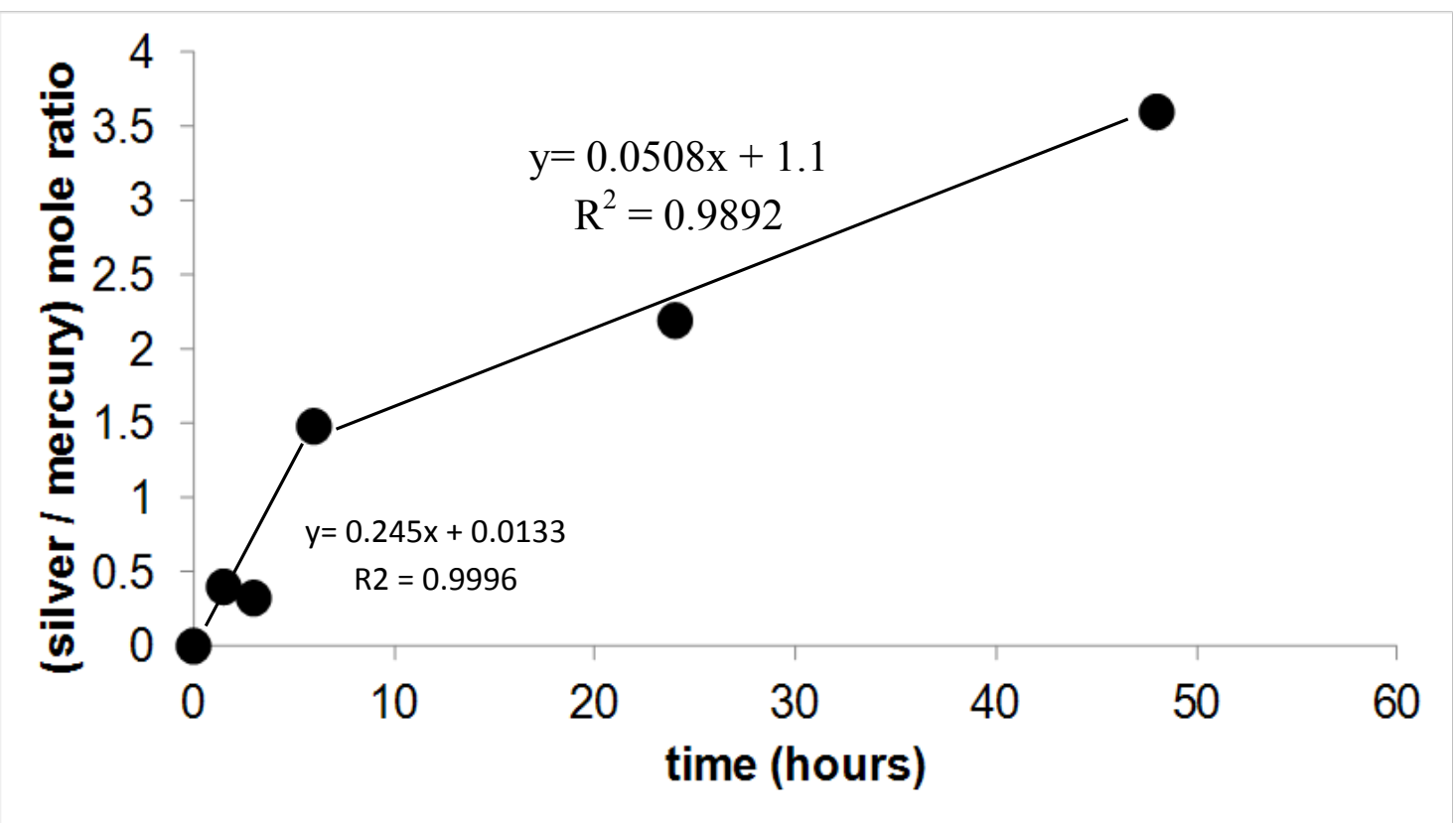

Figure 4.5. Silver dissolution / mercury precipitation mole ratio versus time is shown.

Table 10. The total moles of mercury precipitated and total moles of silver dissolved at a given time are shown, along with the silver to mercury mole ratio.

\begin{tabular}{|r|r|r|r|}
\hline Hours & moles Hg precipitated & moles Ag dissolved & mole ratio \\
\hline 0 & 0 & 0 & 0 \\
\hline 1.5 & $8.29 \mathrm{E}-09$ & $3.30181 \mathrm{E}-09$ & 0.398 \\
\hline 3 & $9.54 \mathrm{E}-09$ & $3.08169 \mathrm{E}-09$ & 0.322 \\
\hline 6 & $1.28 \mathrm{E}-08$ & $1.89304 \mathrm{E}-08$ & 1.478 \\
\hline 24 & $1.57 \mathrm{E}-08$ & $3.43388 \mathrm{E}-08$ & 2.190 \\
\hline 48 & $2.1 \mathrm{E}-08$ & $7.54865 \mathrm{E}-08$ & 3.594 \\
\hline
\end{tabular}

These experiments gave sufficient evidence to continue with experimentation. For further proof of the theorized process shown in Figure 4.2, SEM was used to take images and analyze silver sulfide reacted with mercury cyanide. 


\subsection{SEM Images of $\mathrm{Ag}_{2} \mathrm{~S}$ Reacted with Mercury Cyanide}

\section{Methods}

The mercury cyanide solution $(0.02 \% \mathrm{KCN}$, pH 11 with sodium hydroxide, $10 \mathrm{~mL}$ of $10,000 \mathrm{ppb} \mathrm{Hg}$ ) was added to the sulfide powder and allowed to react 48 hours. The silver sulfide particles were filtered and rinsed three times with distilled water, dried, then mounted for SEM analysis at accelerating voltage of $20 \mathrm{~V}$.

\section{Experimental Results and Discussion}

The EDS analysis is shown in Table 11 and the mapping is shown in Figure 4.6 at 5,500x magnification on a particle about $500 \mu \mathrm{m}$ in diameter. Figure 4.6 shows EDS mapping of the elements, with the maximum calculated error for all EDS experiments at $0.5 \%$. The actual image of the silver sulfide particle appeared the same with and without going through the reaction. This provides further support for mercury precipitating on the silver sulfide particle. An un-reacted silver sulfide particle is shown in Table 6 and Figure 3.8.

Table 11. EDS quantitative analysis of silver sulfide particle reacted with mercury cyanide solution at $20 \mathrm{KeV}$.

\begin{tabular}{|l|l|}
\hline Element & Weight \% \\
\hline Mercury & 49.37 \\
\hline Silver & 17.33 \\
\hline Sulfur & 33.30 \\
\hline
\end{tabular}



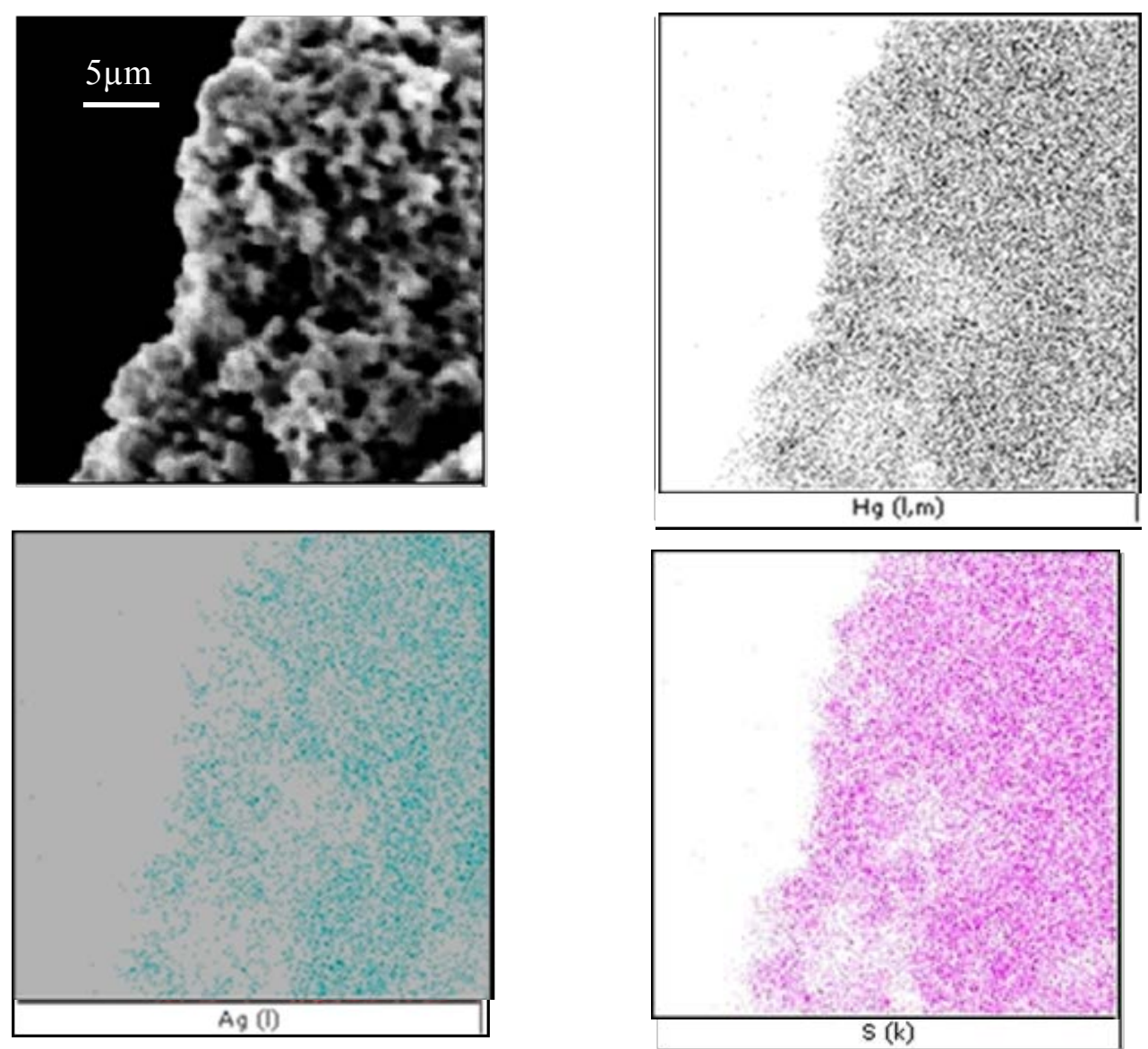

Figure 4.6. EDS mapping image of a silver sulfide particle (about $500 \mu \mathrm{m}$ in diameter) reacted with mercury cyanide solution at 5,500 $\mathrm{x}$ magnification on a particle.

\subsection{Use of Mercury Cyanide Solution to Leach High Hg and High Se ores}

\section{Methods}

A solution of mercury cyanide $(0.02 \% \mathrm{KCN}, \mathrm{pH} 11,200 \mathrm{~mL})$ that had been leaching mercury sulfide ( 0.5 grams) over a couple of weeks was used for the following three related experiments. The solution did have a large quantity of un-dissolved $\mathrm{HgS}$ 
remaining after weeks of allowing for dissolution with $0.02 \% \mathrm{KCN}$. Calculations for a completely "saturated" solution are shown in Appendix 5. Three total vials for each ore (10 grams of ore, used as is) were leached with $50 \mathrm{~mL}$ of solution. One was the ore leach with $0.02 \% \mathrm{KCN}$ only, and the other two were leached with the diluted mercury cyanide solution for 48 hours.

For the first, a small amount of fairly concentrated mercury cyanide solution was added to $\mathrm{pH} 11$ (sodium hydroxide) water, resulting in a $1672 \mathrm{ppb} \mathrm{Hg}$ solution. For the second, a smaller amount of concentrated mercury cyanide solution was used (814 ppb solution), with the mercury solution having sat longer and was considered to have no or very little free cyanide, a theory used to estimate the amount of free cyanide in the first experiment. A lower amount of mercury than was used in the first experiment was used due to observations from the first experiment. The third used a small excess of cyanide. A $0.01 \% \mathrm{KCN}$ solution was chosen to mimic a possible recycled mercury cyanide solution from industry (591 ppb solution). A summary of the solutions is given in Table 12.

Table 12. A summary of the solutions used in this experiment is given.

\begin{tabular}{|l|l|l|}
\hline Experiment & Mercury (ppb) & Cyanide \\
\hline 1 & 1672 & $\begin{array}{l}\approx 222 \mathrm{ppb} \text { free in solution as } \\
\text { compared to experiment } 2\end{array}$ \\
\hline 2 & 814 & none free \\
\hline 3 & 591 & $0.01 \%$ \\
\hline
\end{tabular}

\section{Experimental Results and Discussion}

After further support that the reaction (Equation 40) is occurring, natural ores were used to test the effect mercury cyanide leaching would have on actual ores with other minerals and ions present. A mercury cyanide solution that was heavy in mercury (1672 ppb) was 
used in an attempt to simulate what mercury cyanide solution might be coming from a recycle stream in a plant.

In regards to the first attempt at using a very concentrated mercury cyanide solution for leaching, Figure 4.5 shows the results in ppb for the High Se ore, and Figure 4.6 shows results for the High $\mathrm{Hg}$ ore. Mercury is shown in black and silver in white. The first column in each graph shows the ore (High Se or High $\mathrm{Hg}$ ) leached with cyanide only. This is shown to compare to the ore leached with mercury. The second column in both graphs shows the amount of mercury in the saturated mercury cyanide solution (diluted with $\mathrm{pH} 11$ water) used to leach two fresh samples of ore. The last two columns are duplicates of the ore leached with the mercury cyanide solution.

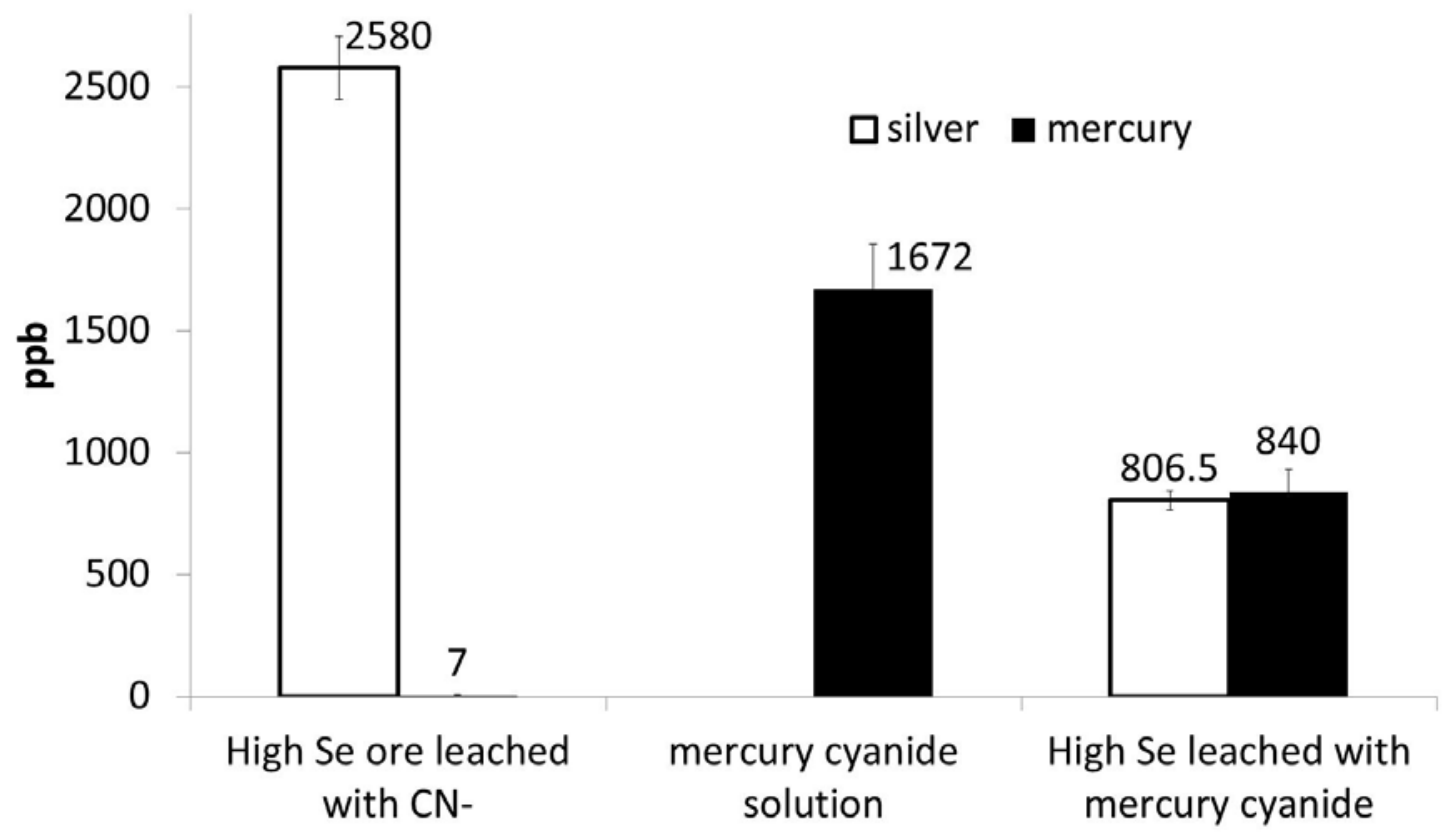

Figure 4.5. High Se ore leached with mercury cyanide solution. The first column shows the ore leached with cyanide only to compare silver recovery to the ore leached with the mercury solution. About half the mercury was removed and a near equal ppb amount of silver was dissolved. 
In ppb, the mercury and silver amounts look similar for the High Se ore, but when converted to moles, there are $3.926 \times 10^{-7}$ moles silver dissolved and $2.041 \times 10^{-7}$ moles mercury (for "High Se 1" in Figure 4.5). This means twice as many moles of silver dissolved as moles mercury were precipitated. In knowing that mercury cyanide has four cyanides in the complex and silver has two, this shows that the reaction had a nearly complete exchange of cyanide in the mercury cyanide for the silver.

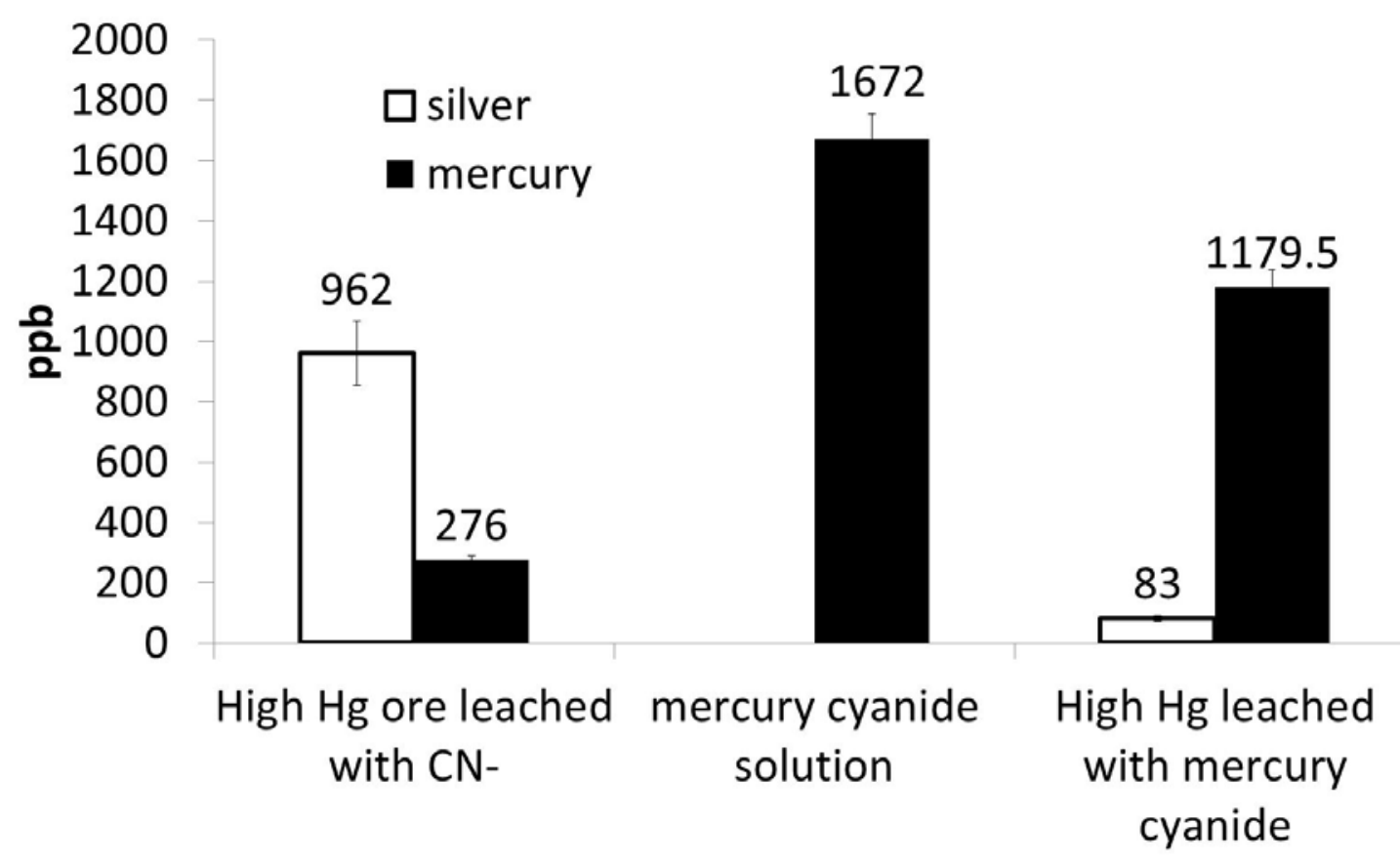

Figure 4.6. High Hg ore leached with mercury solution. The first column shows the ore leached with cyanide only to compare silver recovery to the ore leached with the mercury solution.

In ppb, the mercury amounts look much higher than silver dissolved for the High $\mathrm{Hg}$ ore, but when converted to moles, there are $2.225 \times 10^{-7}$ moles silver dissolved and $2.929 \mathrm{x}$ $10^{-7}$ moles mercury (for "High Hg 1" in Figure 4.6). This means the mole amounts were similar and nearly one-to-one for mercury replacement of silver. Less mercury precipitated most likely due to the higher mercury amount found in the High $\mathrm{Hg}$ ore. 
The High Se ore precipitated more mercury, possibly because the ore has a higher silver concentration (about 60\%) and lower mercury content (about 97\%) than the High Hg ore. Silver recovery for the High Se ore as compared to a cyanide only leach was not very high at around $32 \%$.

The High $\mathrm{Hg}$ ore only removed about $30 \%$ of the mercury from the added mercury cyanide solution. Since there is already a high amount of mercury in the High Hg ore, less mercury is expected to be removed as some of the mercury in the ore is also expected to dissolve. If the mercury from the cyanide leach (mercury naturally occurring in the High $\mathrm{Hg}$ ore, which is not a trivial amount as in the High Se ore) is added to the mercury solution concentration, then $40 \%$ of the mercury was removed or prevented from dissolving. A higher percentage of the silver was also recovered, but still only around $50 \%$. More of the silver being recovered in the High $\mathrm{Hg}$ ore may be due to the accessibility of the silver sulfide, as the High $\mathrm{Hg}$ ore has much more fine particles than the High Se ore. The process and results are illustrated in Figure 4.7. 

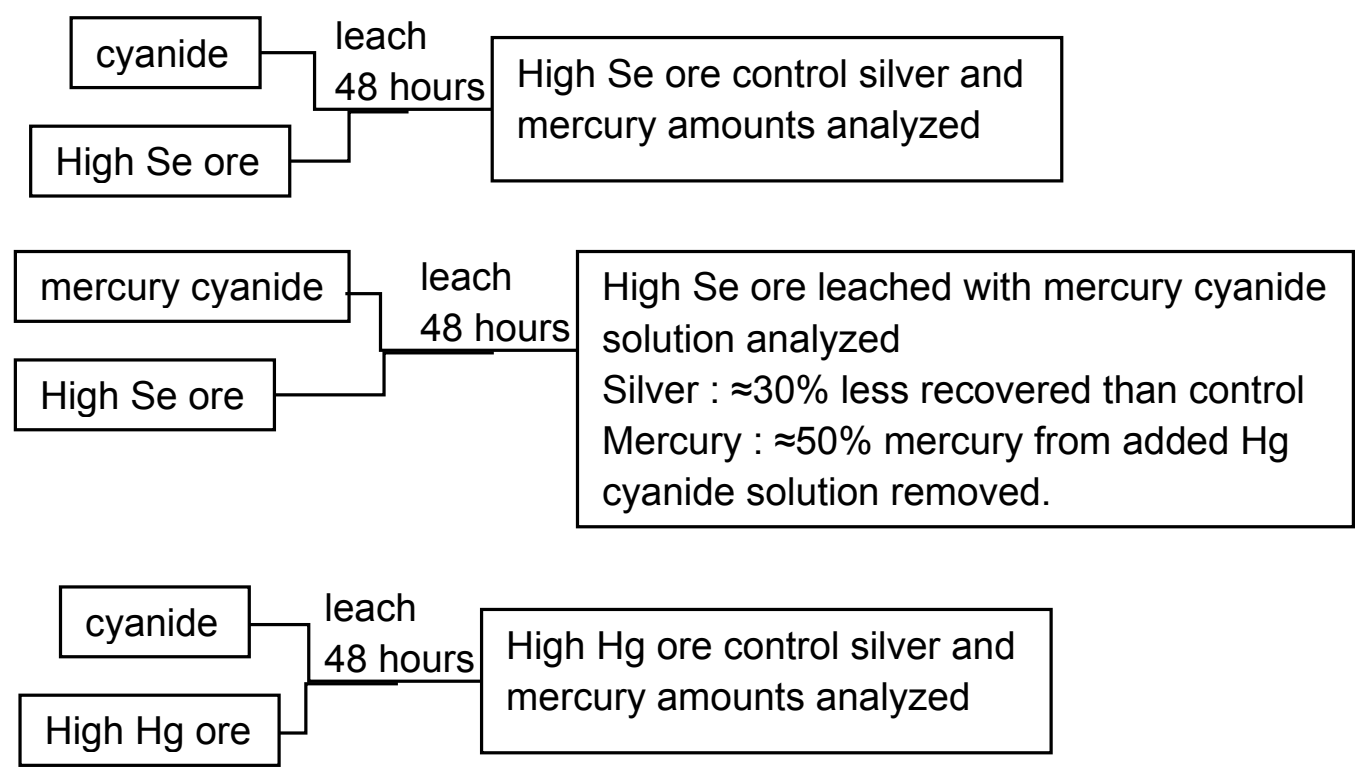

\begin{tabular}{|c|c|c|}
\hline mercury cyanide & $\begin{array}{l}\text { leach } \\
48 \text { hours }\end{array}$ & High $\mathrm{Hg}$ ore leached with mercury cyanide \\
\hline High Hg ore & & $\begin{array}{l}\text { Silver : } \approx 50 \% \text { less recovered than control } \\
\text { Mercury : } \approx 30 \% \text { mercury from added } \mathrm{Hg} \\
\text { cyanide solution removed }\end{array}$ \\
\hline
\end{tabular}

Figure 4.7. Leaching the ores with cyanide or mercury cyanide and their results are shown.

The ores had a very low recovery of silver and only moderatly lowered the mercury concentrations. Therefore, a lower concentration of mercury for leaching the ores was attempted, in expectation that the reulting mercury concentrations in the final leachate would be lower while still getting a similar silver recovery. This was to look for the highest amount of mercury that can be used while still keeping the final ppb of mercury below a certain limit for potentail use in industry, preferably higher than $98 \%$ removal of mercury in one leach. 


\subsection{Two-step Leaching on High Se Ore with $\mathrm{Hg}(\mathrm{CN}) 4^{-2}$ Solution}

\section{Methods}

Two experiments were carried out. The first experiment used concentrated $\mathrm{Hg}(\mathrm{CN})_{4}{ }^{-2}$ solution (7708 ppb Hg solution, the same solution used to make dilutions in 3.2.6). This solution was used to leach the High Se ore (10grams, as is) for 48 hours. The solution was filtered and analyzed. A second batch of the mercury solution leached the same High se ore for another 48 hours. The solution was filtered and the sample analyzed. The second experiment carried out the same methods, but with an addition of $0.01 \%$ $\mathrm{KCN}$ to the mercury solution, resulting in a concentration of $889 \mathrm{ppb} \mathrm{Hg}$. This was done to further confirm the previous sections results and see if using the solution for two batches of ore would change the effectiveness of the concentrated mercury solution without the addition of $0.01 \% \mathrm{KCN}$. A flow diagram is shown in Figure 4.8.

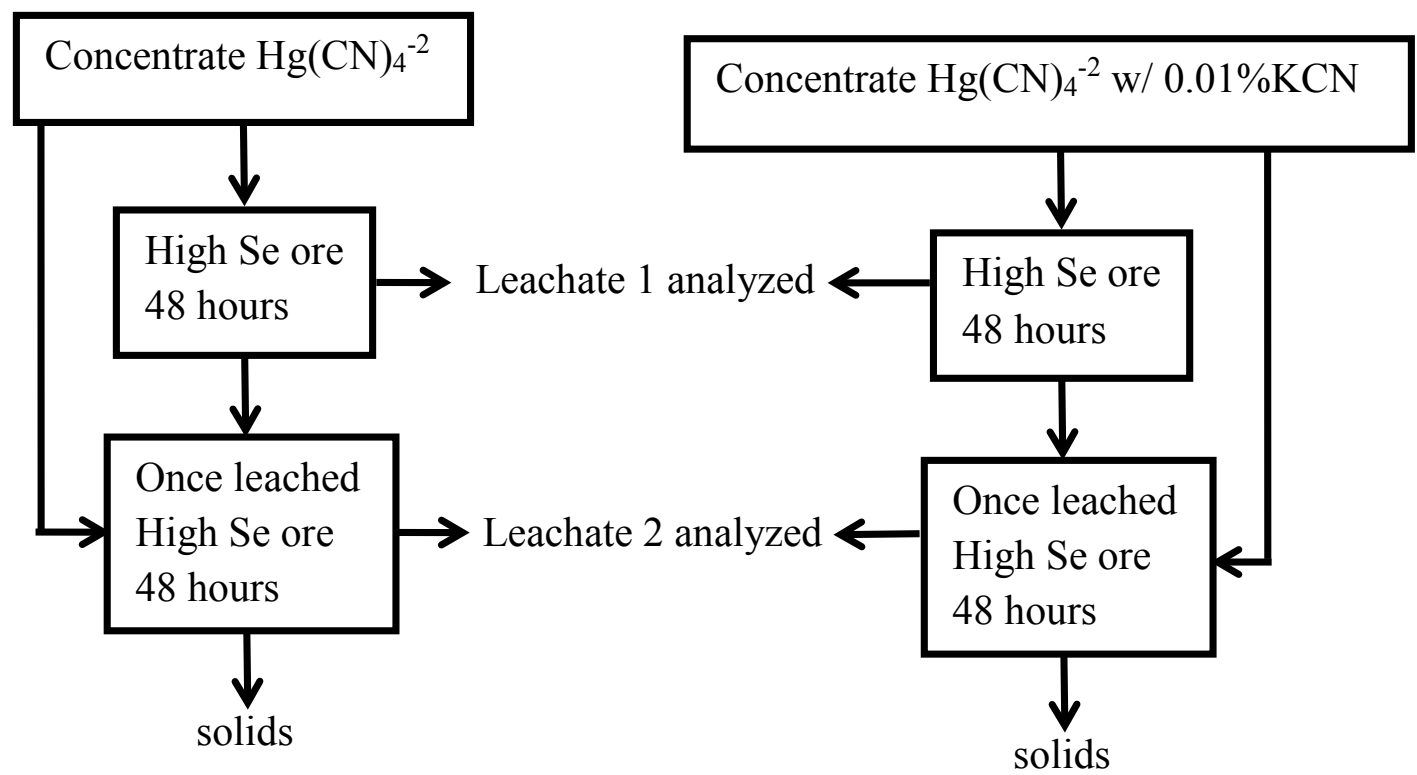

Figure 4.8. Leaching High Se ore with mercury cyanide, then leached again with more mercury cyanide solution. The process was carried out for the concentrated mercury cyanide solution and for the mercury cyanide with $0.01 \% \mathrm{KCN}$ added. 


\section{Experimental Results and Discussion}

The use of a lower concentration of mercury (from about $1600 \mathrm{ppb}$ previously to about $800 \mathrm{ppb}$ for this experiment) was used to leach the High Hg ore (Figure 4.9). The first column for the High $\mathrm{Hg}$ ore results shows a $0.8 \mathrm{ppb}$ solution was used for leaching the ore. The next columns show duplicate runs of the High $\mathrm{Hg}$ ore with the first duplicate at $64 \%$ mercury removed, and the second duplicate shows $49 \%$ mercury removed from the mercury solution. Mercury is shown in black and silver in white.

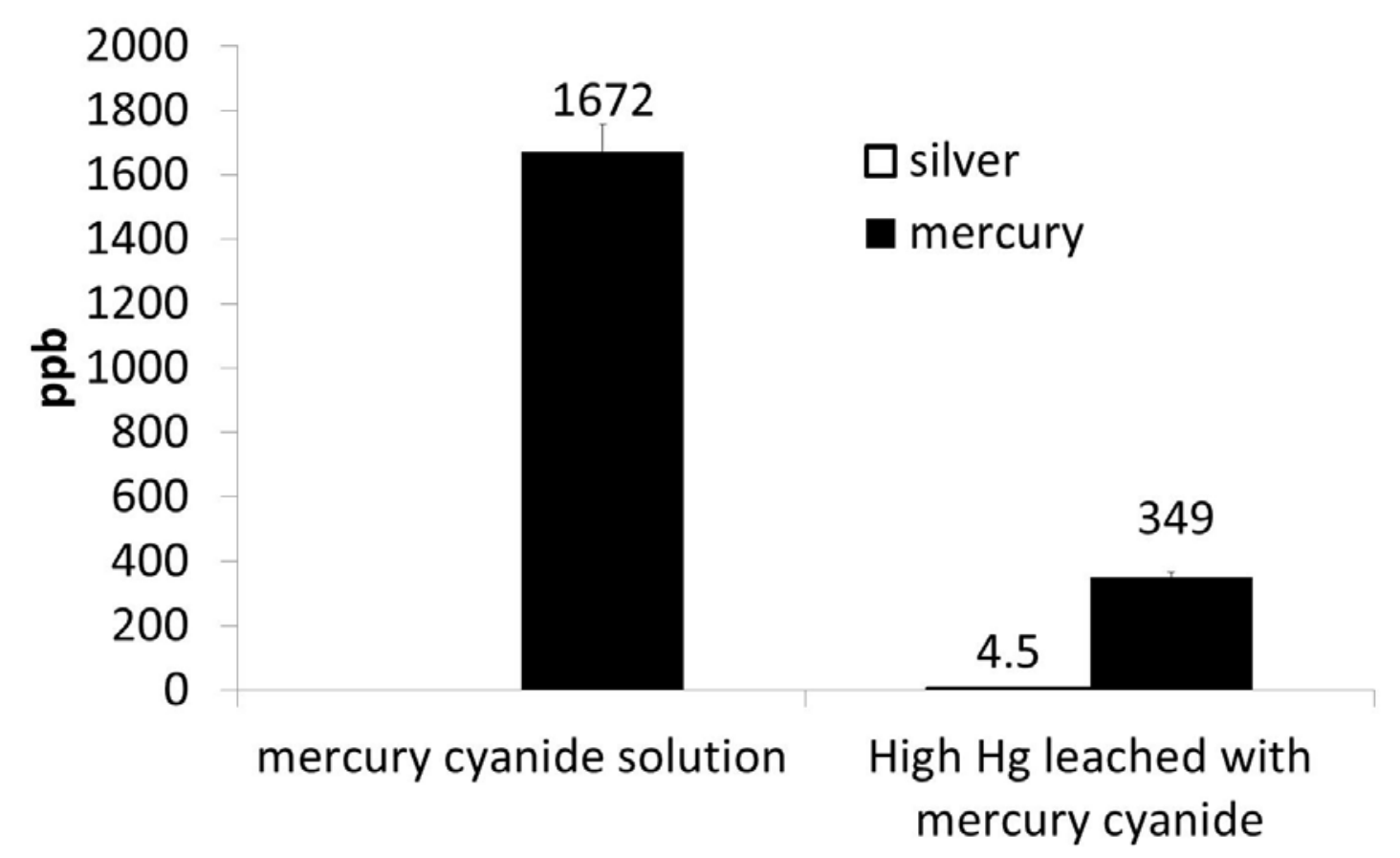

Figure 4.9. A lower concentration of mercury cyanide was used to leach the High Hg ore.

The decrease in mercury concentration was about $500 \mathrm{ppb}$, which is about the same amount as the previous experiment with higher mercury concentrations. This could indicate that around 500ppb is the maximum amount that the High $\mathrm{Hg}$ ore can precipitate from a mercury solution. If the mercury that could be leached out in the High $\mathrm{Hg}$ ores is added to the mercury solution concentration, the mercury removal is $73 \%$ at the highest. 
The most notable, and undesirable, results from this experiment show the near complete lack of silver recovered. Even though the same amount of mercury was removed as the previous experiment with higher mercury concentrations, no silver was recovered.

Another factor must therefore be influencing the silver dissolution.

The High Se ore was also leached in a similar manner, but with only about $300 \mathrm{ppb}$ mercury cyanide in solution. This was to see if both ores were acting the same and it was the solution being added, not some other factor in the ore. The results for the High Se ore are shown in Figure 4.10. The High Se ore for percent mercury removed from added mercury only was $55 \%$ and $41 \%$, but only around 140 ppb mercury was removed where the previous High Se ore leach removed around $800 \mathrm{ppb}$. Silver recovery was also near zero.

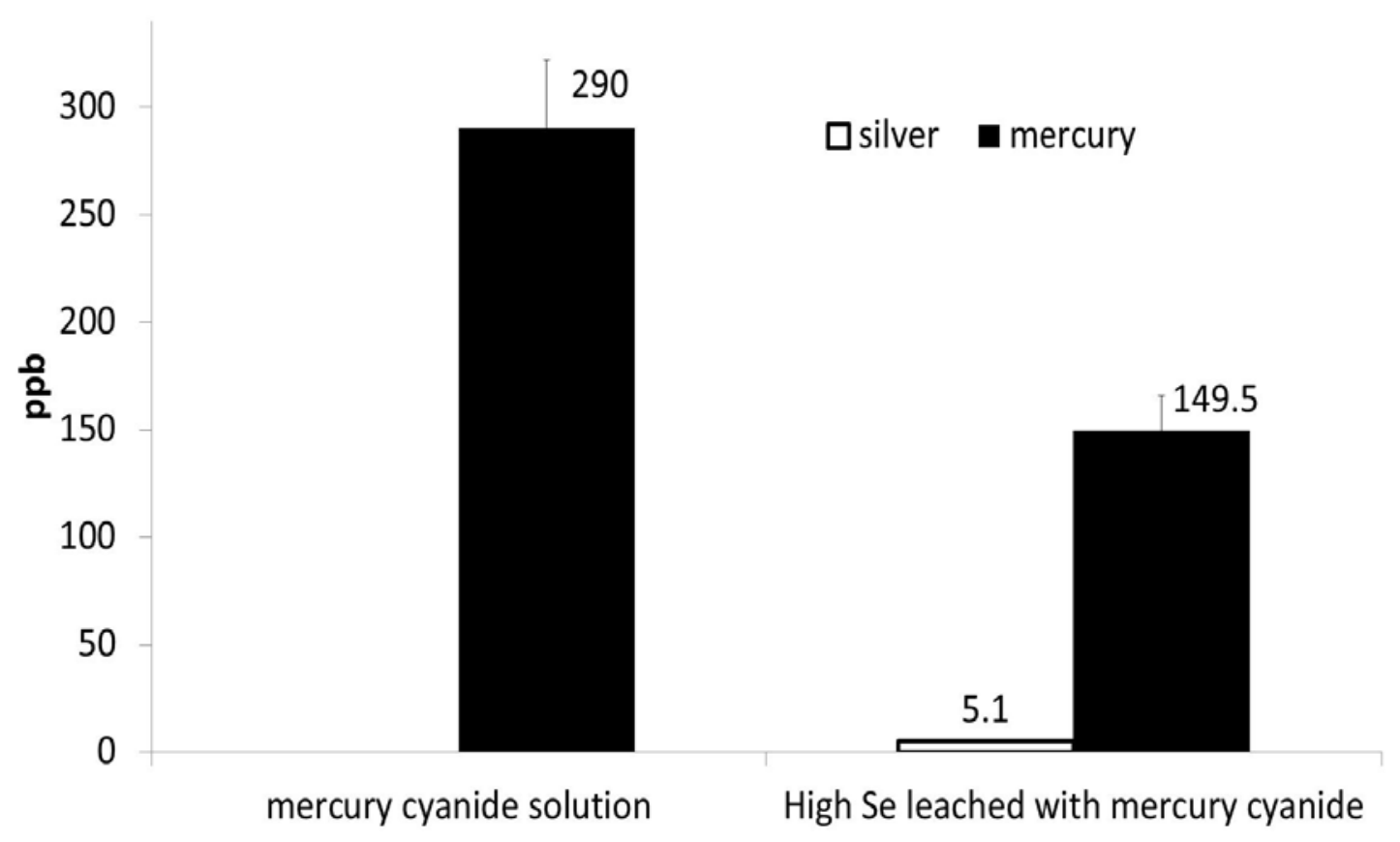

Figure 4.10. A lower concentration of mercury cyanide was used to leach the High Se ore. 
The ores were not causing the difference in dissolution and precipitations. Instead, the lack of silver recovery was due to mercury cyanide solution used to leach them. The concentrated mercury cyanide solution used to make the solutions had been leaching for several weeks in order to avoid having excess cyanide in solution. The second experiments with lower mercury concentrations used a mercury cyanide solution which had been sitting even longer than the previous experiment, mostly likely removing nearly all free cyanide in solution. Since the concentrated mercury solution had sat longer and was more saturated, the amount of free cyanide in solution was thought to be making a difference and perhaps some free cyanide was needed to start the mercury precipitation and silver dissolution reactions.

The cause for this might be due to cyanide acting like a catalyst to free up sulfur for precipitation with mercury. Equation 41 shows silver sulfide reacting with cyanide alone in solution to produce dissolved silver and a sulfide ion, but the reaction is not favorable. Equation 42 shows mercury cyanide favorably precipitating from mercury cyanide to mercury sulfide, thereby freeing cyanide for silver. The combination of these two equations becomes Equation 40 with a favorable overall $\Delta \mathrm{G}=-13 \mathrm{~kJ}$.

$$
\begin{array}{ll}
\operatorname{Ag}_{2} \mathrm{~S}(\mathrm{~s})+4 \mathrm{CN}^{-}(\mathrm{aq}) \rightarrow 2 \operatorname{Ag}(\mathrm{CN})_{2}^{-}(\mathrm{aq})+\mathrm{S}^{-2}(\mathrm{aq}) & \text { Equation } 41 \\
\Delta \mathrm{G}=+47 \mathrm{~kJ} &
\end{array}
$$

$\mathrm{Hg}(\mathrm{CN})_{4}^{-2}(\mathrm{aq})+\mathrm{S}^{-2}(\mathrm{aq}) \rightarrow \mathrm{HgS}+4 \mathrm{CN}^{-}(\mathrm{aq}) \quad$ Equation 42 $\Delta \mathrm{G}=-61 \mathrm{~kJ}$

A low amount of cyanide was added to the concentrated mercury cyanide solution (1\%). Figure 4.11 shows the results for the previous experiment (first three columns), and from 
the results of this experiment (last three columns) for comparison, with mercury shown in black and silver in white. . The High Se ore had 61\% mercury removed and the High $\mathrm{Hg}$ ore with 54\% removed (nearly $69 \%$ if the mercury in the High Hg ore is added to the mercury solution leach). This is around 300 ppb mercury removed, which isn't any better than previous leaching, but around the same as about 600ppb mercury solution was used for the leach. The biggest difference is seen with significant amounts of silver being leached out as mercury is removed.

Silver recovery was decent as compared to cyanide only leaching. The High Se ore had about $21 \%$ less silver recovered than with a cyanide only leach and the High $\mathrm{Hg}$ also had about $21 \%$ less silver recovered as well (Figure 4.12 shows this). A lower amount of silver leached out than from a cyanide only leach was expected since a mercury sulfide is probably forming on the silver sulfide, preventing silver from leaching out. 


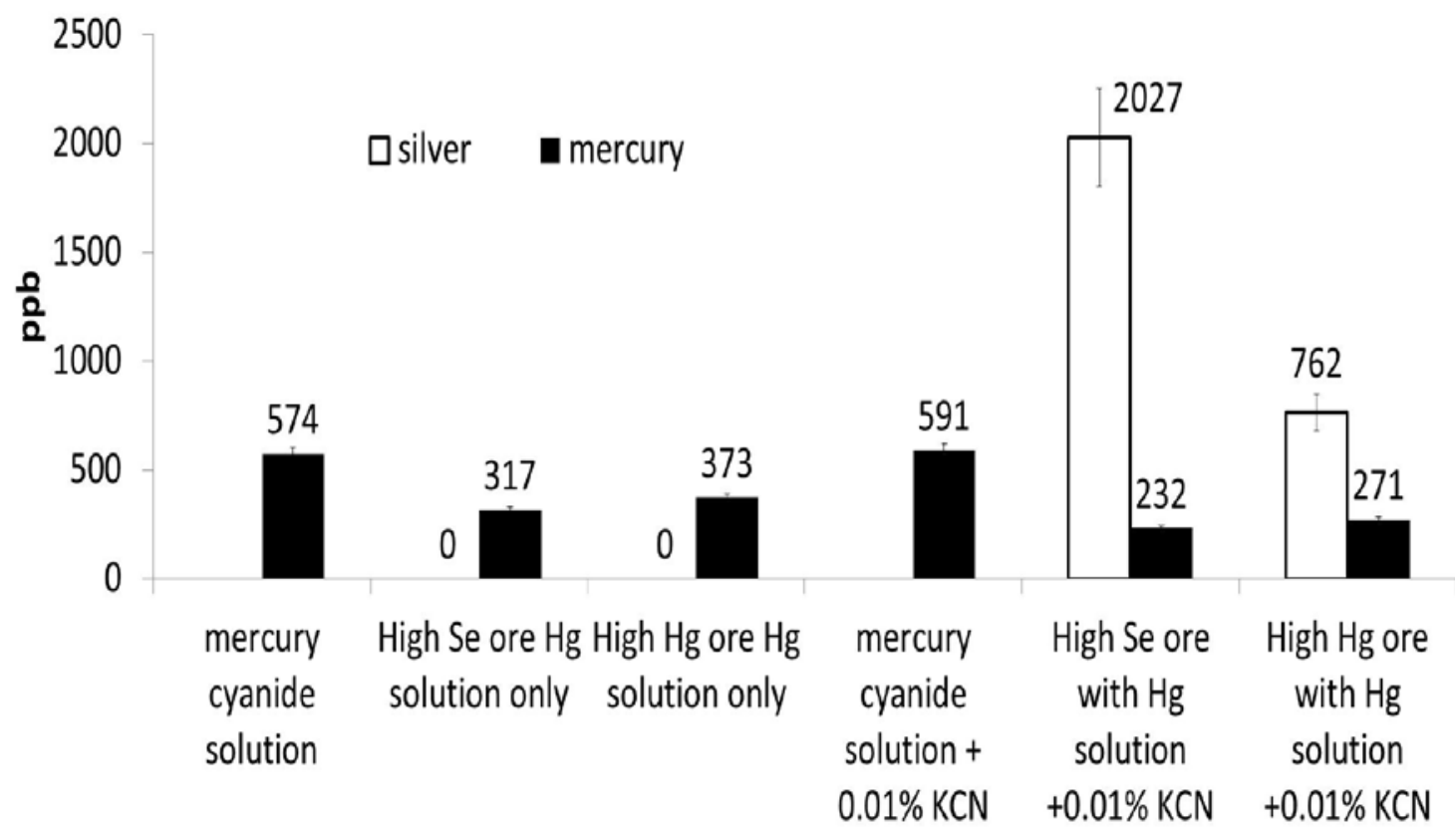

Figure 4.11. The previous experiment's results for using a mercury solution to leach ore with no excess cyanide is shown compared to this experiment's (red square) mercury solution with $0.01 \% \mathrm{KCN}$ to leach ore. 


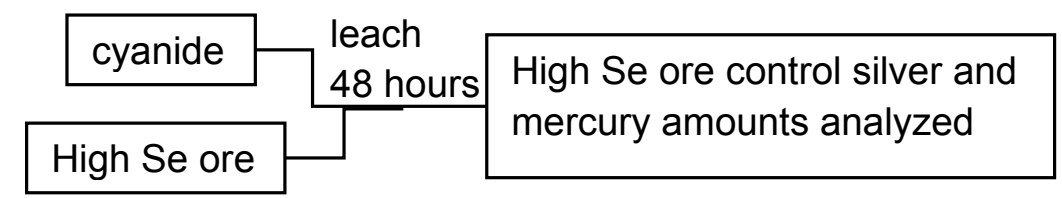

\begin{tabular}{|l|l|l|}
\hline $\begin{array}{l}\text { mercury cyanide } \\
\text { with } 0.01 \% \mathrm{KCN}\end{array}$ & $\begin{array}{l}\text { leach } \\
48 \text { hours }\end{array}$ & $\begin{array}{l}\text { High Se ore leached with mercury cyanide } \\
\text { solution analyzed } \\
\text { Silver }: \approx 21 \% \text { less recovered than control } \\
\text { Mercury }: \approx 61 \% \text { mercury from added } \mathrm{Hg}\end{array}$ \\
& & $\begin{array}{l}\text { Migh Se ore } \\
\text { cyanide with } 0.01 \% \mathrm{KCN} \text { solution removed. }\end{array}$ \\
\hline
\end{tabular}

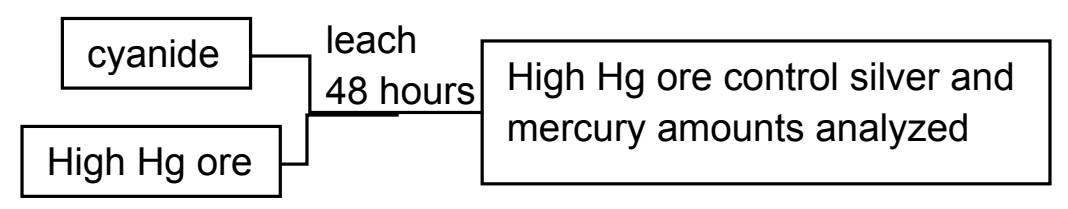

\begin{tabular}{|c|c|c|}
\hline $\begin{array}{l}\text { mercury cyanide } \\
\text { with } 0.01 \% \mathrm{KCN}\end{array}$ & $\begin{array}{l}\text { leach } \\
48 \text { hours }\end{array}$ & $\begin{array}{l}\text { High } \mathrm{Hg} \text { ore leached with mercury cyanide } \\
\text { solution analyzed }\end{array}$ \\
\hline High $\mathrm{Hg}$ ore & & $\begin{array}{l}\text { Silver : } \approx 21 \% \text { less recovered than control } \\
\text { Mercury : } \approx 54 \% \text { mercury from added } \mathrm{Hg} \\
\text { cyanide with } 0.01 \% \mathrm{KCN} \text { solution removed }\end{array}$ \\
\hline
\end{tabular}

Figure 4.12. An illustration showing leaching of ore with cyanide or mercury cyanide and their results are shown.

Since not all of the mercury was removed, nor all the silver recovered, a multiple stage leaching process was tried, but with the saturated mercury solution (without excess cyanide) only to determine if the process could still work well with little to no free cyanide. Since both ore act the same, only the High Se ore was used this time.

The results from the two-step leaching of the High Se ore are shown in Figure 4.13, with mercury in black and silver in white. Figure 4.13 shows the first bottle with only a cyanide leach to indicate silver and mercury amounts expected out of the ore for comparison purposes. The second column is the mercury solution used to leach new 
High Se ore (about $7000 \mathrm{ppb}$ ). The third column shows the results of using the mercury solution to leach the High Se ore (147 ppb silver recovered, 15\% mercury removed). The same High Se ore was then leached with another batch of the same mercury solution, with the results shown in the last column (206 ppb silver recovered, 99\% mercury removed).

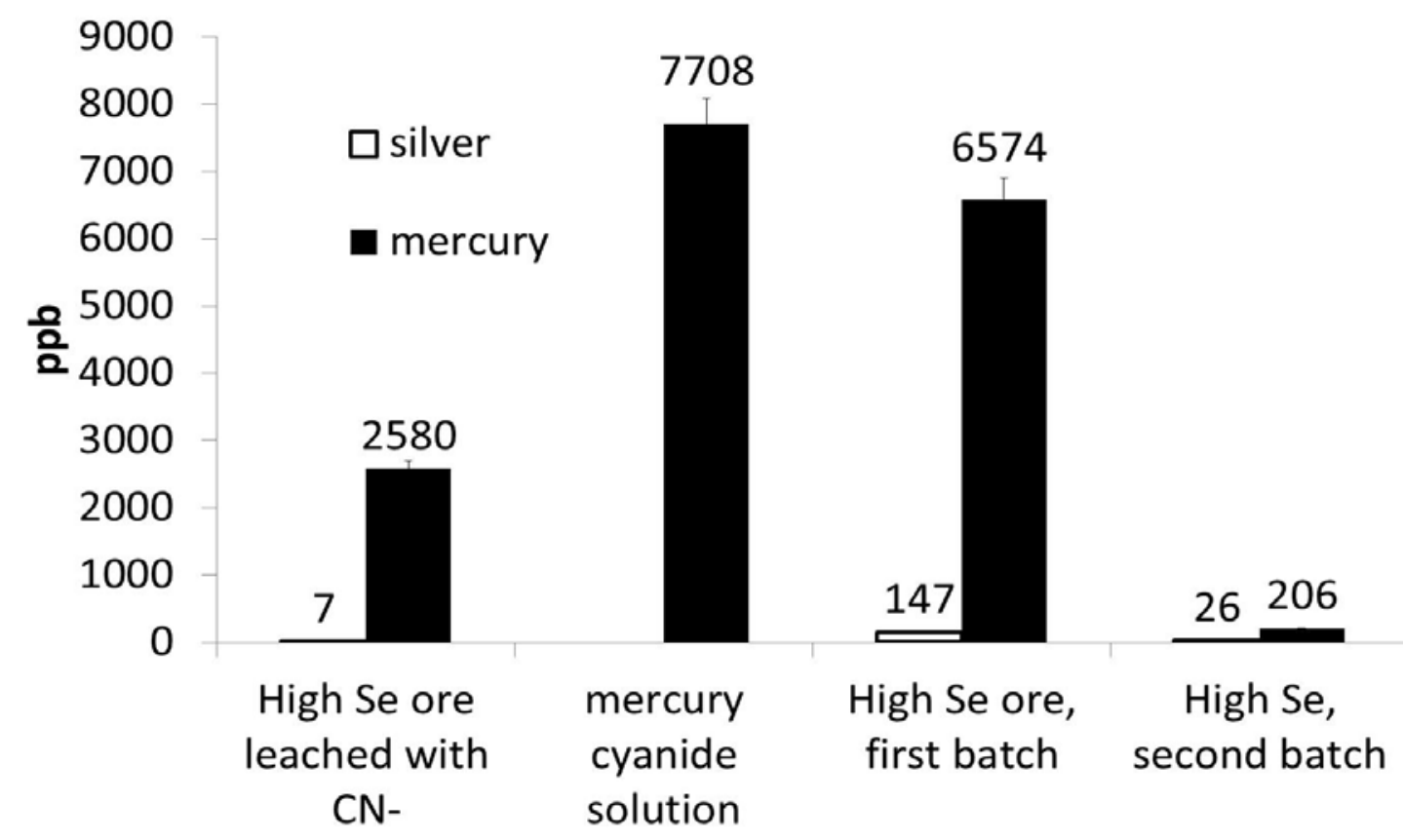

Figure 4.13. High Se ore leached with mercury solution and no excess cyanide.

In between the first batch of solution and the second batch, the ore gained the ability to greatly remove more mercury, $99 \%$ mercury removed as opposed to $15 \%$ in the first batch. The large decrease of mercury in solution for the second batch may indicate that the ore needs to be wetted, or allowed to react longer for the mercury to be removed. Oxygen could also be a crucial part of this, as the ore was exposed to air after the first batch. If the solution is well aerated enough (bubblers in the tank or something similar), then only one step may be necessary to remove a large amount of mercury. 
Also important to note is that though the mercury was greatly removed, the silver concentrations did not increase along with the mercury drop. This suggests that other reactions are occurring within the ore. Perhaps other sulfides (iron sulfides, copper sulfides, zinc sulfide) are precipitating mercury.

As seen with the previous experiment where adding additional $\mathrm{KCN}$ increases silver recovery, this same experiment was done again, but with $0.1 \% \mathrm{KCN}$ added to the saturated mercury solution for leaching the High Se ore.

The same experimental two-step set as just discussed, but with $0.01 \% \mathrm{KCN}$ added, results are shown in Figure 4.14 with mercury in black and silver in white. For the first batch of mercury cyanide with $0.01 \% \mathrm{KCN}$ solution leaching the High Se ore, silver recovered was around $82 \%$ as compared to a cyanide only leach. Mercury removal from the first batch was at $98 \%$. The second pass showed a still significant ppb amount of silver being removed from the ore with mercury being removed at nearly $70 \%$. Silver recovery was significantly more silver (2124 ppb) than the previous experiment without additional KCN (147 ppb). 


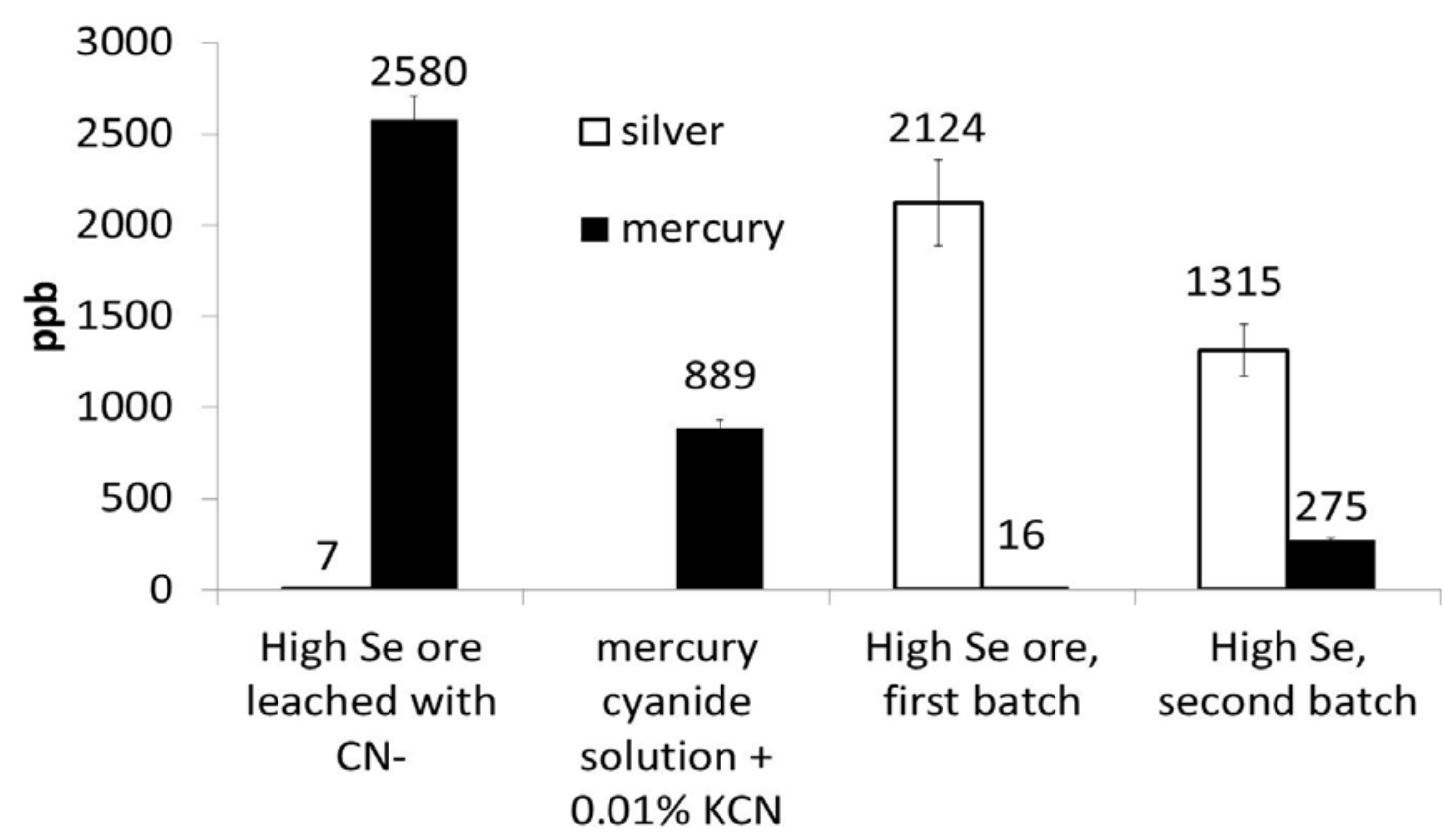

Figure 4.14. High Se ore leached with mercury solution with excess cyanide.

Ideally, only $\mathrm{Hg}(\mathrm{CN})_{4}^{-2}$ would be required for the reaction of replacing mercury with silver in a sulfide mineral, with the possibility of complete mercury elimination, but as shown previously, free cyanide is required for the exchange reaction with silver to take place. The exact reason for this is not known, though some initial dissolution may be needed to liberate $\mathrm{S}^{-2}$ to react with the mercury.

The two-step procedure worked well for the High Se ore in silver recovery and mercury removal, so a counter current flow experiment was set up next. This would hopefully optimize the use of the potentially recycled mercury cyanide solution for mercury removal and silver recovery. Both the High Se ore and High $\mathrm{Hg}$ ores were separately tested for recovery with a counter current flow. 


\subsection{Counter Current Flow of $\mathrm{Hg}(\mathrm{CN}) 4^{-2}, 0.01 \%$ KCN Solution for High Se and High Hg Ores}

The goal of this experiment was to determine if a counter current flow set up would be useful for precipitating mercury from a cyanide solution and dissolving silver. Both High Se and High $\mathrm{Hg}$ ores were tested.

\section{Methods}

A solution of $0.01 \% \mathrm{KCN}$ ( $\mathrm{pH} 11$ with sodium hydroxide) with the saturated $\mathrm{Hg}(\mathrm{CN})_{4}{ }^{-2}$ solution (from 3.2.6) was mixed for this experiment for a final with a mercury concentration of $889 \mathrm{ppb}$.

A bottle (labeled "used/old" in Figure 4.15) of ore (approximately 5 grams) was leached with $0.01 \% \mathrm{KCN} / \mathrm{mercury}$ cyanide solution $(10 \mathrm{~mL})$ for 48 hours. This first run was to make the ore "used", as if having been used in a counter current flow set up for some time. After the bottle 1 ore was made "used", fresh $\mathrm{Hg}(\mathrm{CN})_{4}{ }^{-2}$ in a $0.01 \% \mathrm{KCN}$ solution (889 ppb mercury, 20mL) was used to leach bottle 1 for 48 hours. Part of the resulting leached was analyzed and $10 \mathrm{~mL}$ were used to leach bottle 2 containing fresh ore $(5$ grams). The leach from bottle 2 was analyzed as what would be considered the "final leach product". Two batches of fresh $\mathrm{Hg}(\mathrm{CN})_{4}^{-2}$ solution were run through the set up for both ores, separately. Figure 4.15 shows a diagram of the process. 


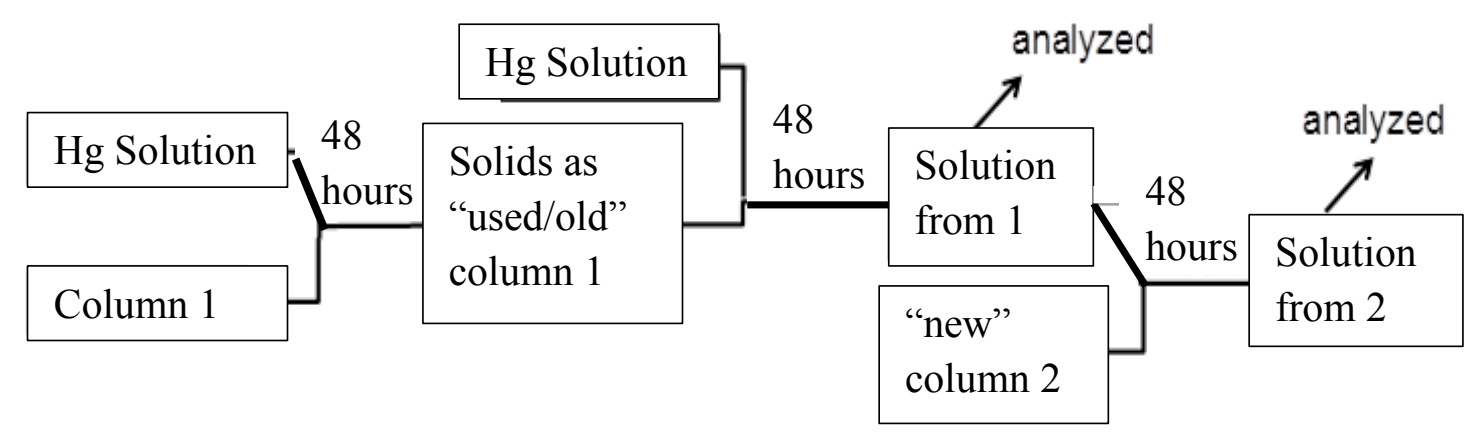

Figure 4.15. Counter current flow of mercury cyanide solution (with $0.01 \% \mathrm{KCN}$ ) with ore is shown.

\section{Experimental Results and Discussion}

The High Se ore showed good removal of mercury in both the first and second batches (Table 13). The final concentration of mercury in the second batch was $1.7 \mathrm{ppb}$, or a $99.8 \%$ lower mercury concentration. Silver was also recovered at final concentrations of about $300 \mathrm{ppb} / \mathrm{gram}$ ore (total about $1.5 \mathrm{ppm}$ for the outflow of the second batch). The High $\mathrm{Hg}$ ore also showed mercury removal (Table 14) $97 \%$ for the first batch and $91 \%$ for the second batch. Silver recovered was about $160 \mathrm{ppb} / \mathrm{grams}$ ore (total $835 \mathrm{ppb}$ for the outflow of the second batch). Nearly $2 \mathrm{ppm}$ of silver from the first and second batch were recovered for the High $\mathrm{Hg}$ ore.

Table 13. High Se ore results from counter current flow trial.

\begin{tabular}{|l|l|l|l|l|}
\hline Batch 1 & \multicolumn{2}{|c|}{ Silver } & \multicolumn{2}{c|}{ Mercury } \\
\hline unit & ppb/ore (grams) & $\mathrm{mg} /$ ore (grams) & $\mathrm{ppb} /$ ore (grams) & $\mathrm{mg} /$ ore (grams) \\
\hline funnel 1 & 225 & $4.5 \times 10^{-3}$ & 47 & $9.4 \times 10^{-4}$ \\
\hline funnel 2 & 228 & $2.8 \times 10^{-3}$ & 0.69 & $6.9 \times 10^{-6}$ \\
\hline Batch 2 & \multicolumn{2}{|c|}{ Silver } & \multicolumn{2}{c|}{ Mercury } \\
\hline unit & ppb/ore (grams) & mg/ore (grams) & ppb/ore (grams) & mg/ore (grams) \\
\hline
\end{tabular}




\begin{tabular}{|l|l|l|l|l|}
\hline funnel 1 & 172 & $3.4 \times 10^{-3}$ & 70.6 & $1.4 \times 10^{-3}$ \\
\hline funnel 2 & 304 & $3.0 \times 10^{-3}$ & 0.35 & $3.5 \times 10^{-6}$ \\
\hline
\end{tabular}

Table 14. High $\mathrm{Hg}$ ore results from counter current flow trial.

\begin{tabular}{|l|l|l|l|l|}
\hline Batch 1 & \multicolumn{2}{|c|}{ Silver } & \multicolumn{2}{c|}{ Mercury } \\
\hline bottle & ppb/ore (grams) & $\mathrm{mg} /$ ore (grams) & ppb/ore (grams) & $\mathrm{mg} /$ ore (grams) \\
\hline 1 & 84 & $1.6 \times 10^{-3}$ & 106.0 & $2.12 \times 10^{-3}$ \\
\hline 2 & 212 & $2.1 \times 10^{-3}$ & 5.41 & $5.4 \times 10^{-5}$ \\
\hline Batch 2 & \multicolumn{2}{|r|}{ Silver } & \multicolumn{2}{c|}{ Mercury } \\
\hline bottle & ppb/ore (grams) & $\mathrm{mg} /$ ore (grams) & ppb/ore (grams) & $\mathrm{mg} /$ ore (grams) \\
\hline 1 & 46 & $9.2 \times 10^{-4}$ & 115.6 & $2.31 \times 10^{-3}$ \\
\hline 2 & 167 & $1.6 \times 10^{-3}$ & 15.16 & $1.5 \times 10^{-4}$ \\
\hline
\end{tabular}

Less mercury was again observed to be removed by the High $\mathrm{Hg}$ ore. This is expected, as discussed previously, since there is significantly more mercury in that ore and less silver than there is in the High Se ore. With more batches of mercury cyanide run through the High Se ore, the mercury removal and silver recovery would decrease, as seen in the High $\mathrm{Hg}$ ore. More passes of the solution through ore are expected to remove more mercury, which could potentially reach negligible amounts in the High Se ore. The High Hg ore may always have an amount of mercury present, although greatly lower than just leaching it with cyanide, due to the high amounts of mercury already in the ore. There are other sulfide in the ores, as suggested as previously, which may also be affecting mercury removal.

A counter current flow for a continuous process in industry would be desirable over a batch process. This experiment demonstrated that a counter current flow would work well in removing mercury and recovering silver when using a potential waste material of 
mercury cyanide solution. The results were shown as ppb per grams of ore used in order to compare how much a gram of the ore can put out in silver and remove in mercury. This could later be used for scaling the process up to a larger sized operation.

\subsection{Conclusions}

Initial trials with chemical grade compounds indicated that $99 \%$ of mercury $(760 \mathrm{ppb} \mathrm{Hg}$ to $6 \mathrm{ppb} \mathrm{Hg}$ ) could be precipitated out of a cyanide solution over a period of 48 hours while dissolving silver (200 ppb). The initial precipitation of mercury is fairly fast, with less silver being dissolved than mercury precipitated. After about 6 hours, the rate of mercury precipitation to silver dissolution does slow down. Analysis using EDS also supported the theory that mercury was precipitating on the silver sulfide surface.

Using natural ores, one containing high selenium and the other with high mercury, leached with a synthetic mercury cyanide solution indicated that both would precipitate the mercury in solution (50\% and 30\%, respectively). Less mercury precipitated out using the High $\mathrm{Hg}$ ore, probably due to the fact that the ore already had mercury in it whereas the High Se ore had almost none. Silver recovered, as compared to a cyanide only leach as about $43 \%$ for the High Se ore and about 50\% for the High $\mathrm{Hg}$ ore, which might be due to the larger amount of fine particles found in the High $\mathrm{Hg}$ ore.

Various leaching experiment were tried after finding that leaching natural ores with mercury cyanide could work, and found that a small amount of free cyanide was needed to start the exchange process. While both ore could remove over half the mercury in this manner (with the High Se ore still removing more mercury), the big change was seen in silver dissolution. As compared to a cyanide only leach, the silver recovery was only about $21 \%$ lower than could be expected for both ores.

Finally, running mercury cyanide solution over the same ore more than once indicated that a counter current flow set up could be advantageous by showing that several passes 
with the mercury solution would recover more silver and precipitate more mercury than with one pass alone in a continual flow process. In the High Se ore, one pass with the first batch through two funnels showed $2.8 \times 10^{-3} \mathrm{mg} \mathrm{Ag} / \mathrm{grams}$ ore, and the second batch showed nearly the same recovery. Mercury for the High Se ore for the first batch with two funnels was removed to about $7 \times 10^{-6} \mathrm{mg} \mathrm{Hg} / \mathrm{grams}$ ore, and the second batch showed $3.5 \times 10^{-6} \mathrm{mg} \mathrm{Hg} /$ grams ore. The High $\mathrm{Hg}$ ore showed similar trends with the silver around $2 \times 10^{-3} \mathrm{mg} \mathrm{Ag} /$ grams ore. The mercury amounts coming out of the second funnel also were lowered by $5.25 \times 10^{-3} \mathrm{mg} \mathrm{Hg} /$ grams ore going from the first batch to the second.

As stated earlier, some silver loss might be expected with this method due to potential encapsulation of silver sulfide by precipitated mercury sulfide on the surface. Therefore, the method of using mercury cyanide to leach silver from ore is a plausible option under certain circumstances. Under conditions when leaching of a poor grade silver ore would not be worth using fresh cyanide solution, used solution with mercury cyanide would lower the mercury in solution and still recover silver. 


\section{Zinc Sulfide Precipitation of Mercury Cyanide as Mercury Sulfide}

\subsection{Introduction}

The goal of these experiments was to use zinc sulfide (taking the role of the silver sulfide

in the previous experiments) to selectively precipitate mercury as mercury sulfide, while having silver cyanide stay in solution. A flow diagram of the experiment is shown in Figure 5.1. 


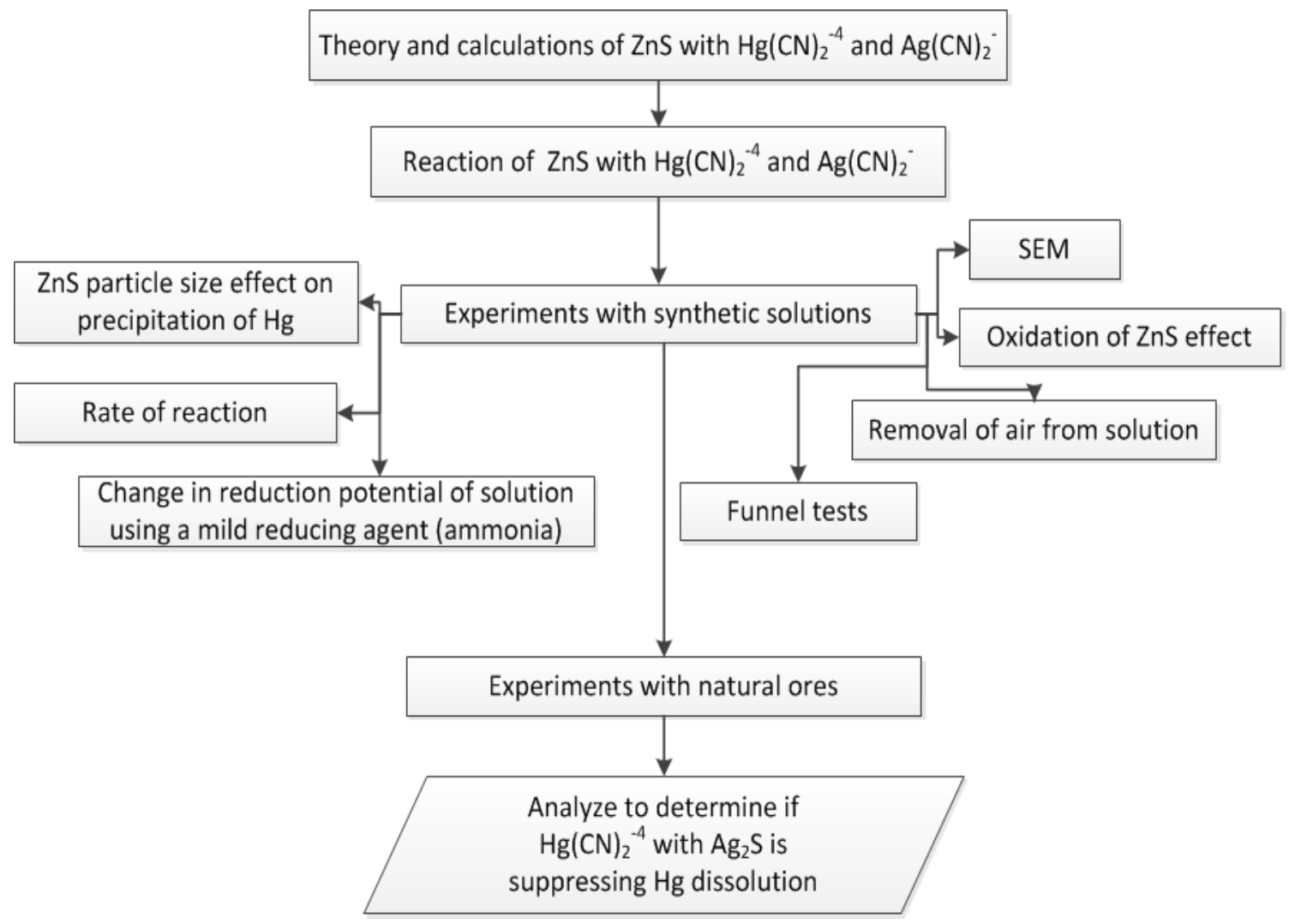

Figure 5.1. Diagram showing what experiments were done and how they are related.

\subsection{Theoretical Discussion}

Naturally occurring zinc sulfide (sphalerite) has potential to be used for a replacement reaction with mercury. As shown in Equation 43, mercury cyanide is thermodynamically favorable to precipitate out as mercury sulfide, replacing a zinc ion. Silver cyanide is also thermodynamically favorable (Equation 44), but less so than the mercury cyanide.

$$
\begin{aligned}
& \mathrm{Hg}(\mathrm{CN}) 4^{-2}(\mathrm{aq})+\mathrm{ZnS}(\mathrm{s}) \rightarrow \mathrm{HgS}(\mathrm{s})+\mathrm{Zn}(\mathrm{CN}) 4^{-2}(\mathrm{aq}) \quad \text { Equation } 43 \\
& \Delta \mathrm{G}=-43 \mathrm{~kJ}
\end{aligned}
$$


$\Delta \mathrm{G}=-30 \mathrm{~kJ}$

A solution of mercury and silver cyanide added to zinc sulfide could be expected to precipitate both mercury and some silver sulfide onto the zinc sulfide core. The zinc sulfide core would support a thin layer of silver sulfide that will be completely replaced with mercury sulfide. This avoids encapsulation of the silver sulfide core from the previously mentioned mercury precipitation method. Figure 5.2 shows how the replacement reaction with zinc is expected to work.

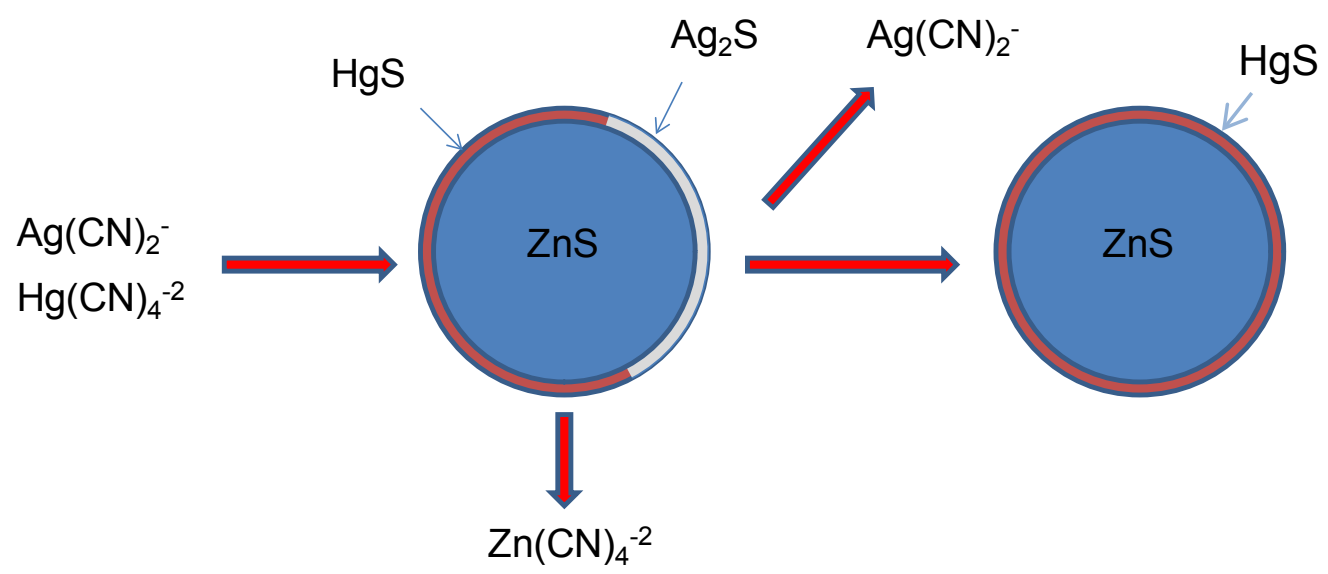

Figure 5.2. The zinc sulfide surface will precipitate both silver and mercury sulfides from cyanides. Mercury cyanide will progressively displace the silver sulfide as silver cyanide and precipitate mercury sulfide. (Gabby and Eisele 2012)

The silver may be even less likely to precipitate and replace a zinc ion due to steric hindrance. The sphalerite crystal is hextetrahedral (Figure 5.3, approximated) with sides being $0.54 \mathrm{~nm}$ (Mineral Publishing Data 2001-2005), the ionic radii of zinc is $0.074 \mathrm{~nm}$, and sulfur is $0.190 \mathrm{~nm}$ (Shannonn 1969, 1976). Mercury is $0.083 \mathrm{~nm}$ (which is only $12 \%$ larger than the zinc ion, allowing it to replace zinc with minimal crystal lattice distortion) 
and silver is $0.129 \mathrm{~nm}$ (Shannonn 1969, 1976). Bond lengths for mercury and zinc are also very similar with $\mathrm{HgS}$ averaging at $0.236 \mathrm{~nm}$ (Holleman et al. 2001) and $\mathrm{ZnS}$ at $1.235 \mathrm{~nm}$ (Zhang et al 2008). Furthermore, mercury will theoretically fit in one space vacated by a $\mathrm{Zn}^{+2}$ ion, whereas two silver ions would have to fit into the same site to maintain charge balance.

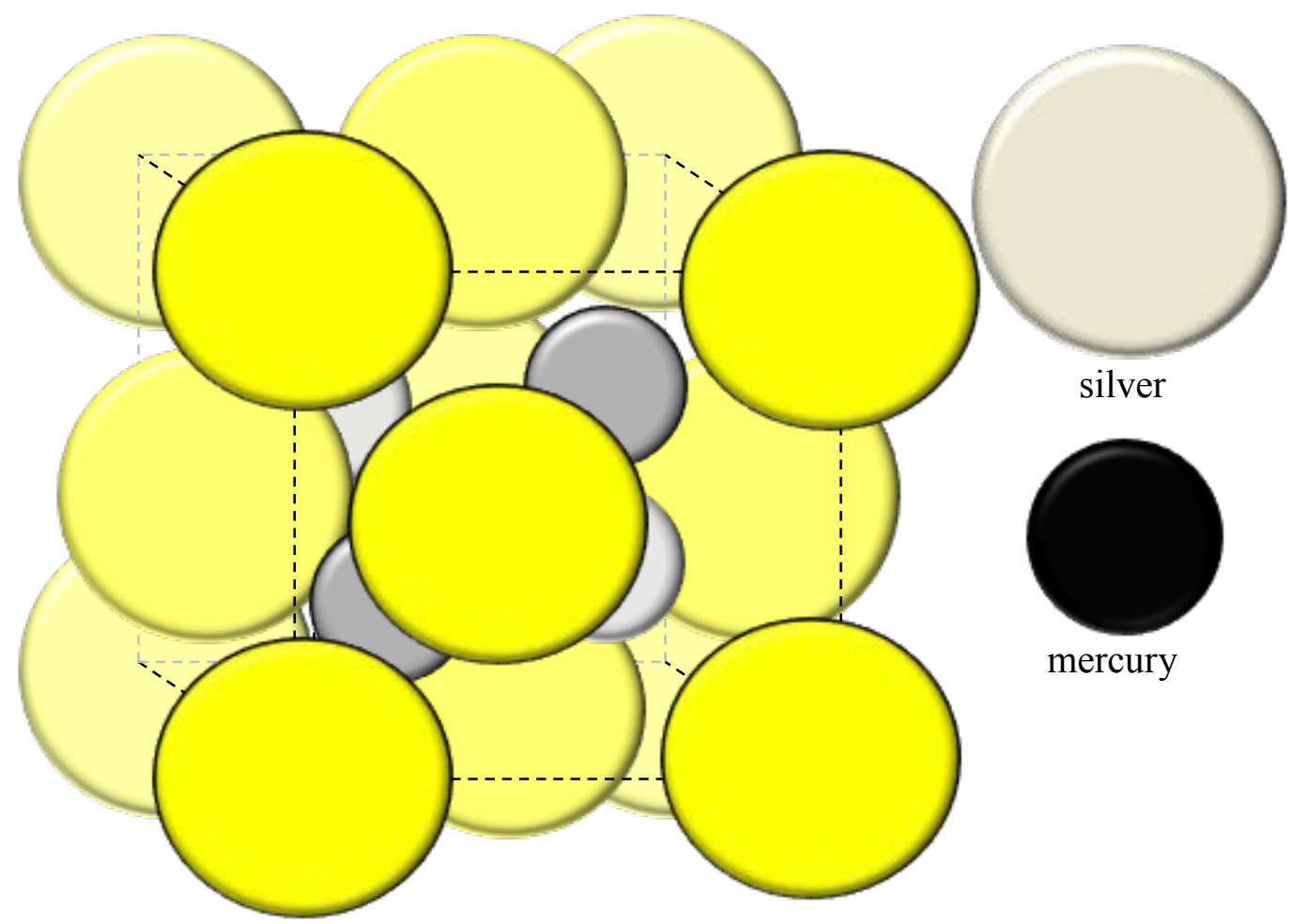

Figure 5.3. The zinc sulfide cell (shown in its most commonly found structure as zinc blende) is shown approximated as a ball and stick model, where the larger ions in the cell are sulfur and the smaller ones are zinc. Silver and mercury are also shown off to the side, with mercury being slightly larger than the zinc ion and silver being slightly smaller than the sulfur ions.

Other factors expected to affect precipitation and selectivity are the reduction potential of the solution and other ions in the leach heaps present in large enough amounts to potentially make a difference. Mercury sulfide is expected to precipitate at lower 
reduction potentials while silver can still stay in a cyanide complex at $\mathrm{pH} 11$, as can be seen by looking at the Pourbaix diagrams of mercury sulfide and silver sulfide (Figure 5.4 and Figure 5.5). There is a very small range at $\mathrm{pH} 11$ where silver sulfide could also precipitate out, explaining why some silver does precipitate, but then can be re-dissolved by cyanide, as suggested by Equation 44.

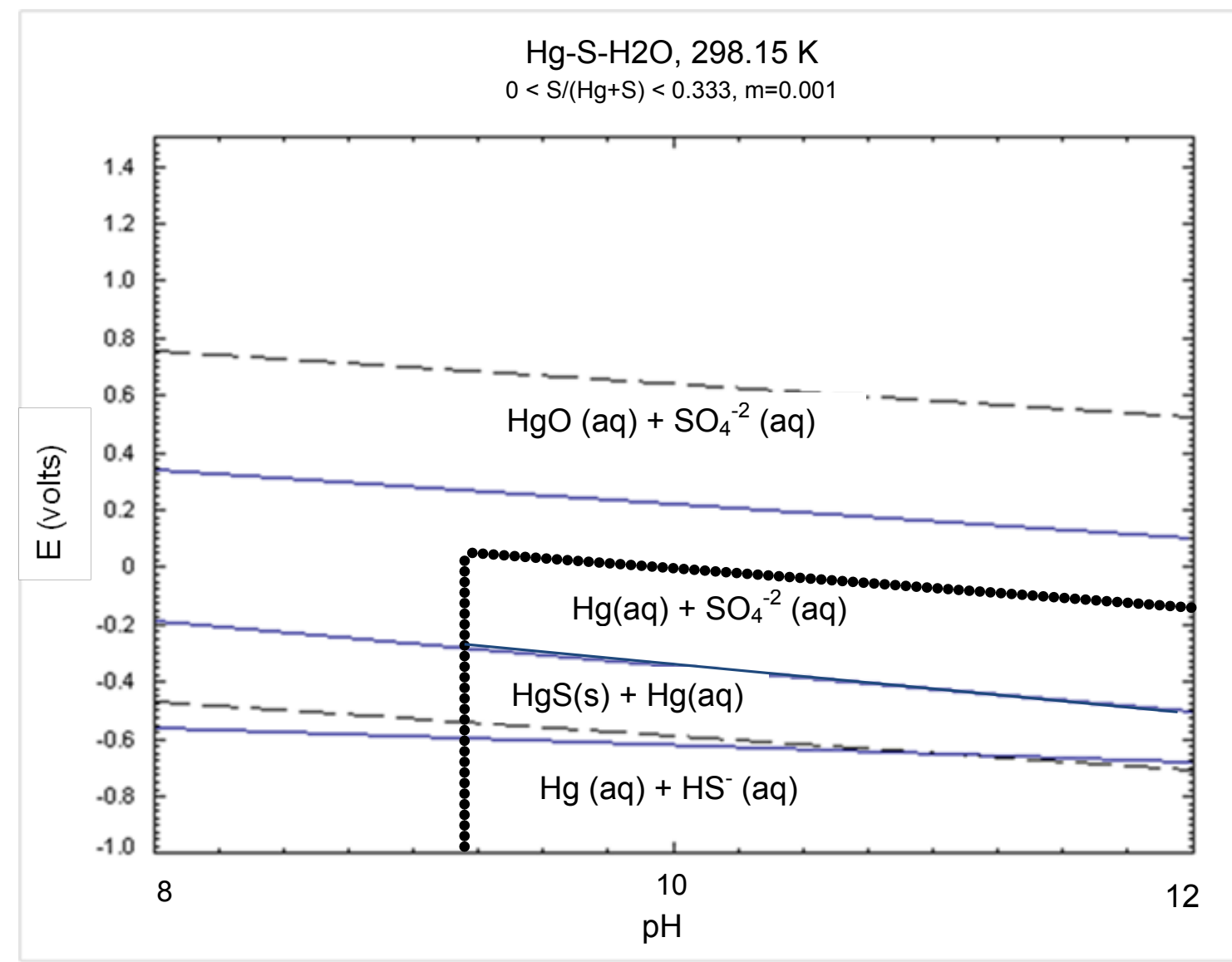

Figure 5.4. Pourbaix diagram generated by FactSage $($ of mercury and sulfide in aqueous solution with the black circle lines indicating the $\mathrm{CN}^{-}$stability region. 


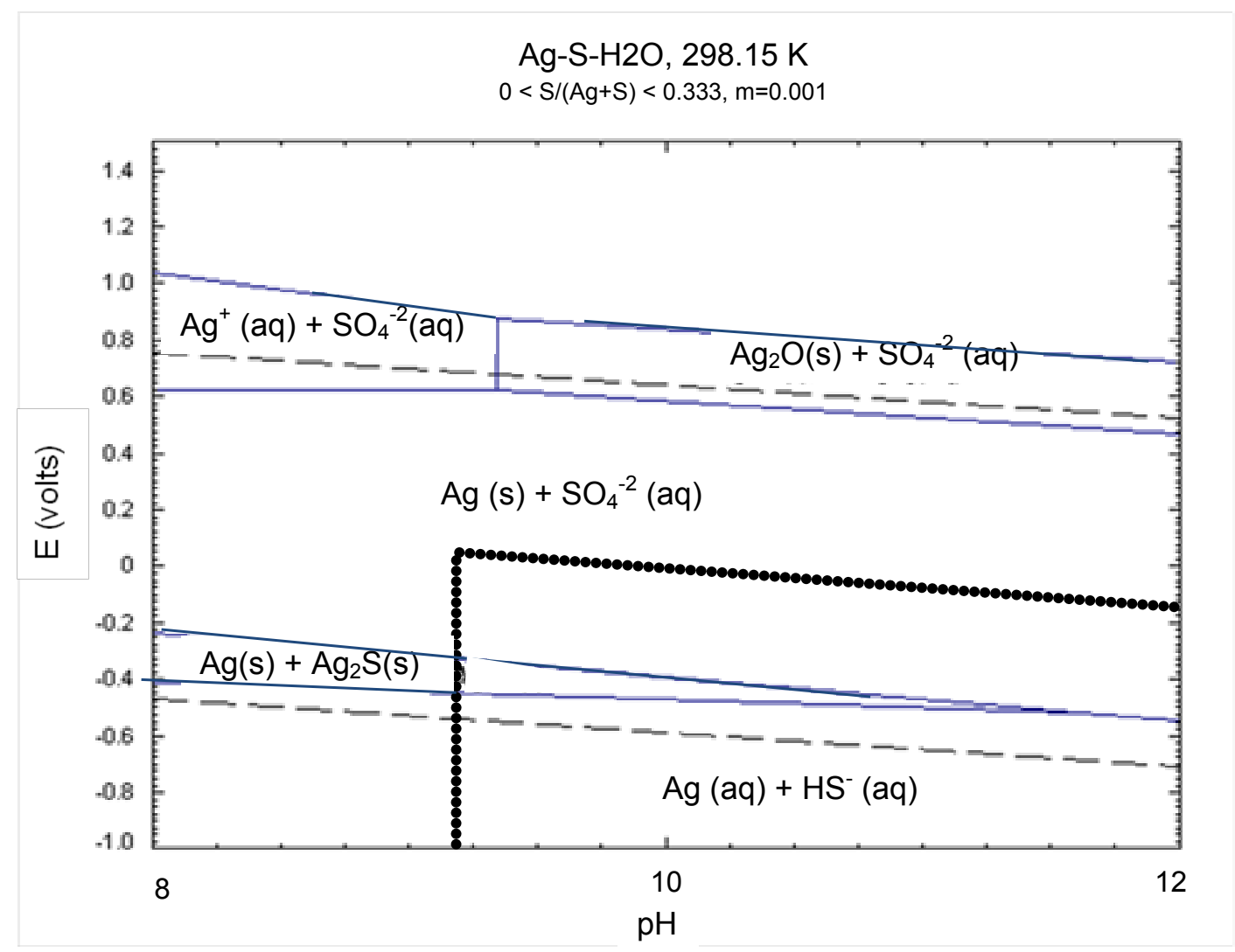

Figure 5.5. Pourbaix diagram generated by FactSage $\odot$ of silver and sulfide in aqueous solution with the black circle lines indicating the $\mathrm{CN}^{-}$stability region.

This section of the paper involving sphalerite has been broken up into three sections. Chapter 5 shows preliminary work covering feasibility, SEM, gram and time trials, particle size affect, rate of reaction, oxidation of sphalerite, de-aeration, reduction potential effects of the solution, removal of mercury not in a cyanide complex, and solid waste. Chapter 6 covers exclusive use of a pipette and filter funnels. Chapter 7 deals with possible complication ions in natural ores. 


\subsection{Experimental Procedures}

\section{Materials}

Reagents used were distilled water, synthetic mercury sulfide (black), synthetic silver sulfide, sodium hydroxide, hydrogen peroxide, potassium cyanide, sphalerite (naturally occurring $\mathrm{ZnS})$.

\subsection{Vial feasibility trials}

The goals of these experiments were to determine if sphalerite (naturally occurring $\mathrm{ZnS}$ ) could be used to remove mercury from a leached solution of mercury cyanide and silver cyanide.

\section{Methods}

Reactions were carried out in $60 \mathrm{~mL}$ vials with screw-top caps and were not shaken or stirred during the experiment. All experiments were done at room temperature. Four experiments were carried out, summarized in Table 15. For more detailed methods, see Appendix 6.

Table 15. Summary of experiments for initial feasibility tests are shown.

\begin{tabular}{|l|l|l|l|l|l|}
\hline Experiment & $\begin{array}{l}\text { zinc sulfide } \\
(\text { grams })\end{array}$ & silver $(\mathrm{ppb})$ & $\begin{array}{l}\text { mercury } \\
(\mathrm{ppb})\end{array}$ & $\begin{array}{l}\text { time } \\
(\text { hours })\end{array}$ & $\begin{array}{l}\text { volume of } \\
\text { liquid }(\mathrm{mL})\end{array}$ \\
\hline 1 & $\begin{array}{l}0.010 \\
\text { natural sphalerite, } \\
\text { used as found }\end{array}$ & 100 & 640 & 24 & 50 \\
\hline 2 & $\begin{array}{l}0.10 \\
\text { natural sphalerite, } \\
\text { used as found }\end{array}$ & 5000 & 803 & 24 & 50 \\
\hline 3 & $\begin{array}{l}1.0 \\
\text { natural sphalerite, } \\
\text { used as found }\end{array}$ & 2480 & 1880 & $\begin{array}{l}24 \text { and } \\
1\end{array}$ & 50 \\
\hline 4 & 1.0 & 2250 & 438 & 24 and & 50 \\
\hline
\end{tabular}




\begin{tabular}{|l|l|l|l|l|l|}
\hline & $\begin{array}{l}\text { puck mill ground } \\
\text { sphalerite }\end{array}$ & & 1 & \\
\hline
\end{tabular}

\section{Experimental Results and Discussion}

The first three experiments indicated that a reaction with sphalerite would occur and are summarized in Appendix 6.

The fourth experiment demonstrated that grinding the sphalerite greatly increased the reaction. This could be from increased surface area due to use of smaller particles, or possibly exposure of fresh surface. The sphalerite had been sitting for quite some time, leaving the zinc available for oxidation. Silver and mercury do not react with zinc oxide and the replacement reaction would not happen (Equation 45 and Equation 46).

$\mathrm{ZnO}(\mathrm{s})+2 \mathrm{Ag}(\mathrm{CN})_{2}^{-}(\mathrm{aq}) \rightarrow \mathrm{AgO}(\mathrm{s})+\mathrm{Zn}(\mathrm{CN}) 4^{-2}(\mathrm{aq}) \quad$ Equation 45 $\Delta \mathrm{G}=+118 \mathrm{~kJ}$

$\mathrm{ZnO}(\mathrm{s})+\mathrm{Hg}(\mathrm{CN})_{4}^{-2}(\mathrm{aq}) \rightarrow \mathrm{HgO}(\mathrm{s})+\mathrm{Zn}(\mathrm{CN})_{4}^{-2}(\mathrm{aq}) \quad$ Equation 46 $\Delta \mathrm{G}=+63 \mathrm{~kJ}$

These experiments suggested that zinc sulfide was selectively precipitating mercury over silver and had potential for further studies. 


\subsection{SEM Images of Sphalerite Reacted with Mercury Cyanide}

The goal of this experiment was to give further evidence for the mercury cyanide precipitating onto the zinc sulfide particles.

\section{Methods}

The sphalerite used was ground, to an $80 \%$ passing particle size about $200 \mu \mathrm{m}$. Sphalerite (1 gram) was placed in a vial and $20 \mathrm{~mL}$ of mercury cyanide solution (about $10000 \mathrm{ppb}$ mercury, $0.02 \%$ potassium cyanide) added and allowed to react 45 minutes. The solution was filtered and the solids kept. The solution was tested to make sure some mercury was still in solution, which would suggest the sphalerite particle surfaces were saturated with mercury sulfide. The solids were then triple rinsed with distilled water, dried at $100^{\circ} \mathrm{C}$ overnight, and mount for SEM analysis. The SEM was run at $20 \mathrm{KeV}$.

\section{Experimental Results and Discussion}

SEM images were done for further evidence of the mercury depositing on the surface of sphalerite. The solution after the reaction showed only about $50 \%$ of the mercury was removed. This was done to make sure enough mercury was present for the given amount of sphalerite to adequately cover the sphalerite surface. Analysis of the sphalerite particles by EDS showed a consistent $\approx+2 \%$ of mercury on the surface of the $\mathrm{ZnS}$ particles (Table 16). The element map (Figure 5.6) image and EDS also support that mercury is precipitating onto the surface of the $\mathrm{ZnS}$ particles in a thin layer surrounding the non porous particles.

Table 16. SEM EDS showing nearly $2 \%$ mercury on the surface of the $\mathrm{ZnS}$ particle, accelerating voltage $20 \mathrm{KeV}$ for a 60 second dwell time.

\begin{tabular}{|l|l|}
\hline Element & Weight \% \\
\hline Mercury & 1.79 \\
\hline
\end{tabular}




\begin{tabular}{|l|l|}
\hline Sulfur & 38.86 \\
\hline Silver & 59.35 \\
\hline
\end{tabular}
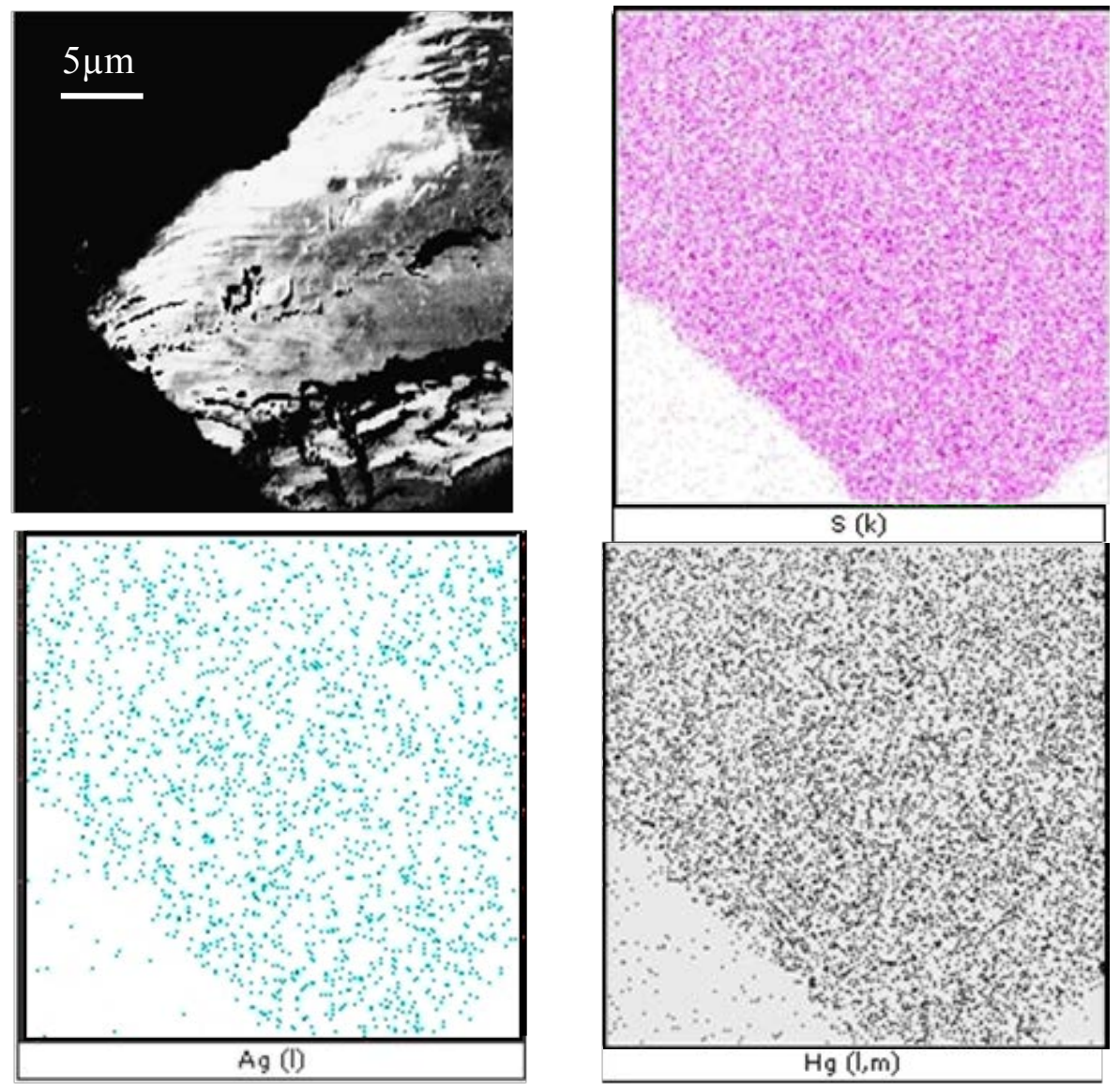

Figure 5.6. SEM element map showing mercury on the surface of the $\mathrm{ZnS}$ particle (particles were $80 \%$ passing about $220 \mu \mathrm{m}$ ), accelerating voltage $20 \mathrm{KeV}$, magnification 5,500x.

After using the SEM to confirm that the mercury was precipitating on the sphalerite, gram and time trials were carried out. 


\subsection{Time and Gram Trials with Sphalerite}

The goal of this experiment was to determine how much/little sphalerite could be used with good mercury removal and low silver losses, and how much time the reaction would need to precipitate mercury and re-dissolve silver sulfide, if any formed.

\section{Methods}

The sphalerite used was $80 \%$ passing $11 \mu \mathrm{m}$ from a puck mill. Reactions were carried out in $60 \mathrm{~mL}$ vials with screw-top caps and were not shaken or stirred during the experiment. All experiments were done at room temperature. An experiment with various amounts of puck mill ground sphalerite at a fixed time (1 hour) was run, and an experiment with a fixed amount of puck mill ground sphalerite (0.0625) at various times was run, all experiment with $30 \mathrm{~mL}$ of solution. Starting solutions were around $930 \mathrm{ppb}$ mercury and $300 \mathrm{ppb}$ silver.

\section{Experimental Results and Discussion}

The grams trials experiment showed that a fairly wide range of sphalerite, even at small amount, could be used to remove mercury with little silver loss. The time trials showed mercury removed from the solution (99\%) after 15 minutes (Table 17). Silver losses were highest at the beginning, but lowered to negligible amounts after 45 minutes (Table $18)$.

Another trial was done with high mercury concentrations and low sphalerite $(0.0100$ grams, $80 \%$ passing particle size $155 \mu \mathrm{m}$ ), which showed what mercury was removed after 15 seconds (starting at 19 ppm, going to, and remaining at, 18 ppm at 15, 30, 60, and 120 second). 
Table 17. Various amounts of powdered sphalerite were used with the same solution (930 ppb mercury and 300ppb silver) for one hour. (Gabby and Eisele 2012. Use agreement found in Appendix 7)

\begin{tabular}{|r|r|r|}
\hline grams ZnS used & \% mercury removed & \% silver loss \\
\hline 1 & 97.4 & 39.2 \\
\hline 0.25 & 99.9 & 0 \\
\hline 0.0625 & 99.8 & 1.2 \\
\hline 0.0316 & 98.7 & 2.7 \\
\hline 0.0156 & 98.5 & 0 \\
\hline 0.0039 & 86.6 & 0 \\
\hline 0.0009 & 44.8 & 0 \\
\hline
\end{tabular}

Table 18. Time trials using 0.0625 grams puck-mill ground sphalerite were carried out in vials with no stirring. (Gabby and Eisele 2012)

\begin{tabular}{|l|l|l|}
\hline Time trials (minutes) & \% mercury removed & \% silver loss \\
\hline 15 & 99.29 & 6.03 \\
\hline 30 & 99.32 & 2.62 \\
\hline 45 & 99.44 & 0.68 \\
\hline 60 & 98.87 & 0.60 \\
\hline
\end{tabular}

The sphalerite grams trials and time trials demonstrate that the mercury cyanide precipitation reaction to mercury sulfide is relatively fast and a wide range of sphalerite could be used. The time trials also support the theory shown in Figure 5.2 that the silver also initially precipitates, but then dissolves back into solution when allowed to react longer. 


\subsection{Particle Size Effects on Mercury Precipitation}

The goal of this experiment was to demonstrate the effects of particle size on mercury precipitation rate.

\section{Methods}

The sphalertie ( 0.625 grams used per sample) was ground to the average $80 \%$ passing sizes of: $245,189,165,11 \mu \mathrm{m}$. All sphalerite samples were placed in filter funnels and pre-rinsed with $20 \mathrm{~mL}$ distilled water and allowed to dry. Mercury cyanide $(20 \mathrm{~mL})$ was added to the sphalerite (all the solution added in at once).

Experimental Results and Discussion

After obtaining approximate times for puck mill ground sphalerite with a silver/mercury cyanide solution, the effect of the sphalerite particle size was determined.

Particle size did affect the reaction, as expected. The size fractions of $80 \%$ passing sphalerite particles used are shown in Table 19. When plotting the $y$-axis as log moles of mercury removed divided by the specific surface area and the $\mathrm{x}$-axis as the $80 \%$ passing particle size, a trend was found (Figure 5.7, Table 20). The smallest particles size $(11 \mu \mathrm{m})$ precipitated the most mercury $(99.8 \%)$, while the largest size precipitated the least $(79.7 \%)$.

Table 19. Sphalerite particle size fractions used, $80 \%$ passing.

\begin{tabular}{|l|l|}
\hline $80 \%$ passing particle size $(\mu \mathrm{m})$ & Standard deviation \\
\hline 245 & 39 \\
\hline 189 & 6 \\
\hline 165 & 14 \\
\hline 11 & 0 \\
\hline
\end{tabular}




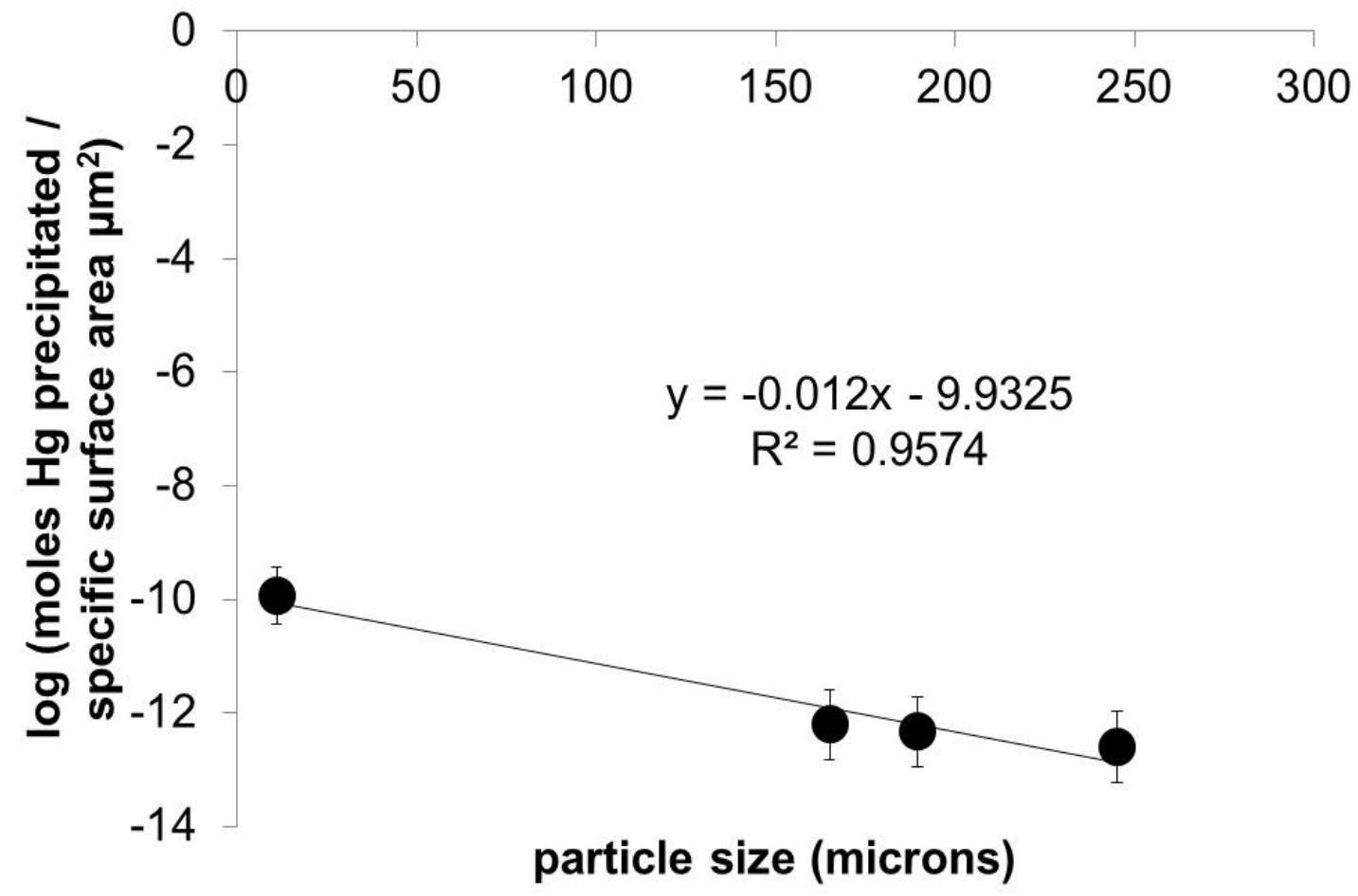

Figure 5.7. Sphalerite particle size effects on mercury precipitation is shown on a semi-log plot.

Table 20. The log (base 10) of the mole mercury removed divided by the specific surface area and the size fraction of particles is shown.

\begin{tabular}{|r|r|}
\hline $80 \%$ passing particle size $(\mu \mathrm{m})$ & $\log \left(\right.$ moles Hg precipitated / specific surface are in $\left.\mu \mathrm{m}^{2}\right)$ \\
\hline 245 & -12.387 \\
\hline 185 & -12.153 \\
\hline 165 & -11.998 \\
\hline 11 & -.9875 \\
\hline
\end{tabular}


From this, the amount of mercury expected to precipitate at a size fraction for a particular amount of sphalerite can be found. With this, industrial processes could figure out how small to grind (and filter) sphalerite depending on costs and mercury removal.

Example: Particles sizes of $300 \mu \mathrm{m}$ can remove from a $20 \mathrm{~mL}$ solution, $0.053 \mathrm{ppm}$ mercury. Particles of $2 \mu \mathrm{m}$ could remove, from a $20 \mathrm{~mL}$ solution, $554 \mathrm{ppm}$ mercury.

In theory, a monolayer of synthetic zinc sulfide would be ideal for use, as there would be no waste from unused zinc sulfide in the core of the particle (Figure 5.2) and no contaminates as there may be in natural sphalerite. In practice, this might be more expensive due to additional steps for dissolution and precipitation onto selected media than using natural sphalerite. Zinc sulfide is inexpensive enough at $99 \%$ pure for 36 cents / $\mathrm{kg}$ (Jiangyin, 2002) that creating a monolayer of zinc sulfide might not be economical for practical use. If, perhaps, a very fine precipitate of $\mathrm{ZnS}$ were made by adding $\mathrm{Na}_{2} \mathrm{~S}$ to a soluble zinc compound or zinc ion in an acidic environment, then surface area could be maximized without the need for grinding $\mathrm{ZnS}$ down. The issue here would be extra steps for processing the very finely precipitated $\mathrm{ZnS}$ versus buying $\mathrm{ZnS}$ and grinding.

The amount of mercury that can precipitate on one particle of $245 \mu \mathrm{m}$ diameter $\mathrm{ZnS}$ has been estimated at $4.309 \times 10^{-10}$ grams $\mathrm{Hg}$ (calculations in Appendix 8).

\subsection{Rate of Reaction}

The goal of this experiment was to find the approximate rate at which mercury precipitated onto the sphalerite (Equation 40). The first experiment was attempted at room temperature. The second and third experiments were at $7^{\circ} \mathrm{C}$, with the fourth experiment used a vacuum filter to increase filtration rate at $3.2^{\circ} \mathrm{C}$. 


\section{Gravity Filtration at Room Temperature}

\section{Methods}

The room temperature experiment used a mercury cyanide solution $(20 \mathrm{~mL}, 3236 \mathrm{ppb}$, $0.02 \% \mathrm{KCN}, \mathrm{pH} 11,20 \mathrm{~mL})$, and 0.010 grams sphalerite ( $80 \%$ passing $220 \mu \mathrm{m})$. The time intervals used from when the solution contacted the sphalerite to when it was poured into the filter was $15,30,60$, and 120 seconds. The time for $10 \mathrm{~mL}$ of solution to pass through the filter with gravity was 50 seconds.

\section{Gravity Filtration at $7^{\circ} \mathrm{C}$}

\section{Methods}

For the $7^{\circ} \mathrm{C}$ with gravity filtration, a high concentration of mercury was used in solution (10mL, $1569 \mathrm{ppb}, 0.02 \% \mathrm{KCN}, \mathrm{pH} 11)$. The liquid and sphalerite $(0.0625$ grams, 80\% passing $220 \mu \mathrm{m}$ ) were put on ice for an hour. The final temperature of the liquid before use was $7^{\circ} \mathrm{C}$. The time intervals used from when the solution contacted the sphalerite to when it was poured into the filter was $5,10,25$, and 40 seconds. The mercury cyanide solution $(10 \mathrm{~mL})$ was added to the sphalerite $(0.0625$ grams $)$ in vials. The liquid $(10 \mathrm{~mL})$ took about 50 second to drain from the filter completely.

\section{Vacuum Filtration at $3.2^{\circ} \mathrm{C}$}

\section{Methods}

The $3.2^{\circ} \mathrm{C}$ with vacuum filtration was identical to the previous experiment, except 724 ppb mercury in solution was used $(10 \mathrm{~mL})$ with 1 gram of sphalerite was used for every time trial.

According to the time trials with sphalerite amount, about ten times the amount of the first experiment would be needed to remove most of the mercury when using puck mill ground sphalerite (about $80 \%$ passing size $11 \mu \mathrm{m}$ ). 


\section{Experimental Results and Discussion}

The rate of the reaction is also very important to consider: if the reaction is too slow, the use of sphalerite at room temperature may not be profitable or useful.

Finding the rate of the mercury cyanide reacting with sphalerite was attempted at three different temperatures. Since the gravity filtrations actually took $\approx 50$ seconds longer to filter than the vacuum filtration, Figure 5.8 shows the percent of mercury removed plotted over the adjusted times.

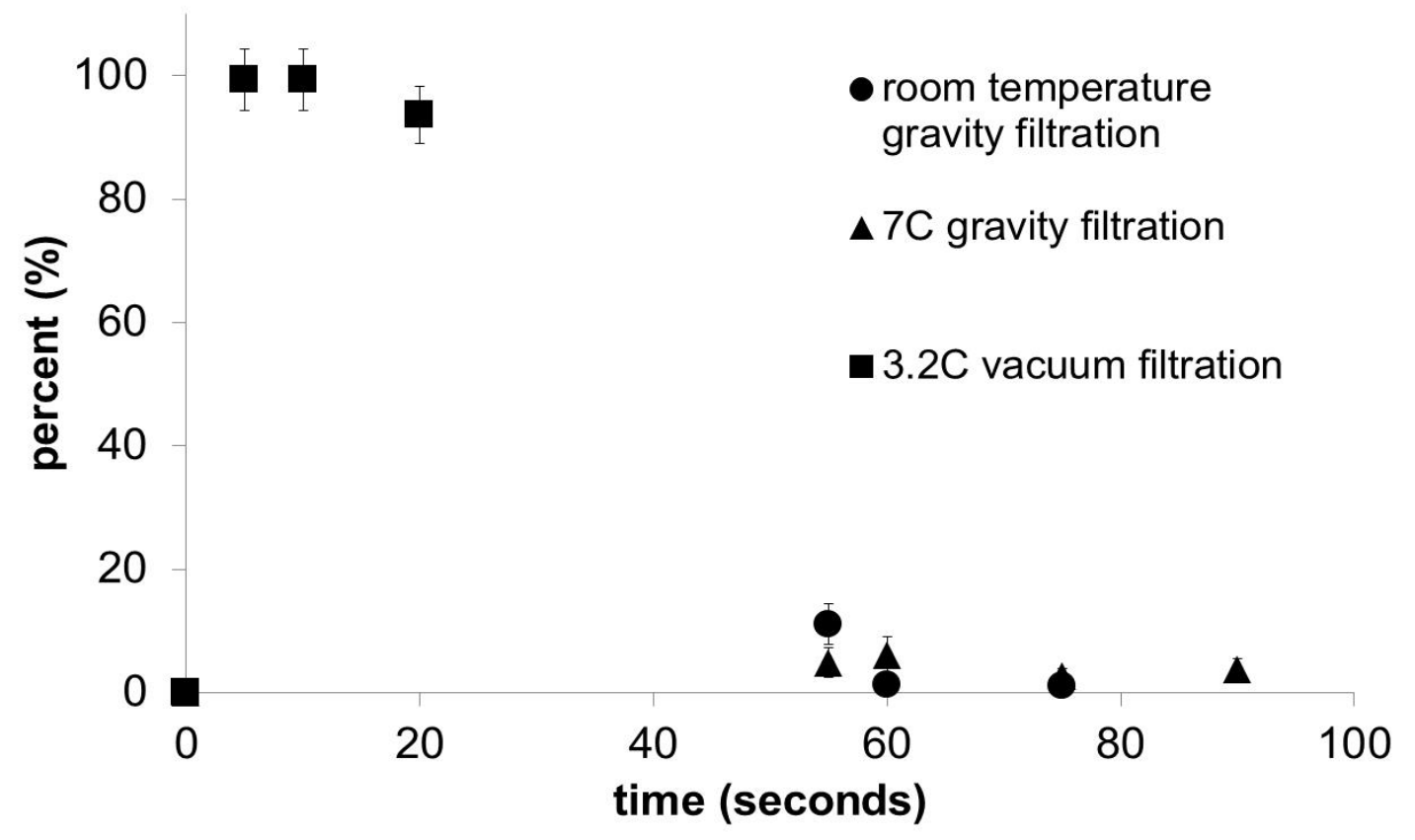

Figure 5.8. Percent of mercury cyanide removed from solution at time of filtration adjusted for filtering time.

The room temperature and $7^{\circ} \mathrm{C}$ filtration looked very similar at the first time stop of " 5 second". The $3^{\circ} \mathrm{C}$ shows a fast initial decrease of mercury in solution, possibly going into a plateau 
The room temperature solution probably had too high of a mercury concentration for the amount of sphalerite used with the fast times $(3236 \mathrm{ppb}$ In $10 \mathrm{~mL}$ for 0.01 grams sphalerite), explaining the low mercury removal. The same could be said for the $7^{\circ} \mathrm{C}$ run (1569 ppb in $10 \mathrm{~mL}$ for 0.625 grams sphalerite). The $3^{\circ} \mathrm{C}$ run shows nearly all the mercury removed after 5 seconds $(724 \mathrm{ppb}$ in $10 \mathrm{~mL}$ for 1 gram sphalerite). A good reaction curve cannot be obtained for between $0-5$ seconds at $3.2^{\circ} \mathrm{C}$, where the reaction appears to be happening, with the current method we are using. The slope between the 0 5 second for $3.2^{\circ} \mathrm{C}$ is $7.175 \times 10^{-9}$ moles $\mathrm{Hg} / \mathrm{sec}$ removed from solution.

From an engineering stand point, the reaction happens quickly enough that the reaction rate is not a limiting factor, particularly under room temperature or higher temperature conditions. From a chemistry standpoint, finding the rate of this reaction would be of interest for knowledge about the mechanism of the reaction.

\subsection{Oxidation Effects on Sphalerite}

The goal of this experiment was to determine if oxidation of zinc sulfide would inhibit the replacement reaction for precipitating mercury sulfide.

\section{Methods}

In the first experiment, freshly powdered sphalerite $(11 \mu \mathrm{m})$ was placed in the drying oven over night $\left(100^{\circ} \mathrm{C}\right.$, about 16 hours $)$. The sphalerite from the oven was then cooled until at room temperature in a desiccator. Samples of $20 \mathrm{~mL}$ of mercury/silver cyanide (1120 ppb Ag, 1640 ppb Hg) were run in vials with 0.063 grams sphalerite ("regular" for freshly ground sphalerite used, "oven” for sphalerite placed in the drying oven) for 45 minutes. 
In the second experiment, sphalerite ( $80 \%$ passing about $220 \mu \mathrm{m})$ two different methods of oxidation were used. One had water $(5 \mathrm{~mL})$ added to sphalerite (1 gram) and was then put in the drying oven for 24 hours. Another had $1 \% \mathrm{H}_{2} \mathrm{O}_{2}(50 \mathrm{~mL})$ added to sphalerite (4 grams) and was allowed to react at room temperature for 3 hours. It was then placed in the drying oven $\left(100^{\circ} \mathrm{C}\right.$ for 16 hours). The 4 grams of sphalerite were reacted with hydrogen peroxide to do a particle size analysis after the reaction to check if the particles were reduced in size. The sphalerite ( 0.625 grams) for both oxidized samples and a freshly ground sample were placed in filter funnels. The filters and sphalerite were rinsed with $10 \mathrm{~mL}$ distilled water and allowed to dry. A mercury solution (661 ppb Hg, $20 \mathrm{~mL}$ ) was run through the samples and analyzed.

\section{Experimental Results and Discussion}

As previously mentioned, sphalerite may oxidize with time and under certain conditions, and could affect how well the sphalerite works to remove mercury.

In the oxidized sphalerite experiment, the oxidized sphalerite was expected to react less well for these experiments than freshly ground. The results (shown in Figure 5.9 as percent of the ion removed from solution, with mercury in black and silver in white) agreed with this assumption. The first experiment showed silver losses were at $5 \%$ for the regular sample and 3\% for the oven dried samples. Mercury reduction shows slightly less mercury (about $1 \%$ ) removed than the regular sample. The differences are within error of the measurement so that no definite change could be seen. 


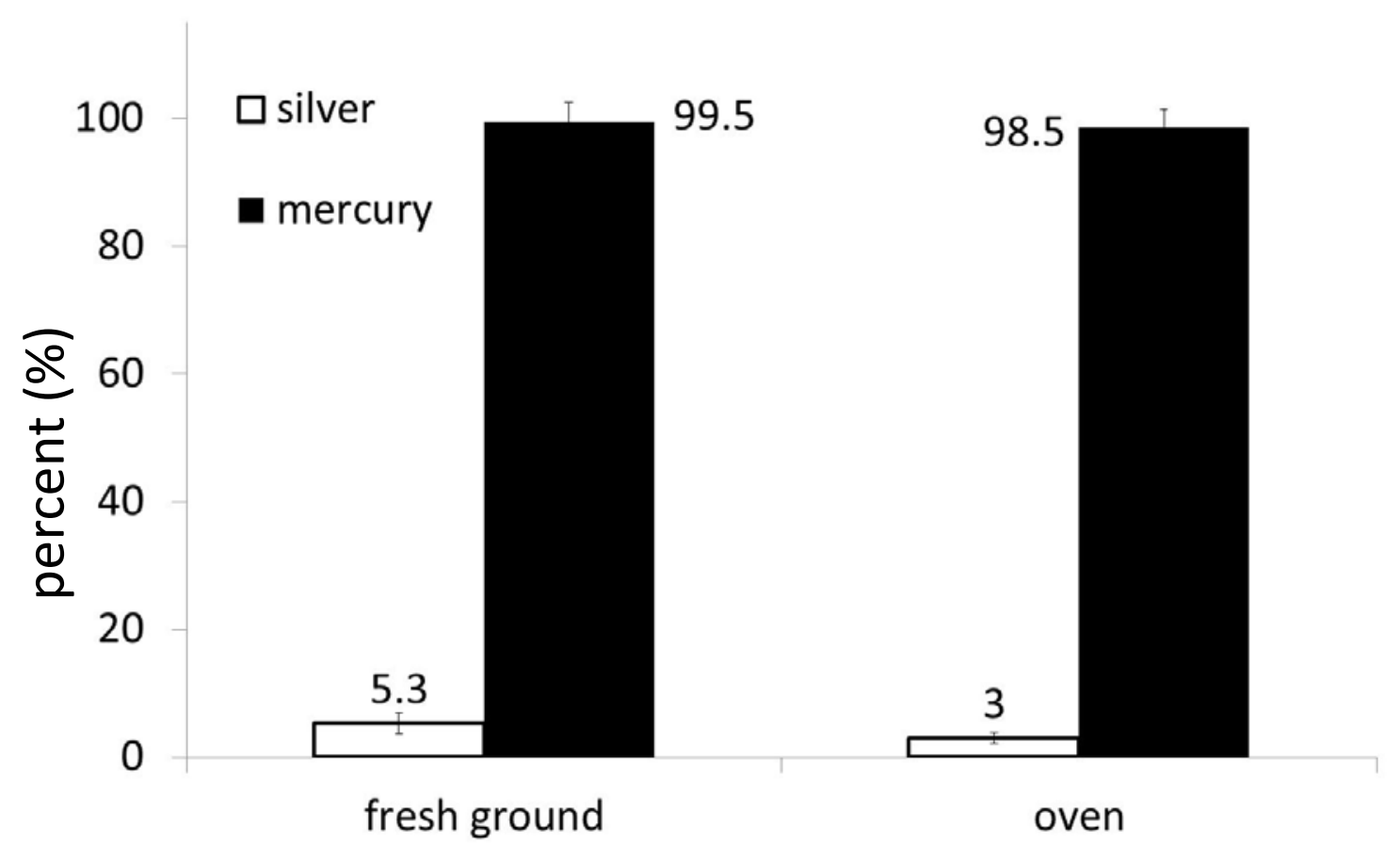

Figure 5.9. Oven dried sphalerite and freshly ground sphalerite compared for mercury precipitation, shown in percent of the ion removed from solution.

The second experiment showed the oven dried sample removed about $15 \%$ less mercury than the freshly ground sample, and the hydrogen peroxide reacted sample removed nearly $51 \%$ less (Figure 5.10 shown as percent ion removed from solution). This experiment shows that, having been left exposed to air long enough, the sphalerite oxidizes and prevents the replacement reaction with zinc. 


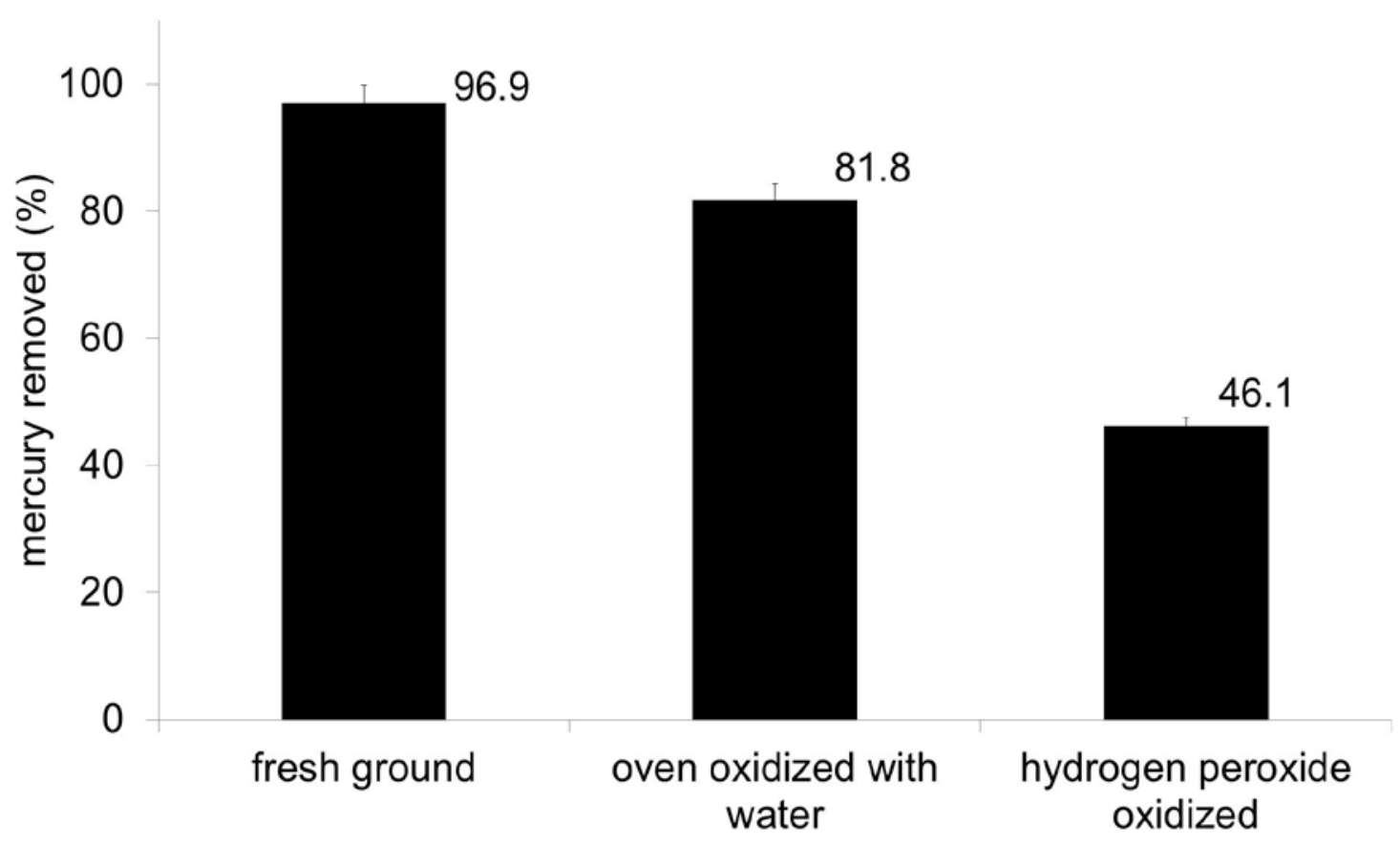

Figure 5.10. Sphalerite freshly ground, dried in the oven with water, and dried in the oven with hydrogen peroxide were tested for mercury removal.

In estimating how oxidized the surface of the sphalerite was, some assumptions were made for simplification. The first assumption was that the "fresh ground" sphalerite was not oxidized at all and the entire surface was available for the reaction with mercury. Therefore, since mercury reacts with only one sulfur:

1)

$1.281 \times 10^{-5} \mathrm{~g} \mathrm{Hg}$ precipitated / (200.59 grams/mole Hg) = moles Hg precipitated moles Hg precipitated * (1 mole S / 1 mole Hg) * $(32$ grams/mole S $)=$ grams S or $2.04 \mu \mathrm{g} \mathrm{S}$ precipitated

2)

$2.0 \times 10^{-6}$ grams $\mathrm{Hg}$ not precipitated from the "oven oxidized" compared to the "fresh ground" 
$2.0 \times 10^{-6}$ grams $\mathrm{Hg}$ not precipitated / (200.59 grams $/$ mole $\mathrm{Hg}$ ) = moles $\mathrm{Hg}$ not precipitated

moles $\mathrm{Hg}$ not precipitated * $(1$ mole $\mathrm{S} / 1 \mathrm{~mole} \mathrm{Hg}) *(32$ grams $/$ mole $\mathrm{S})=$ grams $\mathrm{S}$

or $0.319 \mu \mathrm{g} \mathrm{S}$ replaced

or $15.6 \% \mathrm{~S}$ replaced by oxygen on the surface

or $0.159 \mu \mathrm{g}$ oxygen on the surface

3)

$6.0 \times 10^{-6}$ grams $\mathrm{Hg}$ not precipitated from the "hydrogen peroxide oxidized" compared to the "fresh ground"

$6.0 \times 10^{-6}$ grams Hg not precipitated / (200.59 grams $/$ mole Hg) $=$ moles Hg not precipitated

moles $\mathrm{Hg}$ not precipitated * $(1$ mole $\mathrm{S} / 1 \mathrm{~mole} \mathrm{Hg}) *(32$ grams $/$ mole $\mathrm{S})=$ grams $\mathrm{S}$

or $1.07 \mu \mathrm{g}$ S replaced

or $52.4 \% \mathrm{~S}$ replaced by oxygen on the surface

or $0.536 \mu \mathrm{g}$ oxygen on the surface

This experiment demonstrates the negative effect of having oxidized sphalerite to use. For use in industry, the sphalerite should be fresh ground right before use. Another alternative would be to "clean" the zinc sulfide by removing the oxide. This may be done with mild acids, such as acetic acid, to remove the zinc oxide and leave the zinc sulfide since the sulfide is not soluble in acetic acid. Another possibility could use hydrogen sulfide gas which would form zinc sulfide and water. The down side to hydrogen sulfide is its toxicity and flammability as a gas.

After studying possible effects of the sphalerite particles, the solution was tested for possible affects of oxygen demand and reduction potential variations. 


\subsection{De-aeration}

\section{Methods}

Mercury/silver cyanide solution (30mL, $129 \mathrm{ppb} \mathrm{Hg}, 170 \mathrm{ppb} \mathrm{Ag}$ ) was de-aerated for about 40 seconds using the "house" vacuum, then re-pressurized with nitrogen gas. The de-aerated leachate was added to 0.625 grams sphalerite $(80 \%$ passing particles size about $270 \mu \mathrm{m}$ ) for 45 minutes. This experiment was done to test the effects of low oxygen in the system on the reactions.

\section{Experimental Results and Discussion}

Removing oxygen from the leaching solution was tested. The results are shown in Figure 5.11 with mercury in black, silver in white, and zinc in grey. In the sample with air, only $1 \%$ of the silver was lost, $93 \%$ of the mercury removed, and 1,795 ppb zinc was dissolved. In the sample with nitrogen, no silver or mercury was detected remaining in solution and there was a 5\% increase of zinc in solution as compared to the "air" sample. This experiment shows evidence that both the silver and mercury precipitate onto the sphalerite, and oxygen is needed for silver dissolution with cyanide as shown in Equation 4. 


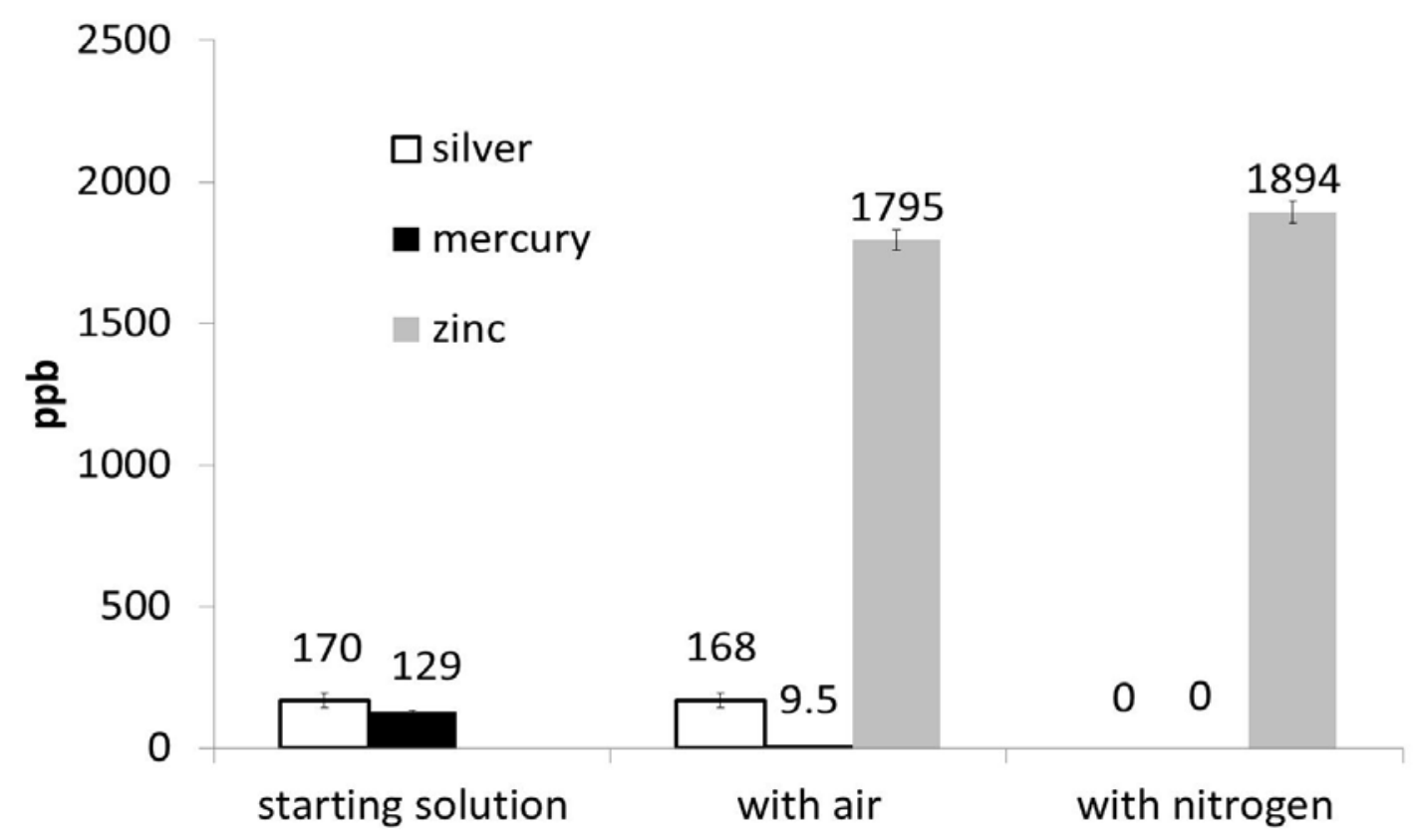

Figure 5.11. The results of de-aeration and use of nitrogen for a silver and mercury cyanide solution reacted with sphalerite are shown.

\subsection{Reduction potential}

The goal of this experiment was to test the affect of reduction potential on the sphalerite's effectiveness of selectively removing mercury form silver.

\section{Methods}

Ammonia was used as the agent to bring down the $\mathrm{pH}$ and also create a reducing environment. Measurements of reduction potential and $\mathrm{pH}$ of solution were carried out with a Thermo Scientific Orion Dual Star pH/ISE Bench top system with pH $( \pm 0.002)$ and reduction potential $( \pm 0.2 \mathrm{mV})$ electrodes. Filter funnels were used with 0.625 grams hand-ground sphalerite. Solutions were made with 1) only ammonia, 2) about 1/5 the reduction potential of the sodium hydroxide solution reduction potential, and 3) only sodium hydroxide. Each solution $(50 \mathrm{~mL})$ was made, cyanide added, and mercury sulfide (0.001 grams) and silver sulfide (0.002 grams) were leached for 48 hours. Starting mercury levels in each solution were: ammonia $20 \mathrm{ppb}, 4 / 5$ the reduction potential to 
sodium hydroxide $34 \mathrm{ppb}$, sodium hydroxide 46ppb. Starting silver levels in each solution were ammonia $400 \mathrm{ppb}, 4 / 5$ the reduction potential to sodium hydroxide $438 \mathrm{ppb}$, sodium hydroxide, $488 \mathrm{ppb}$.

\section{Experimental Results and Discussion}

The affect of changing reduction potential was examined. The results are shown in Figure 5.12 as percent of ion removed from solution (mercury in black, silver in white on the secondary axis) and Table 21. Results indicated that at lower reduction potentials more silver was lost: $8 \%$ silver loss for ammonia versus $4.5 \%$ silver loss for sodium hydroxide. Also at lower reduction potentials, less mercury removed: $93.8 \%$ for ammonia as compared to $100 \%$ for sodium hydroxide. A lower reduction potential (solution with ammonia) was shown to precipitate more silver and removed less mercury and that of the higher reduction potential solution (sodium hydroxide). 


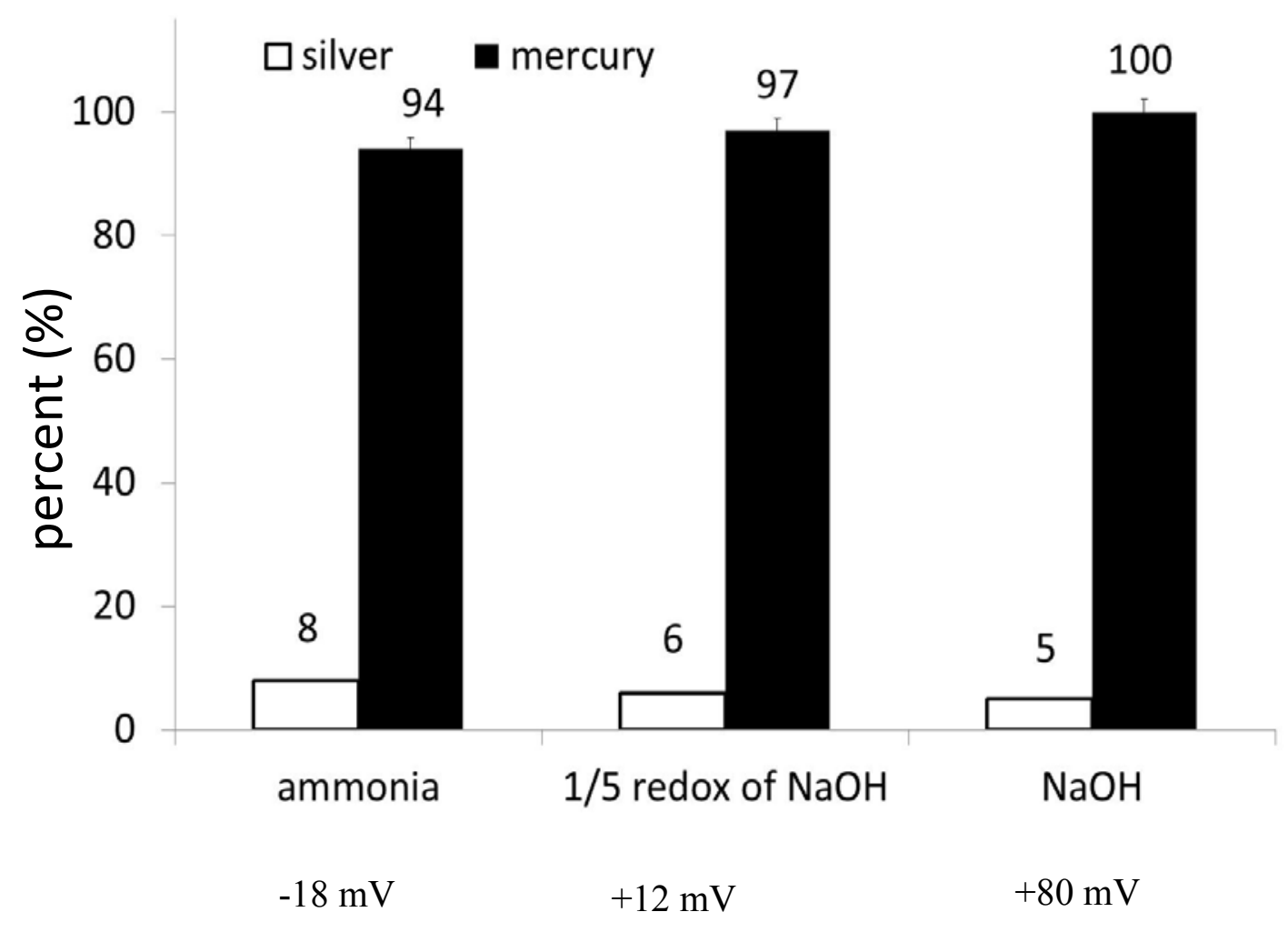

Figure 5.12. Results of changing reduction potential of solution with ammonia in use with to filter funnels of sphalerite to remove mercury selectively from silver, as shown by percent ion removed from solution.

Table 21. Reduction potential effects on mercury and silver reaction with sphalerite.

\begin{tabular}{|l|l|l|l|l|}
\hline Sample & \% silver loss & \% mercury removed & zinc ppb & redox $(\mathrm{mV})$ \\
\hline Ammonia & $8.1 \pm 1.7$ & $93.8 \pm 2.6$ & $2897 \pm 610$ & -18 \\
\hline $\begin{array}{l}1 / 5 \text { redox } \\
\text { NaOH }\end{array}$ & $5.9 \pm 0.3$ & $96.5 \pm 4.0$ & $1865 \pm 597$ & 12 \\
\hline $\begin{array}{l}\text { Sodium } \\
\text { hydroxide }\end{array}$ & $4.5 \pm 0.8$ & $100 \pm 0.0$ & $2127 \pm 1135$ & 80 \\
\hline
\end{tabular}

In addition to silver precipitating and mercury being less likely to precipitate when run through the sphalerite, the initial values of silver and mercury were lower for the ammonia trial and highest for the sodium hydroxide trial. 
Reduction potential is expected to affect the selectivity of mercury precipitation versus silver precipitation by looking at the Pourbaix diagram of silver sulfide over laid on that of mercury sulfide generated by FactSage $\odot$ (2010) (Figure 5.13). The solid lines (at pH 9 starting at $0 \mathrm{mV}$ for the upper line and about -0.5 for the lower line) outline an area where mercury sulfide is expected to precipitate. The dashed lines (at pH 9 starting at $0.3 \mathrm{mV}$ for the upper line and about -0.5 for the lower line) outline an area where silver sulfide is expected to precipitate. Note that the range in which mercury sulfide precipitates totally includes the range of silver sulfide. The two black dots represent the measured reduction potentials from the ammonia experiment plotted at $\mathrm{pH} 11$, where the more negative dot represents the ammonia trial and the high is the sodium hydroxide trial. As seen with the intermediate reduction potential, there is not clear cut off for mercury versus silver precipitation, but the lower the reduction potential, the more favored silver sulfide is to precipitate over mercury sulfide. It is important to note that too high of a reduction potential would also result in undesirable results, as neither mercury not silver are expected to precipitate as sulfides. 


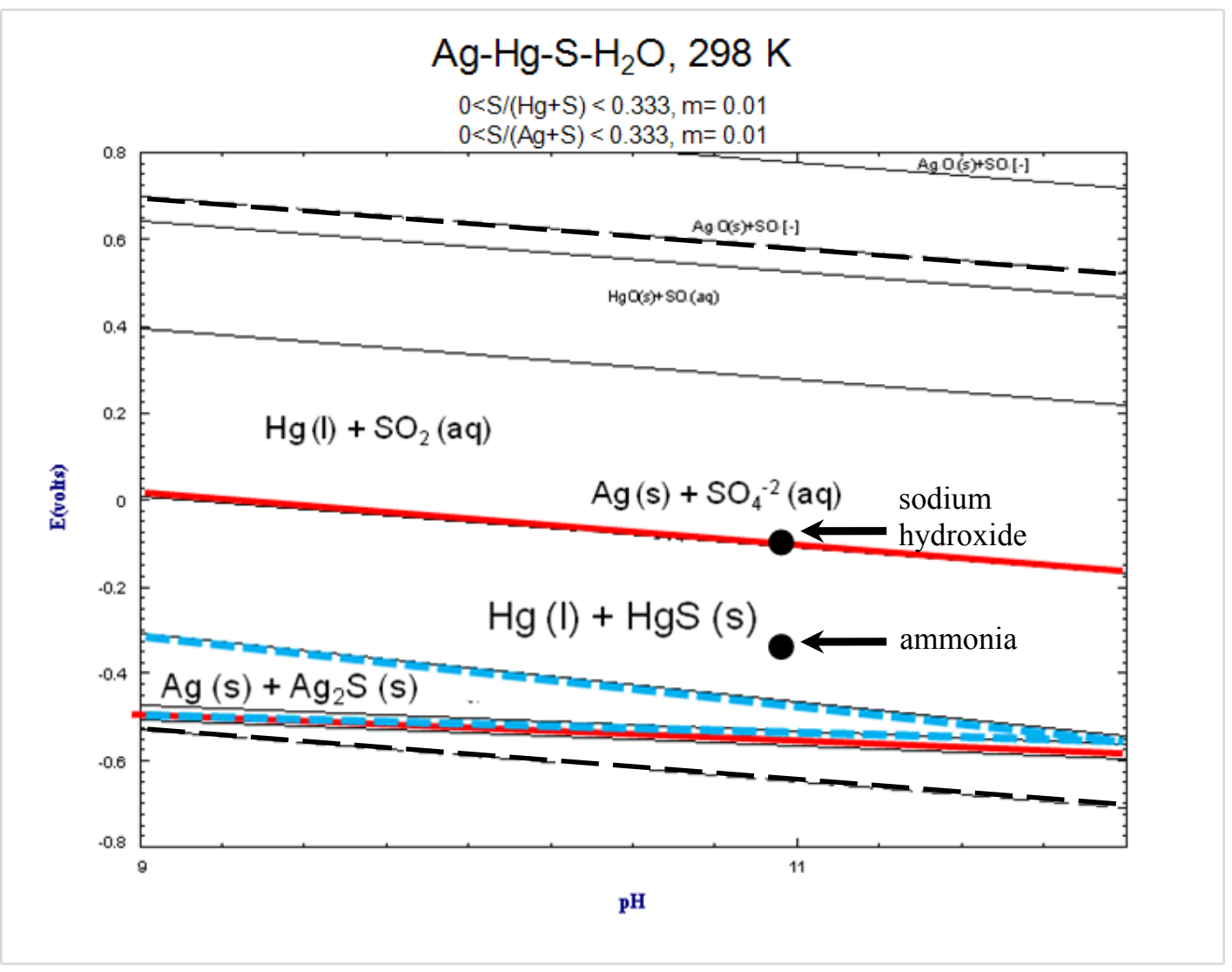

Figure 5.13. Pourbaix diagrams generated by FactSage $\odot$ of silver and mercury sulfide with the reduction potentials from the ammonia experiment plotted at $\mathrm{pH}$ 11. 


\subsection{Removal of Mercury Not in Cyanide Complex}

\section{Methods}

Mercury cyanide solution (from synthetic mercury sulfide leached with $0.02 \% \mathrm{KCN}$ ) was used. The cyanide was first destroyed with excess hydrogen peroxide $(30 \%, 20 \mathrm{~mL})$ for two days (Equation 47)

$2 \mathrm{H}_{2} \mathrm{O}_{2}(\mathrm{aq})+\mathrm{Hg}(\mathrm{CN})_{4}^{-2}(\mathrm{aq}) \rightarrow 4 \mathrm{CNO}^{-}(\mathrm{aq})+\mathrm{Hg}^{+2}(\mathrm{aq})+2 \mathrm{H}_{2}(\mathrm{~g}) \quad$ Equation 47 $\Delta \mathrm{G}=-575 \mathrm{~kJ}$

It was then reduced further by acidification with $\mathrm{CO}_{2}$ at $\mathrm{pH} 5.1$ for three days (Equation 48).

$\mathrm{CNO}^{-}(\mathrm{aq})+\mathrm{H}^{+}(\mathrm{aq})+\mathrm{H}_{2} \mathrm{O}(\mathrm{l}) \rightarrow \mathrm{CO}_{2}(\mathrm{~g})+\mathrm{NH}_{3}(\mathrm{aq}) \quad$ Equation 48 $\Delta \mathrm{G}=-86 \mathrm{~kJ}$

Equation 48 shows that nitrogen will be in the aqueous phase, and will not prefer the gas phase in Equation 49.

$\mathrm{CNO}^{-}(\mathrm{aq})+\mathrm{H}_{2} \mathrm{O}(\mathrm{l}) \rightarrow \mathrm{CO}_{2}(\mathrm{~g})+\mathrm{NH}_{2}(\mathrm{~g})$

Equation 49 $\Delta \mathrm{G}=-76 \mathrm{~kJ}$

Mercury in solution after destroying the cyanide was 32ppb. Sphalerite $(0.0625$ grams, $80 \%$ passing $220 \mu \mathrm{m}$ ) was then added and allowed to sit for 45 minutes before filtering and analyzing. 


\section{Experimental Results and Discussion}

After observing the possible complicating ions, and although sphalerite had been shown to remove mercury from a mercury cyanide complex well, there was the question if sphalerite could remove other forms of mercury. After destroying the cyanide complex in a mercury cyanide solution, sphalerite was used to remove the mercury.

The results show that from a 31.8ppb solution of mercury (after the cyanide degradation), the sphalerite reduced levels to an estimated $0.3 \mathrm{ppb}$ for a $99 \%$ reduction. This shows that the replacement reaction does not require the presence of cyanide. The presence of oxygen may be needed, though, as Equation 50 suggests that a direct replacement with mercury for zinc is unlikely, but Equation 51 shows that with oxygen the reaction is favorable if zinc oxide is formed. $\begin{array}{ll}\mathrm{Hg}(\mathrm{l})+\mathrm{ZnS}(\mathrm{s} 1) \rightarrow \mathrm{HgS}(\mathrm{s} 1)+\mathrm{Zn}^{+2}(\mathrm{aq})+\mathrm{e}^{-}(\mathrm{aq}) & \text { Equation } 50 \\ \Delta \mathrm{G}=+7 \mathrm{~kJ} & \end{array}$

$\mathrm{Hg}(\mathrm{l})+\mathrm{ZnS}(\mathrm{s} 1)+1 / 2 \mathrm{O}_{2}(\mathrm{aq}) \rightarrow \mathrm{HgS}(\mathrm{s} 1)+\mathrm{ZnO}(\mathrm{s}) \quad$ Equation 51 $\Delta \mathrm{G}=-173 \mathrm{~kJ}$ 


\subsection{Solid Waste Treatment and Disposal}

\section{Water Rinse}

Methods

Potential short-term leaching issues were tested. Leachate with mercury and silver cyanide (30 mL, 680ppb Hg, 1235ppb Ag) was passed through a pipette with sphalerite, then three, $30 \mathrm{ml}$ aliquots of distilled water were put through the pipette, saved, and analyzed.

\section{EDTA Leach Test}

\section{Methods}

A more rigorous leaching test was carried out with ethylenediaminetetraacetic acid (EDTA), a chelating agent (adapted from Kosson et al,2002). All glassware had been acid washed with nitric acid, rinsed three times with deionized water, and allowed to dry completely. Sphalerite (1 gram) was saturated with mercury (starting at 10420ppb Hg, $54 \%$ mercury remaining in $50 \mathrm{~mL}$ solution), rinsed with distilled water, dried in a $100^{\circ} \mathrm{C}$ oven over night, and allowed to cool completely in a desiccator. The solids were put in an extraction vessel: a 1L plastic (Nalgene) bottle that was leak-proof and would remain so for end over end tumbling. A pH 7.5, $50 \mathrm{mM}$ EDTA solution (100 mL) was made with deionized water and added to the extraction vessel. The vessel was subjected to a 48 hour tumble, end over end. The liquid was filtered from the solids using a filter funnel. The $\mathrm{pH}$ remained at approximately 7.5 for the entire experiment. .

\section{Experimental Results and Discussion}

The solid was (sphalerite coated in HgS) product was tested for stability. First, a triplicate of simple water rinses over a solid waste sample was tried. None of the three rinses showed any mercury or silver. The detection limits for mercury were $0.2 \mathrm{ppb}$ and for silver were 2ppb. Next a well-known EDTA leach test was carried out. Results showed no mercury in the distilled water rinse or in the EDTA leach test. 
If conditions were to become favorable for dissolution at 298K, any exposed zinc would dissolve before mercury (Equation 52 and Equation 53).

$2 \mathrm{ZnS}(\mathrm{s} 1)+3 \mathrm{O}_{2}(\mathrm{aq}) \rightarrow 2 \mathrm{Zn}^{+2}(\mathrm{aq})+2 \mathrm{SO}_{3}^{-2}(\mathrm{aq})$

Equation 52

$\Delta \mathrm{G}=-897 \mathrm{~kJ}$

$\mathrm{HgS}(\mathrm{s} 1)+1.5 \mathrm{O}_{2}(\mathrm{aq}) \rightarrow \mathrm{Hg}^{+2}(\mathrm{aq})+\mathrm{SO}_{3}^{-2}(\mathrm{aq})$

Equation 53

$\Delta \mathrm{G}=-291 \mathrm{~kJ}$

The Pourbaix diagram also shows that mercury will stay as a solid (either $\mathrm{HgS}$ or $\mathrm{HgO}$, if there is enough oxygen present) under most conditions, while zinc becomes aqueous (Figure 5.14). At $\mathrm{pH}$ below $\mathrm{pH} 1.9$, mercury does have the possibility of dissolution, but the thermodynamics indicate that zinc would dissolve first. 


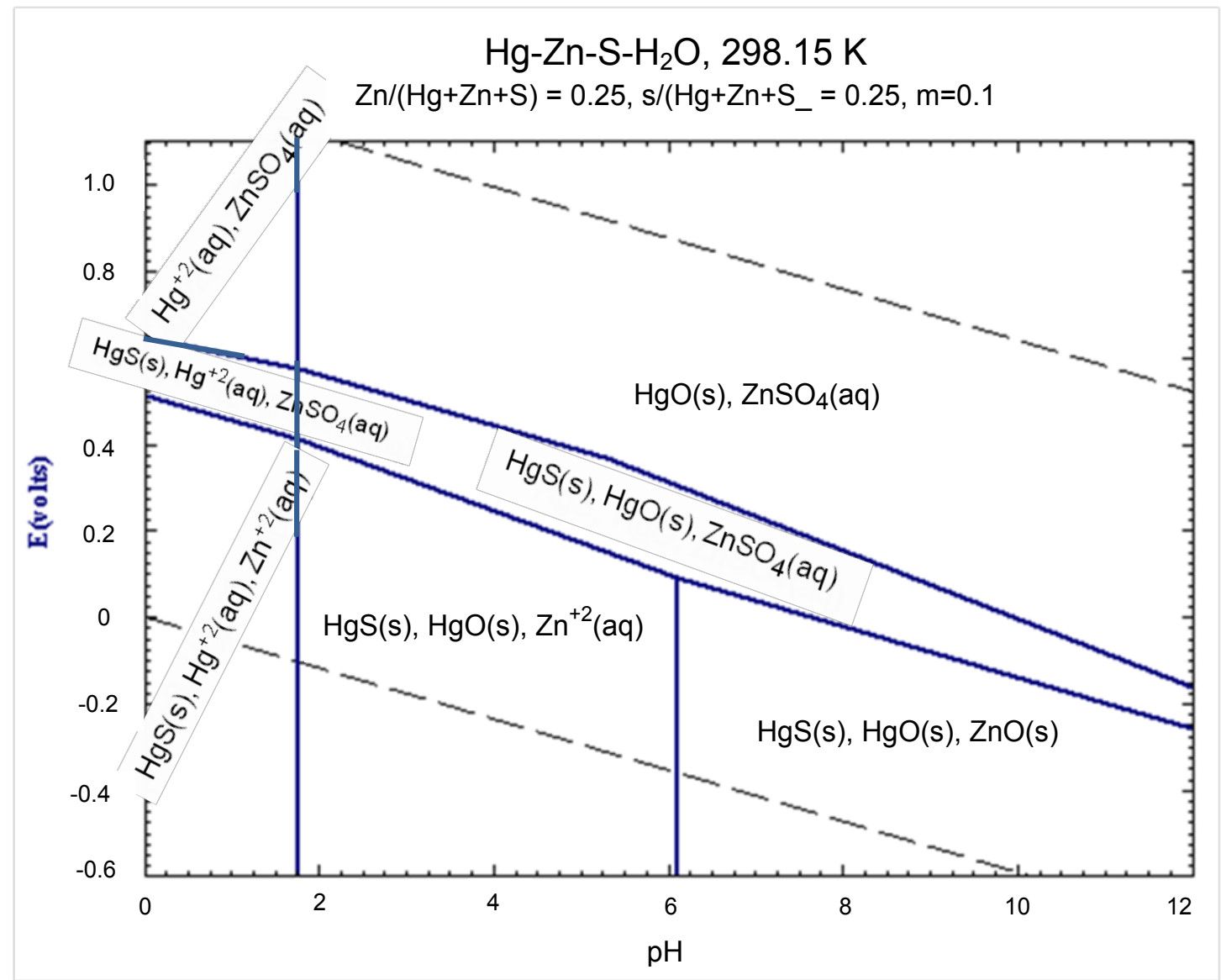

Figure 5.14. Pourbaix diagram generated by FactSage $(\mathrm{C}$ of mercury, zinc, and sulfur.

\subsection{Conclusions}

The first sets of experiments were to explore the possibility and variables affecting the use of zinc sulfide for selectively precipitating mercury from silver in solution.

After determining that sphalerite could precipitate mercury, the SEM did shown further evidence of the mercury depositing on the surface of sphalerite at $\approx+2 \%$ of mercury on the surface of the $\mathrm{ZnS}$ particles. The gram and time trials demonstrated that nearly all the 
mercury could be removed from solution while having negligible effect on the silver concentrations.

The particle size did affect the reaction and was found that the smallest particles size $(11 \mu \mathrm{m})$ precipitated the most mercury $(99.8 \%)$, while the largest size precipitated the least (79.7\%). The rate of the reaction between the $\mathrm{ZnS}$ and mercury was found to be faster than 5 seconds at $\approx 3^{\circ} \mathrm{C}$. The replacement of any precipitated silver by mercury is expected to follow the kinetics found in the experiments using only mercury cyanide and silver sulfide (section 3.2). The amount of oxidation on the $\mathrm{ZnS}$ surface was found to negatively affect the amount of mercury that could be precipitated: the freshly ground sphalerite assuming no oxidation, had $96 \%$ mercury removed; the $\approx 16 \%$ oxidation showed $82 \%$ mercury removed; and the $\approx 62 \%$ oxidation had only $46 \%$ mercury removed.

Finally, the removal of oxygen from the system and effect of different reduction potentials were tested. The standard sample with air showed only $1 \%$ of the silver lost, $93 \%$ of the mercury removed. The sample vacuum and flushed with nitrogen showed no silver or mercury detectable in solution. Reduction potential effects showed that at low reduction potentials $(-0.1 \mathrm{mV})$, more silver was precipitated and less mercury precipitated than compared to high reduction potentials $(+0.1 \mathrm{mV})$. This could readily be explained by the Pourbaix diagrams of silver sulfide and mercury sulfide.

The question if sphalerite could remove other forms of mercury was tested, showing $99 \%$ mercury removal. The solid waste product that would be discharged into tailings ponds was tested for stability and showed no detectable mercury leached from the $\mathrm{HgS}$ coated sphalerite particles. 


\section{Zinc Sulfide Precipitation of Mercury Cyanide as Mercury Sulfide with the Use of Columns and Funnels}

\subsection{Experimental Procedures}

\section{Materials}

Reagents used were distilled water, synthetic mercury sulfide (black), synthetic silver sulfide, High Se and High Hg ores, sodium hydroxide, hydrogen peroxide, potassium cyanide, sphalerite (naturally occurring $\mathrm{ZnS}$ ), and ethylenediaminetetraacetic acid (EDTA).

\subsection{Pasteur Pipette Column}

The goal of this experiment was to test a small "column" and determine if using a column would be advantageous as compared to using a vial.

\section{Pass with Silver/Mercury Cyanide Solution}

\section{Methods}

A 9 inch Pasteur pipettes had the stems broken off near the where the neck narrows to allow liquid to flow freely (at about 4.5 inches). The top opening was $7.0 \mathrm{~mm}$ and the outlet was about $5 \mathrm{~mm}$. Glass wool was stuffed into the top of the pipette down to the neck, and sphalerite ( 0.0625 grams, $80 \%$ passing particle size was about $11 \mu \mathrm{m})$ added on top. The solution of mercury/silver cyanide (30mL, 6810ppb Hg, 1230ppb Ag) was passed slowly through the column (about 15 minutes) in a single pass. The set up is shown in Figure 6.1. 
mercury and silver cyanide solution (opening $7.0 \mathrm{~mm}$ )

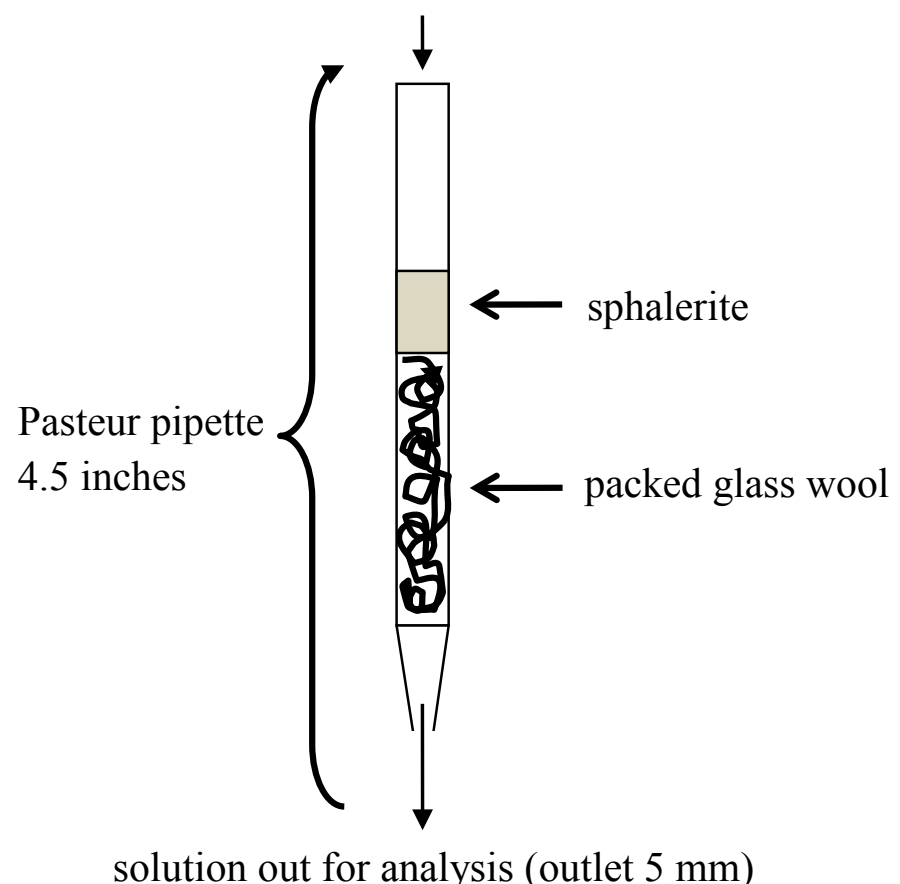

Figure 6.1. "Column" set up for mercury removal testing with sphalerite.

\section{Mercury Rinse of Sphalerite Reacted with Mercury/Silver Cyanide}

The goal of this experiment was to determine if excess mercury (a mercury "rinse") of sphalerite reacted with a mercury/silver cyanide solution would recover any silver losses. This would give further support for the expected reaction in Figure 5.2.

\section{Methods}

The set up for the Pasteur pipette column was described in the previous section. After running the mercury/silver cyanide solution through the column $(30 \mathrm{~mL}, 681 \mathrm{ppb} \mathrm{Hg}$, $1235 \mathrm{ppb} \mathrm{Ag}$ ) and collecting for analysis, a solution containing only mercury cyanide (5 
$\mathrm{mL}, 661 \mathrm{ppb} \mathrm{Hg}$ ) was then passed through and analyzed. A flow diagram is shown in Figure 6.2.

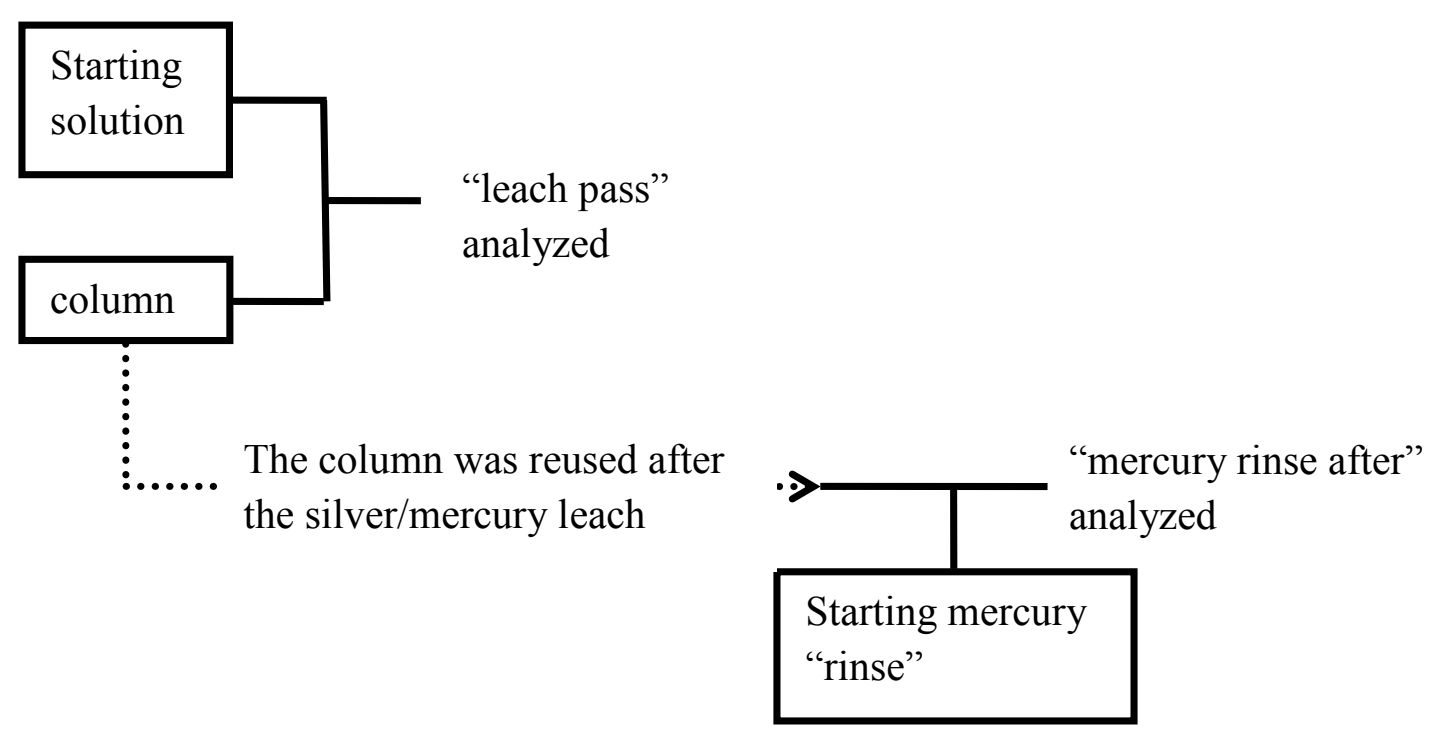

Figure 6.2. A flow diagram of the experiment using a mercury solution to rinse a previously used column is shown.

\section{Experimental Results and Discussion}

In industrial settings, a continuous flow process would be preferred over a batch process to save time and increase efficiency by constantly getting a product steam as opposed to having to wait for a batch to be done. This was tested first with a Pasteur pipette and the results showed good removal of mercury still (Figure 6.3 as shown by percent ion in solution removed, with mercury in black and silver in white). The Pasteur pipette removed mercury well and showed possible slight improvement in silver recovery, but there appeared to be no clear advantage in using the Pasteur pipette set-up, strictly speaking in terms of mercury removal. The Pasteur pipette was difficult to load and run, so another the filter set up (Figure 6.5) was used other experiments. 


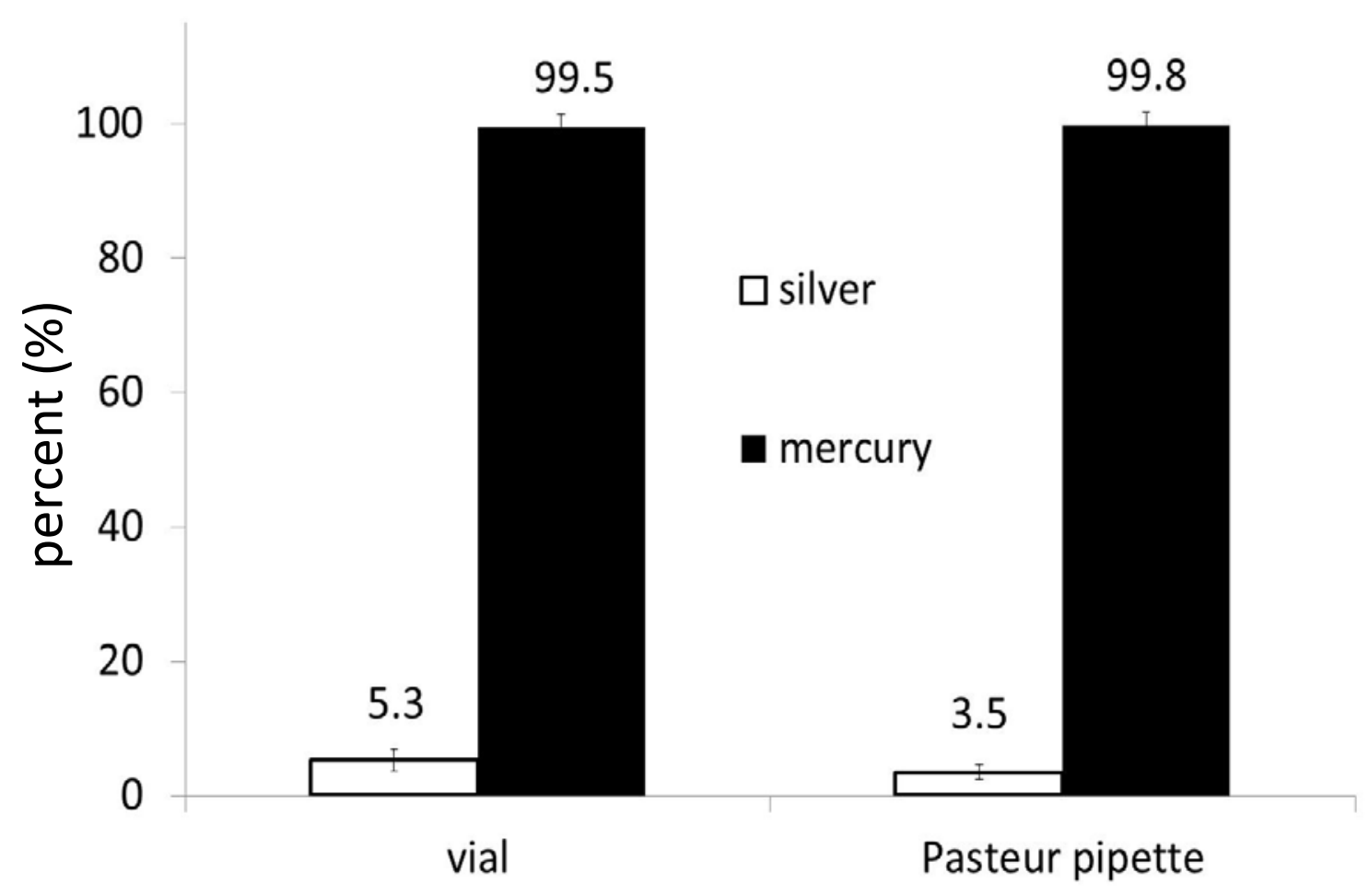

Figure 6.3. Results of the "column" used versus a vial, or batch, of mercury and sphalerite, as shown by percent ion removed from solution.

\footnotetext{
Also using the Pasteur pipette set up, mercury was rinsed through sphalerite that had already had one pass of mercury/silver cyanide solution (Figure 6.4 with mercury in black and silver in white). The first pass through the pipette of the mercury/silver cyanide removed most of the mercury ( $86 \%$ was removed), with some silver loss. When the mercury only solution was run through afterwards, nearly all the mercury was removed and some silver was recovered.
} 


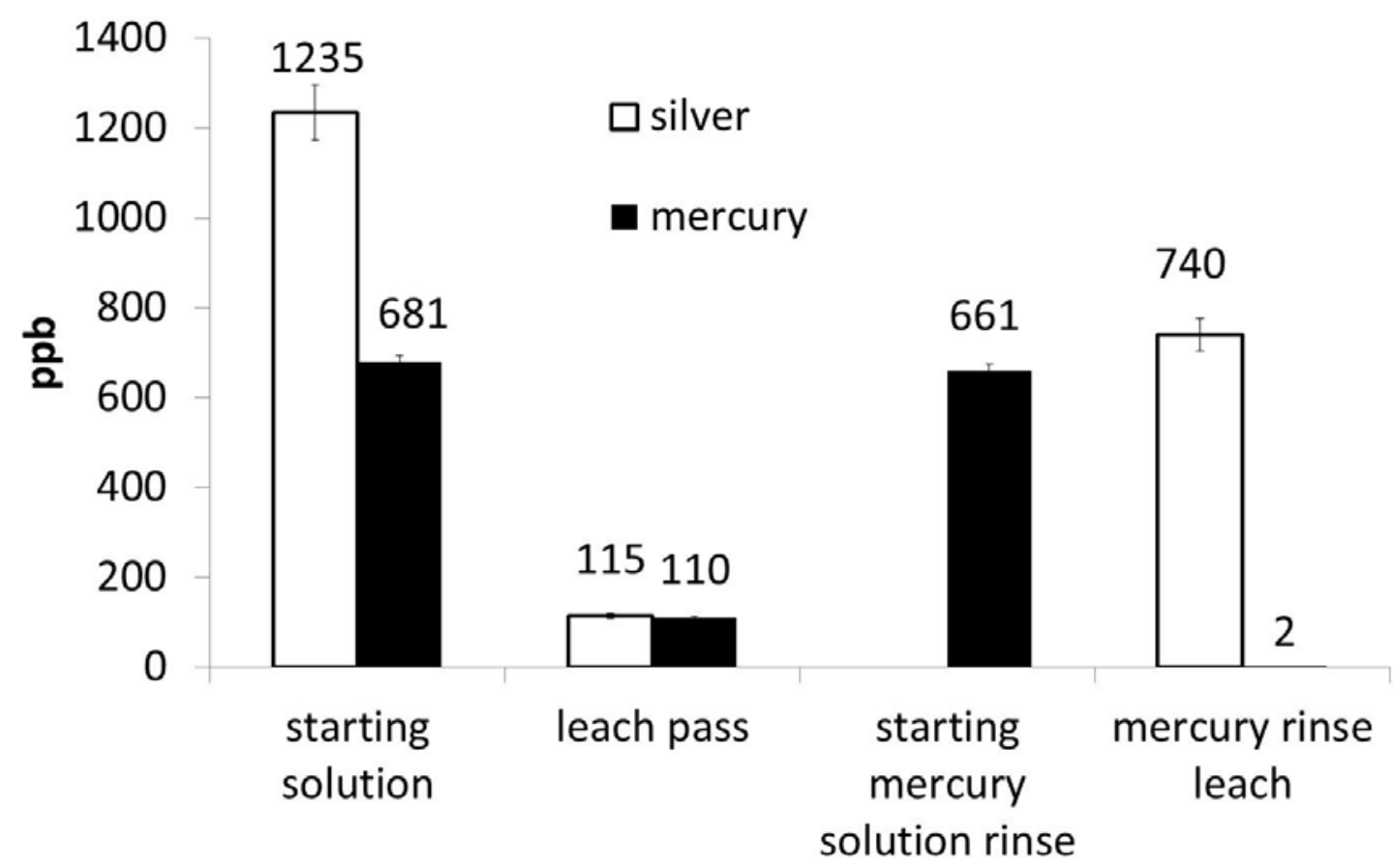

Figure 6.4. Sphalerite used to separate mercury from silver and then more mercury was added to the same sphalerite to show mercury removal and silver recovery.

\subsection{Filter Funnels}

The goals of these experiments were to determine the effects of running a mercury/silver cyanide solution through a filter funnel set-up.

The set up for the filter funnels is shown in Figure 6.5. A glass filter was lined with filter paper and the sphalerite ( 0.625 grams) added to the bottom. The mercury/silver cyanide solution was poured into the filter all at once and allowed to drain. 

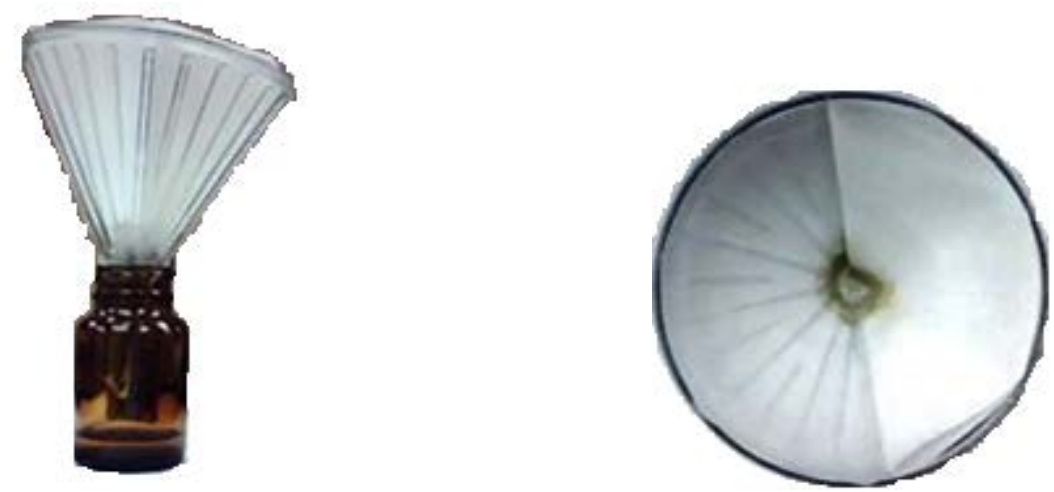

Figure 6.5. Shows the side view and top view of the filter funnel with sphalerite set up.

Experiments were run on the effects of multiple passes through sphalerite. Two of these experiments differed only in the sphalerite having a pre-rinse of distilled water, showing lower mercury concentrations coming out from the filters, which lead all following experiments to have the sphalerite pre-rinsed, unless otherwise indicated.

Experiments for testing counter current flow, effects of reduction potential, removal of mercury not in a cyanide complex, and testing the reacted sphalerite for re-leaching of mercury were also done. These tests were done to show zinc sulfide could selectively remove mercury from silver cyanide under the right conditions and that the resulting product (mercury sulfide on zinc sulfide) was stable. 
Two Funnels, Fresh Sphalerite

Methods

The sphalerite used was $80 \%$ passing particles size $277 \mu \mathrm{m}$. Two filter funnels as described before were used with freshly ground sphalerite (0.625grams). A solution of mercury/silver $(60 \mathrm{~mL}, 32 \mathrm{ppb} \mathrm{Hg}, 333 \mathrm{ppb} \mathrm{Ag})$ cyanide was fed into only funnel 1 . The resulting solution coming from funnel 1 was fed into funnel 2; three batches were done. The set-up is shown in Figure 6.6.

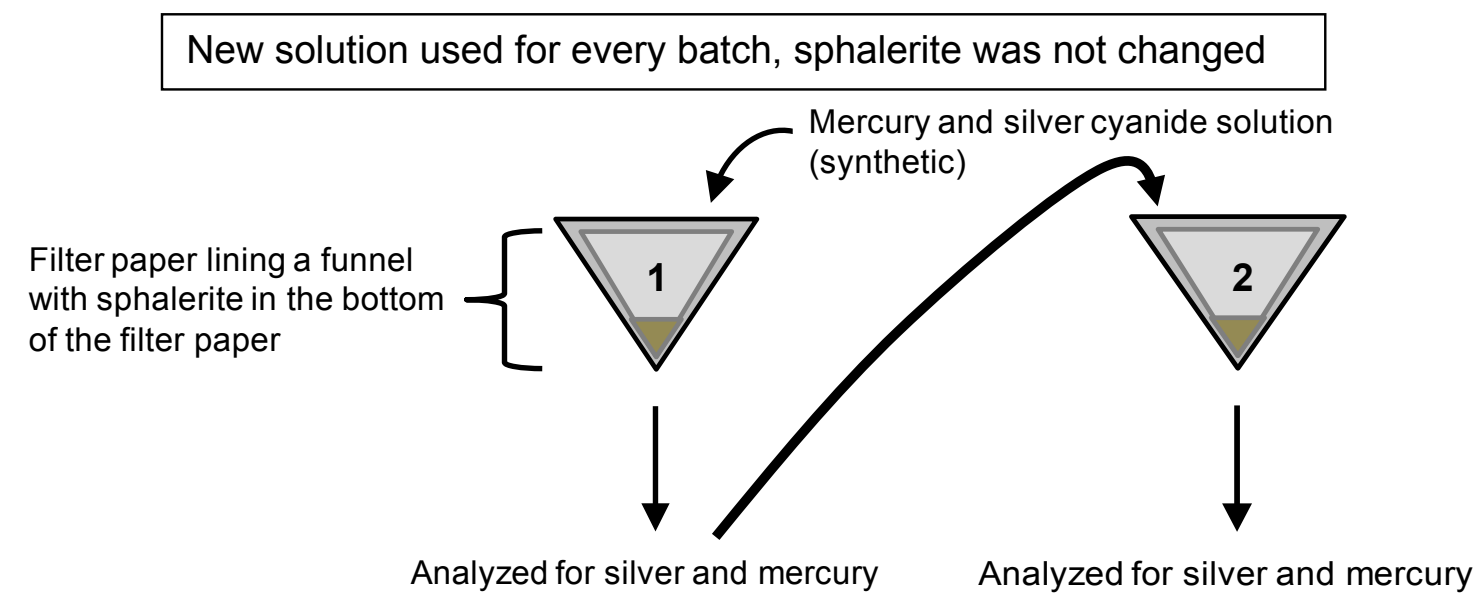

Figure 6.6 Three batches of fresh mercury and silver cyanide solution were passed through filter funnels with sphalerite.

\section{Methods}

The same experiment as above was run again, but the filter funnels were flushed with $50 \mathrm{~mL}$ distilled water and allowed to air dry shortly before passing the mercury/silver cyanide solution through. Five batches were done. The set-up and results are shown in Figure 6.7. 


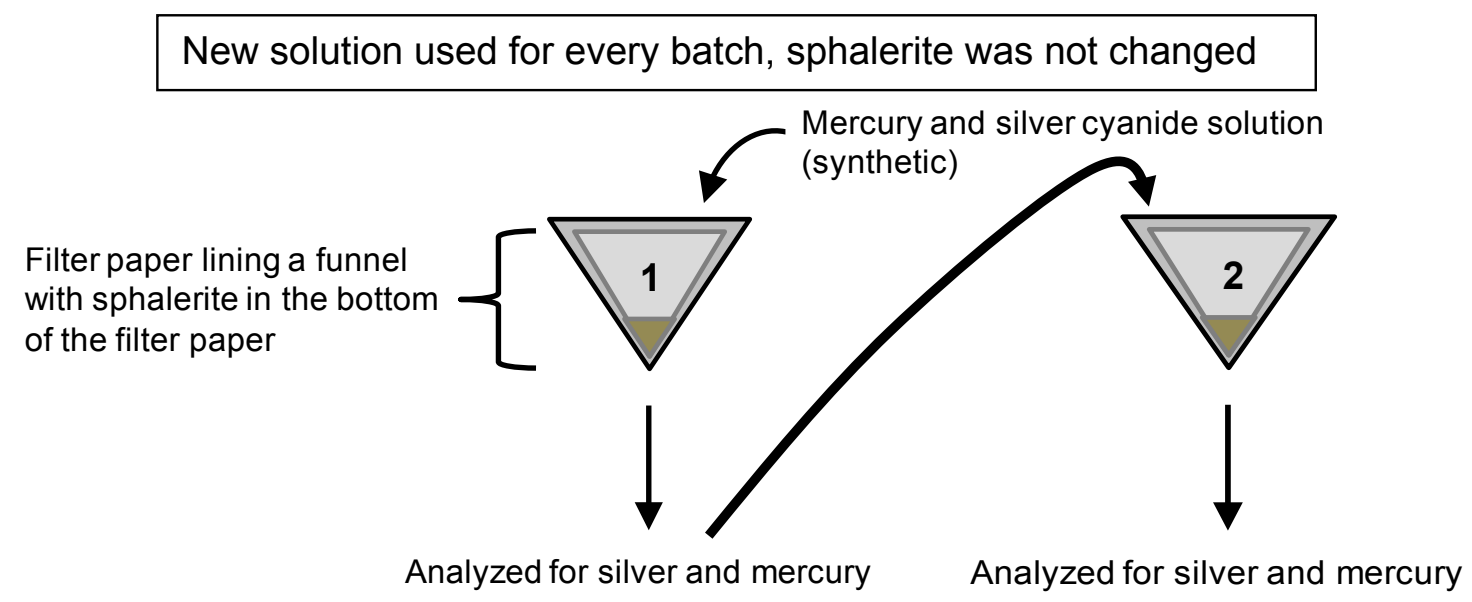

Figure 6.7. Sphalerite pre-rinsed with distilled water was used for mercury and silver cyanide solution passes.

\section{Three Funnels, Counter Current Flow \\ Methods}

A mercury/silver cyanide solution (60mL, 922ppb Hg, 704ppb Ag) was used with sphalerite $(80 \%$ passing particles size $277 \mu \mathrm{m})$. Three filter funnels were used in a counter-current flow attempt. Pictures of the funnels used are shown in Figure 6.8.

All funnels had 0.625 grams of sphalerite added. Funnel 1 had sphalerite with the same starting solution of silver and mercury cyanide solution passed through it six (6) times, with an initial pre-rinse with $50 \mathrm{~mL}$ of distilled water. Funnel two was treated the same, but with only three (3) passes of silver/mercury cyanide solution. Funnel three had fresh sphalerite with the $50 \mathrm{~mL}$ distilled water rinse. Fresh solution was fed into Funnel 1, then Funnel 2, and finally Funnel 3. 
Mercury and silver cyanide solution

(synthetic)

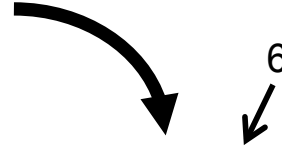

6 passes with $20 \mathrm{~mL} \mathrm{Ag/Hg}$ cyanide solution

Filter paper lining a funnel with sphalerite in the bottom of the filter paper

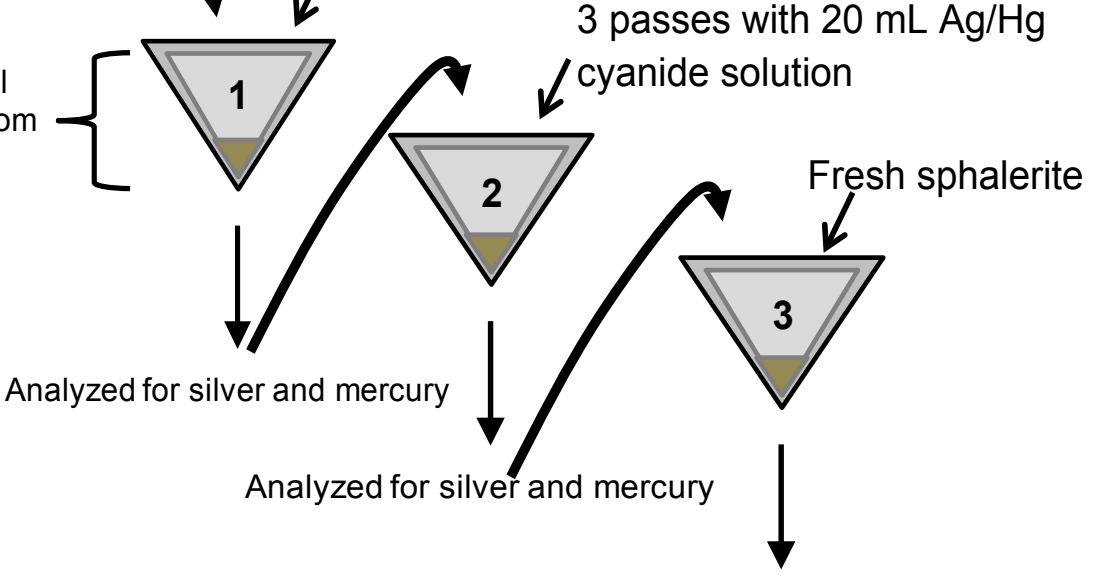

Analyzed for silver and mercury

Figure 6.8. A counter-current flow for new mercury and silver cyanide solution passes through the most used sphalerite first. (adapted from Gabby and Eisele 2012) 


\section{Experimental Results and Discussion}

Filter funnels were used after the pipette due to their simplicity and usability. In using two funnels with fresh sphalerite, total silver losses were $16.3 \%$ and all mercury was removed by the end batch (Figure 6.9). This suggests that in an industrial setting, a column flow set up would work well.

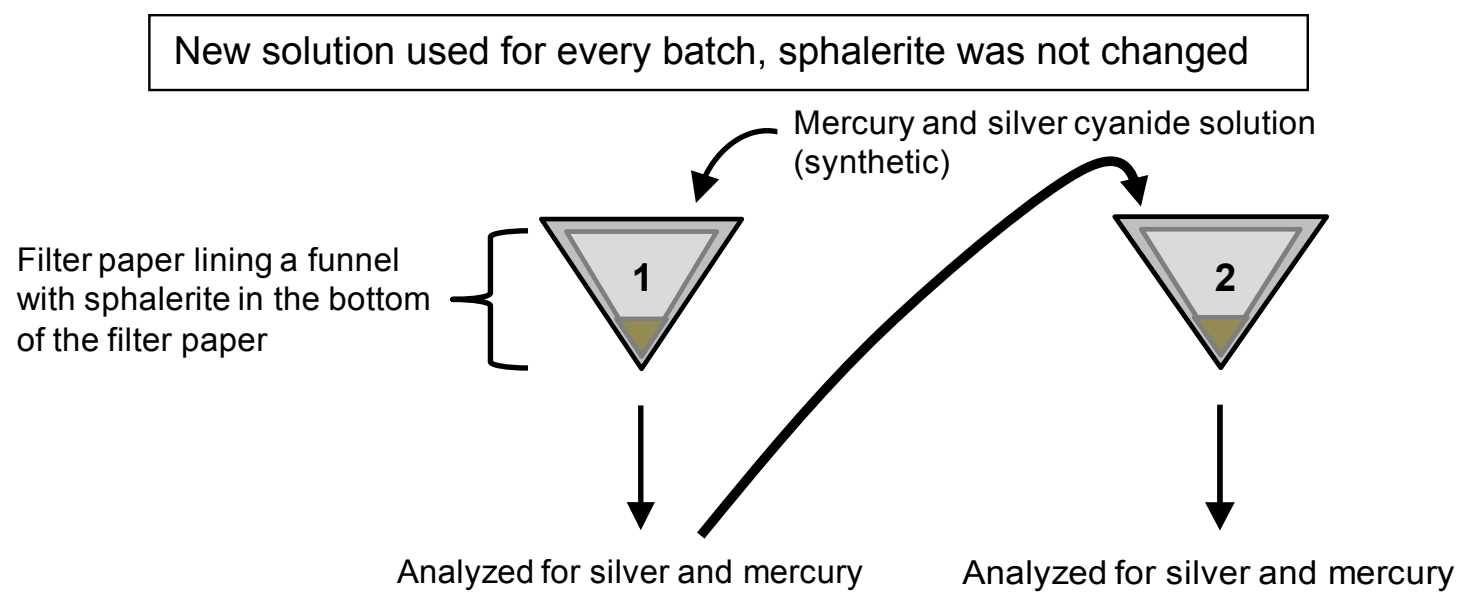

\begin{tabular}{|l|r|r|r|}
\hline Batch 1 & Starting Solution & Funnel 1 & Funnel 2 \\
\hline silver (ppb) & 333.5 & 311 & 289 \\
\hline mercury (ppb) & 31.6 & 4.2 & 12.8 \\
\hline Zinc (ppb) & & 18.4 & 53 \\
\hline
\end{tabular}

\begin{tabular}{|l|r|r|r|}
\hline Batch 2 & Starting Solution & Funnel 1 & Funnel 2 \\
\hline silver (ppb) & 333.5 & 283 & 274 \\
\hline mercury $(\mathrm{ppb})$ & 31.6 & 19.9 & 0 \\
\hline Zinc $(\mathrm{ppb})$ & & 2.2 & 12.6 \\
\hline
\end{tabular}

\begin{tabular}{|l|r|r|r|}
\hline Batch 3 & Starting Solution & Funnel 1 & Funnel 2 \\
\hline silver (ppb) & 333.5 & 277 & 274 \\
\hline mercury $(\mathrm{ppb})$ & 31.6 & 6.3 & 0 \\
\hline Zinc $(\mathrm{ppb})$ & & 3.7 & 6.3 \\
\hline
\end{tabular}

Figure 6.9 Three batches of fresh mercury and silver cyanide solution were passed through filter funnels with sphalerite. 
Using the exact same set up as previously, the sphalerite was first rinsed with water. From this procedure, total silver losses were $3.7 \%$ with all the mercury removed at the end (Figure 6.10). The pre-rinse with water increased efficiency of mercury removal and decreased silver loss. This may be due to the water rinse removing natural salts found in the sphalerite. A possibility for why the mercury removal appeared better could be that the water removed very fine particles of $\mathrm{ZnS}$ which are not filtered out, but follow the flow of solution. These very fine particles would have mercury on them, showing in the AA as more mercury in solution. 


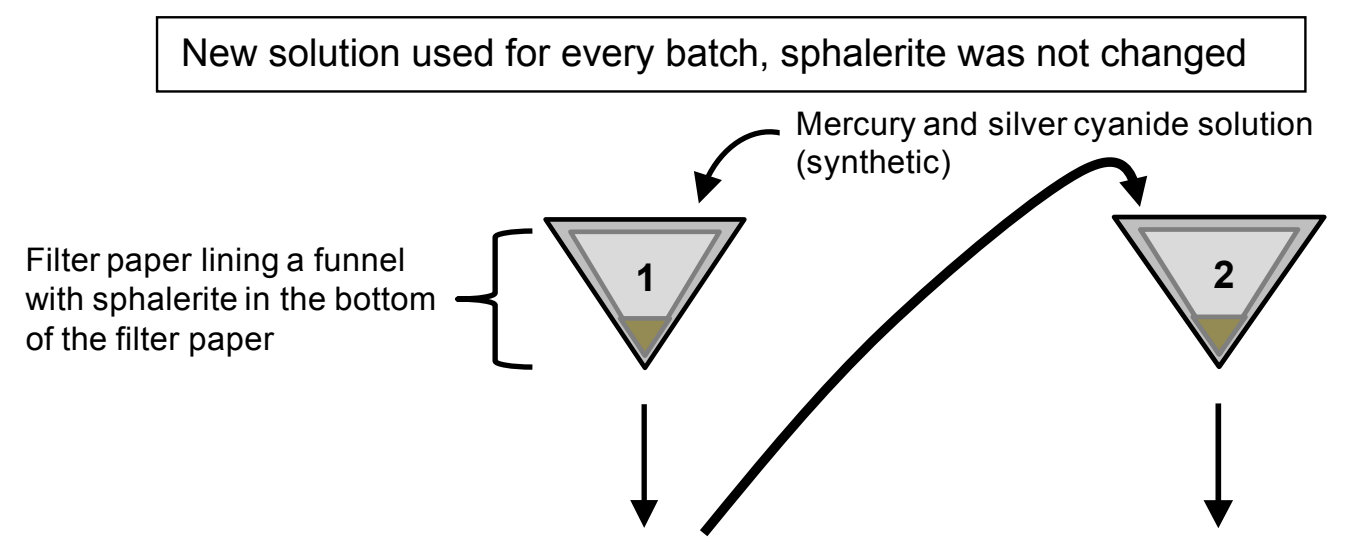

Analyzed for silver and mercury

Analyzed for silver and mercury

\begin{tabular}{|l|r|r|r|}
\hline Batch 1 & Starting Solution & Funnel 1 & Funnel 2 \\
\hline silver (ppb) & 333.5 & 364.2 & 318.3 \\
\hline mercury $(\mathrm{ppb})$ & 31.6 & 0.09 & 0 \\
\hline zinc $(\mathrm{ppb})$ & & 1441 & 2463 \\
\hline
\end{tabular}

\begin{tabular}{|l|r|r|r|}
\hline Batch 2 & Starting Solution & Funnel 1 & Funnel 2 \\
\hline silver (ppb) & 374.4 & 377.8 & 369.3 \\
\hline mercury $(\mathrm{ppb})$ & 24.2 & 0.21 & 0 \\
\hline zinc $(\mathrm{ppb})$ & & 728 & 2391 \\
\hline
\end{tabular}

\begin{tabular}{|l|r|r|r|}
\hline Batch 3 & Starting Solution & Funnel 1 & Funnel 2 \\
\hline silver $(\mathrm{ppb})$ & 374.4 & 371 & 374.4 \\
\hline mercury $(\mathrm{ppb})$ & 24.2 & 0.28 & 0 \\
\hline zinc $(\mathrm{ppb})$ & & 371 & 1335 \\
\hline
\end{tabular}

\begin{tabular}{|l|r|r|r|}
\hline Batch 4 & Starting Solution & Funnel 1 & Funnel 2 \\
\hline silver (ppb) & 374.4 & 372.7 & 369.3 \\
\hline mercury (ppb) & 24.2 & 0.06 & 0 \\
\hline zinc (ppb) & & 250 & 823 \\
\hline
\end{tabular}

\begin{tabular}{|l|r|r|r|}
\hline Batch 5 & Starting Solution & Funnel 1 & Funnel 2 \\
\hline silver $(\mathrm{ppb})$ & 374.4 & 369.3 & 371 \\
\hline mercury $(\mathrm{ppb})$ & 24.2 & 0 & 0 \\
\hline zinc $(\mathrm{ppb})$ & & 210 & 1035 \\
\hline
\end{tabular}

Figure 6.10. Sphalerite pre-rinsed with distilled water was used for mercury and silver cyanide solution passes. 
Finally, a counter current flow, using three funnels, was tested. Total silver losses were $4.4 \%$ with all mercury removed by the end. The batch and filter results are shown in Figure 6.11. The counter current flow showed good mercury removal and negligible silver loss. 


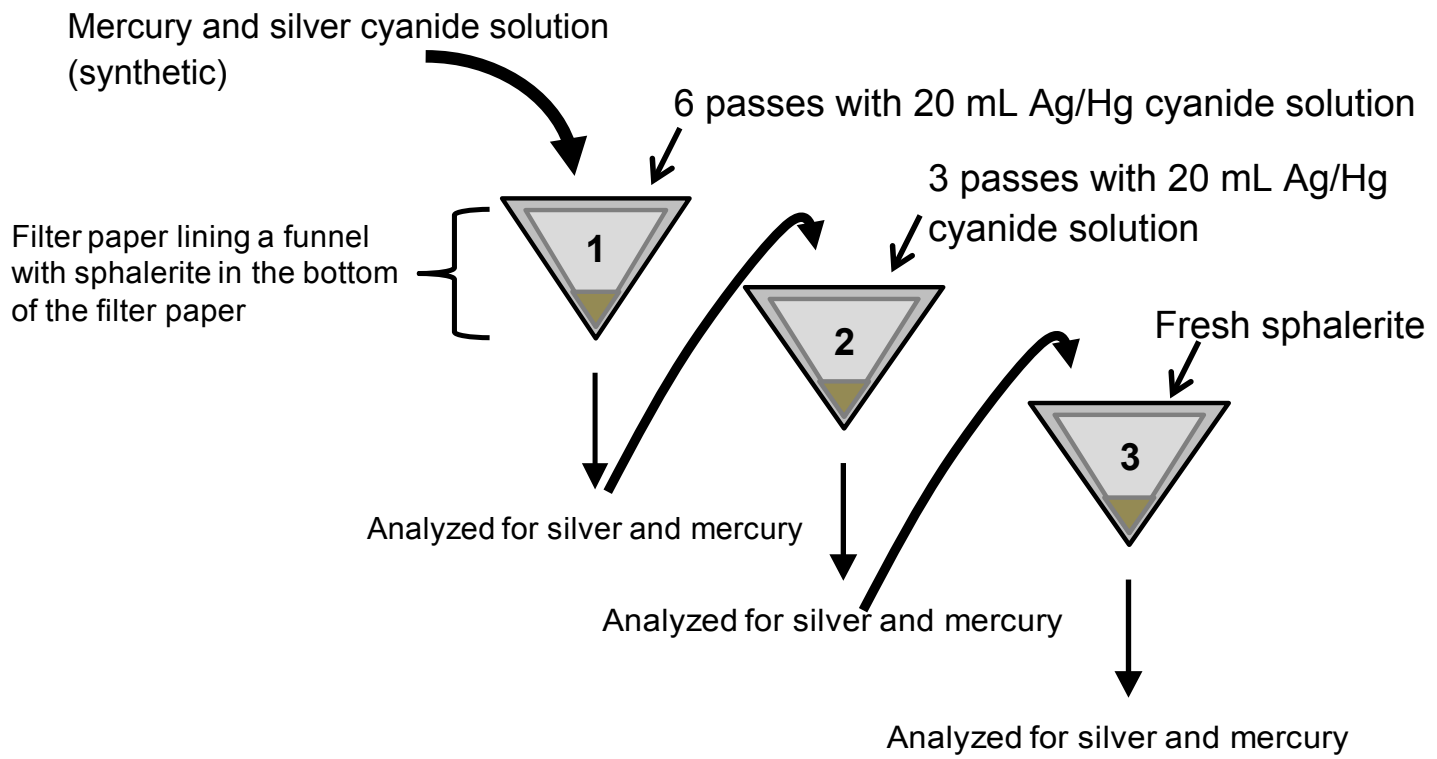

\begin{tabular}{|l|r|r|r|r|}
\hline Batch 1 & Starting solution & Filter 1 & Filter 2 & Filter 3 \\
\hline silver $(\mathrm{ppb})$ & 704 & 676 & 678 & 629 \\
\hline mercury $(\mathrm{ppb})$ & 921.9 & 18.6 & 3.3 & 2.5 \\
\hline zinc $(\mathrm{ppb})$ & & 314 & 690 & 1834 \\
\hline
\end{tabular}

\begin{tabular}{|l|r|r|r|r|}
\hline Batch 2 & Starting solution & Filter 1 & Filter 2 & Filter 3 \\
\hline silver $(\mathrm{ppb})$ & 704 & 686 & 691 & 691 \\
\hline mercury $(\mathrm{ppb})$ & 921.9 & 22.9 & 3.1 & 0 \\
\hline zinc $(\mathrm{ppb})$ & & 314 & 430 & 1110 \\
\hline
\end{tabular}

\begin{tabular}{|l|r|r|r|r|}
\hline Batch 3 & Starting solution & Filter 1 & Filter 2 & Filter 3 \\
\hline silver (ppb) & 704 & 691 & 697 & 698 \\
\hline mercury (ppb) & 921.9 & 34.1 & 3.4 & 0 \\
\hline zinc (ppb) & & 153 & 287 & 684 \\
\hline
\end{tabular}

Figure 6.11. A counter-current flow for new mercury and silver cyanide solution passes through the most used sphalerite first. (Gabby and Eisele 2012) 


\section{Naturals ores}

\section{Methods}

The High Se and High Hg ores (20 grams each) were leached un-pulverized for 49 hours with $0.02 \% \mathrm{KCN}$ at $\mathrm{pH} 11(115 \mathrm{~mL})$. The solutions were filtered and analyzed for silver and mercury. A sample from each ore leach $(30 \mathrm{~mL})$ was run through 0.625 grams sphalerite $(\approx 220 \mu \mathrm{m} 80 \%$ passing size $)$ in a filter funnel. The samples were analyzed.

\section{Experimental Results and Discussion}

The High Se ore leached with cyanide started with 7 ppb mercury and 2848 ppb silver in solution. After the one pass through the sphalerite, mercury was at $2 \mathrm{ppb}$ and silver was at $2690 \mathrm{ppb}$. This is a 71\% removal of mercury and a 5\% silver loss. The High $\mathrm{Hg}$ ore leached with cyanide started with 78 ppb mercury and $1136 \mathrm{ppb}$ silver in solution. After the one pass through the sphalerite, mercury was at $6 \mathrm{ppb}$ and silver was at $1060 \mathrm{ppb}$. This is a $92 \%$ removal of mercury and a $7 \%$ silver loss. The demonstrated that the sphalerite could be used with natural ores to selectively remove mercury.

\subsection{Conclusions}

A column set up was tested first with a Pasteur pipette, showing decent mercury removal (86\%) with minimal silver losses, but was difficult to load and work with. Filter funnels were used after the pipette due to their simplicity and usability. Set ups of two filter funnels were tested, leading to the use of a counter current flow. Total silver losses were less than $5 \%$ and all the mercury removed by the end. With longer running times, silver is expected to be recovered as mercury replaces the silver. Use of the natural ores demonstrated that there is still selectivity between mercury and silver when other ions are present.

This method seems promising both in feasibility, recovery, and waste management. Mercury has been shown to precipitate from solution selectively from silver cyanide under the right conditions. Since mercury sulfide is most likely formed, re-leaching of 
mercury is not expected as mercury sulfide is stable, as shown from the solid waste treatment and disposal experiments. 


\section{Possible Complicating Ions}

The goal of this experiment was to determine if particular metals ions may affect the precipitation of mercury or silver when passed through the sphalerite.

\subsection{Introduction}

In deciding what possible ions may lower the efficiency of precipitation of mercury with zinc sulfide, besides prevalence of the ions in the leach heaps, the Gibbs free energy was considered in addition to ion sizes as compared to zinc. First, copper was considered. There are several possible forms of copper cyanide in alkali and metal solution (Schlesinger and Paunovic 2010). These possible forms and their reaction with sphalerite are shown in Equations 54 through 57.

$$
\begin{aligned}
& \mathrm{Cu}^{+}(\mathrm{aq})+4 \mathrm{CN}^{-}(\mathrm{aq})+\mathrm{ZnS}(\mathrm{s}) \rightarrow \mathrm{Zn}(\mathrm{CN})_{4}^{-2}(\mathrm{aq})+\mathrm{Cu}_{2} \mathrm{~S}(\mathrm{~s}) \quad \text { Equation } 54 \\
& \Delta \mathrm{G}=-267 \mathrm{~kJ}
\end{aligned}
$$

$$
\begin{array}{lr}
2 \mathrm{Cu}(\mathrm{CN})_{2}^{-}(\mathrm{aq})+\mathrm{ZnS}(\mathrm{s}) \rightarrow \mathrm{Cu}_{2} \mathrm{~S}(\mathrm{~s})+\mathrm{Zn}(\mathrm{CN})_{4}^{-2}(\mathrm{aq}) & \text { Equation } 55 \\
\Delta \mathrm{G}=-173 \mathrm{~kJ} & \\
2 \mathrm{Cu}(\mathrm{CN})_{3}^{-2}(\mathrm{aq})+\mathrm{ZnS} \rightarrow \mathrm{Zn}(\mathrm{CN})_{4}^{-2}(\mathrm{aq})+\mathrm{Cu}_{2} \mathrm{~S}(\mathrm{~s})+2 \mathrm{CN}^{-}(\mathrm{aq}) & \text { Equation } 56 \\
\Delta \mathrm{G}=-220 \mathrm{~kJ} & \\
2 \mathrm{Cu}(\mathrm{CN}) 4^{-2}(\mathrm{aq})+\mathrm{ZnS}(\mathrm{s}) \rightarrow \mathrm{Zn}(\mathrm{CN})_{4}^{-2}(\mathrm{aq})+\mathrm{Cu}_{2} \mathrm{~S}(\mathrm{~s})+4 \mathrm{CN}^{-}(\mathrm{aq}) & \text { Equation } 57 \\
\Delta \mathrm{G}=-300 \mathrm{~kJ} &
\end{array}
$$


Thermodynamically, all forms are favorable to react, as well as in considering the ion size of copper (I) at $0.071 \mathrm{~nm}$ (Shannonn 1969, 1976), even more close to the size of the zinc ion than that of mercury

Next, iron was considered with Equation 58.

$\mathrm{Fe}(\mathrm{CN})_{6}^{-4}(\mathrm{aq})+2 \mathrm{ZnS}(\mathrm{s})+2 \mathrm{CN}^{-}(\mathrm{aq}) \rightarrow \mathrm{FeS}_{2}(\mathrm{~s})+2 \mathrm{Zn}(\mathrm{CN})_{4}^{-2}(\mathrm{aq})+2 \mathrm{e}^{-}(\mathrm{aq})$

$\begin{array}{ll}\Delta \mathrm{G}=+41 \mathrm{~kJ} & \text { Equation } 58\end{array}$

This reaction does not appear to be favorable, even though the ion size $\left(\mathrm{Fe}^{+2}\right)$ is only slightly larger than that of zinc at $0.075 \mathrm{~nm}$ (Shannonn 1976).

Also considered was selenium, due to its strong binding properties with mercury, which may also enable it to bind similarly with zinc sulfide. FactSageC (2010) was not able to provide thermodynamic data on such a reaction with cyanide or with sulfide. The expected ion size of selenium in a crystal would be $0.056 \mathrm{~nm}$ (Shannon 1969, 1976), but instead of replacing zinc would replace sulfur.

Arsenic might also pose a problem. Although the information for the arsenic ion size in a complex was not available, the ionic radii is smaller than that of zinc (Shannon 1969, 1976), which suggests arsenic in a crystal might also be smaller than that of zinc.

Arsenic may also take the place of the sulfur ions, similar to arsenopyrite versus iron pyrite where half the sulfur ions are replaced by arsenic. FactSage(C) (2010) was not able to provide thermodynamic data on such a reaction with sulfide, and no arsenic cyanide compound has been found to form. 
Finally, lead was considered due to its potential prevalence in the heaps as seen from the High Se and High Hg ore analyses (Table 3: $21 \mathrm{ppm}$ and $706 \mathrm{ppm}$, respectively). No thermodynamic data for lead as a cyanide was found, and therefore no thermodynamic could be obtained for lead cyanide. Lead in the aqueous phase will favorably replace zinc when cyanide is present, as shown in Equation 59, but $\mathrm{Pb}^{+2}$ will also only form below pH 6 (FactSage(C) 2010).

$\mathrm{Pb}^{+2}(\mathrm{aq})+\mathrm{ZnS}(\mathrm{s})+4 \mathrm{CN}^{-}(\mathrm{aq}) \rightarrow \mathrm{PbS}(\mathrm{s})+\mathrm{Zn}(\mathrm{CN})_{4}^{-2}(\mathrm{aq}) \quad$ Equation 59 $\Delta G=-140 \mathrm{~kJ}$

Since the expected form of lead will have two cyanides and no charge (Haz-Map 2012), this reaction may happen with excess cyanide in solution. The ion size of lead in a crystal is $0.149 \mathrm{~nm}$ which is much larger than that of zinc and more similar to that of silver.

For comparative purposes, typical or high levels of the ions of interest in this study were considered. In the Yanacocha ore, a high estimate of copper in a leach would be at $15 \mathrm{ppm}$ (Young 2008), iron at 1 to $3 \mathrm{ppm}$ is a typical amount in other silver ores (Davidson 1978; Rennert 2005), and lead can be around 0.3 ppm (Young 2008). In our experiments, the highest copper amount added to the cyanide solution for dissolution with cyanide was approximately 166 times higher, the iron was over 900 times higher, and lead was over 7000 times higher. For selenium, 30ppm in tailing ponds for cyanide leaching facilities is one of the highest reported numbers, and arsenic one mine's tailings ponds reached 1.2ppm (EPA 1994). In our experiments, the highest selenium amount added to the cyanide solution for dissolution with cyanide was approximately 62 times higher, and the arsenic was over 1300 times higher. 


\subsection{Experimental Procedures}

\section{Materials}

Reagents used were distilled water sodium hydroxide, potassium cyanide, sphalerite (naturally occurring $\mathrm{ZnS}$ ), copper (II) sulfate pentahydrate, ferrous sulfate heptahydrate , sodium arsenate, sodium selenide, lead (II) oxide, copper $\left(\mathrm{Cu}^{0}\right)$, lead $\left(\mathrm{Pb}^{0}\right)$, and iron $\left(\mathrm{Fe}^{0}\right)$. Metal additions were desired to be high, as with the mercury and silver concentrations, and were used with small amounts of sphalerite in comparison to the amounts of mercury/silver cyanide used. This was done in order to better show any effect the metal ions were having to prevent mercury or silver from precipitating.

\section{Methods}

For the addition of metals to the first experiment, compounds used were at $10 \mathrm{mM}$ concentrations were: copper (II) sulfate pentahydrate, ferrous sulfate, sodium arsenate, sodium selenide, lead oxide.

For the second experiment, ammonia was used to bring the $\mathrm{pH}$ down for the copper sulfate only.

For the third experiment, copper and lead were leached from metals and not compounds. The copper metal was leached in cold conditions, near $0^{\circ} \mathrm{C}$. No information was available of the Gibbs energy for lead cyanide, $\mathrm{Pb}(\mathrm{CN})_{2}$, so it was allowed to leach at room temperature. The rest of the compounds were added at $1 \mathrm{mM}$ concentrations. For the above experiment, all compound or metal additions were leached for four days in a $0.02 \% \mathrm{KCN}$ solution starting with at a $\mathrm{pH} 11$. Also leached were silver and mercury in 
a $0.02 \% \mathrm{KCN}$ solution at $\mathrm{pH} 11$ with sodium hydroxide (silver at $1772 \mathrm{ppb}$, mercury at $1920 \mathrm{ppb}$ ). A diagram of the experiment, with amounts used, is shown Figure 7.1.

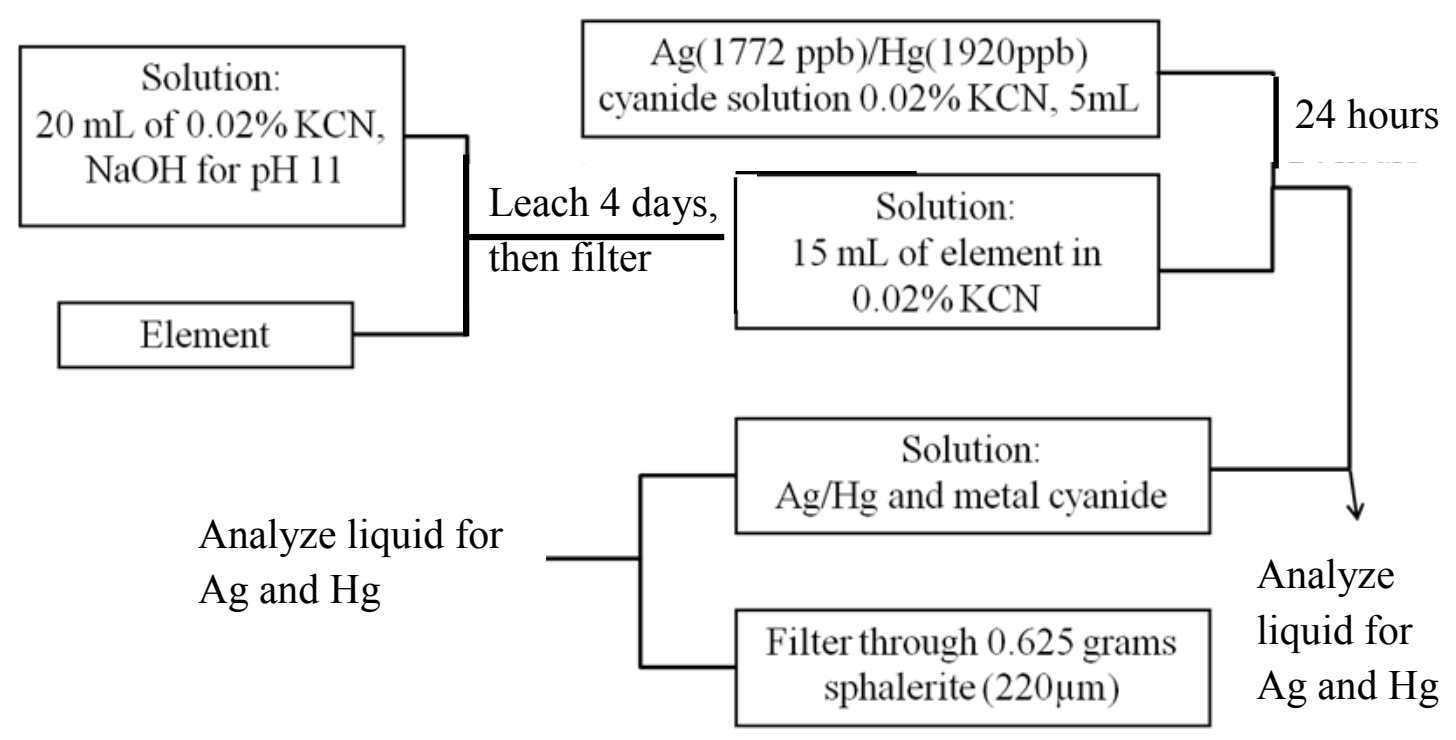

Figure 7.1. Experimental design for testing complicating ion effects on silver and mercury using a sphalerite filter.

In the fourth experiment, copper, lead, and iron were leached in $20 \mathrm{~mL}$ of a $0.02 \%(\mathrm{pH} 11$ with sodium hydroxide) cyanide solution for four days. These were the ions deemed most likely to be affecting the system. Lead and iron were leached at room temperature, copper was leached at $0^{\circ} \mathrm{C}$. The solutions were filtered. Concentrations after leaching for the $20 \mathrm{~mL}$ solutions were: $\mathrm{Cu}=11.05 \mathrm{ppm}, \mathrm{Pb}=0.46 \mathrm{ppm}, \mathrm{Fe}=3.11 \mathrm{ppm}$.

$15 \mathrm{~mL}$ of each metal cyanide solution was used. $5 \mathrm{~mL}$ of a silver/mercury cyanide solution was added to the metal cyanide solutions, giving a total of $20 \mathrm{~mL}$. The solutions of metal, silver, and mercury cyanide sat for 1 day. 
The $10 \mathrm{~mL}$ of the solutions were run through freshly ground sphalerite $(0.0625$ grams, $80 \%$ passing $\approx 220 \mu \mathrm{m})$. A diagram of the methods is shown in Figure 7.2.

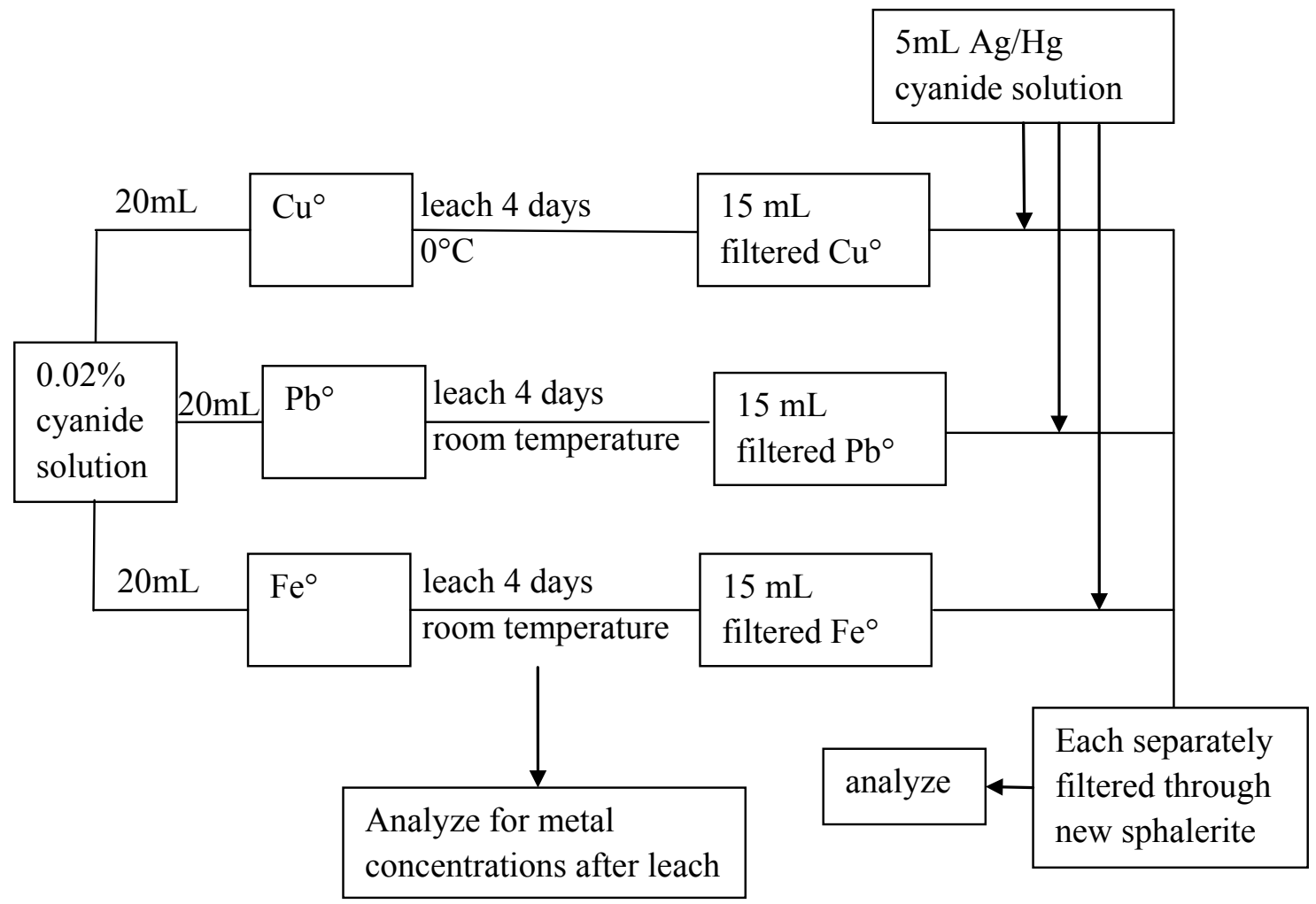

Figure 7.2. A diagram for the method of leaching the metals, then adding the silver/mercury cyanide solution is shown.

The compounds were leached in vials, filtered, and then the silver and mercury cyanide solutions were added and allowed to sit for one day. Finally, the element/Ag/Hg solution was passed through a filter funnel with sphalerite (0.625 grams, $80 \%$ passing $220 \mu \mathrm{m})$ and analyzed. All experiments were carried out at room temperature. 


\section{Experimental Results and Discussion}

After using the synthetic ores and testing the real ores to demonstrate that sphalerite would selectively separate mercury from silver as well, ions that night disrupt the separation processes were considered. For all graphs, mercury in shown in black, silver in white, and reduction potential in grey.

The results from the first experiment are in Figure 7.3, as shown by percent ion removed from solution.

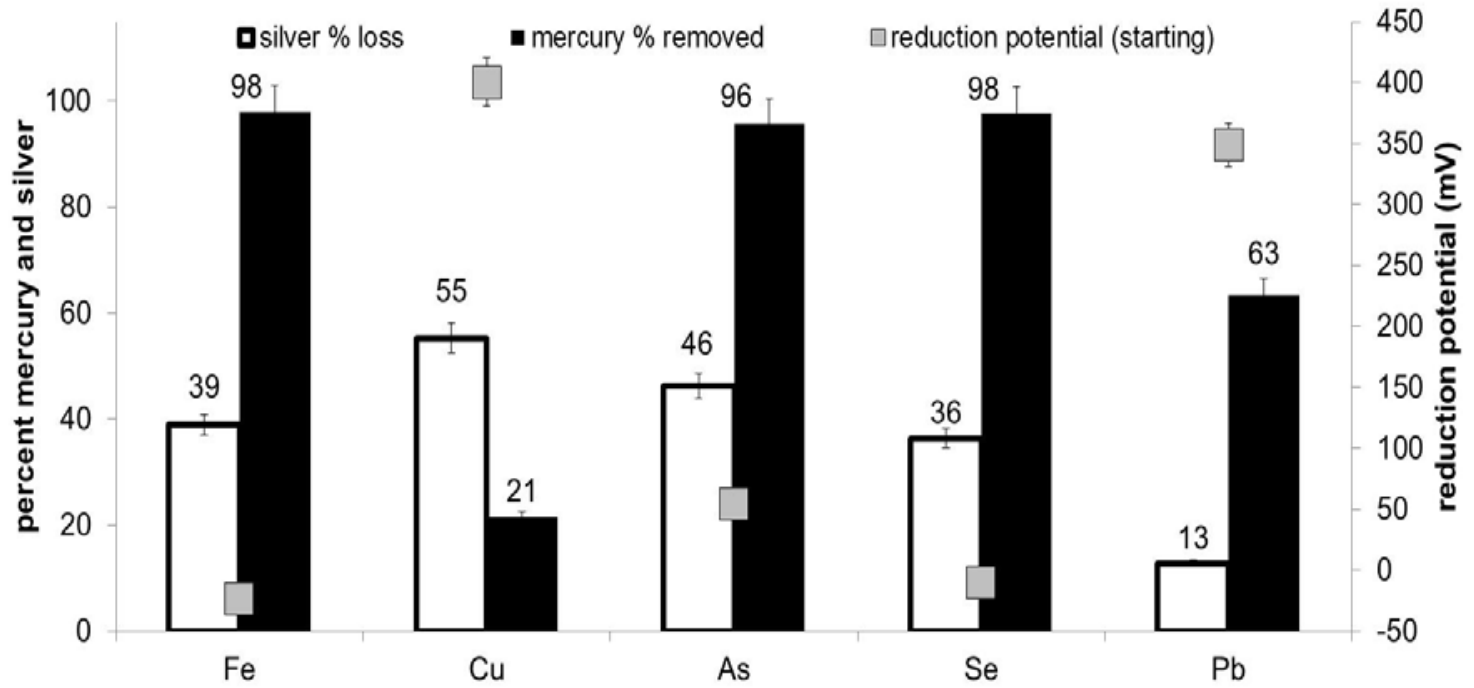

Figure 7.3. Results from the $10 \mathrm{mM}$ additions of possible complicating ions to mercury and silver separation by sphalerite, as shown by percent ion removed from solution

For a similar leach with only silver and mercury, there is about $37 \%$ silver loss and $98 \%$ mercury removal. Iron, arsenic, and selenium all fall close to those numbers. Copper show very poor mercury removal (21\%) and a larger silver loss $(55 \%)$. The reduction potential of copper was also higher than all the other leaches, which would explain why silver precipitated instead of mercury (Pourbaix diagrams Figure 5.12). Copper may also 
be binding with the sulfur instead of silver or mercury, as copper is favored over mercury in a reaction with zinc sulfide to precipitate as copper sulfide (Equation 60). Silver sulfide might have also precipitated from the free sulfides in the solution (the sulfides being from the dissolved the metal-sulfide compounds).

$\mathrm{Cu}(\mathrm{CN})_{2}^{-}(\mathrm{aq})+\mathrm{ZnS}(\mathrm{s})+2 \mathrm{CN}^{-}(\mathrm{aq}) \rightarrow \mathrm{Zn}(\mathrm{CN})_{4}^{-2}(\mathrm{aq})+\mathrm{CuS}(\mathrm{s})+\mathrm{e}^{-}(\mathrm{aq}) \quad$ Equation 60 $\Delta \mathrm{G}=-120 \mathrm{~kJ}$

The second experiment carried out with ions only changed by using ammonia to lower the reduction potential of copper sulfate leach solution. The results are in Figure 7.4, as shown by percent ion removed from solution. Copper still had one of the highest reduction potentials, but more mercury was precipitated out than silver ( $99 \%$ of mercury removed), but silver also precipitated out in a relatively high amount (81\%). This might mean that at a higher reduction potential copper is preferably reacting with the sphalerite, preventing the mercury and silver from precipitating. It could also mean that the reduction potential alone is affecting the mercury and silver precipitation, which led to the next experiment in using copper as metals to determine if copper is having an effect. 


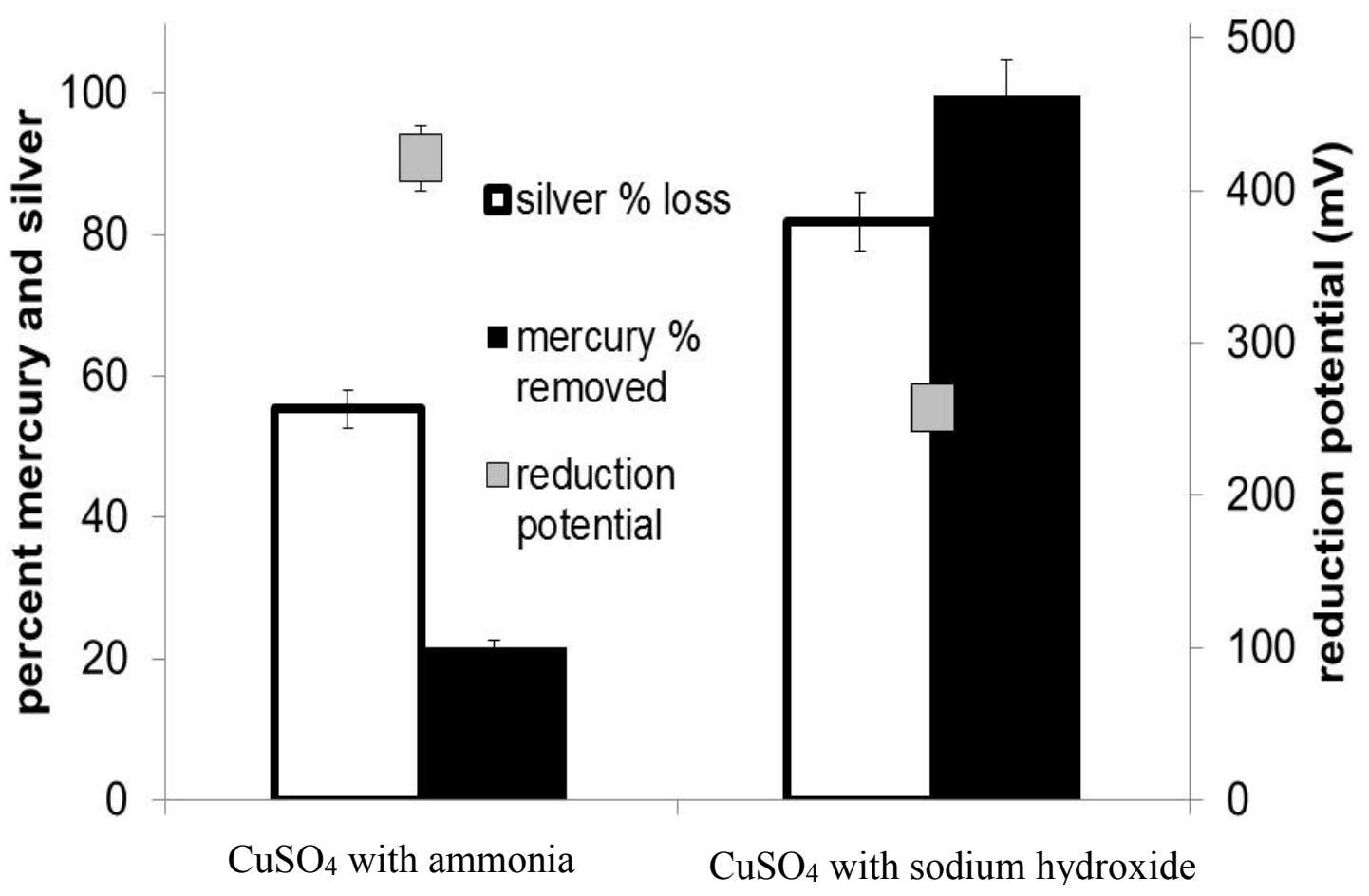

Figure 7.4. The copper sulfate $(10 \mathrm{mM})$ used for this experiment had a lower reduction potential by using ammonia. The $\mathrm{Cu}$ results are shown with the sodium hydroxide experiment for comparison, The results are shown by percent ion removed from solution.

The results from the third experiment, using copper, iron, and lead leached as metals, and $1 \mathrm{mM}$ of the other compounds, are in Figure 7.5, as shown by percent ion removed from solution. For iron, all the silver was removed from solution along with $79 \%$ of the mercury. A similar trend is seen in the copper with $92 \%$ silver loss and $87 \%$ mercury removed. Arsenic and selenium were similar with $67 \%$ and $73 \%$ in silver losses, and $87 \%$ and $88 \%$ in mercury removal. Lead again had the lowest silver and mercury amounts removed with $29 \%$ silver loss and $80 \%$ mercury removal. 


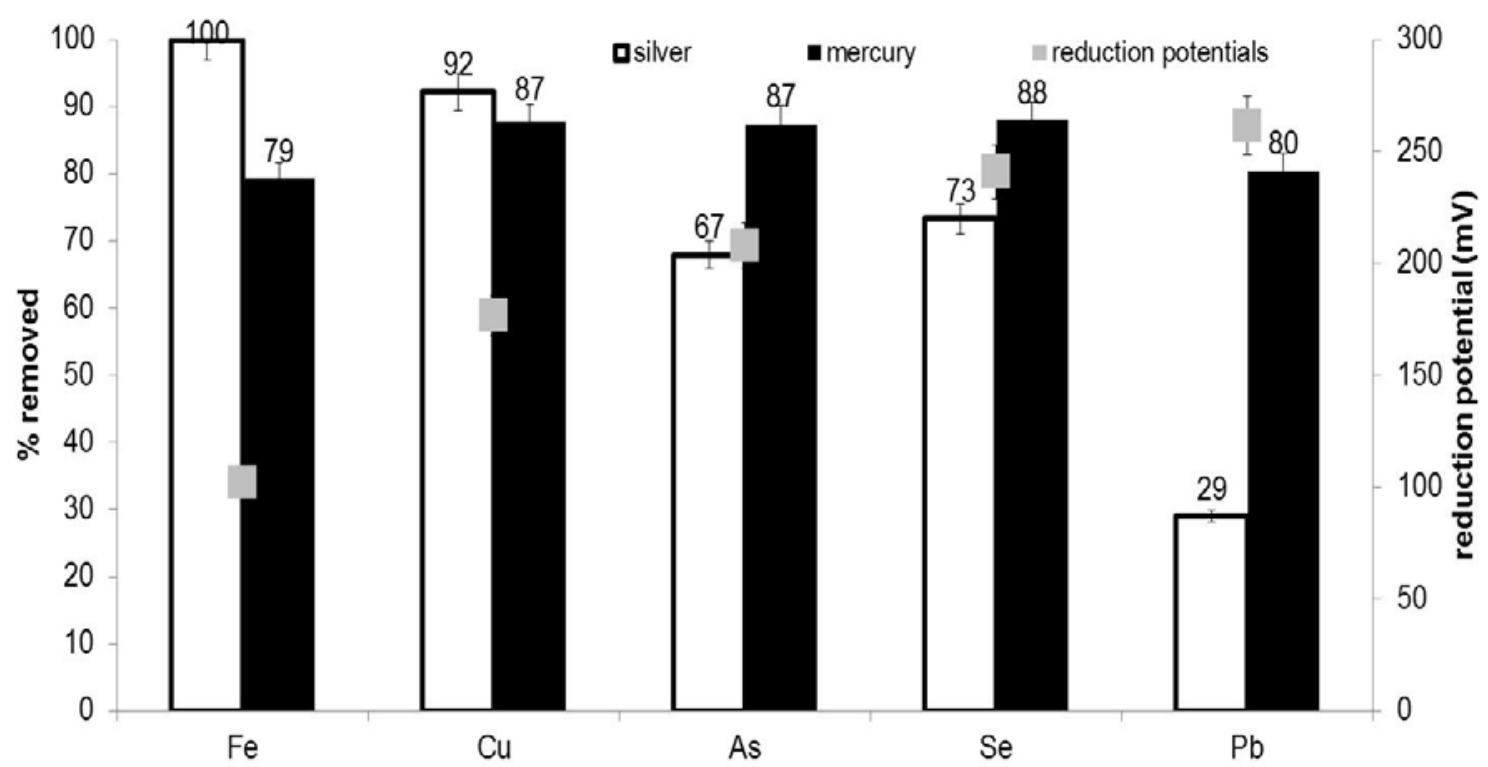

Figure 7.5. Complicating ions $(1 \mathrm{mM})$ results shown as percents, with the use of copper and lead as metals. The purpose was to show what affect smaller amounts of the metal compound would have on the system, and to see what the effects were for using metals. Shown by percent ion removed from solution.

Figure 7.6 shows the mercury and silver as ppb in solution with the element before and after going through the sphalerite (shown as pairs: starting = before, $\mathrm{zns}=$ has been through the $\mathrm{ZnS}$ ). The starting silver and mercury amounts added were around $450 \mathrm{ppb}$ silver and $30 \mathrm{ppb}$ mercury. This illustrated that silver was being removed by just contacting it with the compound's solution. 


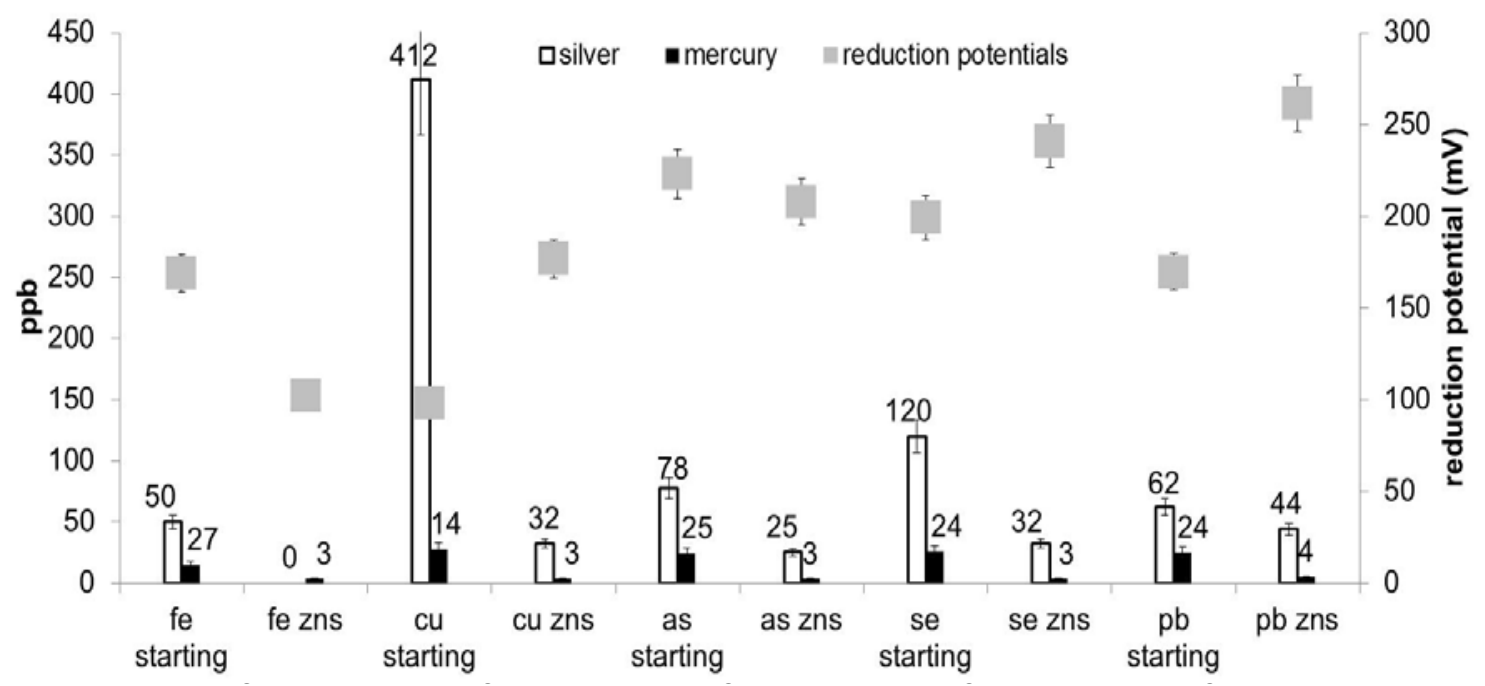

Figure 7.6. Complicating ions $(1 \mathrm{mM})$ results shown, with the use of copper and lead as metals in ppb.

A summary of the graphs in Figure 7.4, 7.5, and 7.6 are shown in Table 22.

Table 22. Use of metal compound and metals with a silver/mercury cyanide solution, which were passed through sphalerite, is shown. The $\%$ silver loss and $\%$ mercury loss for each are shown.

\begin{tabular}{|l|l|l|l|l|l|}
\hline Experiment & $\mathrm{Fe}$ & $\mathrm{Cu}$ & $\mathrm{As}$ & $\mathrm{Se}$ & $\mathrm{Pb}$ \\
\hline $10 \mathrm{mM}$ of metal & $38 \% \mathrm{Ag}$ & $55 \% \mathrm{Ag}$ & $46 \% \mathrm{Ag}$ & $36 \% \mathrm{Ag}$ & $12 \% \mathrm{Ag}$ \\
compounds with & $97 \% \mathrm{Hg}$ & $21 \% \mathrm{Hg}$ & $95 \% \mathrm{Hg}$ & $97 \% \mathrm{Hg}$ & $63 \% \mathrm{Hg}$ \\
sodium hydroxide & & & & & \\
\hline $10 \mathrm{mM}$ of copper & & $81 \% \mathrm{Ag}$ & & & \\
sulfate with ammonia & & $99 \% \mathrm{Hg}$ & & & \\
\hline $1 \mathrm{mM}$ compounds, & $100 \% \mathrm{Ag}$ & $92 \% \mathrm{Ag}$ & $67 \% \mathrm{Ag}$ & $73 \% \mathrm{Ag}$ & $29 \% \mathrm{Ag}$ \\
sodium hydroxide, with & $79 \% \mathrm{Hg}$ & $87 \% \mathrm{Hg}$ & $87 \% \mathrm{Hg}$ & $88 \% \mathrm{Hg}$ & $80 \% \mathrm{Hg}$ \\
\hline
\end{tabular}




\begin{tabular}{|l|l|l|l|l|l|}
\hline $\mathrm{Cu}^{0}, \mathrm{Fe}^{0}$ and $\mathrm{Pb}^{0}$ & & & & & \\
\hline
\end{tabular}

The only ion that lowered both the silver and mercury precipitation in all experiments compared to the other ions was lead. This suggests that lead might be either precipitating out on the sulfur in the sphalerite (Equation 61) or the oxide is precipitating mercury and silver oxide at well.

$$
\begin{aligned}
& \mathrm{Pb}^{+2}(\mathrm{aq})+\mathrm{ZnS}(\mathrm{s})+\mathrm{CN}^{-}(\mathrm{aq}) \rightarrow \mathrm{PbS}(\mathrm{s})+\mathrm{Zn}(\mathrm{CN})_{4}^{-2}(\mathrm{aq}) \quad \text { Equation } 61 \\
& \Delta \mathrm{G}=-140 \mathrm{~kJ}
\end{aligned}
$$

Arsenic and selenium appear to not affect the effectiveness of sphalerite. Iron with a low reduction potential (around $0 \mathrm{mV}$ ) also appears not to affect the precipitation, but at higher reduction potentials (about $100 \mathrm{mV}$ ) it facilitates in the precipitation of silver. Copper appears to negatively affect the selective precipitation reaction.

The ions tested were at some of the highest amounts, or higher, than any found in the ores and would most likely not be a problem when selectively separating the mercury. If the solutions were to be recycled enough times and built up other ions in higher concentrations, then a problem might occur. Furthermore, the precipitation of silver and mercury seem before even passing through the sphalerite is most likely from sulfides readily available in the solutions. The fourth experiment used only metals for the cyanide leach, using the most likely ions to bind with sphalerite as well.

For the fourth experiment, results showed in the control sample $50 \%$ of the mercury removed and an $18 \%$ silver loss. All the samples with added metals showed lower amounts of silver and mercury being removed from the solution (Figure 7.7 , as shown by percent ion removed from solution): 
$\mathrm{Cu}$ : mercury $24 \%$ removed, silver $1 \%$ loss

$\mathrm{Pb}$ : mercury $23 \%$ removed, silver $0 \%$ loss

Fe: mercury $32 \%$ removed, silver $2 \%$ loss

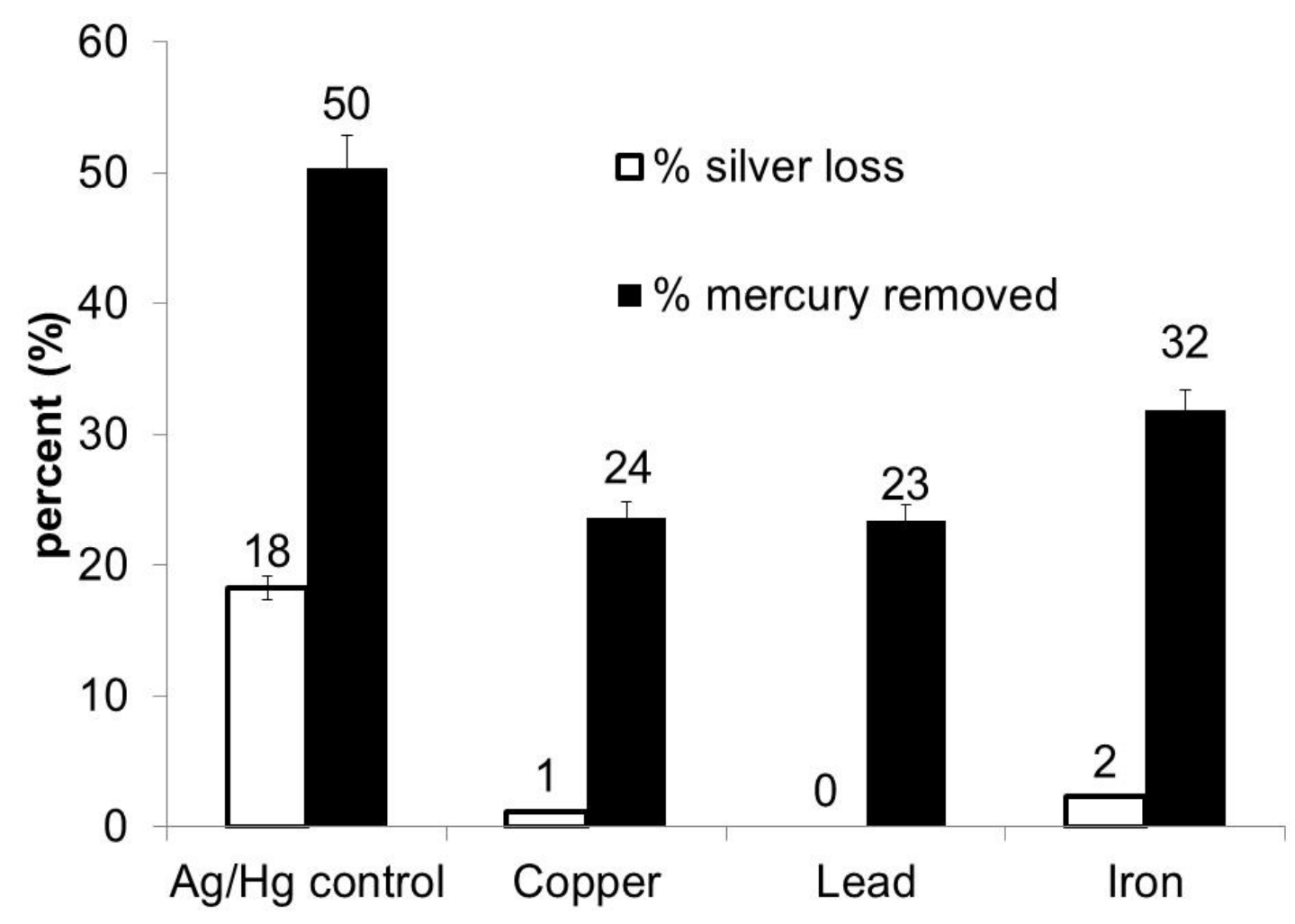

Figure 7.7. Silver loss and mercury removed, in percents, is shown for a control and with various additional metals. Shown by percent ion removed from solution.

This suggests that all three ions did react with the sphalerite to some extent, preventing the silver and mercury from coming out of solution. Lead and copper were nearly identical and likely reacted the most with the sphalerite. Iron was only slight less reactive, but still prevented silver and mercury reactions. 
Figure 7.8 shows the silver and mercury amounts in ppb. The control solution (only silver and mercury) are shown in the last two columns. Clearly, all solutions with other metals precipitated silver and mercury from solution. Reduction potential was also seen to have an effect on leaching the natural ores in regards to silver and mercury concentrations (Appendix 9).

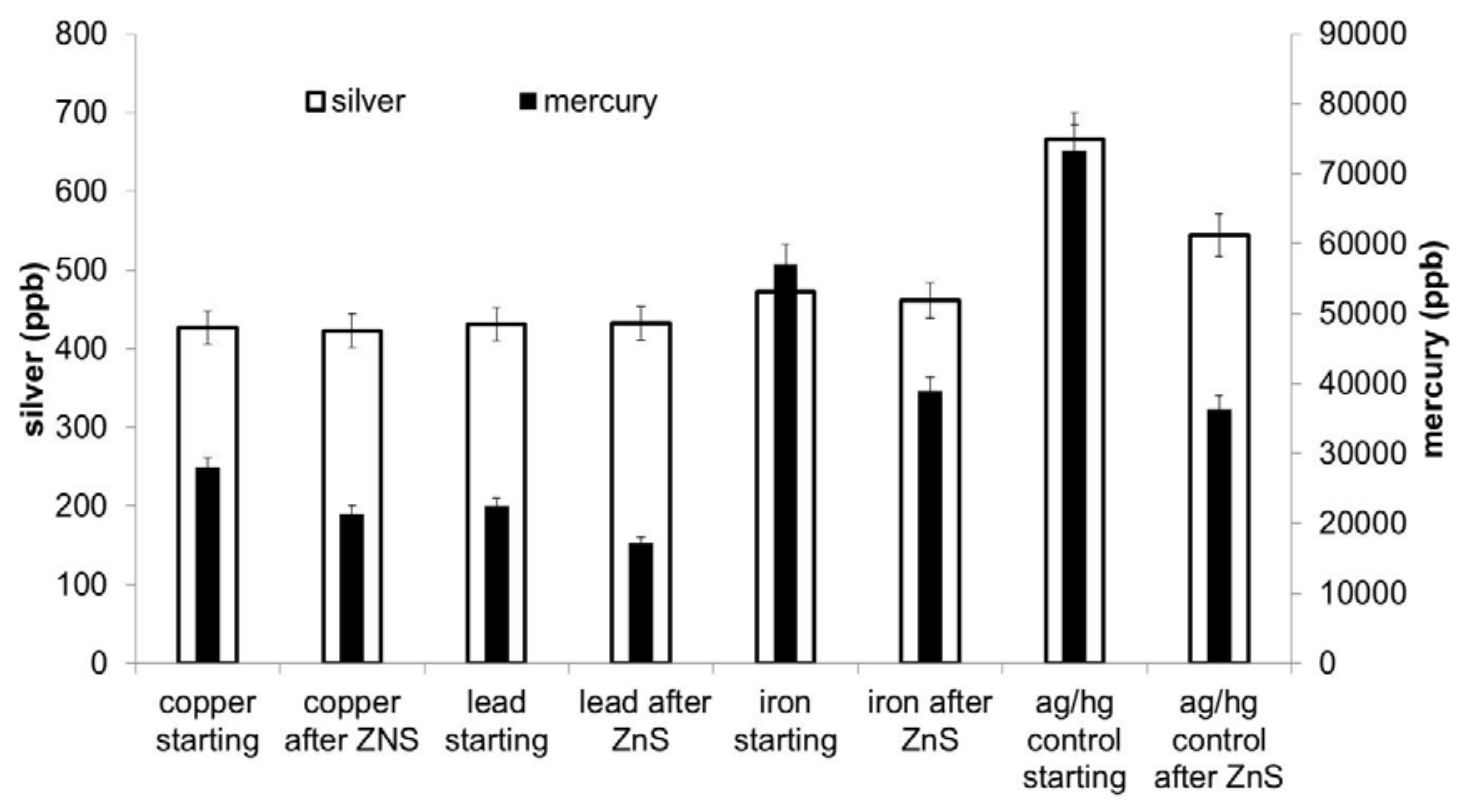

Figure 7.8. Silver and mercury in ppb for all experiments for Figure 72 are shown.

\subsection{Conclusions}

The results from the complicating ions experiments suggested that copper, lead, and iron will also precipitated on the sphalerite. Although less mercury was removed, almost no silver was lost (maximum $2 \%$ silver loss with $\mathrm{Fe}^{0}$ versus $18 \%$ silver loss without). These 
ions $(\mathrm{Cu}, \mathrm{Pb}$, and $\mathrm{Fe})$ are not wanted in the process anyway, so the additional removal of them is positive.

\section{Overall Conclusions}

The main focus of this work was to selectively remove mercury from silver before an amalgam was made, which would reduce or eliminate the need to use a retort to vaporize mercury. Three approaches were attempted:

- use of selenium to precipitate mercury

- mercury cyanide to dissolve silver sulfide and precipitate mercury sulfide,

- use of sphalerite to selectively precipitate mercury from a silver/mercury cyanide solution.

Experiments with the selenium indicated that when using cyanide, selenium would not keep mercury from dissolving. Experiments with the mercury cyanide did show silver dissolution and mercury precipitation, but could only be used in industrial practices in specific instances. Experiments using sphalerite showed selective mercury precipitation from a silver/mercury cyanide solution, and appears promising for an industrial application.

Initially, the plan was to use a High $\mathrm{Hg}$ ore and a High Se ore to precipitate mercury sulfide in the leach heap. Results suggested that selenium is most likely not precipitating mercury under the tested conditions. There were several reasons for not pursuing the $\mathrm{Se} / \mathrm{Hg}$ route, some of which were: studying selenium/mercury binding was not the main 
goal of this research, selenium and mercury have been shown to bind in numerous other works (not in cyanide solution, though), selenium is a valuable commodity (electronics) and would not want to be used solely to prevent mercury precipitation. If the process had worked very well then, having High $\mathrm{Hg}$ and High Se ores anyway, they might as well be used to prevent a large problem (mercury), but if not there is no reason to go out of our way to find how to make it work, as selenium may be desired to be recovered at some later point.

The results to the data suggest that mercury sulfide and selenium (both synthetic) could be used in various amounts to determine an optimum ratio, and for the time to obtain a rate of reaction and optimum time to let the ore and pre-leached selenium react. Sodium hydroxide should be used to adjust the $\mathrm{pH}$, since the theory and two sets of MTU results suggest it would work best for silver recovery. Variations for the effect of reduction potential could be observed by adding increasingly small amounts of ammonia to determine what effect reduction potential has on mercury and selenium binding. Finally, real ores could again be used, testing again the effects of time and reduction potential per ore.

From the selenium experiments, mercury cyanide was found to be precipitating as mercury sulfide by silver sulfide. The application of using mercury cyanide to recover silver and leave behind mercury does work, but has selective limitation of use industrially. For a wider application of use, a similar compound to silver sulfide was desired, which led to zinc sulfide.

Selective precipitation of mercury, while leaving silver in solution, has been shown to be possible with zinc sulfide, used as the naturally occurring mineral sphalerite. Sphalerite has been shown to have possible applications outside of cyanide leaching, leaving options open for other applications of use as well. Although selenium ended up not being utilized 
as initially planned, removal of mercury from silver in an aqueous cyanide solution was accomplished. This has previously been an impossible task prior to this work. 


\section{Proposed Implementation}

A probably application for the use of zinc sulfide would be in the Merrill-Crowe process after the counter current decantation thickeners and before the pressure clarification and de-aeration steps as shown in Figure 9.1.

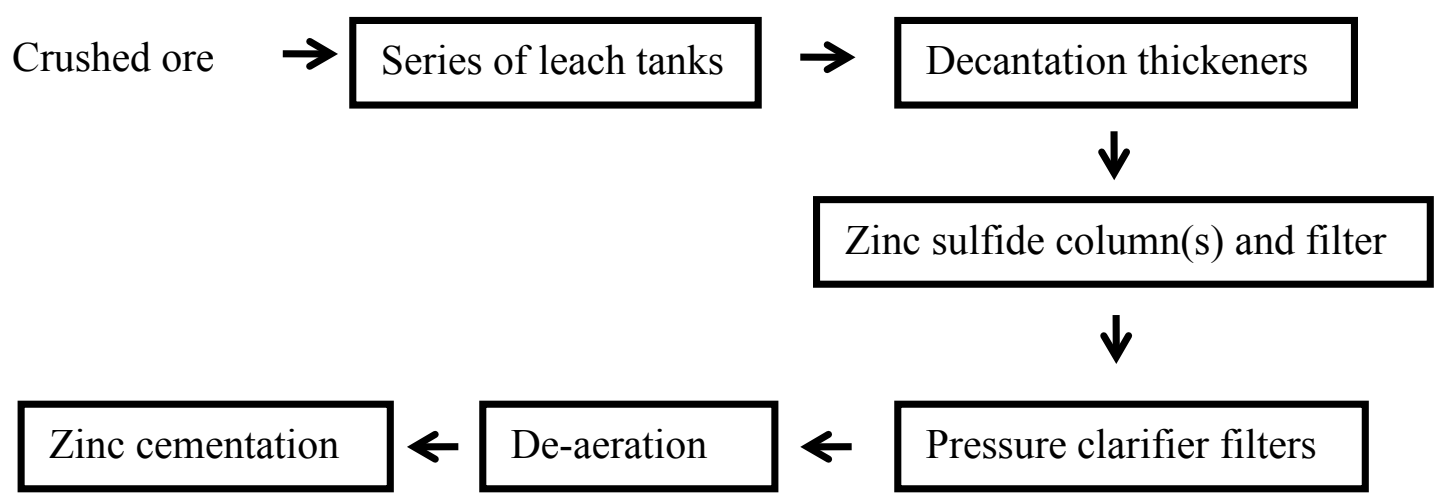

Figure 9.1. Suggested addition of $\mathrm{ZnS}$ to the Merrill-Crowe process by the addition of a column, or series of columns, containing the $\mathrm{ZnS}$ is shown.

Since the High $\mathrm{Hg}$ ore has the largest mercury problem, that ore will be used for theoretical calculations if applied and assume that one column with $\mathrm{ZnS}$ (80\% passing $11 \mu \mathrm{m}$ ) were to be used for all solution passing through. The High $\mathrm{Hg}$ ore has approximately 12 ppm mercury (Table 3), or 0.012 grams per kg ore. Using the information from Table 17, for an $86.6 \%$ removal of mercury from the system with little affect on silver, 161 grams $\mathrm{ZnS}$ per grams mercury are needed. This means that about 2 grams of $\mathrm{ZnS}$ are needed to completely precipitate the 0.012 grams of mercury per $\mathrm{kg}$ High Hg ore. See Appendix 10 for complete calculations. Costs may be less if the mine owns its own zinc sulfide ore source.

Another possible source of zinc sulfide would be recovered from the waste product of the Merrill-Crowe process. Zinc cyanide is formed when zinc is added to precipitate the 
metals. If sodium sulfide were added to the zinc cyanide solution, a very zinc sulfide would precipitate. At room temperature (298K) this reaction is favorable (Equation 62).

$\mathrm{Zn}(\mathrm{CN}) 4^{-2}(\mathrm{aq})+\mathrm{S}^{-2}(\mathrm{aq}) \rightarrow \mathrm{ZnS}(\mathrm{s})+4 \mathrm{CN}^{-}(\mathrm{aq})$

Equation 62

$\Delta \mathrm{G}=-17 \mathrm{~kJ}$

This would regenerate cyanide solution from a waste product (zinc cyanide), forming a product (very fine sphalerite) to safely remove another waste product (mercury). The cost for operating would have to include labor, disposal of the spent ZnS, any extra filtering needed, and wear on the equipment.

Instead of inserting a new column in the circuit, the $\mathrm{ZnS}$ could be added to the decant thickener tanks (Figure 9.2). Since a counter current flow is already used, the newest $\mathrm{ZnS}$ could be added to the tank going to the pressure clarifiers. A feed hopper directly going to a fine grinder to maximize surface area and non-oxidized surfaces for the $\mathrm{ZnS}$ could be added directly into the last, or close to last, decant thickener. The amount of $\mathrm{ZnS}$ ground in would correspond to the amount of liquid flowing through and expected mercury, as shown in the paragraph above. 


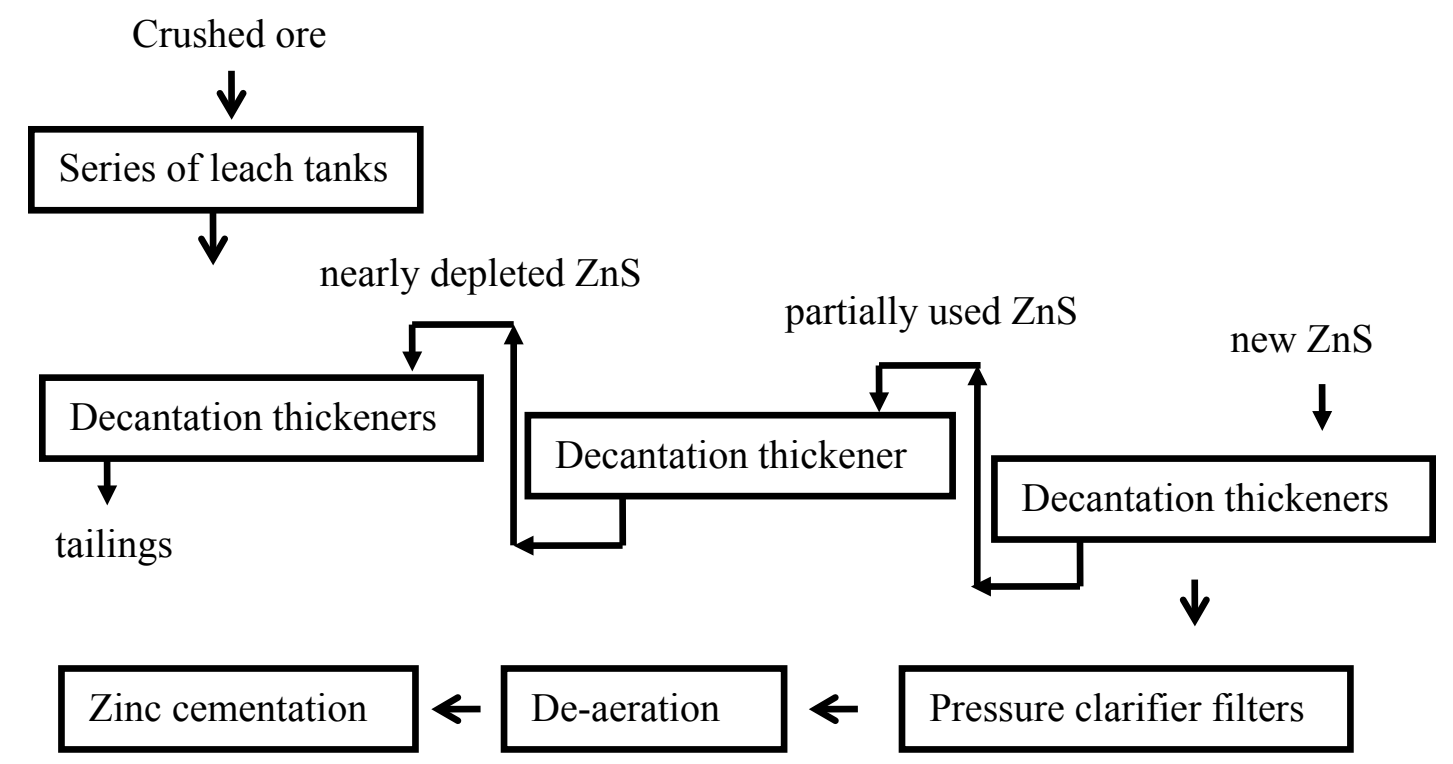

Figure 9.2. Suggested addition of $\mathrm{ZnS}$ to the Merrill-Crowe process in the decant thickeners is shown.

A diagram showing implication of adding $\mathrm{ZnS}$ to the Merril-Crowe process in the decant thickeners, where the waste products go, where the mercury and silver are separated, where the silver is precipitated, and regeneration of zinc powder and cyanide is shown in Figure 9.3. 


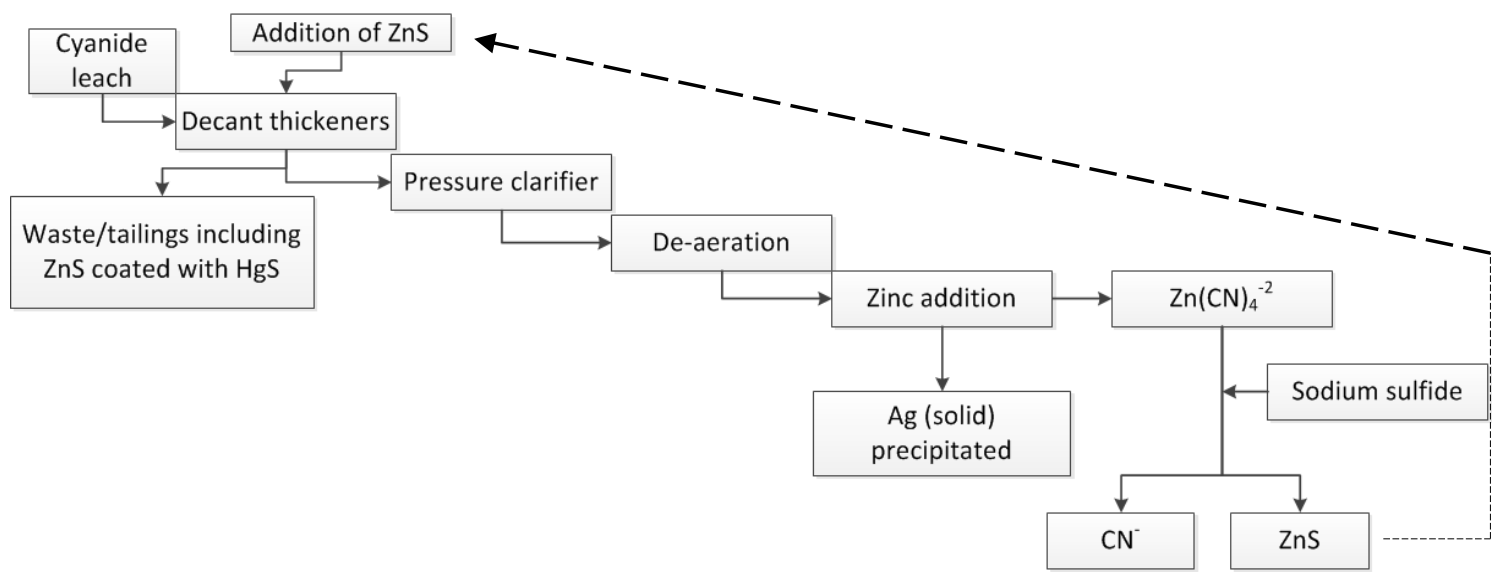

Figure 9.3. The Merrill-Crowe process with implementation of the addition of sphalerite to the decant thickeners is shown.

In 2006, the United States Environmental Protection Agency estimated that to store 7,500 metric tons of mercury for 40 years would cost between $\$ 50$ to $\$ 144.4$ million, including transportation costs (EPA 2006). The amount of mercury produced in the United States over a 40 year period (7,500 metric tons accumulated over 40 years) produced from chlor-alkali plants, recycling, and gold mining was used for this estimate (EPA 2006). There are other sources of mercury, such as coal emissions, which were not taken into account. Current prices for $60 \%$ zinc ore as zinc sulfide runs around $\$ 500$ per metric ton (Alibaba (c) 2013). To theoretically sequester 7,500 metric tons of mercury, using the information mentioned previously on page 158 in reference to Table 3 ,

- $2 \mathrm{~g} \mathrm{ZnS}$ needed for 0.012 grams $\mathrm{Hg}=166.7 \mathrm{~g} \mathrm{ZnS/gram} \mathrm{Hg}$

- $166.7 \mathrm{~g} \mathrm{ZnS} /$ gram Hg * $7.5 \times 10^{9}$ grams mercury = about $1.25 \times 10^{12} \mathrm{~g} \mathrm{ZnS}$ needed

- $1,250,000$ metric tons of sphalerite ore $* \$ 500$ per ton $=$ a little over $\$ 625$ million

For a cost per ton analysis, that comes to around $\$ 83,000$ /metric ton of mercury sequestered. 
About 4,250 metric tons of mercury from the above analysis is produced by the gold mining industry alone (EPA 2006). This industry would therefore incur costs of around $\$ 352$ million over the 40 year period using sphalerite to sequester mercury (about $\$ 8.8$ million a year, and about $56 \%$ of the total cost over 40 years).

For sequestering mercury, not including any additional equipment costs or the cost of disposal and storage of the waste sphalerite with mercury sulfide precipitated, the cost of using only purchased zinc sulfide for mercury sequestration would be higher than existing methods. Both zinc sulfide and mercury sulfide in ores are considered nonhazardous wastes, which would lead to vastly smaller transportation and storage or disposal costs. Additional costs may be incurred from laboratory analysis of the waste material to assure it is not leaching mercury. The benefit of using zinc sulfide would not be monetary, but for environmental and human safety, and also selectivity against loss of silver. The value is likely to be subject to considerable improvement since there is a theoretical 1:1 mole ratio of $\mathrm{ZnS}$ to $\mathrm{Hg}$.

Under theoretically perfect conditions, where the $\mathrm{ZnS}$ to $\mathrm{Hg}$ ratio is $1: 1$,

- 1 grams $\mathrm{Hg} / 200.59 \mathrm{~g} / \mathrm{mole} \mathrm{Hg}=0.004985$ moles $\mathrm{Hg}$

- $\quad 0.004985$ moles $\mathrm{Hg} *$ moles $\mathrm{S} /$ moles Hg * moles $\mathrm{ZnS} /$ moles $\mathrm{S} * 97.47$ grams/mole $\mathrm{ZnS}=0.4859$ grams $\mathrm{ZnS}$

- For every grams of $\mathrm{Hg}$, nearly 0.50 grams of $\mathrm{ZnS}$ would be needed

- 0.50 grams $\mathrm{ZnS} /$ grams $\mathrm{Hg} * 1 \times 10^{6}$ grams mercury $=5 \times 10^{5} \mathrm{~g} \mathrm{ZnS}$ needed to capture 1 metric ton of $\mathrm{Hg}$

- $\quad 0.5$ metric tons $\mathrm{ZnS} * \$ 500=\$ 250$

The cost per metric ton of $\mathrm{ZnS}$ needed comes to $\$ 250 /$ metric ton $\mathrm{Hg}$ (or a little over \$1 million over 40 years for the gold mining industry alone, about $\$ 1.87$ million for all 
industry) if a "best case scenario" were assumed. As shown, there is much room for improvement in the process of utilizing $\mathrm{ZnS}$.

Another source for acquisition of $\mathrm{ZnS}$ is shown in Figure 9.3, where one of the end products for regenerating the cyanide is formation of $\mathrm{ZnS}$. Since the $\mathrm{ZnS}$ formed is by precipitation, very fine particles result, which increase surface area available for precipitation of mercury back at the decant thickeners. In this case, the theoretical "best case scenario" could become a reasonable expectation with super fine $\mathrm{ZnS}$ leading to a near 1:1 ratio of $\mathrm{ZnS}: \mathrm{Hg}$. In addition, the cost of using the precipitated $\mathrm{ZnS}$ will be less than that of purchased $\mathrm{ZnS}$ concentrate, as it is a result of a water-treatment process that is already in use. 


\section{References}

Abdo KM. (1994) Sodium selenate and sodium selenite. National Toxicology Program: Toxcicity Report Series. Number 38. NIH Publication 94-3387.

http://ntp.niehs.nih.gov/ntp/htdocs/ST_rpts/tox038.pdf

Ahrland S, Avsar E, Kullberg L. (1974) Thermodynamic of metal complex formation in aqueous solution VI. Equilibrium and enthalpy measurements on the zinc and cadmium selenocyanate systems. Acta Chemica Scandinavica. A 28: 855-865.

Aktas S, Morcali MH. (2011) Recovery of mercury from spent silver oxide button cells. Peer Review for the Society for Mining, Metallurgy, and Exploration, Inc.

Alibaba (a) (2013, January 7) "Sodium sulfide". http://www.alibaba.com/productgs/51515221/Sodium_Sulphide.html

Alibaba (b) (2013, January 7) “Hypochlorite”. http://www.alibaba.com/productgs/692383654/Calcium Hypochlorite Calcium Process 62 66.html?s=p

Alibaba (c) (2013 June 4) "Sunhill Zinc Sulfide". http://www.alibaba.com/product-gs/713008388/Sunhill_Zinc_Sulphide.html

Aslam S, Walker OL. (1982) Recycling of mercury and silver from COD tests. Water Pollution Control Federation. 54(7):1148-1151

Blue LY, Van Aelstyn MA, Matlock M, Atwood DA. (2008) Low-level mercury removal from groundwater using a synthetic chelating ligand. Water Reseach. 42: 20252028. 
Bucknam C, McComb M. (2007) Study of stability of mercury and silver polythiocarbonate nanofilms generated during optimized mercury removal from cyanidation pregnant eluate. SME Annual Meeting, Denver CO.

Chakraborty S, Bardelli F, Charlet L. (2010) Reactivities of Fe(II) and calcite: selenium reduction. Environ. Sci. Technol. 44: 1288-1294.

Davidson RJ, Brown GA, Schmidt CG, Hanf NW, Duncanson D, Talyor JD. (1978) The intensive cyanidation of gold plant gravity concentrates. Journal of South African Institute of Mining and Metallurgy.

Environmental Protection Agency (EPA). (1994) Treatment of cyanide heap leaches and tailings. Technical Report. Accessed June 14, 2013. http://www.epa.gov/osw/nonhaz/industrial/special/mining/techdocs/cyanide.pdf

Environmental Protection Agency (EPA). (2001) Appendix to method 1631: total mercury in tissue, sludge, sediment, and soil by acid digestion and BrCl oxidation. EPA821-R-01-013

Environmental Protection Agency (EPA). (2007) Mercury storage cost estimates final report. Office of Pollution and Toxics and Office of Solid Waste amd Emergency Response. Accessed June 14, 2013. http://www.epa.gov/mercury/archive/stocks/Storage_Cost_Draft_Updated_11-6-final.pdf

FactSage (version 6.2) (2010) [software] Thermfact and GTT Technologies, www.factsage.com

Gabby K, Eisele T. (in press 2012) Selective removal of mercury using zinc sulfide. Minerals and Metallurgical Processing Journal. 
Goldstein J, Newbury D, Joy D, Lyman C, Echlin P, Lifshin E, Sawyer L, Michael J. (2007) Scanning Electron Microscopy and X-ray Analysis. Third Edition. Springer. New York.

Grosse Ac, Dicinoski GW, Shaw MJ, Haddad PR. (2003) Leaching and recovery of gold using annoniacal thiosulfate leach liquors (a review). Hydrometallurgy. 69: 1-21.

Haz-Map (2012, December) National Institute of Health. Accessed April 52013. http://hazmap.nlm.nih.gov/category-details?id=9595\&table=copytblagents

Hennessy H. (2005, June 1) "Gold mine sparks battle in Peru”. BBC News. http://news.bbc.co.uk/2/hi/business/4600009.stm. Accessed March 18, 2013.

Holleman AF, Wiber E, Wiberg N. (2001) Inorganic Chemistry. Academic Press. San Diego, CA.

Jiangyin Jiazhou International Trade Co.,Ltd (2002) "Zinc sulfide" Canada. Accessed: Nov. 6 2012. http://www.alibaba.com/product-free/108606044/Zinc_Sulfide.html

Jordan N, Ritter A, Foerstendorf H, Scheinost AC, Weiß S, Heim K, Grenzer J, Mücklich A, Reuther H. (2012) Absorption mechanism of selenium (VI) onto maghemite. Geochimica et Cosmochimica Acta. http://dx.doi.org/10.1016/j.gca.2012.09.048

Kosson, D.S., van der Sloot, H.A., Sanchez, F. and Garrabrants, A.C. (2002) An integrated framework for evaluating leaching in waste management and utilization of secondary materials. Environmental Engineering Science 19(3):159-204.

Kongolo K, Mwema MD. (1998) Extractive metallurgy of gold, the. Hyperfine Interactions. 111: 281-289. 
Loewenschuss A, Marcus Y. (1996) Standard thermodynamic functions of some isolated ions at 100-1000K. Journal of Phys. Chem. Ref. Data. 25(6):1495-1507.

Martinez GVF, Torres JRP, Garcia JLV, Munive GCT, Zamarripa GG. (2012) Kinetic aspects of gold and silver recovery in cementation with zinc powder and electrocoagulation iron process. Advances in Chemical Engineering and Science. 2: 342-349.

a) Matlock MM, Howerton BS, Robertson JD, Atwood DA. (2002) Gold ore column studies with new mercury precipitant. Ind. Eng. Chem. Res. 41: 5278-5282.

b) Matlock MM, Howerton BS, Van Aelstyn MA, Nordstrom FL, Atwood DA. (2002) Advanced mercury removal from gold leachate solutions prior to gold and silver extraction: a field study from an active gold mine in Peru. Environ. Sci. Technol. 36: 1636-1639.

Meng X, Bang S, Korfiatis GP. (2002) Removal of selenocyanate from water using elemental iron. Water Research. 36: 3867-3873.

Mineral Publishing Data, version 1 (2001-2005). Sphalerite. Accessed January 11, 2013.

http://rruff.info/doclib/hom/sphalerite.pdf

Misra M, Lorengo J, Nanor JB, Bucknam CB. (1998) Removal of mercury cyanide species from solutions using dimethyl dithiocarbamates. Minerals \& Metallurgical Processing. 15, 4: 60 . 
Papadoyannis IN, Stratis JA, anthemidis AN. (1984) Simultaneous determination of selenocyanate and thiocyanate ions in the presence of cyanide by oxidation with bis(trifluoroacetoxy)iodobenze. Analytical Letters. 17(A13): 1511-1517.

Parga-Torres J, Valenzuela-Garcia L, Vazquez V, Rodriguez M, Moreno H. (2011) Treatment and recovery of silver and gold from cyanides solution of mine processing, with species formed in the electrocoagulation process. Mineral Processing and Extractive Metallurgy Review.

Pai P, Niemi D, Powers B. (2000) North American inventory of anthropogenic mercury emissions, A. Fuel Processing Technology. 65-66; 101-115.

Pedroso ACS, Gomes LER, de Carvalho JMR. (1994) Mercury removal from process sludges via hypochlorite leaching. Environmental Technology, 15: 7, 657 - 667

Pettine M, Gennari F, Campanella L. (2012) The reaction of selenium (IV) with ascorbic acid: its relevance in aqueous and soil systems. Chemosphere. http://dx.doi.org/10.1016/j.chemosphere.2012.06.061

Rath RK, Hiroyoshi N, Tsunekawa M, Hirajima T. (2003) Ammoniacal thiosulphate leaching of gold ore. European Journal of Mineral Processing and Environmental Protection, The. 3(3): 344-352.

Ravichandran M. (2004) Interactions between mercury and dissolved organic matter-a review. Chemosphere. 55: 319-331.

Raymond LJ, Ralston NVC. (2004) Mercury: selenium interactions and health implications. SMDJ Seychelles Medical and Dental Journal. 7, 1: 72-77. 
Rennert T, Mansfeldt T. (2005) Iron-cyanide complexes in solution. European Journal of Soil Science. 56(4).

Schaefer JK, Rocks SS, Zheng W, Liang L, Gu B, Morel FMM. (2011) Active transport, substrate specificity, and methylation of $\mathrm{Hg}(\mathrm{II})$ in anaerobic bacteria. PNAS. 108(21). www.pnas.org/cgi/doi/10.1073/pnas.1105781108

Schlesinger M, Paunovic M. (2010) Electrodeposition of copper. Modern Electroplating. $5^{\text {th }}$ Ed. John Wiley \& Sons, Inc. DOI: 10.1002/9780470602638

Shannon RD (1976) Acta Crystallographica A23:751-761

Shannon RD Prewitt CT (1969) Acta Crystallographica B25:925-946

Shrader DE, Hobbins WB. (1983) Determination of mercury by cold vapor atomic absorption, the. Varian AA Instruments at Work. Number AA-32.

Skopenko VV, Tsintsadze GV, Ivanova EI. (1982) Metal selenocyanates. Russian Chemical Reviews. 51(1). http://iopscience.iop.org/0036-021X/51/1/R03

Smith T, Pitts K, McGarvey JA, Summers AO. (1998) Bacterial oxidation of mercury metal vapor, $\mathrm{Hg}(0)$. Applied and Environmental Microbiology. 64(4): 1328-1332.

Waehner KA, Giammarise AT. (1976) Recovery of selenium. US patent number: 3992511.

Wagner-Döbler. (2003) Pilot plant for bioremediation of mercury-containing industrial wastewater. Applied Microbiol. Biotechnol. 62: 124-133. 
Washburn C, Hill E. (2003) Mercury retorts for the processing of precious metals and hazardous wastes. Precious Metals: Pyrometallurgy. 45-50

Winkel LHE, Johnson CA, Lenz M, Grundl T, Leupin OX, Amini M, Charlet L. (2011) Environmental selenium research: from microscopic processes to global understanding. Environmental Science and Technology. 46: 571-579

Wright WG. (1999) Oxidation and mobilization of selenium by nitrate in irrigation drainage. Journal of Environmental Quality. 28(4): 1182-1187.

Ye ZH, Lin Z-Q, Whiting SN, de Souza MP, Terry N. (2003) Possible use of constructed wetland to remove selenocyanate, arsenic, and boron from electric utility wastewater. Chemosphere. 52: 1571-1579.

Young C, Talyor OR, Anderson CG, Choi Y. Hydrometallurgy 2008. proceedings of the sixth international symposium. Society for Mining, Metallurgy, and Exploration, Inc. United States.

Zhang X, Zhao M, Yan S, He T, Li W, Lin X, Xi Z, Wang Z, Liu X, Xia Y. (2008) First-principles study of ZnS nanostructures: nanotubes, nanowires and nanosheets. Nanotechnology. 19. DIO: 10.1088/0957-4484/19/30/305708 


\section{Appendix}

\section{1) Variation in mercury and silver concentrations in solutions explanation}

As can be seen throughout the experiments, mercury and silver concentration do not remain steady and can vary greatly even for only synthetic solutions. There are several reasons for this.

1. small batch quantities of silver and mercury solutions were made at a time to lower the amount of waste generated.

2. even using the synthetic powders, particle size could vary significantly, leading to more or less surface are for dissolution.

3. grinding the synthetic powders in a separate container would results in a significant amount of waste for the $\mathrm{Ag}_{2} \mathrm{~S}$ and $\mathrm{HgS}$ particles. This was attempted twice, but made such a mess that further attempted were not carried out and limited crushing in the container used for dissolution was done.

4. solutions sat for different times. Instead of throwing out unused solution, if any could be used for another experiment, it was. This was to lower waste generation.

5. very small amounts, in ppb, were being used and tested, making accuracy in delivering exact amounts for different tests very difficult. In some cases, one drop of solution could double the amount of mercury present.

6. silver and mercury were often leached in separate containers, then after filtering were combine. The second set of experiments explained why this was done. In taking out different amounts and creating dilutions, error was introduced, sometimes very large depending on the other mentioned factors.

7. use of standards already prepared, like AA standards, could not be used due to contaminating ions, forms of ions present, and acidity of solutions. 


\section{2) EDS analysis and EDS element mapping background (Goldstein et al. 2007).}

The EDS (energy-dispersive spectrometer) can tell you quickly what elements are found in a sample, approximate amounts of elements, and can map out the elements to show how they are distributed. This can be used to assist in determining what the sample consists of and if there are any clear boundaries between elements.

The electron beam from the SEM hit elements and sends x-ray photons scattering to the $\mathrm{Si}(\mathrm{Li})$ detector, which are then converted into electronic peaks. The peaks are measured and compared to reference peaks to give approximate amounts of the elements seem in the sample. Since the $\mathrm{x}$-ray penetrate into the sample some depth (depending on the element in question, some x-rays scatter more than others), so the sample should not be too thin.

When collecting data for quantitative analysis, an area is chosen for analysis and the magnification increased all the way. No image is seem, just blurs, for the "picture" of the sample, and an analysis of that area is taken.

When collecting data for qualitative analysis (element mapping), an image of the sample at a particular magnification is taken along with collection of what elements are there and roughly where they are located. The software then colors the images to show the different elements separately.

For this study, the picture of the crystal, or particle, was irrelevant. Instead, the EDS quantitative analysis was used to verify how much mercury was on the sample (if any), and the qualitative (mapping) was used to show an even distribution of the mercury over the surface of $\mathrm{ZnS}, \mathrm{Ag} 2 \mathrm{~S}$, or $\mathrm{Se}$ on $\mathrm{HgS}$. 


\section{3) Procedure for mercury analysis using the Cold Vapor apparatus on the Atomic}

Absorption Spectrophotometer (Varian 240FS)

1) Make standard solutions of mercury at 5, 10, and 20 parts per billion (ppb)

2) Make reductant solution: $20 \%(\mathrm{v} / \mathrm{v}) \mathrm{HCl}, 20 \%(\mathrm{w} / \mathrm{v}) \mathrm{SnCl}$ in distilled water.

3) Verify that the ventilation over the AA is running properly

4) Set up the cold vapor apparatus on the AA

a) If the $\mathrm{CV}$ has not been run for over a week, run about $100 \mathrm{~mL}$ of $50 \%(\mathrm{v} / \mathrm{v}) \mathrm{HCl}$ and flush with at least $250 \mathrm{~mL}$ distilled water.

b) If the $\mathrm{CV}$ has been run recently, flush with at least $100 \mathrm{~mL}$ distilled water

c) While flushing with water, set the flow rate of the pump. Do not tighten the screws down all the way. Tighten just enough to allow for flow if an air bubble is present in the tubing.

d) Turn on argon (or nitrogen) to $40-60 \mathrm{psi}$

5) Run the lamp according to specifications: let it warm up at the proper $\mathrm{mV}$ for at least 5 minutes

6) Run standards

The program will prompt for the first (lowest) standard, 5ppb. Allow the solution to go through the tubing before allowing the program to take the measurement.

This will allow for enough time for the standard sample to steadily reach the detection chamber. Repeat with the remaining two standards.

7) Have at least two waters/blanks between every sample, including after the standards.

8) Each sample should have a pre-collection time of about 40 seconds before reading the sample. This allows enough time for the sample fluid to travel through the CV and the mercury ions into the AA chamber.

9) When the run is finished, turn off the AA and, flush the CV with at least $100 \mathrm{~mL} 50 \%$ $\mathrm{HCl}$ and then at least $250 \mathrm{~mL}$ distilled water.

10) Allow the argon (or nitrogen) to run about 1 minute after the water flush. 
11) Turn off the gas, un screw the pump and take off the tubing.

12) Store CV properly if needed 


\section{4) Sponsoring company's analysis of experiment}

A sample was sent to the company funding the project for analysis. The analysis by Newmont (Figure, Table 23) shows better silver recovery and lower selenium for the "High Se leach to High Hg" than simply mixing the two ores together ("High $\mathrm{Se}+\mathrm{High}$ Hg"). Important to note is that samples sent to Newmont for analysis did sit for an extended period of time (several months) before analysis and did have some very fine particulates, which may have affected results.

Mercury was very similar between the "High Se leach to High Hg" and "High Se + High $\mathrm{Hg}$ ". This might mean that pre-leached selenium is better at removing selenium from solution by binding with mercury and either precipitating out as selenium or forming a selenocyanate (which is favored to react with silver and mercury) (suggested by the lower reduction potential with using ammonia in the Pourbaix diagram, Figure 3.1.13), leading to more silver dissolution. This is only a rough guess, as selenocyanates would form with cyanide in solution, potentially changing the reactions, but thermodynamic data is not available for selenocyanates. This could suggest that, at a lower reduction potential, preleached selenium (probably at a selenocyanate) works better at binding mercury only and precipitating selenium, and allowing the silver to dissolve. When the two ores are simply combined together, at a lower reduction potential, selenium may suppress silver dissolution by not allowing enough time for the cyanide to re-dissolve the silver. 


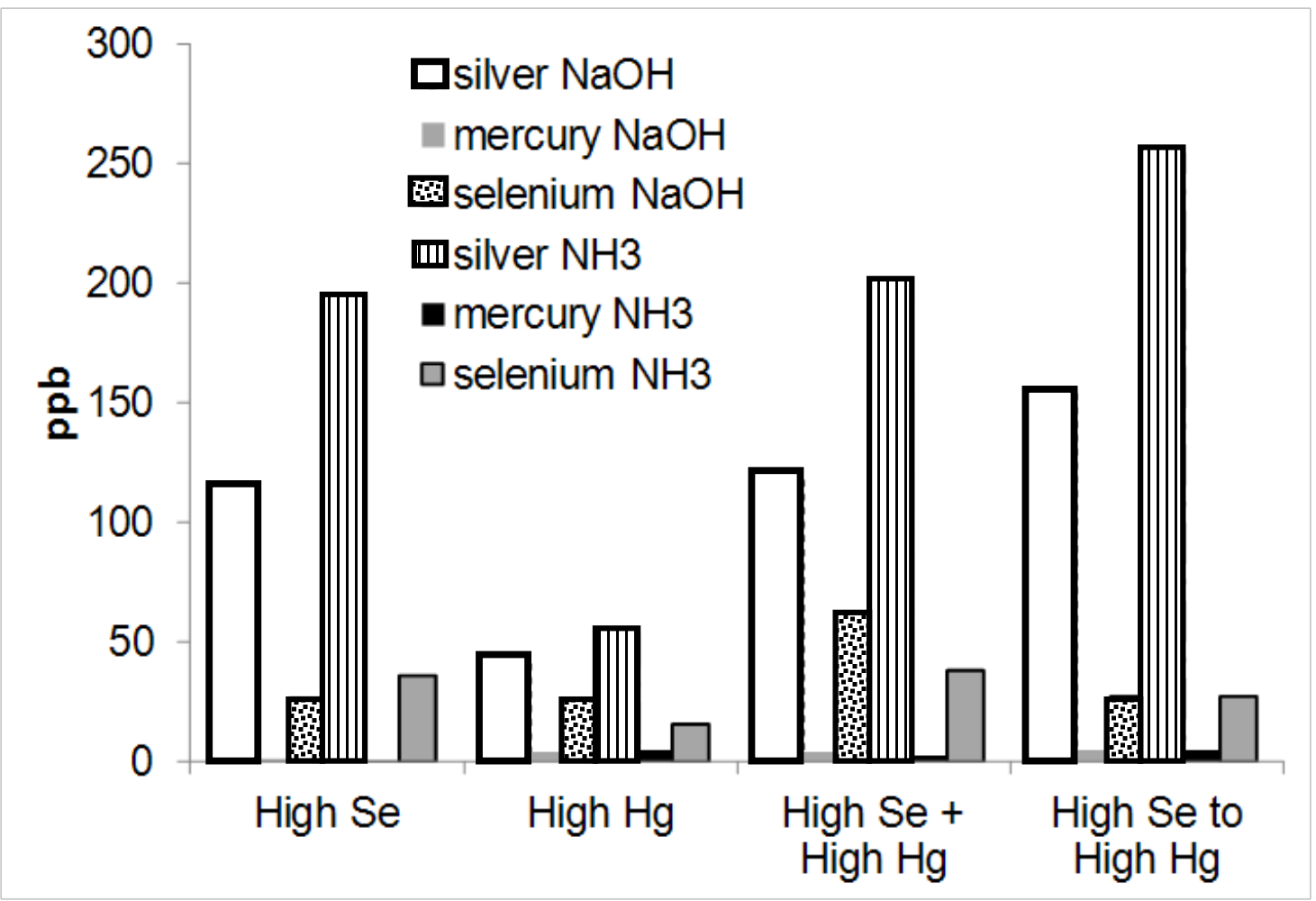

Figure A4. Results from natural ore leach, analysis by Newmont.

Table 23. Newmont analysis with ammonia and sodium hydroxide for the High Se ore and High $\mathrm{Hg}$ ores are shown.

\begin{tabular}{|l|l|l|l|l|}
\hline Sample & $\begin{array}{l}\text { High Se } \\
(\mathrm{ppb})\end{array}$ & $\begin{array}{l}\text { High Hg } \\
(\mathrm{ppb})\end{array}$ & $\begin{array}{l}\text { High Se + High Hg } \\
(\mathrm{ppb})\end{array}$ & $\begin{array}{l}\text { High Se to High Hg } \\
(\mathrm{ppb})\end{array}$ \\
\hline Silver NaOH & 115 & 41.7 & 118.1 & 153.3 \\
\hline $\begin{array}{l}\text { Mercury } \\
\mathrm{NaOH}\end{array}$ & 1 & 3.8 & 4 & 4.9 \\
\hline $\begin{array}{l}\text { Selenium } \\
\mathrm{NaOH}\end{array}$ & 26.7 & 22.6 & 58.1 & 27.1 \\
\hline Silver NH3 & 193.4 & 53.8 & 199 & 254.2 \\
\hline
\end{tabular}




\begin{tabular}{|l|l|l|l|l|}
\hline Mercury NH3 & 0.3 & 4.8 & 2.7 & 4.9 \\
\hline Selenium NH3 & 35.6 & 16 & 38.3 & 27.5 \\
\hline
\end{tabular}

Pourbaix diagram analysis done above for the MTU results explains why the Newmont analysis for the sodium hydroxide obtained different results than the analysis done immediately at MTU, as solubilities will change over time as the redox potential of stored samples shifts. The important point here to make is that the trends of mercury in solution between the Newmont and MTU analyses are different in the key point in the processes of just mixing the two ores together versus using the leach of the High Se to leach the High Hg. The two-step process (simplified diagram shown in Figure 3.1.12) works best in both cases, keeping in mind the disagreement in highest silver dissolution from use of higher or lower reduction potentials is suspected to be from the longer sitting time with the Newmont analyses. 


\section{5) Calculations for a saturated $\mathrm{Hg}(\mathrm{CN}) 4^{-2}$ solution from $0.02 \% \mathrm{KCN}$ and $\mathrm{HgS}$}

$0.02 \% \mathrm{KCN}$ in $100 \mathrm{~mL}$ of distilled water, assuming $100 \mathrm{~mL}$ water $=100$ grams water

1. $(0.02$ grams $\mathrm{KCN} / 100 \mathrm{~mL}) * 100=0.02 \% \mathrm{KCN}$ solution

2. $[0.02$ grams $\mathrm{KCN} /(65$ grams/mole $\mathrm{KCN})] *(1$ moles $\mathrm{CN} / 1$ mole $\mathrm{KCN})=$ $3.0769 \times 10^{-4}$ moles $\mathrm{CN}^{-}$

3. $3.0769 \times 10^{-4}$ moles $\mathrm{CN}^{-} *\left(1\right.$ moles mercury cyanide $/ 4$ moles $\left.\mathrm{CN}^{-}\right) *(1$ mole $\mathrm{Hg} / 1$ mole mercury cyanide) $=7.6923 \times 10^{-5}$ moles $\mathrm{Hg}$

4. $7.6923 \times 10^{-5}$ moles Hg * $(1$ mole $\mathrm{HgS} / 1$ mole $\mathrm{Hg}) *(232.6$ grams $/$ mole HgS $)=$ 0.01789 grams $\mathrm{HgS}$

For a $100 \mathrm{~mL}$ solution of $0.02 \% \mathrm{KCN}, 0.0179$ grams $\mathrm{HgS}$ are needed to completely saturate the solution as $\mathrm{Hg}(\mathrm{CN})_{4}{ }^{-2}$, leaving no free cyanide. For a $0.02 \% \mathrm{KCN}$ solution in $200 \mathrm{~mL}, 0.0358$ grams $\mathrm{HgS}$ would be needed. 


\section{6) Methods for Vial Feasibility Tests}

\section{Methods}

An initial experiment was done with natural sphalerite used as found. The $80 \%$ passing particles size was around $300 \mu \mathrm{m}$ and the sample had been stored in a glass container for several years. A silver/mercury cyanide solution (50 mL, $100 \mathrm{ppb} \mathrm{Ag}, 640 \mathrm{ppb} \mathrm{Hg}$ ) was added to the vial with sphalerite (0.010 grams) and allowed to sit for 24 hours.

A second similar experiment was run with sphalerite, used as found, with a mercury/silver cyanide solution $(50 \mathrm{~mL}, 5000 \mathrm{ppb} \mathrm{Ag,} \mathrm{803ppb} \mathrm{Hg)} \mathrm{with} \mathrm{two} \mathrm{vials} \mathrm{with}$ 0.1 grams sphalerite, and a third vial using chemical grade synthetic zinc sulfide $(0.10$ grams, not ground or altered from as received).

A third experiment with silver/mercury cyanide $(50 \mathrm{~mL}, 2480 \mathrm{ppb} \mathrm{Ag}, 1880 \mathrm{ppb} \mathrm{Hg})$ was carried out in vials, with mercury/silver cyanide, but with 1 gram natural sphalerite (not altered) for 24 hours and 1 hour.

A fourth experiment used sphalerite that was ground in a puck mill for 30 seconds $(80 \%$ particle passing size was about $11 \mu \mathrm{m})$. A mercury/silver cyanide solution $(50 \mathrm{~mL}, 2250$ ppb Ag, $438 \mathrm{ppb} \mathrm{Hg}$ ) was added to 1 gram ground natural sphalerite for 1 hour and 24 hours.

\section{Experimental Results and Discussion}

For the feasibility tests done in vials, the first experiment with using the sphalerite "as found" showed only a $2 \%$ removal of mercury (640 ppb to $620 \mathrm{ppb}$ ) and no change in the silver. The second experiment with ten times more sphalerite showed little change for the mercury (no change for the sphalerite and 5\% for the synthetic $\mathrm{ZnS}$ ) and negligible decreases in silver, most likely due to variation for error. The third experiment using 1 gram sphalerite showed no silver losses and about 53\% removal of mercury from both the 
24 hours and 1 hour trials using sphalerite. The fourth experiment with the puck mill ground sphalerite $(1 \mathrm{~g})$ for the 24 hours showed a $34.8 \%$ silver loss and $97.4 \%$ mercury removed from solution. The 1 hour showed a $39.2 \%$ silver loss and $97.0 \%$ mercury removed from solution.

The first two experiments initially suggested the reaction would not happen quickly, but did prefer mercury precipitation. The third experiment showed that the reaction did remove mercury from solution and less than 1 hour was needed for the reaction, but a larger amount of sphalerite was needed. The difference seen with the synthetic $\mathrm{ZnS}$ for precipitating some mercury might be due to the different crystal structure of the natural versus synthetic zinc sulfide, or possibly due to not having as oxidized of a surface as the sphalerite. 
7) Use agreement for Gabby and Eisele 2012

http://mc.manuscriptcentral.com/societyimages/sme-peerreview/Copyright.pdf

\section{"What the society permits:}

1. The author(s) may reproduce for or allow reproduction by coworkers, employees, employers and professional colleagues for individual research and informational purposes including internal distribution within the company or organization by whom the work was

authorized.

2. Use of the work as the basis for preparing future works.

3. Retention by the author and/or employer of all patent rights.

4. Reproduction for classroom purposes in accordance with the "fair use" doctrine." 


\section{8) Calculations for theoretical amount of mercury on one particle of $245 \mu \mathrm{m} \mathrm{ZnS}$}

1). The unit square of $\mathrm{ZnS}$ has two available sulfurs on one side, or enough for two mercury atom to bind. The surface area of exposed side of the square is $2.916 \times 10^{-7}$ $\mu \mathrm{m}^{2}$.

2.) The surface area of a $245 \mu \mathrm{m}$ particle is $188568 \mu \mathrm{m}^{2}$

3.) By dividing the surface area of the particle by that of the area of the unit square, the molecules of mercury on the surface on the particle can be found when multiplied by 2 (1.293 x $10^{12}$ molecules of mercury).

4.) The molecules of mercury can be divided by Avogadro's number $\left(6.02 \times 10^{23}\right)$ to obtain moles of mercury ( $2.14839 \times 10^{-12}$ moles $\left.\mathrm{Hg}\right)$, which can then be converted into grams $\left(4.309 \times 10^{-10}\right.$ grams mercury). 


\section{9) Affect on leaching High Se and High $\mathrm{Hg}$ ores under different reduction potentials.}

\section{Methods}

High Se and High Hg ores $(\approx 10$ grams per sample) were leached at different reduction potentials in a $0.02 \% \mathrm{KCN}$ solution $(50 \mathrm{~mL})$ at $\mathrm{pH} 11$. Starting reduction potentials of the $\mathrm{pH} 11$ water: sodium hydroxide only $=+92 \mathrm{mV}$, some ammonia $=+76 \mathrm{mV}$, ammonia only $-0.2 \mathrm{mV}$. The ores were leached for seven days, filtered, and analyzed.

\section{Results and Discussion}

The results are shown for the High Se ore and High Hg ores in Figure A9.1 and Figure A9.2. Both silver and mercury ions are one the y-axis as "moles ions in solution/grams ore used". The x-axis are the samples with the first column as only sodium hydroxide and the last column as only ammonia. The ending reduction potentials are graphed on the secondary y-axis.

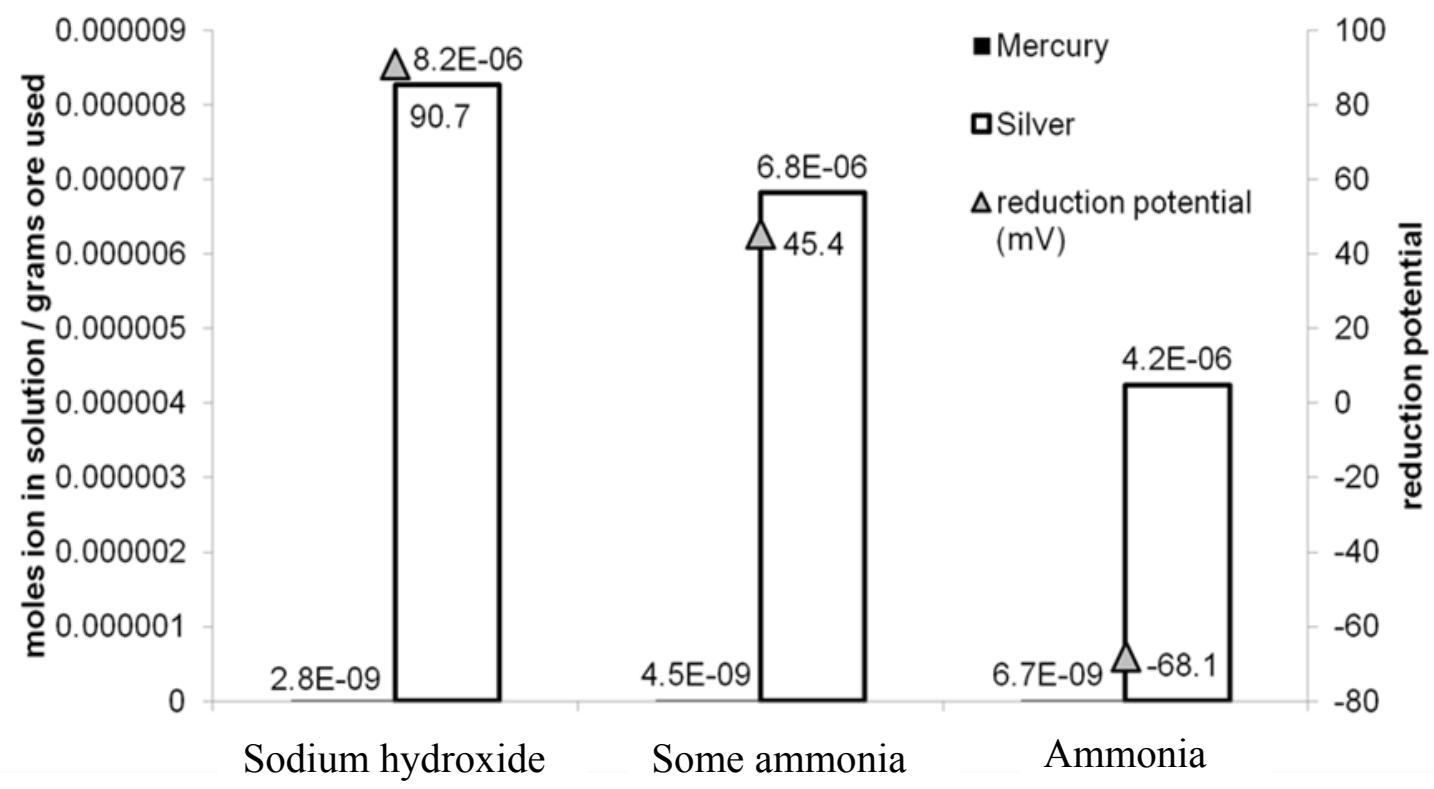

Figure A9.1. High Se ore leached at different reduction potentials in a $0.02 \%$ $\mathrm{KCN}, \mathrm{pH} 11$ solution. 


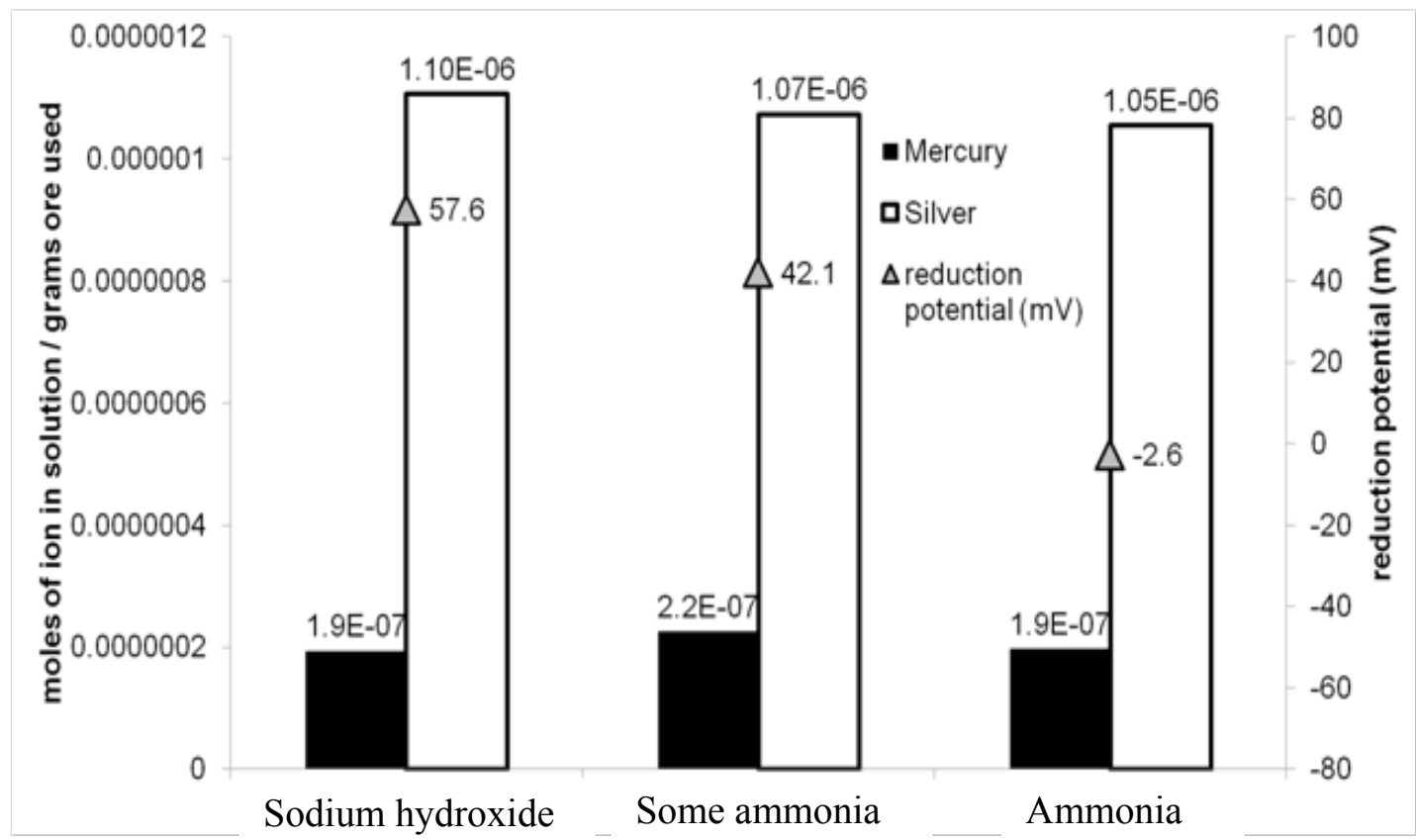

Figure A9.2. High $\mathrm{Hg}$ ore leached at different reduction potentials in a $0.02 \%$ $\mathrm{KCN}, \mathrm{pH} 11$ solution.

When looking at the ending reduction potentials, there is a wider spread of reduction potentials for the High Se ore (from about $90 \mathrm{mV}$ to $-68 \mathrm{mV}$ for a $158 \mathrm{mV}$ difference) than compared to that of the High $\mathrm{Hg}$ ore (from about $57 \mathrm{mV}$ to $-2 \mathrm{mV}$ for a $60 \mathrm{mV}$ difference). This suggests that the High $\mathrm{Hg}$ ore has minerals which act as buffers in solution.

Another obvious difference can be seen in comparing the silver changes in solution. The High Se ore shows silver going from about $8 \times 10^{-6}$ ions/ grams ore with sodium hydroxide down to $4 \times 10^{-6}$ ions/ grams ore with ammonia, showing the ammonia solution only dissolved about half that of the sodium hydroxide solution. The High $\mathrm{Hg}$ 
ore showed about $1 \times 10^{-6}$ ions/ grams ore for both the sodium hydroxide and ammonia trials with only a $0.05 \times 10^{-6}$ ions/ grams ore difference.

Finally, the mercury in the High Se ores are seem to be increasing in amounts by $3.9 \mathrm{x}$ $10^{-9}$ ions/ grams ore, whereas the High Se ore has no change in mercury concentrations.

When considering the Pourbaix diagrams for silver (Figure 3.12) and mercury (Figure 3.13) for the High Se ore, at first glance the lowering of silver does not seem to fit. Silver should be soluble in cyanide at both the high and lower reduction potentials, but the forms of sulfur released are very different. As discussed in Section 4.7, Equation 41 and Equation $42, \mathrm{~S}^{-2}$ (aq) might be needed for mercury to bind and release cyanide to continue with dissolution of silver. The form of sulfur in the high reduction potential might be more favorable for mercury to precipitate with than those found at lower reduction potentials. The mercury solubility raising slightly could be that at the high reduction potential, $\mathrm{HgO}$ is more stable and the lower reduction potentials clearly favor mercury cyanide.

For the High $\mathrm{Hg}$ ore, the entire reduction potential range tested were within the area where silver dissolved best for the High Se ore as well, explaining why little change was seen. The same can be said for the mercury.

Most probably due to other soluble minerals present in the High $\mathrm{Hg}$ ore, it is less likely to be effected by changes in leaching solution reduction potential. The High Se ore may have fewer "buffering" minerals present, leading to greater changes in the affect that changes in the reduction potential of the leaching solution can have. This would be important to know with ores for how tightly to control leaching conditions and effect of introducing a new method for leaching the ores might have on recovery. 


\section{0) Calculations for sphalerite needed in High $\mathrm{Hg}$ ore to remove mercury}

From Table 17, 0.0039 grams $\mathrm{ZnS}(80 \%$ passing $11 \mu \mathrm{m})$ precipitated $86.6 \%$ of $930 \mathrm{ppb}$ $\mathrm{Hg}$ in $30 \mathrm{~mL}$ of solution:

$930 \mu \mathrm{g} \mathrm{Hg} / \mathrm{L} * 0.866=805 \mathrm{ppb} \mathrm{Hg}$ removed

$805 \mu \mathrm{g} \mathrm{Hg} / \mathrm{L} * 0.03 \mathrm{~L}$ of solution $=24.16 \mu \mathrm{g} \mathrm{Hg}$ precipitated by 0.0039 grams $\mathrm{ZnS}$

$24.16 \mu \mathrm{g} \mathrm{Hg} *\left(1 \times 10^{-6}\right.$ grams $\left./ \mu \mathrm{g}\right)=2.416 \times 10^{-5}$ grams Hg

$2.416 \times 10^{-5}$ grams $\mathrm{Hg} / 0.0039$ grams $\mathrm{ZnS}=0.0062$ grams $\mathrm{Hg} /$ gram $\mathrm{ZnS}$

0.0062 grams $\mathrm{Hg}$ will precipitate out per gram $\mathrm{ZnS}$ at $80 \%$ passing $11 \mu \mathrm{m}$.

Given that there are $12 \mathrm{ppm}$ (or 0.012 grams $/ \mathrm{kg}$ ore) mercury for the High $\mathrm{Hg}$ ore (Table 3):

0.012 grams $\mathrm{Hg} / \mathrm{kg}$ ore * (grams $\mathrm{ZnS} / 0.0062$ grams Hg) $=1.94$ grams $\mathrm{ZnS} / \mathrm{kg}$ ore

2 grams $\mathrm{ZnS}$ are needed to precipitate the $0.012 \mathrm{ppm} \mathrm{Hg}$ from the High $\mathrm{Hg}$ ore.

Furthermore, a $11 \mu \mathrm{m}$ particle as an approximate surface area of about $380 \mu \mathrm{m}^{2}$, assuming a spherical particle. 
By following the same procedure as in Appendix 8, divide the surface area of the particle by that of the area of the unit square, the molecules of mercury on the surface on the particle can be found when multiplied by $2\left(2.606 \times 10^{9}\right.$ molecules of mercury $)$

The molecules of mercury can be divided by Avogadro's number $\left(6.02 \times 10^{23}\right)$ to obtain moles of mercury ( $4.329 \times 10^{-15}$ moles $\left.\mathrm{Hg}\right)$, which can then be converted into grams ( $8.684 \times 10^{-13}$ grams mercury).

$8.684 \times 10^{-13}$ grams mercury can be precipitated on $380 \mu \mathrm{m}^{2}$ (or one particle) of $11 \mu \mathrm{m}$ $\mathrm{ZnS}$.

So if 1 gram $\mathrm{ZnS}$ is needed to precipitated 0.0062 grams $\mathrm{Hg}$

0.0062 gram $\mathrm{Hg} / 8.684 \times 10^{-13}$ grams mercury per particle $=7.139 \times 10^{9}$ particles

$7.139 \times 10^{9}$ particles $* 380 \mu \mathrm{m}^{2}$ per particle $=2.7129 \times 10^{12} \mu \mathrm{m}^{2}$

$2.7129 \times 10^{12} \mu \mathrm{m}^{2}$ of $\mathrm{ZnS}$ (or 1 gram $\mathrm{ZnS}$ ) needed to precipitate 0.0062 grams $\mathrm{Hg}$

For the surface area of $\mathrm{ZnS}$ needed to precipitate $0.012 \mathrm{ppm} \mathrm{Hg}$ from the High $\mathrm{Hg}$ ore: $2.7129 \times 10^{12} \mu \mathrm{m}^{2}$ of $\mathrm{ZnS}$ (or 1 gram $\mathrm{ZnS}$ ) $82=5.425 \times 10^{-12} \mu \mathrm{m}^{2}$ are needed

$5.425 \times 10^{-12} \mu \mathrm{m}^{2} * 1 \times 10^{-12} \mathrm{~m}^{2} / \mu \mathrm{m}^{2}=5.425 \mathrm{~m}^{2}$

$5.425 \mathrm{~m}^{2}$ (or 2 grams) $11 \mu \mathrm{m} \mathrm{ZnS}$ are needed to precipitate $0.012 \mathrm{ppm} \mathrm{Hg}$ from the High Hg ore. 